GCR-01-820

\title{
Application of Natural Ventilation for U.S. Commercial Buildings Climate Suitability Design Strategies \& Methods Modeling Studies
}

Prepared for U.S. Department of Energy Office of Building Systems

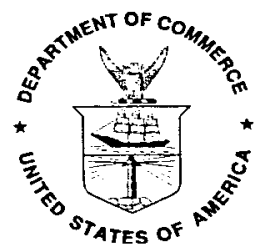

U.S. Department of Commerce Donald L. Evans, Secretary

Technology Administration Phillip J. Bond, Under Secretary for Technology 


\section{ABSTRACT}

Natural ventilation systems have long been employed in European residences to control indoor air quality. Increasingly, European building designers have turned to natural ventilation to control air quality and cool commercial and institutional buildings as well, hoping to take advantage of the potential of natural ventilation systems to conserve energy associated with mechanical cooling and fan operation. Encouraged by early successes of the past decade, European building designers have advanced natural ventilation technology, introduced promising hybrid ventilation technologies that combine mechanical and natural means, and developed analytical tools for the design of these systems. These systems may be adapted to the North American context, but much work will need to be done to realize the full potential natural ventilation may offer to North America.

This report reviews the application of natural ventilation to commercial buildings, the potential advantages these systems offer, and some of the pitfalls that must be considered. An approach to the analysis of climate suitability is presented and applied to a number of North American climates, European physical design strategies and the analytical methods developed to support them are reviewed, and a detailed modeling study of a representative naturally ventilated building recently constructed in The Netherlands is presented. A multizone coupled thermal/airflow simulation tool CONTAM97R is used to investigate the performance of this building in two challenging North American climates. An approach to apply natural and hybrid ventilation strategies to the North American context is outlined that considers all relevant phases of design from predesign analysis through to design development of system component sizes and operational details. Two relatively new analytical tools are central to this proposed procedure - the loop design method used to size system components and coupled thermal/airflow analysis used to conduct detailed performance evaluation of system behavior. Finally, research and development recommendations are put forward.

Keywords: cooling, coupled thermal/airflow analysis, design, energy efficiency, loop equations, modeling, natural ventilation, hybrid ventilation

Cover Photo: Exhaust vents of the Queen's Building of De Monfort University, Leicester, England designed by Short, Ford \& Associates, architects, and Max Fordham \& Partners, environmental engineers, 1993. 


\section{ACKNOWLEGEMENTS}

This work was supported by the U.S. Department of Commerce under contract reference number RFQ 53SBNB06712 through the National Institute of Standards and Technology, under a research project sponsored by the U.S. Department of Energy, Office of Building Systems under Interagency Agreement No. DE-AI01-01EE27615.

The critical review of Steven J. Emmerich and Andrew Persily of the Indoor Air Quality and Ventilation Group of NIST proved to be most important to the development of this report. 


\section{Disclaimer}

Commercial equipment referred to in this report are identified for informational purposes only, and does not imply recommendation of or endorsement by the National Institute of Standards and Technology or the author, nor does it imply that the products so identified are necessarily the best available for the purpose. 


\section{TABLE OF CONTENTS}

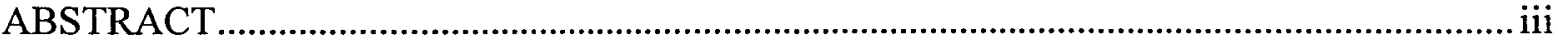

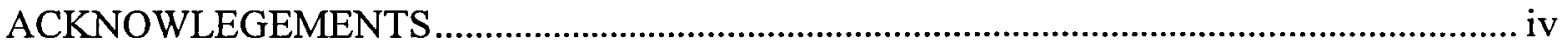

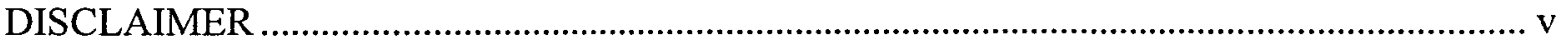

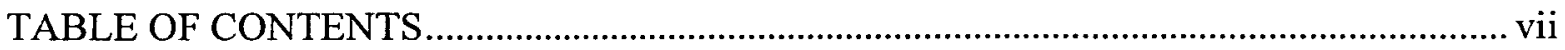

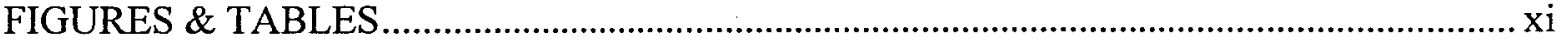

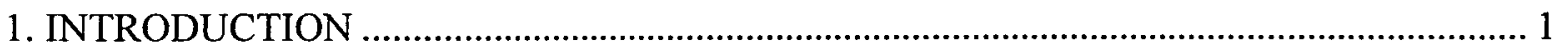

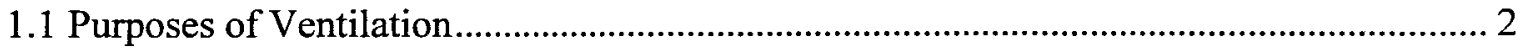

1.2 Pros and Cons of Natural versus Mechanical Ventilation ................................................... 2

1.2.1 Cooling Energy Savings and Limits of Applicability .................................................... 2

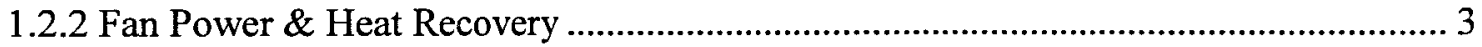

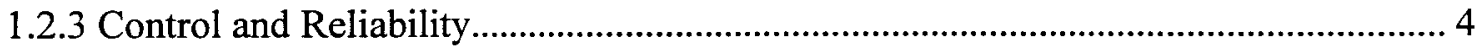

1.2.4 Occupant Health, Comfort \& Productivity ................................................................ 5

1.2.5 HVAC Equipment Cost \& Space Requirements ...................................................... 6

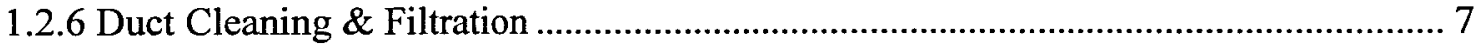

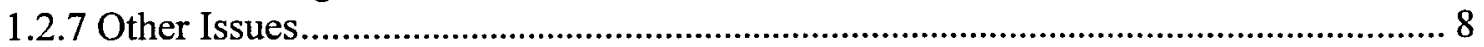

1.3 Future Prospects of Natural Ventilation \& the Emergence of Hybrid Strategies ................ 8

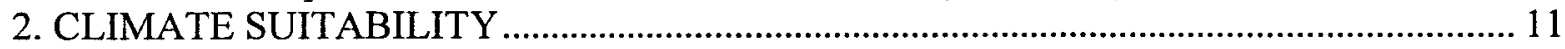

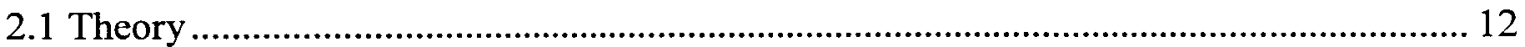

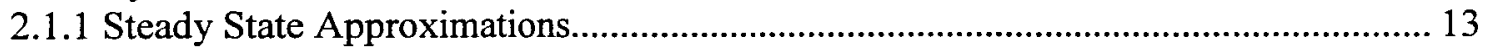

2.1.2 Thermal Comfort and Humidity Control ..................................................................... 14

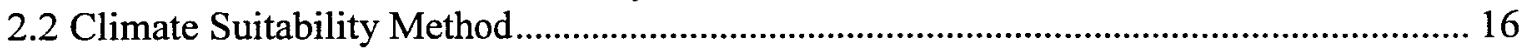

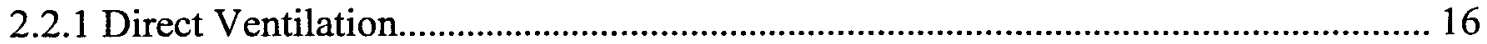

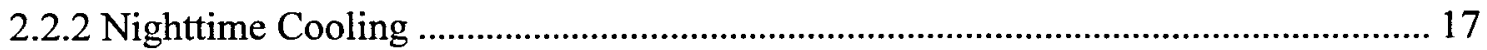

2.2.3 Climate Suitability Evaluation Algorithm ................................................................ 18

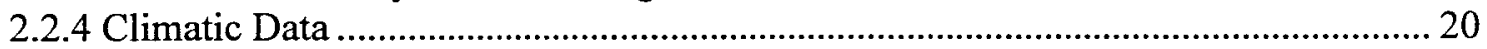

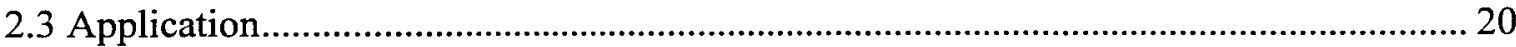

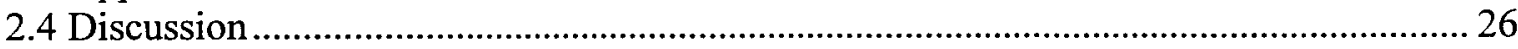

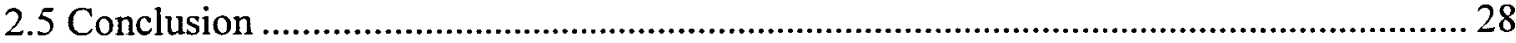

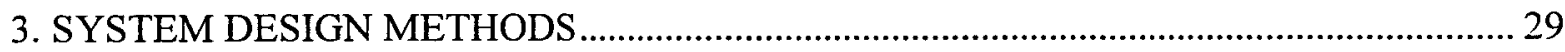

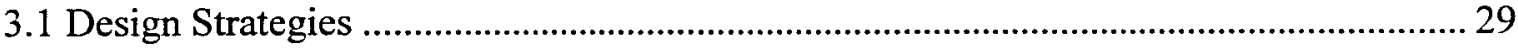

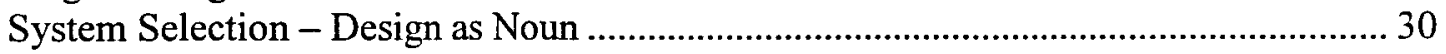

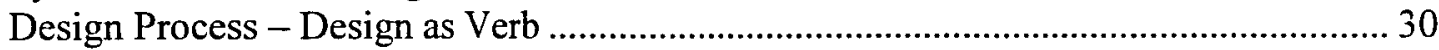

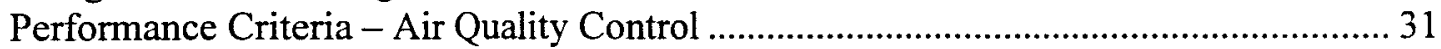

Performance Criteria - Ventilative Cooling .............................................................. 32

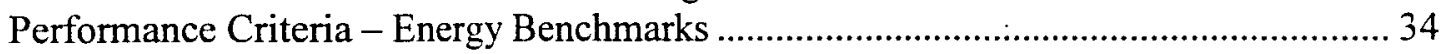

Anticipated Environmental Conditions..................................................................... 37

3.1.1 Natural Ventilation for Direct Cooling \& Air Quality Control ................................... 38

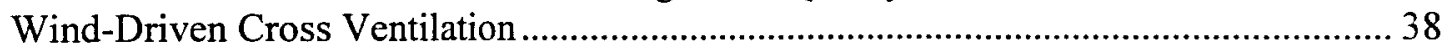

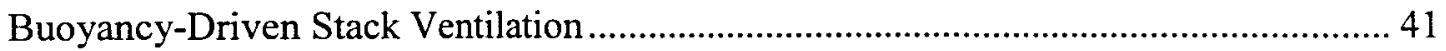

Combined Wind + Buoyancy-driven Stack Ventilation .......................................... 43

Turbulence-Induced Single-Sided Ventilation ........................................................ 45

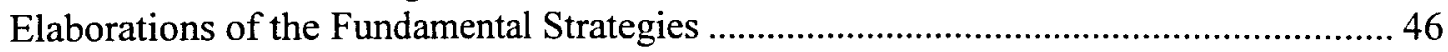

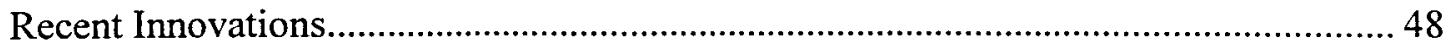

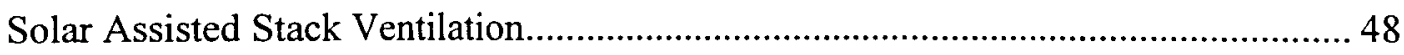

Top-Down or Balanced Stack Ventilation................................................................ 49

Passive Downdraught Evaporative Cooling (PDEC) Stack Ventilation...................... 50 
Heat Recovery - Air-to-Air \& Air-to-Fabric.

Passive-Mechanical.

3.1.2 Natural Ventilation for Indirect Cooling - Night Cooling Strategies...

Active Thermal Capaciy

3.1.3 Natural Ventilation System Components.

Component Flow Relations.

3.1.4 Hybrid \& Mixed-Mode Ventilation Strategies

3.1.5 Operation \& Control

3.2 Design Tools

3.2.1 Predesign Tools

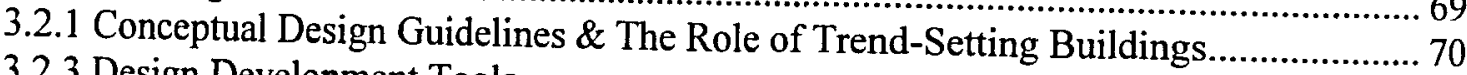

3.2.3 Design Development Tools.

The Loop Design Method.

3.2.4 Macroscopic Tools for System Performance Evaluation

3.2.5 Microscopic Tools for Room Performance Evaluation

3.3 Appendix - Notable Projects.

New Construction

Renovation

4. MODELING STUDIES.

4.1 Description of Building Models.

4.1.1 Wind Pressures.

4.1.2 Natural Ventilation System.

Self-Regulating Inlet Vents \& Design

Ventilation Stack.

Assist Fans

Natural Ventilation Control

Detailed Multi-Zone Model Assumptions

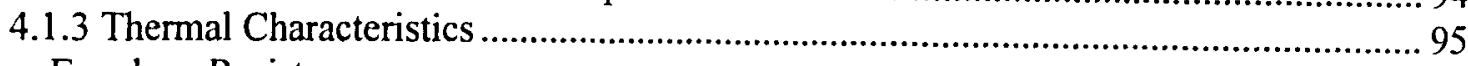

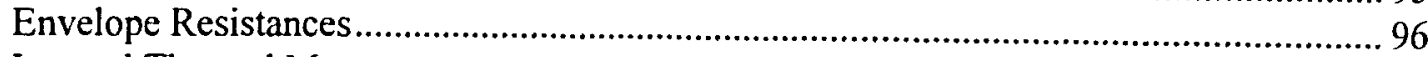

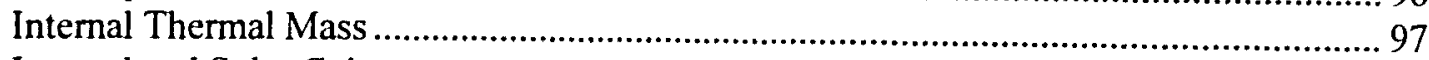

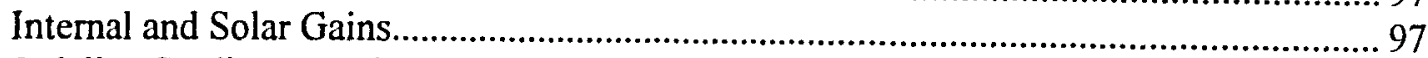

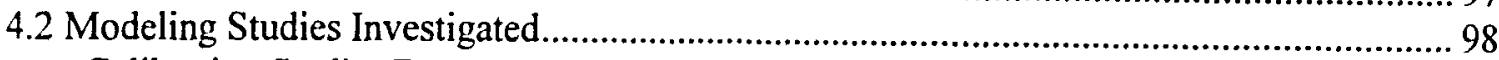

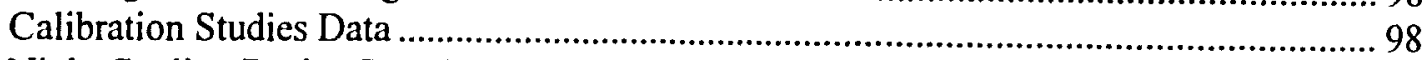

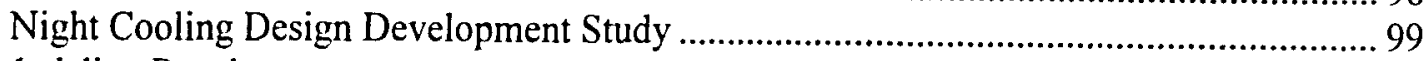

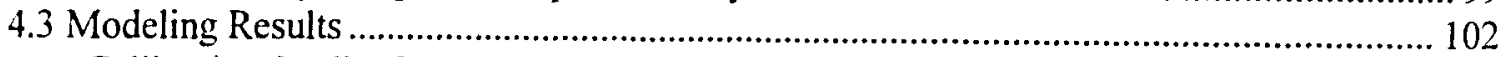

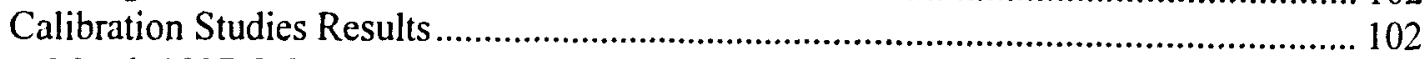

March 1997 \& June 1997 Results: Simplified Single-Zone Building Model................ 102

March 1997 \& June 1997 Results: Detailed Multi-Zone Building Model ................. 104

August 1997 Results: Simplified Single-Zone Building Model .............................. 106

August 1997 Results: Detailed Multi-Zone Building Model.................................. 112

Summary of Calibration Modifications .................................................................... 116

Night Cooling Design Development Study Results .................................................... 117

Design Development of the Night Cooling System for Los Angeles, California....... 117

Design Development of the Night Cooling System for Los Angeles, California....... 121

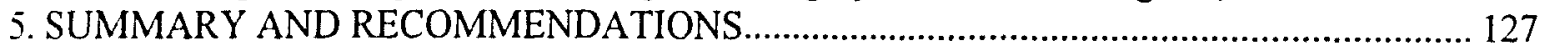

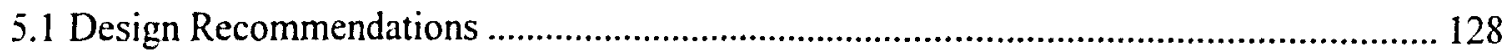

5.1.1. Predesign Analysis. 
5.1.2 Preliminary or Conceptual Design.

5.1.3 Design Development

5.1.4 Design Performance Evaluation

5.2 Research Recommendations 


\section{FIGURES \& TABLES}

Figure 2.1 Single-zone model of a commercial building........................................................ 12

Figure 2.2 Comparison of the ventilative cooling comfort zone used in the present study with

ASHRAE summer and winter comfort zones [44] ......................................................... 15

Table 2.1 Heating balance point temperatures for a range of specific internal gains.................. 19

Table 2.2 Table of U.S. locations used for initial climate suitability evaluation....................... 21

Table 2.3 Climate suitability statistics for eight U.S. locations................................................. 23

Figure 2.3 Direct ventilative cooling results for the coastal locations....................................... 25

Figure 2.4 Direct ventilative cooling results for the continental locations ................................ 26

Figure 3.1 Adaptive thermal comfort zone used in subsequent evaluations based on Brager [46]

utilizing CIBSE dry resultant temperature rather than ASHRAE's operative temperature.. 33

Table 3.1 Energy requirements and corresponding ventilation benchmark for heating based on

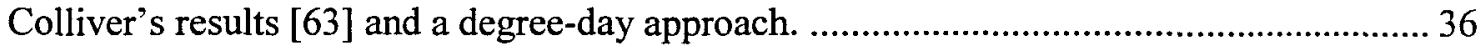

Figure 3.2 Wind-driven cross ventilation and the pressure drops associated with it................... 39

Figure 3.2 Buoyancy-driven stack ventilation and the pressure drops associated with it. .......... 42

Figure 3.3 Wind + buoyancy-driven stack ventilation and the pressure drops associated with it. 43

Figure 3.4 Single-sided ventilation driven, primarily, by turbulence-induced effects. ............... 45

Figure 3.5 Mixed natural ventilation strategies in a single building ....................................... 46

Figure 3.6 The Queen's Building of De Montfort University, Leicester, England. .................... 47

Figure 3.7 Diagrammatic representation of combined wind and buoyancy-driven stack ventilated

building with sub-slab or access-floor distribution of fresh air. ...................................... 47

Figure 3.8 Top-down or balanced stack natural ventilation systems........................................ 49

Figure 3.9 Passive downdraught evaporative cooling (PDEC) stack ventilation. ........................ 51

Figure 3.10 The run-around heat recovery system used in the Gross Gerau building.................. 53

Table 3.2 Active thermal capacity per $\mathrm{m}^{2}$ gross floor area......................................................... 57

Figure 3.11 The Gross Gerau building designed by Transsolar Energietechnik, GmbH ............ 58

Figure 3.12 Air diffuser detail of the Gross Gerau building ................................................... 59

Figure 3.13 Stack terminals used in the Queen's Building De Monfort University................... 60

Figure 3.14 Comparison of proposed logarithmic self-regulating vent model with measured data and

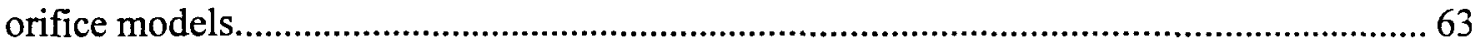

Table 3.3 Recommended night cooling control strategies from three different investigations.... 66

Figure 3.15 Global geometry, topology, and pressure nodes for the ventilation flow loops of a first design example based on the Inland Revenue Building, England (after [56]) ..................... 74

Figure 3.16 Three-zone model of a typical floor for a centrally loaded office building used for design

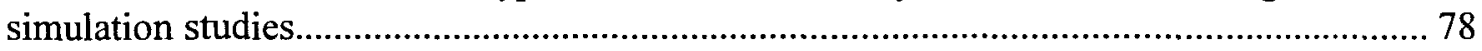

Figure 4.1 Plan of the Enschede Tax Office showing the section of the building modeled........ 84

Figure 4.2 Representative section of the Enschede Tax Office illustrating airflow paths........... 85

Figure 4.3 Plan and section of the simplified single-zone model of a representative segment of the

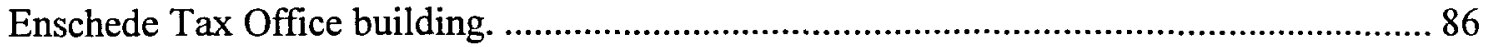

Figure 4.4 Plan and section of the detailed multizone model of a representative segment of the

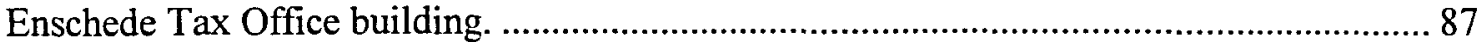

Table 4.1 Spatial variation of wind pressure coefficients used in modeling studies.................. 88

Figure 4.5 Comparison of power law models, and the relation chosen to model the self-regulating inlet

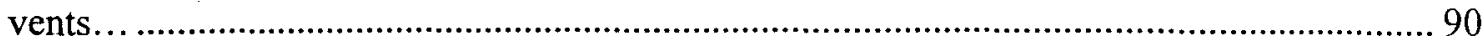

Figure 4.6 Fan performance curve used to model fan-assisted natural ventilation ................... 93

Figure 4.7 Schedule for self-regulating inlet vent used to model the night ventilating control strategy

implemented in the Enschede Tax Office building............................................................ 94 
Table 4.2 Materials and their thermal properties used in the modeling studies.

Figure 4.8 Summertime outdoor temperatures time histories for Fresno and Los Angeles, CA used for modeling studies

Figure 4.9 Histograms of summer time wind speed data for Fresno and Los Angeles, CA used for modeling studies ....

Table 4.3 Climate suitability results for Los Angeles and Fresno CA based on WYEC2 ….... 101

Table 4.3 Comparison of computed and measured ventilation rates for assumed stack terminal free area of $0.5 \mathrm{~m}^{2}$ for the simplified single-zone model of the Tax Office. 102

Table 4.4 Comparison of computed and measured ventilation rates for an increased stack terminal free area of the Tax Office. 104

Table 4.5 Comparison of computed and measured ventilation rates for the detailed multi-zone models of the Tax Office with assumed tight envelope construction. 105

Figure 4.10 Simplified single-zone CONTAM97R model of the Enschede Tax Office used for modeling the transient coupled thermal/airflow response 106

Figure 4.11 Measured indoor and outdoor temperatures for the August 1997 heat wave ........ 107

Figure 4.12 Computed indoor and outdoor temperatures using single-zone model ................. 108

Figure 4.13 Computed stack airflow rates using single-zone model for heat wave .................. 109

Figure 4.14 Computed office airflow exchange rates for offices on the first, third, and fifth levels using single-zone model for heat wave 110

Figure 4.15 Computed indoor and outdoor temperatures using single-zone model for original and three additional system strategies. 111

Figure 4.16 Representative floor of the detailed CONTAM97R model of the Enschede Tax Office used for modeling the transient coupled thermal/airflow response 112

Figure 4.17 Computed atrium and outdoor temperatures using multi-zone model …............. 113

Figure 4.18 Computed office and outdoor temperatures using multi-zone model ................... 114 Figure 4.19 Computed office air exchange rates using multi-zone model ............................. 115 Figure 4.20 Representative floor of the simplified multi-zone CONTAM97R model of the Enschede Tax Office with a combined central zone.... 116

Figure 4.21 Computed office and combined internal zone temperature responses using simplified multi-zone model

Figure 4.22 Atrium temperature response for Enschede Tax Office building to Los Angeles' summer conditions operated in a natural night cooling mode. 118

Figure 4.23 Detailed stack airflow rate response for Enschede Tax Office building to Los Angeles' summer conditions operated in a natural night cooling mode.

Figure 4.24 Detailed atrium temperature response for Enschede Tax Office building to Los Angeles' summer conditions operated in a natural night cooling mode.

Figure 4.25 Detailed office inlet airflow rate responses for Enschede Tax Office building to Los Angeles' summer conditions operated in a natural night cooling mode.

Figure 4.26 Detailed office temperature responses for Enschede Tax Office building to Los Angeles' summer conditions operated in a natural night cooling mode.

Figure 4.27 Atrium temperature response for Enschede Tax Office building to Fresno's summer conditions operated in a natural night cooling mode.

Figure 4.28 Stack airflow rate response for Enschede Tax Office building to Fresno's summer conditions operated in a natural night cooling mode.

Figure 4.29 Atrium temperature response for Enschede Tax Office building to Fresno's summer conditions operated in a natural night cooling mode.

Figure 4.30 Stack airflow rate response for Enschede Tax Office building to Fresno's summer conditions operated in a fan-assisted night cooling mode 
Figure 4.31 Atrium temperature response for Enschede Tax Office building to Fresno's summer conditions operated in a fan-assisted night cooling mode ..... 124

Figure 4.32 Stack airflow rate response for Enschede Tax Office building to Fresno's summer conditions operated in natural night cooling mode with resized inlet vents.

Figure 4.33 Atrium temperature response for Enschede Tax Office building to Fresno's summer conditions operated in natural night cooling mode with resized inlet vents. 125

Table 4.6 Computed overheating degree hours for night cooling design alternatives of the Enschede Tax Office 125 
xiv 


\section{INTRODUCTION}

Commercial enterprises necessarily depend on the health, comfort, and productivity of the occupants of the buildings in which commercial activities occur. During the long history of commercial building architecture, natural ventilation and daylighting have been instrumental, indeed, determinate in shaping buildings for commercial use. These natural technologies proved important simply because no other technologies were available to provide illumination, acceptable indoor air quality, and, when needed, cooling until the mid-to-late nineteenth century when artificial lighting and mechanical ventilation systems first became available and began to displace their natural alternatives [1]. Cooling by means of natural ventilation flourished even longer within the commercial building tradition, to well within the twentieth century when mechanical means of cooling began to displace natural ventilation cooling methods [2]. By the end of the twentieth century, however, mechanical cooling and mechanical ventilation had become so widespread in the U.S. that they effectively replaced natural means altogether in the commercial building sector.

During the past century, similar trends occurred in Europe but the displacement of natural ventilation by mechanical means has not been as complete and widespread. Cultural preferences for natural ventilation and a growing concern in Europe for the rapid spread of air conditioning systems - and the demand they place on electric power supplies - have instead fostered a renewed interest in the building research community for natural ventilation and daylighting strategies [3-7]. Simultaneously, a number of trend-setting buildings have emerged from the European building design community that attempt to extend the daylighting and natural ventilation strategies of the past to offset the energy consumption associated with artificial lighting and mechanical cooling and ventilation while also providing the level of performance now expected of commercial buildings [8-11]. The majority of these innovative projects have been constructed in central and northern European climates - climates similar to many of the climatic regions of North America - thus begging the question:

\section{Can and should new European natural ventilation systems be adapted to North America?}

To logically answer this question we must first clearly understand the purposes that ventilation can serve, whether naturally- or mechanically-driven, then articulate the advantages and disadvantages of how both means to ventilate can serve these purposes. Only then can the future prospects of natural ventilation be properly assessed. 


\subsection{Purposes of Ventilation}

Ventilation may be used for:

- Air Quality Control: to control building air quality, by diluting stale indoor air with presumably fresher outdoor air,

- Direct Advective Cooling: to directly cool building interiors by replacing or diluting warm indoor air with cooler outdoor air when conditions are favorable,

- Direct Personal Cooling: to directly cool building occupants by directing cool outdoor air over building occupants at sufficient velocity to enhance convective transport of heat and moisture from the occupants' bodies (see [12] for example), and

- Indirect Night Cooling: to indirectly cool building interiors by precooling thermally massive components of the building fabric or a purpose-provided thermal storage chamber with cool nighttime outdoor air.

While these four distinct purposes must be kept in mind when designing a natural ventilation system, direct advective and personal cooling are reasonably achieved in an integrated manner by a properly designed direct cooling strategy. Consequently, just three purposes are most often noted in the literature - air quality control, direct cooling, and indirect cooling.

\subsection{Pros and Cons of Natural versus Mechanical Ventilation}

A number of issues should reasonably be considered when comparing natural ventilation strategies to mechanical alternatives. Here, sets of these issues that are inextricably linked will be considered including a) cooling energy savings and limits of applicability, b) fan power savings and heat recovery, c) control and reliability, d) occupant health, comfort and productivity, e) HVAC equipment costs and space requirements, f) duct-cleaning and filtration, and $\mathrm{g}$ ) other related issues such as acoustical isolation, privacy, security, etc.

\subsubsection{Cooling Energy Savings and Limits of Applicability}

When applicable, natural ventilation can offset cooling energy consumption and the associated energy costs and carbon dioxide emissions thought to be related to global climate changes. In direct comparisons of naturally ventilated and air-conditioned offices in the United Kingdom, naturally ventilated buildings offset from 14 to $41 \mathrm{kWh} / \mathrm{m}^{2}$ of cooling energy annually, for good practice standard office buildings to typical prestige office buildings respectively, saving from 0.77 to $2.05 \mathrm{f} / \mathrm{m}^{2}$ (i.e., approximately 0.12 to $0.33 \$ / \mathrm{ft}^{2}$ ) annually in energy costs [13]. These savings account for approximately $10 \%$ of total energy costs in a climate with outdoor air temperatures seldom exceeding thermal comfort limits in the summer and thus, one well-suited for ventilative cooling of office buildings.

The potential cooling energy that may be saved depends, of course, on both the climate in which a building is located and the relative level of internal and other gains that impact the buildings thermal performance. Clearly, when natural ventilation is not applicable due either to outdoor temperatures or, in some instances, outdoor humidities that are too high, then these energy savings can not be realized. The general question of climatic suitability will be addressed in a subsequent section of this report and methods presented to evaluate the limits of applicability of
ventilative cooling strategies. 


\title{
1.2.2 Fan Power \& Heat Recovery
}

Of course, ventilative cooling may be accomplished by either natural means or mechanical means (e.g., using so-called economizer cycle operation). When resorting to mechanical means to cool buildings, however, fans and pumps will consume a significant amount of the energy. In all-air systems - the most common mechanical system cooling category in the U.S. - fans consume at least two-thirds of the total energy consumed for cooling in office buildings in the United Kingdom [13]. Thus, when compared to all-air mechanical cooling systems, naturally ventilated buildings in the U.K. offset from 20 to $60 \mathrm{kWh} / \mathrm{m}^{2}$ of fan energy consumption annually for cooling purposes, saving from 1.0 to $3.0 \mathrm{f} / \mathrm{m}^{2}$ (i.e., approximately 0.16 to $0.48 \$ / \mathrm{ft}^{2}$ ) annually in energy costs (i.e., again for good practice standard to typical prestige office buildings). By implication, these savings account for approximately $15 \%$ of total energy consumption in U.K. office buildings.

These statistics from the U.K. thus establish the potential that natural ventilation offers when climatic and operational conditions prove particularly suitable. Roughly, natural ventilation may be expected to provide cooling energy savings on the order of $10 \%$ and fan power savings (i.e., for all-air systems) on the order of $15 \%$ of annual energy consumption when climatic and operational conditions are suitable.

U.S. statistics to support these U.K. observations are a bit sparse but are available. Kavanaugh reports that as mechanical cooling systems have become increasingly complex in the U.S. the relative importance of fan power energy consumption has increased:

\begin{abstract}
"The good news is that chillers, furnaces, compressors, and other HVAC components are becoming increasingly efficient. The bad news is that air system friction losses, high ventilation rates, filter efficiency requirements, part-load air distribution methods, and the lack of spacework for ductwork can combine to make fan demand and energy the largest component in HVAC systems. ..." [14]
\end{abstract}

Kavanaugh investigated three systems - two centralized air handling systems with variable air volume (VAV) air distribution systems and a distributed system with multiple fan coil units (FCU). Full-load energy consumption was estimated for each of these three options indicating fans accounted for $53 \%$ of energy consumption in the more common relatively high pressure VAV system, $36 \%$ for a low-pressure VAV system, and $24 \%$ for the very-low-pressure distributed FCU system. The reduced fan power consumption realized by the lower pressure systems, however, were offset in part by increased chilled water pumping costs resulting in the combined fan and pump energy costs ranging from $40 \%$ to $62 \%$. For part-load demand an additional significant penalty is paid in losses of fan efficiency [14]. Combined together, then, Kavanaugh's analysis supports the U.K. findings that in conventional (i.e., higher pressure) allair systems, fans account for approximately two thirds of the total energy consumed for cooling. The less common low-pressure mechanical systems, however, mitigate the impact of these parasitic losses.

Heat recovery, on the other hand, is put forward as the key advantage of mechanical ventilation systems - the demonstrated advantage of a number of mechanical system configurations to recovery thermal energy of ventilative exhaust air through the use of air-to-air and so-called "run-around" air-to-water-to-air heat exchangers. Indeed in the cold climate of Finland it has been estimated that fan-power accounts for only $13 \%$ of annual energy consumed in ventilating 
buildings while the remaining $87 \%$ is used to condition, specifically in Finland to heat, the ventilating air [15]. Even a modest heat recovery efficiency could, therefore, have a significant impact during the heating season in cold climates.

The potential benefit of heat recovery during the cooling season is likely, however, to be marginal. This is due, in part, to the relatively small temperature difference between outdoor and indoor air during even extreme summer conditions in most of the U.S. and, in part, due to additional parasitic energy consumption required by fans again in mechanical heat recovery systems. Indeed, Kavanaugh presents an analysis of an office building in Birmingham, Alabama and concludes: "Annual energy savings with the HRU (heat recovery unit) were non-existent due to the large amount of fan power energy consumed."

Nevertheless, the lesson here is clear enough - if natural ventilation strategies are to be competitive with leading edge mechanical systems during extreme seasons, when either mechanical heating or cooling would normally be provided, then they must be designed to recover heat. This has become a central goal of the most recent work in the development of natural ventilation systems and thus will be considered below. Conversely, however, it must be emphasized that during the shoulder seasons, when mechanical heating or cooling need not be provided, heat recovery is no longer an issue thus the fan power savings offered by natural ventilation systems stands unqualified.

Likewise, as mechanical systems have been devised that more effectively recover heat then the relative importance of the fan-power consumed in these systems becomes more significant. Consequently, recent research on the mechanical side has been directed to the development of low-pressure mechanical systems in an effort to minimize fan-power consumption [16].

One recent study of 3,720 employees of a large Massachusetts manufacturer demonstrated a clear correlation between outdoor air ventilation rate and the risk of lost of productivity due to sick leave [17]. The results of this study indicated a net savings of $\$ 400$ per employee per year could be realized by increasing ventilation above current recommended levels. Another study confirms these findings for office environment as well: "This study shows the benefits for health, comfort and productivity of ventilation rates well above the minimum levels prescribed in existing standards and guidelines" [18]. Clearly, if ventilation rate standards are increased the relative savings of fan power that natural ventilation methods may offer will increase proportionately.

\subsubsection{Control and Reliability}

In mechanical ventilation systems airflow is driven by fans that may, in principle, be directly controlled electronically. Natural ventilation, on the other hand, is driven by wind and buoyancy forces that are stochastic in nature making control more difficult, as a result natural ventilation systems may at times under-ventilate, resulting in overheating or unacceptable air quality conditions, over-ventilate, resulting in unnecessary energy consumption to condition indoor air, or provide unacceptable air distribution, resulting in local thermal discomfort due to cold drafts or insufficient cooling or local air quality problems.

At face value, the control and reliability offered by mechanical ventilation systems would appear to be a significant advantage when compared to natural ventilation systems. Indeed, this is often cited as the primary reason mechanical ventilation should be preferred to natural. However, in practice, mechanical ventilation systems are often regulated to control temperature rather than air 
quality and, thus, may not provide adequate ventilation for air quality control. For example, VAV systems which are commonly used in commercial buildings can fail to maintain acceptable air quality for this reason [19]. On the other hand, air quality controlled mechanical ventilation systems while not commonly used in practice yet have the potential to be both reliable and energy efficient in operation.

The need to maintain ventilation rates reliably and the inherent difficulty of do so when using natural driving forces must be seen as a major challenge for the development of natural ventilation systems. Consequently recent research efforts have been directed to meet this challenge. System design strategies, including axisymmetric exhaust vents and inlet vents linked via a common plenum space, have been identified that reduce sensitivity to wind direction and thus improve the directional reliability of wind-driven flow. Recently developed automatic, selfregulating vents [20-24] and digital control strategies coupled to controlled inlet devices [25] may provide the means to control over-ventilation and the discomfort due to cold drafts associated with it. As promising as these recent developments are, however, purely natural ventilation systems will fail when the natural driving forces are simply not available, consequently recent trends have favored fan-assisted natural ventilation.

\subsubsection{Occupant Health, Comfort \& Productivity}

The actual health, comfort, and productivity provided by mechanical ventilation systems all too often falls short of expectations [26, 27]. In comparisons of negative health symptoms of office workers in a limited number of naturally and mechanically ventilated systems, in both the European and North American context, the naturally ventilated buildings reported lower symptom prevalence in comparison to the mechanically ventilated and, especially, air conditioned buildings [28]. These scientific findings are supported by the all-too-familiar anecdotal evidence we encounter in our workplaces from day-to-day, yet the deeper reasons behind these failings are not at all self-evident.

A recent Dutch study supports these findings and attempts to explain why they are observed:

"Epidemiological studies consistently show that occupants' complaints are more prevalent in office buildings with more sophisticated HVAC systems, that is systems with more technological devices to control and regulate the indoor environment. These complaints not only include physical symptoms, but also complaints about indoor air quality and thermal comfort. Since in most cases these more sophisticated systems primarily aim at better compliance with some set of health and comfort standards, the higher complaint levels seem odd. The most frequent explanation of this phenomenon is that more sophisticated HVAC systems contain more potential sources of indoor air pollution, like filter sections, cooling sections and humidifiers. The authors of this paper submit that this, though in itself correct, is only part of the explanation, and that a more comprehensive explanation can be hypothesized." [19]

Leyten and Kurvers go on to introduce the notion of system robustness - the ability of a system to perform up to expectations when assumptions and conditions underlying its design are 
violated. They offer a number of reasons HVAC systems may lack robustness: systems may be particularly sensitive to "aberrations" in their underlying design assumptions, maintenance requirements of systems may not be feasible, integration of heating (or cooling) and ventilation places conflicting demands on system operation and control, systems sensitive to the regulation of airflow rates (especially recirculation airflow rates) may not be feasible, and system illegibility to both occupants and building operators. In short, they put forward the hypothesis that the more complex, "sophisticated," HVAC systems tend to be less robust than the simpler, more comprehensible systems. Importantly they conclude that natural ventilation systems tend to rank high in terms of robustness [19].

The growing importance of adaptation in thermal comfort considerations [12, 29] may well be linked to Leyten and Kurvers' identification of system legibility or transparency as a prerequisite of robustness. If a system is transparent to the occupants of the building the occupants can act directly to identify the causes of problems that compromise health, comfort, and even productivity. If, in addition, occupants are offered control of these systems they will make changes to mitigate these problems. This has led to the conclusion that natural ventilation systems that offer occupant control over ventilation rates (and solar gain) can be effectively designed for slightly larger comfort zones than commonly used in the design of mechanical HVAC systems $[30,31]$. Indeed, a recent study of a school whose mechanical system was replaced by a natural ventilation system offering user control concluded [32]: "The school users were as good, or better, at obtaining comfortable temperature and air quality as the poorly maintained mechanical ventilation system with central automation."

While it is tempting to conclude from these limited studies that natural ventilation systems can provide more healthful, comfortable, and productive environments, with the notion of robustness in mind, it may be more reasonable to conclude that robust natural ventilation systems may offer this advantage. There is a trend in the design of natural ventilation systems in recent years towards complexity - these complex natural ventilation systems may well prove to be less robust and thus may suffer shortcomings similar to those of the more complex mechanical ventilation systems.

Beyond quantitative evaluations of health, comfort, and productivity advantages that natural ventilation systems may offer, it is important to recognize that many if not most building occupants simply prefer natural ventilation systems qualitatively. One should not underestimate the value of the pleasure of fresh outdoor air, when available, and the ability to personally control ventilation. Largely for these reasons alone, architects have accepted natural ventilation as one of several objectives of high quality sustainable design.

\subsubsection{HVAC Equipment Cost \& Space Requirements}

Mechanical heating, ventilating, and air conditioning equipment often account for a large fraction of the cost of construction of new buildings and the renovation of existing buildings. In larger office and institutional buildings these costs may be expected to range from $35 \%$ to $45 \%$ of construction costs. Consequently, the first cost savings that may be realized by replacing, or at least reducing, mechanical systems for ventilation and cooling by natural ventilation systems is, potentially, quite large.

Yet this represents only part of the advantage that may be offered by natural ventilation. Mechanical air handling equipment including fans, filters, heating and cooling coils, vertical 
distribution shafts and ducts, horizontal distribution duct networks, dampers, reheat or VAV boxes and the like, and supply diffusers and return grilles consume vast amounts of space. In larger commercial buildings an enclosed ceiling space from 0.6 to $1.2 \mathrm{~m}$ high, typically, will be required for the horizontal distribution system components alone - i.e., 0.6 to $1.2 \mathrm{~m}^{3}$ per $\mathrm{m}^{2}$ of useful floor area. Vertical shaft areas usually range from 0.1 to $0.2 \%$ of floor area served while fan rooms require from 2 to $4 \%$ of this floor area [33]. For the common commercial building ceiling height of $3.7 \mathrm{~m}$, the combined requirements of fans, vertical distribution, and horizontal distribution systems will, therefore, consume 0.68 to $1.36 \mathrm{~m}^{3}$ per $3.7 \mathrm{~m}^{3}$ of useful space in the building or 18 to $37 \%$ of the total volume of the building.

Innovative natural ventilation system designs recover much of this volume as occupied space by configuring the spatial interior of the building to serve, in essence, as part of the natural ventilation airflow pathway. Not only is space (volume) recovered that may serve more formal architectural objectives, this space may serve to facilitate daylight distribution, by increasing the height to depth of room sections, and to mitigate rapid increases in indoor air pollutants by simply increasing the total volume of air hence contaminant capacity contained within rooms. Alternatively, the space recovered may be used to reduce the total floor-to-floor height in multistory construction to either effect a savings in the cost of building construction or to allow the inclusion of one or more additional floors - and thus the income generated from their rent or sale - within a given urban building height limitation.

\subsubsection{Duct Cleaning \& Filtration}

The daylighting, air quality, and construction savings benefits that may result from the removal of mechanical air handling systems could, conceivably, exceed the first cost savings offered by replacement of these mechanical systems with natural alternatives. Yet another advantage must also be acknowledged. It is now widely recognized that duct cleanliness and building air quality are linked [34] - indeed, it is claimed that ductwork may be a principle source of indoor odors even in new construction [35]. As a result, an entirely new business industry has been formed to clean existing ductwork - an often very difficult and expensive undertaking - and guidelines and standards have been and are being formulated to address this problem [34, 36-38].

Many natural ventilation systems circumvent this problem altogether by, in essence, replacing ductwork with habitable spaces that serve to direct naturally-driven airflows. The routine cleaning and maintenance of these spaces and the ease with which their cleanliness may be inspected provides an inexpensive solution to the general problem of cleaning ventilation airflow paths. On the other hand, natural ventilation systems that admit outdoor air without filtration still the most common situation in most natural ventilation systems - can, in those urban environments where outdoor particulate levels are excessive, result in increased building cleaning and maintenance costs and the annoyance associated with working in an environment with excessive dust and particle loads. Consequently, on one hand mechanical ventilation systems offer the significant advantage of air filtration yet the potential cost and health penalties of unclean ducts while natural ventilation systems, as commonly configured, avoid the duct cleaning problem altogether yet provide little or no filtration of ventilation airflows. Again, it should come as no surprise that research to address these problems is currently underway. 


\subsubsection{Other Issues}

A number of other related issues must be considered when evaluating the potential of natural and/or hybrid ventilation systems (see, for example $[39,40]$ ). Of these, the inherent compatibility of daylighting with natural ventilation design strategies is perhaps most significant from an energy point of view. In its survey of U.K. buildings, the Building Research Establishment Conservation Service Unit (BRECSU) data indicate that naturally ventilated buildings typically consume 23 to $52 \%$ of the energy consumed for artificial lighting in mechanically air conditioned office buildings [13]. In principle, lighting efficiency should be independent of the ventilation system employed, yet building configurations that serve natural ventilation purposes well are often most appropriate for daylighting strategies that, when applied properly, can significantly offset artificial lighting.

\subsection{Future Prospects of Natural Ventilation \& the Emergence of Hybrid Strategies}

Natural ventilation offers the means to control air quality in buildings, to directly condition indoor air with cooler outdoor air, to indirectly condition indoor air by night cooling of building thermal mass, and to provide refreshing airflow past occupants when desired. When compared to mechanical ventilation alternatives, natural ventilation systems:

- can offset cooling energy consumption when climate and operational conditions are suitable,

- can offset the fan power required to provide ventilation mechanically,

- appear to provide quantitative health, comfort, and productivity advantages that may, in part, be due to the greater robustness of natural ventilation systems,

- provide definite qualitative advantages of truly fresh air in the minds of most occupants,

- may offer users greater direct control of their environments and, as a consequence, may benefit from less restrictive comfort criteria that results from occupants' ability to adapt their environment to their immediate perception of comfort,

- can offset a significant fraction of the relatively large first costs associated with conventional mechanical ventilation systems in commercial buildings by simply replacing them with lower cost natural ventilation systems,

- can recover the large spatial requirements that conventional mechanical systems demand and return them to serve formal architectural, daylighting, and air quality objectives or to reduce nonmechanical construction costs, and

- can avoid the duct cleanliness dilemma, and its attendant costs, simply by circumventing the need for ducts altogether.

Yet natural ventilation systems:

- presently lack proven ventilation heat recovery capabilities, although some methods are currently under development,

- are generally difficult to control and are inherently unreliable when natural driving forces are small, and 
- presently lack proven filtration capabilities thus may be compromised by urban environments with heavy outdoor particle loadings.

The potential of natural ventilation systems depends, in part, on the suitability of a given climate, in part, on the design of the natural ventilation system used, and in part, on the advantages offered by mechanical system alternatives. Recent developments in natural ventilation system design have been matched by collateral developments in mechanical ventilation design. Thus, for example, as the development of natural ventilation systems offered a means to ventilate without fan power consumption, research into low pressure ventilation systems answered with mechanical systems with reduced fan power requirements. These and other research developments have led quite naturally to the emergence of so-called hybrid ventilation systems that attempt to combine the benefits of both natural and mechanical ventilation in an optimal way $[16,41]$. Recent reports of the design and performance of two U.K. buildings clearly indicate the advantages hybrid system may have when compared to both purely natural or purely mechanical ventilation alternatives $[42,43]$ :

"Independent studies with new buildings using low-energy heat recovery mechanical ventilation integrated into fabric energy storage designs using hollow core slabs have reported better yearround comfort (including summer cooling) standards, together with significantly lower annual delivered and prime energy consumption with lower maintenance requirements than even the best natural ventilation designs." [43]

Thus, somewhat ironically, the future of both natural and mechanical ventilation now clearly lies in the emerging field of hybrid ventilation system design.

This document will first review an approach to evaluate the suitability of climates for ventilative cooling - whether provided by natural, mechanical, or hybrid systems - then go on to describe design methods presently used for natural ventilation system design, including innovative new proposals, and the rapidly emerging hybrid ventilation methods. 



\section{CLIMATE SUITABILITY}

Cooling residences by opening windows and doors during periods of mild weather is a familiar strategy indigenous to practically all climates - yet it is clearly a strategy that is more useful in some climates rather than others. In a few climates, indigenous residential cooling strategies also include pre-cooling building thermal mass by nighttime ventilation to mitigate anticipated uncomfortably warm conditions during the coming day. While night cooling of a building's thermal mass is less familiar to many, it should be intuitively clear that it also is more useful in some climates than others. A survey of traditional residential building types may serve to identify those climates that are particularly suitable for direct ventilative cooling and those that may be expected to benefit most from the more complex night-time cooling strategies.

Unfortunately, lessons learned regarding climate suitability for residential ventilative cooling are not directly applicable to commercial buildings for a number of reasons. Commercial buildings typically have larger internal heat gains than residences; consequently cooling tends to be required for larger portions of the year in the commercial building sector. The impact of larger internal heat gains is mitigated to some extent by the fact that commercial buildings, with typically higher occupancy levels, generally require larger minimum ventilation airflow rates for air quality control. During cooler periods of the year, these minimum ventilation rates tend, naturally, to offset the relatively higher internal gains common to commercial buildings. On the other hand, commercial buildings are generally larger than residences and, consequently, are characterized by having relatively smaller envelope areas to enclosed volume. As a consequence, heat transfer through the building envelope is relatively less important, typically, in commercial buildings in comparison to residential. We say the thermal behavior of commercial buildings tends to be (internal gain) load-dominant rather than skin-dominant as in residences.

The question of climate suitability for ventilative cooling of commercial buildings thus must be approached fundamentally - residential success cannot reasonably be used to identify suitable climates for the commercial building sector. A method to evaluate climate suitability based on a single-zone model of natural ventilation heat transfer in commercial buildings is presented in this section. This method is applied to specific climatic data to characterize:

1. the statistical distribution of the natural direct ventilation rates needed to offset given internal heat gains rates (i.e., due to occupants, equipment and lighting) to achieve thermal comfort during overheated periods, and

2. the potential internal heat gain that may be offset by night-time cooling for those days when direct ventilation is insufficient.

The theory and simplifying assumptions underlying this method will be discussed first, followed by a discussion of the application of the method using ASHRAE WYEC2 records of climatic data [44] for each of eight specific U.S. locations.

Bourgeois has published a similar method [45] using outdoor air temperatures and relative humidities as criteria for control of hybrid ventilation systems. The method proposed here differs in that, in addition, internal gains are considered using the concept of the balance point temperature. Specifically, direct ventilative cooling is allowed as long as the outdoor air temperature exceeds the buildings heating balance point temperature. In contrast, Bourgeois limits direct ventilative cooling to outdoor air temperatures exceeding $12{ }^{\circ} \mathrm{C}$ (i.e., to avoid cold drafts). Consequently, Bourgeois' method more narrowly limits the ventilative cooling season 
than proposed here to avoid potential cold drafts. Here it is assumed that problems associated with cold drafts will be mitigated using any number of strategies some of which will be presented in the following chapter of this report.

\subsection{Theory}

For preliminary climatic suitability analysis a commercial building may be thermally idealized as a control volume with a uniform temperature distribution within - i.e., the common well-mixed single-zone representation of a building illustrated in Figure 2.1:

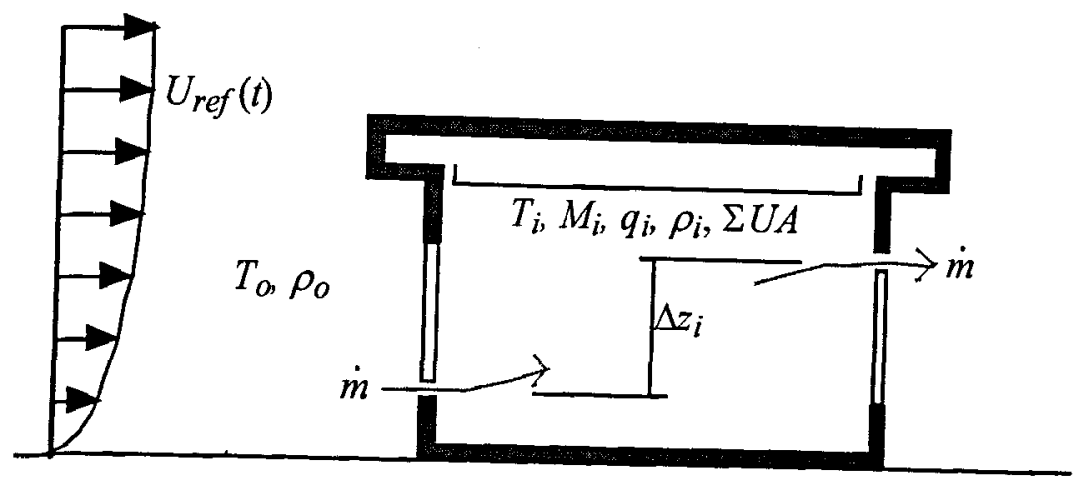

Figure 2.1 Single-zone model of a commercial building.

where:

$\begin{array}{lll}U_{r e f}(t) & = & \text { reference wind speed } \\ T_{o}(t) & = & \text { outdoor air temperature } \\ \rho_{o}(t) & = & \text { outdoor air density } \\ T_{i}(t) & = & \text { indoor air temperature } \\ \rho_{i}(t) & = & \text { indoor air density } \\ q_{i}(t) & = & \text { indoor internal plus solar gains } \\ M_{i} & = & \text { indoor thermal mass } \\ \Sigma U A & = & \text { building envelope thermal conductance } \\ \dot{m} & = & \text { mass flow rate of ventilation air } \\ \Delta z_{i} & = & \text { inlet to outlet elevation change }\end{array}$

With these model parameters and variables defined, the dynamic thermal behavior of this singlezone idealization may be defined by demanding the conservation of thermal energy:

$$
\left(\begin{array}{c}
\text { heat transfer } \\
\text { rate out }
\end{array}\right)+\left(\begin{array}{c}
\text { thermal } \\
\text { energy accumulated }
\end{array}\right)=\left(\begin{array}{c}
\text { heat transfer } \\
\text { rate in }
\end{array}\right)
$$


Dynamic Model $\quad K T_{i}+M \frac{d T_{i}}{d t}=E$

where:

$$
\begin{gathered}
K=\Sigma U A+\dot{m} c_{P} \\
E=K T_{o}+q_{i}
\end{gathered}
$$

In this formulation, conductive heat transfer is arbitrarily separated into a rate out equal to the product of the envelope conductance and the indoor air temperature $(\Sigma U A) T_{i}$ and a rate in $(\Sigma U A) T_{o}$. Thus, the net conductive heat transfer rate is the more familiar product of the envelope conductance and the outside-to-inside temperature difference $(\Sigma U A)\left(T_{o}-T_{i}\right)$. Similarly and more intuitively direct, the ventilative heat transfer rate is separated into a rate out $\dot{m} c_{p} T_{i}$ - where $c_{p}$ is the specific heat capacity of air $\left(1.006 \mathrm{~kJ} / \mathrm{kg}-{ }^{\circ} \mathrm{K}\right.$ or $0.24 \mathrm{kcal} / \mathrm{kg}-{ }^{\circ} \mathrm{K}$ for dry air) - and a rate in $\dot{m} c_{p} T_{o}$. Together, the combined conductive and ventilative heat transfer rate out of the control volume is, thus, $K T_{i}$ where $K$ is the combined conductive and ventilative transfer coefficient defined by Equation 2.3.

This formulation stresses the fact that the response of the thermal system is excited by the sum of conductive, ventilative, and internal gains $K T_{o}+q_{i}$ which are defined by Equation 2.4 to be the system excitation $E$.

\subsubsection{Steady State Approximations}

If either the thermal mass $M_{i}$ of the building system is negligibly small or the indoor air temperature $T_{i}$ is regulated to be relatively constant, then the accumulation term of the governing energy balance of the system, Equation 2.2, may become insignificantly small. Under these conditions the thermal response of the building system will be governed by the steady-state limiting case of Equation 2.2 or:

$$
\text { Steady State Model } \quad K T_{i}=E
$$

This steady-state approximation is the essential basis of the heating and cooling degree day methods used, from one point of view, for preliminary determination of annual heating or cooling energy needs and, from another point of view, as metrics of a given climate's heating and cooling season. It will also provide an approximate means to characterize the ventilative cooling potential of a given climate.

The so-called heating balance point temperature $T_{o-h b p}$ establishes the outdoor air temperature below which heating must be provided to maintain indoor air temperatures at a desired internal heating set point temperature $T_{i-h s p}$. Hence, when outdoor temperatures exceed the balance point temperature direct ventilative cooling can usefully offset internal heat gains to maintain thermal comfort. At or below the balance point temperature ventilative cooling is no longer useful although ventilation would still be maintained at the minimum level required for air quality control. 
At the heating balance point, the combined conductive and ventilative heat loss from the building just offsets internal gains or, using the steady state approximation:

$$
\text { Heating Balance Point } K\left(T_{i-h s p}-T_{o-h b p}\right)=q_{i}
$$

Solving this equation for the balance point temperature and expanding we obtain:

$$
T_{o-h b p}=T_{i-h s p}-\frac{q_{i}}{\dot{m}_{\min } c_{p}+\Sigma U A}
$$

where the ventilation flow rate has been set to the minimum ventilation rate required for air quality control $\dot{m}_{\min }$.

\subsubsection{Thermal Comfort and Humidity Control}

The heating balance point temperature, based on a prescribed heating set point temperature equal to the lowest indoor air temperature that is acceptable for thermal comfort, establishes a lower bound of acceptable outdoor temperatures for ventilative cooling. The outdoor air temperatures equal to the highest acceptable temperature for thermal comfort establishes an upper bound above which ventilative cooling will not be useful. Here, this limiting temperature will be assumed to be equal the indoor cooling set point temperature $T_{i-c p}$ above which mechanical cooling would normally be activated to maintain thermal comfort. In addition, indoor air humidity must be limited to achieve comfortable conditions and to avoid moisture-related problems.

Distinct thermal comfort limits or comfort zones may be identified for summer conditions, when occupants tend to wear lighter clothing, and winter conditions, when occupants tend to wear heavier clothing. However, due to internal gains, natural ventilation may be expected to be useful to limit overheating in commercial buildings during both summer and cooler periods of the year. Consequently, for ventilative cooling of commercial buildings it is useful to use a combined comfort zone that covers all seasons of the year.

A reasonable comfort zone for ventilative cooling, based on combining ASHRAE's winter and summer comfort zones [46], would be delimited by lower and upper dry bulb temperatures of 20 ${ }^{\circ} \mathrm{C}$ and $26^{\circ} \mathrm{C}$ and a dew point temperature of $17^{\circ} \mathrm{C}$ as illustrated in Figure 2.2. Thus for all subsequent considerations:

- the indoor heating set point temperature will be assumed to be, $T_{i-h s p}=20^{\circ} \mathrm{C}$,

- the indoor cooling set point temperature will be assumed to be $T_{i-c s p}=26^{\circ} \mathrm{C}$, and

- indoor air humidity will be limited to a dew point temperature of $T_{i-d p}=17^{\circ} \mathrm{C}$.

Recent surveys of comfort in naturally ventilated office buildings in the U.K. indicate occupants tolerate a larger range of temperatures than in air-conditioned buildings. This is thought to be due to occupant adaptive behavior that is fostered by naturally ventilated buildings [12, 47]. Similar, and even more compelling, observations have been reported for naturally ventilated buildings in North America [48]. When occupant adaptive behavior is considered, the upper limit of the comfort zone may, arguably, be increased by as much as $2{ }^{\circ} \mathrm{C}$ to $5{ }^{\circ} \mathrm{C}$ in still air conditions and even more when occupants can control local air speeds. Furthermore, slightly 
higher relative humidities may be tolerated when local air speeds of $1.5 \mathrm{~m} / \mathrm{s}$ or thereabouts are available [30]. Thus, the comfort zone used here may be considered conservative if adaptive behavior is considered and the ventilation system is designed to provide relatively high local air speeds.

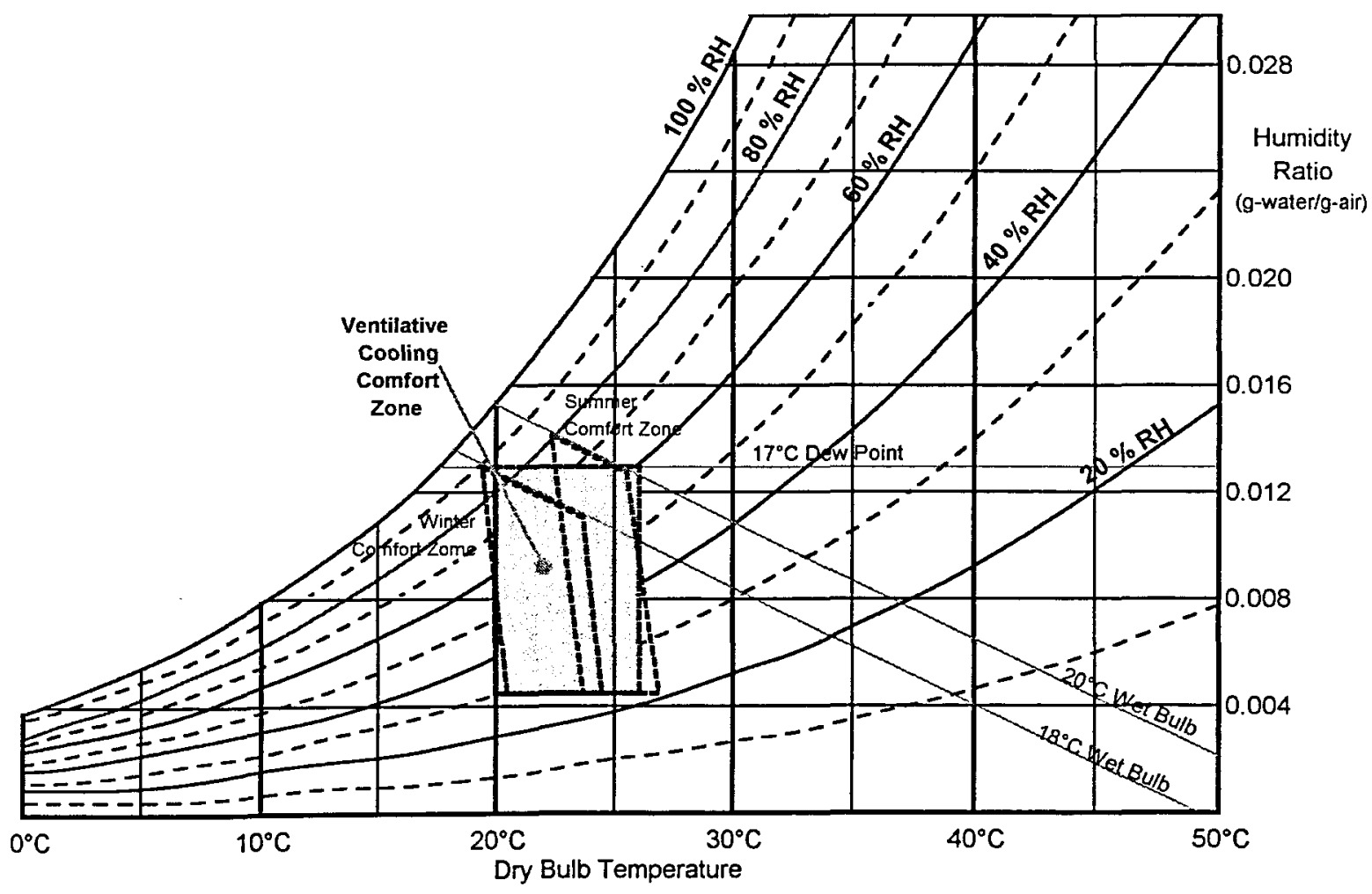

Figure 2.2 Comparison of the ventilative cooling comfort zone used in the present study (gray rectangle) with ASHRAE summer and winter comfort zones [46].

Thus direct ventilative cooling will be considered to be useful (although perhaps not sufficient) when outdoor conditions fall below both the cooling set point and the dew point limit yet above the outdoor heating balance point temperature determined based on the indoor heating set point temperature limit above. Formally, these conditions may be defined as:

Direct Ventilative Cooling Criteria:

$$
T_{o-h b p}\left(q_{i}, T_{i-h s p}=20^{\circ} \mathrm{C}\right) \leq T_{o} \leq T_{i-c s p}=26^{\circ} \mathrm{C} \text { and } T_{o-d p} \leq 17^{\circ} \mathrm{C}
$$

For night ventilative cooling, no lower limit need be placed on outdoor air temperatures and while the air humidity limit is not likely to be immediately important for thermal comfort reasons, it will be maintained to avoid moisture-related problems in building materials and furnishings:

Night Ventilative Cooling Criteria:

$$
T_{o} \leq T_{i-c, p}=26^{\circ} \mathrm{C} \text { and } T_{o-d p} \leq 17^{\circ} \mathrm{C}
$$




\subsection{Climate Suitability Method}

With the theory and comfort criteria established above, a method to evaluate the suitability of a given climate for ventilative cooling may be formulated. This method involves a procedure for estimating the ventilation rate needed to offset internal gains when direct ventilation can be effective and a second procedure for estimating the internal gains that may be offset by nighttime ventilation when direct ventilation is not useful.

\subsubsection{Direct Ventilation}

Relative to enclosed volume, commercial buildings typically have small envelope surface areas yet require relatively large minimum ventilation rates for air quality control. Consequently, the conductive conductance of commercial buildings $\Sigma U A$ may be expected to be small relative to the minimum ventilative conductance $\dot{m}_{\min } c_{p}$ :

$$
\dot{m}_{\min } c_{p}>\Sigma U A
$$

For example, the five story, $4,300 \mathrm{~m}^{2}$ Enschede Tax Office building, that will be the subject of modeling studies presented in Chapter 4 , has a heat loss surface area of $3,930 \mathrm{~m}^{2}$, a total conditioned volume of $15,000 \mathrm{~m}^{3}$, and a relatively low average envelope resistance of 0.57 $\mathrm{W} / \mathrm{m}^{2}-^{\circ} \mathrm{C}$ (i.e., $\mathrm{R} 10$ in I-P units). The design minimum ventilation rate for this building is 2 air changes per hour (ACH) per office or approximately $1 \mathrm{ACH}$ for the building as a whole. Consequently, for this particular building $\dot{m}_{\text {min }} c_{p}=5,000 \mathrm{~W} /{ }^{\circ} \mathrm{C}$ while $\Sigma U A=2,240 \mathrm{~W} /{ }^{\circ} \mathrm{C}$. At the higher ventilation rates used for direct ventilative cooling or for higher resistance envelopes the difference will be proportionately greater.

Thus, the heating balance point temperature of commercial buildings - which is approached from above as ventilation is reduced to the minimum value needed for air quality control - may be roughly estimated by introducing the condition of Equation 2.10 into Equation 2.7 to obtain:

$$
T_{o-h b p}=T_{i-h s p}-\frac{q_{i}}{\dot{m}_{\min } c_{p}+\Sigma U A} \approx T_{i-h s p}-\frac{q_{i}}{\dot{m}_{\min } c_{p}}
$$

or, in terms of rates per unit floor area of building:

$$
T_{o-h b p} \approx T_{i-h s p}-\frac{q_{i} / A}{\left(\dot{m}_{\min } / A\right) c_{p}}
$$

When outdoor air temperatures exceed this balance point temperature, yet fall below the upper limit of the comfort zone - here, taken as the indoor cooling set point temperature $T_{i-c s p}$ ventilation can directly offset internal gains. Recognizing conductive losses during warm periods are typically small relative to internal gains for commercial buildings (i.e., $\left.\Sigma U A\left(T_{i}-T_{o}\right)<q_{i}\right)$, the ventilation rate required to offset internal gains while maintaining indoor air temperatures within the comfort zone, $\dot{m}_{c o o l}$, may be estimated using the steady state model, Equation 2.5 as:

$$
\dot{m}_{c o n l}=\frac{q_{i}-\Sigma U A\left(T_{i}-T_{0}\right)}{c_{p}\left(T_{i}-T_{o}\right)} \approx \frac{q_{i}}{c_{p}\left(T_{i}-T_{o}\right)}
$$


Again, the Enschede Tax Office provides a useful representative example. The net specific internal gain reported for this building was $27.5 \mathrm{~W} / \mathrm{m}^{2}$ thus the total internal gain for this 4,300 $\mathrm{m}^{2}$ building would have been $q_{i}=118,250 \mathrm{~W}$. With a building conductive conductance of $\Sigma U A$ $=2,240 \mathrm{~W} /{ }^{\circ} \mathrm{C}$, even a relatively large inside-to-outside temperature difference of, say, $20{ }^{\circ} \mathrm{C}$ would produce a conductive loss of only $44,800 \mathrm{~W}$ or $38 \%$ of the internal gain. For warmer weather conditions - i.e., as indoor-to-outdoor temperatures approach equality with increased ventilation - the relative impact of conductive losses becomes diminishingly small and Equation 1.12 becomes exact.

Given the width of the comfort zone $\left(T_{i-c s p}-T_{i-h s p}\right)$, two ventilation possibilities must be considered. When outdoor air temperatures fall within an increment of $\left(T_{i-c . s p}-T_{i-h s p}\right)$ above the balance point temperature, the minimum ventilation rate will suffice:

$$
\dot{m}_{c o o l}=\dot{m}_{\min } \text { when } T_{o-h b p} \leq T_{o} \leq T_{o-h b p}+\left(T_{i-c s p}-T_{i-h s p}\right)
$$

Above this range, the ventilation rate will have to increase as outdoor air temperatures increase:

$$
\dot{m}_{\text {cool }}=\frac{q_{i}}{c_{p}\left(T_{i-c s p}-T_{o}\right)} \text { when } T_{o-h b p}+\left(T_{i-c s p}-T_{i-h s p}\right)<T_{o} \leq T_{i-c s p}
$$

or, in terms of rates per unit floor area of building:

$$
\dot{m}_{\text {cool }} / A=\frac{q_{i} / A}{c_{p}\left(T_{i-c s p}-T_{o}\right)} \text { when } T_{o-h b p}+\left(T_{i-c s p}-T_{i-h s p}\right)<T_{o} \leq T_{i-c s p}
$$

Equations (1.12), (1.13), and (1.15) may be used to determine periods when direct ventilative cooling may be applied and to estimate the ventilation rates needed to maintain thermal comfort during these periods. For comparative purposes, it will be useful to further express the ventilation rates in terms of an equivalent air change rate in air changes per hour (ACH) by assuming an average story height of the building, $H$, as:

$$
A C H \approx \frac{\dot{m}_{c o o l}}{A H}
$$

\subsubsection{Nighttime Cooling}

To account for night cooling an alternative strategy must be employed. When daytime outdoor temperatures exceed the upper comfort limit - here, taken as the cooling set point temperature $T_{i-c s p}$ - direct ventilation is no longer useful. One may be able to offset daytime internal gains, however, by cooling the building's thermal mass with outdoor air during the previous night if, of course, the outdoor air temperature drops below the cooling set point temperature during the night. When this is possible, the heat transfer rate at which energy may be removed from the buildings thermal mass $q_{\text {night }}$ approaches, in the limit for a very massive building:

$$
q_{\text {night }} \approx \dot{m} c_{p}\left(T_{i-c s p}-T_{o}\right) \text { when } T_{o}<T_{i-c s p}
$$


The total energy removed from the building's thermal mass during the evening may then be used to offset internal gains on the subsequent workday. On average, the internal gain that may be offset $\bar{q}_{c o o l}$ is thus simply equal to the integral of the night removal rate divided by the workday time period $\Delta t$ :

$$
\bar{q}_{\text {cool }}=\int_{\text {nightime }} q_{\text {night }} / \Delta t
$$

Here, it is useful to rewrite this relation in terms of average cooling rate per unit floor area per air change rate by algebraic manipulation:

$$
\frac{\bar{q}_{c o o l} / A}{\dot{m} / A H}=\frac{\int_{\text {nightime }} c_{p}\left(T_{i-c s p}-T_{o}\right) d t}{H \Delta t} \text { when } T_{o}<T_{i-c s p} .
$$

Equation 2.19 will be used to estimate the internal gain that may be offset (i.e., for very massive construction) for a nominal unit nighttime air change rate to maintain thermal comfort.

\subsubsection{Climate Suitability Evaluation Algorithm}

The relations and criteria established above were used to develop a multi-step algorithm to evaluate the suitability of a given climate for ventilative cooling. Given detailed records of outdoor dry bulb and dew point temperatures the algorithm involves the following steps:

1. Problem Specification: The cooling and heating set point temperatures, limit on dew point temperatures, specific internal gains, and minimum specific ventilation rate, or the equivalent air change rate are specified. Specifically:

- The cooling set point temperature was set equal to the upper limit of the ventilative cooling comfort zone, $T_{i-c s p}=26^{\circ} \mathrm{C}$

- The heating set point temperature was set equal to the lower limit of the ventilative cooling comfort zone, $T_{i-h p p}=20^{\circ} \mathrm{C}$

- The limiting outdoor dew point temperature was set equal to the upper limit of the ventilative cooling comfort zone, $T_{o-d p}=17^{\circ} \mathrm{C}$

- Specific internal gains of $10 \mathrm{~W} / \mathrm{m}^{2}, 20 \mathrm{~W} / \mathrm{m}^{2}, 40 \mathrm{~W} / \mathrm{m}^{2}$, and $80 \mathrm{~W} / \mathrm{m}^{2}$ were considered. The low end of this range corresponds to the combination of state-of-the-art low-energy lighting systems combined with minimal plug-loads in addition to relatively low occupant densities. The upper end corresponds to very intensive lighting, plug loads, and occupancy levels that might be associated with, for example, commodities trading floors. While this range is commonly considered for commercial building design purposes, recent research indicates the upper levels of this range may no longer be realistic $[39,49,50]$.

- Minimum ventilation rates for commercial buildings are prescribed by ASHRAE Standard 62 [51]. Here, the rates specified for offices will be used to establish a typical minimum specific ventilation rate. Due to relatively low occupancy levels (e.g., 7 person $/ 100 \mathrm{~m}^{2}$ ) and moderate rate requirements (i.e., $10 \mathrm{~L} / \mathrm{s}$-person) for offices, the specific ventilation rate required for offices is $0.7 \mathrm{~L} / \mathrm{s}-\mathrm{m}^{2}\left(\dot{m}_{\min } / \mathrm{A} \approx 0.00084 \mathrm{~kg} / \mathrm{s}-\mathrm{m}^{2}\right.$ for air at standard conditions). For an 
assumed story height of $H=2.5 \mathrm{~m}$, this minimum specific ventilation rate corresponds to an air change rate of $1.008 \approx 1.0 \mathrm{ACH}-\mathrm{a}$ convenient, and familiar rate.

2. Balance Point Temperature Computation: Compute the outdoor heating balance point temperature for each specific internal gain considered.

$$
T_{o-h b p} \approx T_{i-h s p}-\frac{q_{i} / A}{c_{p} \dot{m}_{\min } / A}
$$

For the conditions specified above in Step 1 we obtain the results presented in Table 2.1. It is clearly evident from these numbers that internal gains expected in commercial buildings can quite easily extend the ventilative cooling season well into winter months in North America.

Table 2.1 Heating balance point temperatures for a range of specific internal gains.

\begin{tabular}{|c|c|c|c|c|}
\cline { 2 - 5 } \multicolumn{1}{c|}{} & \multicolumn{4}{|c|}{ Specific Internal Gains $\left(q_{i} / A\right)$} \\
\cline { 2 - 5 } & $10 \mathrm{~W} / \mathrm{m}^{2}$ & $20 \mathrm{~W} / \mathrm{m}^{2}$ & $40 \mathrm{~W} / \mathrm{m}^{2}$ & $80 \mathrm{~W} / \mathrm{m}^{2}$ \\
\hline$T_{v-h b p}$ & $8.1^{\circ} \mathrm{C}$ & $-3.8^{\circ} \mathrm{C}$ & $-27.6^{\circ} \mathrm{C}$ & $-75 .{ }^{\circ} \mathrm{C}$ \\
\hline
\end{tabular}

3. Direct Ventilative Cooling Evaluation: For each hour of an annual climatic record for a given location compute the following:

3.1. If $T_{o}<T_{o-h b p}$ no ventilative cooling will be required.

3.2. If $T_{o-h b p} \leq T_{o} \leq T_{o-h b p}+\left(T_{i-c s p}-T_{i-h s p}\right)$ and $T_{o-d p} \leq 17^{\circ} \mathrm{C}$ the cooling ventilation rate may be maintained at the minimum ventilation rate, $\dot{m}_{c o o l}=\dot{m}_{\min }$ while the indoor air temperature $T_{i}$ floats between the balance point temperatures. Record the corresponding air change rate $A C H \approx \dot{m}_{\text {cool }} /(A H)$.

3.3. If $T_{a-h b p}+\left(T_{i-c s p}-T_{i-h s p}\right) \leq T_{o}<T_{i-c s p}$ and $T_{o-d p} \leq 17^{\circ} \mathrm{C}$ the minimum cooling ventilation rate needed to maintain indoor air conditions within the comfort zone (i.e., at the cooling set point temperature) may be computed as:

$$
\frac{\dot{m}_{c o o l}}{A}=\frac{q_{i} / A}{c_{p}\left(T_{i-c s p}-T_{n}\right)}
$$

Record the corresponding air change rate $A C H \approx \dot{m}_{c o o l} /(A H)$.

3.4. Else if $T_{o}>T_{i-c s p}$ or $T_{o-d p}>17^{\circ} \mathrm{C}$ then ventilative cooling is not useful. Record this condition for subsequent evaluation of cooling using nighttime ventilation.

4. Nighttime Ventilative Cooling Evaluation:

4.1. Scan the results of step 3 to identify days for which direct ventilative cooling was not useful for at least one daytime hour. 
4.2. For each day identified in 4.1 , compute the (limiting) rate at which thermal energy can be removed from the building's thermal mass for each hour of the proceeding night (i.e., from $6 \mathrm{pm}$ to $6 \mathrm{am}$ ) as:

$$
q_{n i g h t} \approx \dot{m} c_{p}\left(T_{i-c s p}-T_{o}\right) \text { when } T_{o}<T_{i-c s p} \text { and } T_{o-d p} \leq 17^{\circ} \mathrm{C}
$$

4.3. Using the results from 4.2 compute the average internal gain that may be offset $\bar{q}_{\text {cool }}$ the next day:

$$
\frac{\bar{q}_{\text {cool }} / A}{\dot{m} / A H}=\frac{\int_{\text {nightime }} q_{\text {night }} d t}{H \Delta t}
$$

5. Statistical Analysis: Using standard statistical analysis, characterize the results of Steps 3 and 4 and summarize.

\subsubsection{Climatic Data}

In the application of this method that follows, WYEC2 (Weather Year for Energy Calculations 2) data were used [44]. TheWYEC data sets were devised to be "typical year" data sets intended to be used to evaluate typical year energy consumption:

These "typical year" hourly weather data sets were designed and intended to be primarily representative of long-term temperature means at the respective sites. Their construction and design did not specifically address the needs of equipment sizing calculations, which must properly account for extreme weather sequences. WYEC2 User's Manual and Toolkit [44]

Thus, the WYEC data should be useful for evaluating the climatic suitability (potential) of a given site for natural ventilation applications in buildings for typical year conditions.

When evaluating the performance of a specific (proposed) natural ventilation system it may be reasonable to consider extreme year rather than typical year conditions. Levermore and his colleagues have taken this position, defining an extreme year as the mid-year of the upper quartile of 20 years' climatic data ordered by the average daily mean temperatures for July, August, and September [52]. 


\subsection{Application}

This method was applied to eight U.S. locations using WYEC2 hourly annual climatic data published by ASHRAE [44]. The locations, tabulated below, were selected to be representative of the climate extremes of the country with both coastal and continental locations considered. To evaluate the sensitivity of the method to year-to-year differences in weather records, the method was applied to each of two separate year records for those locations flagged with an asterisk below.

Table 2.2 Table of U.S. locations used for initial climate suitability evaluation.

\begin{tabular}{|c|c|c|}
\hline & Coastal & Continental \\
\hline Hot-Humid & Miami, FL* & Birmingham, AL \\
\hline Hot-Arid & Los Angeles, CA & Phoenix, AZ* \\
\hline Temperate & Seattle, $\mathrm{WA}^{*}$ & Kansas City, $\mathrm{MO}$ \\
\hline Cold & Portland, ME & Madison, WI* \\
\hline
\end{tabular}

* Climate suitability evaluated for two separate WYEC2 weather records including an annual record based on the original WYEC1 data and a separate annual record based on TMY data [44].

Computed results follow in Table 2.3. Data in this table is organized in two columns of data - a set of four columns that report the direct ventilative cooling results:

- the average air change rate required to effect direct ventilative cooling for each of four specific internal gain rates for each of the eight U.S. locations - when direct cooling is effective,

- the variation of the air change rate about the average value to be expected for each case evaluated by computing the standard deviation of the ventilation rates computed to achieve thermal comfort, and

- the fraction of the year direct cooling is effective for each case - i.e., the number of hours direct ventilation is effective out of the total number of hours in a year's record.

A final column that reports the results for complimentary night cooling:

- the average specific internal gain that can be offset by a nominal unit air change rate of (previous) nighttime cooling for overheated days (i.e., those days when direct ventilative cooling is not effective for all hours from 6 am to $6 \mathrm{pm}$ ),

- the fraction of overheated days that may, potentially, be cooled using nighttime ventilation, and

- the total number of days during the year that nighttime cooling may, potentially, be effective. 
These statistics have been devised to provide design guidance for preliminary considerations. To facilitate preliminary design considerations, the direct ventilative cooling results are shaded to distinguish the ranges of ventilation required. Results in white or light gray boxes will require, on average, ventilation rates in the 0 to $5 \mathrm{ACH}$ and 5 to $10 \mathrm{ACH}$ ranges respectively - both quite possible using commonly available natural ventilation strategies. Results in medium and darker gray - 10 to $15 \mathrm{ACH}$ and above $15 \mathrm{ACH}$ - may be difficult to achieve using available natural ventilation strategies, although at this point in time this is not at all certain.

For example, examining the results for Birmingham, $\mathrm{AL}$ we see that an average ventilation rate of $1.7 \pm 1.6 \mathrm{ACH}$ may be expected to provide direct ventilative cooling when the specific internal gain is $10 \mathrm{~W} / \mathrm{m}^{2}$. Furthermore, for this location direct ventilative cooling may be expected to be useful $44.4 \%$ of the hours of the year for this same specific internal gain. Nighttime cooling can be used in this climate to compliment direct cooling, but only 93 days of the year may benefit from it that account for $51 \%$ of the days that may be expected to be overheated. Thus $49 \%$ of these overheated days (i.e., approximately 90 days) would required mechanical air conditioning to achieve thermal comfort. During the 93 days for which nighttime ventilation is possible internal gains can be offset at the rate of $5.5 \pm 3.2 \mathrm{~W} / \mathrm{m}^{2}-\mathrm{ACH}$. Thus to offset a specific internal gain of $10 \mathrm{~W} / \mathrm{m}^{2}$ the nighttime ventilation rate would have to be $10 \div$ $5.5 \geq 1.8 \mathrm{ACH}$ on average. (Here, the $\geq \operatorname{sign}$ is used as the $\bar{q}_{\text {cool }}$ computation is based on the assumption that the building is thermally massive.) 
Table 2.3 Climate suitability statistics for eight U.S. locations

\begin{tabular}{|c|c|c|c|c|c|}
\hline & \multicolumn{4}{|c|}{ Direct Cooling } & \multirow[t]{2}{*}{ Night Cooling $^{1}$} \\
\hline & $10 \mathrm{~W} / \mathrm{m}^{2}$ & $20 \mathrm{~W} / \mathrm{m}^{2}$ & $40 \mathrm{~W} / \mathrm{m}^{2}$ & $80 \mathrm{~W} / \mathrm{m}^{2}$ & \\
\hline \multicolumn{6}{|c|}{ Miami, FL - FLMIAMIT.WY2 data \{FLMIAMIT.WY2 data\} } \\
\hline $\begin{array}{l}\text { Vent. Rate or } \\
\text { Cooling } \\
\text { Potential }\end{array}$ & $\begin{array}{c}3.1 \pm 2.6 \\
\{2.7 \pm 2.2\} \\
\mathrm{ACH}\end{array}$ & $\begin{array}{r}6.0 \pm 5.3 \\
\{5.2 \pm 4.5\} \\
\mathrm{ACH}\end{array}$ & $\begin{array}{l}119 \pm 10.6 \\
10.5 \pm 9.0\} \\
\text { ACH }\end{array}$ & 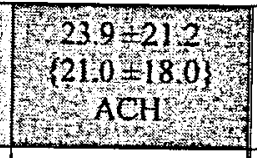 & $\begin{array}{c}2.9 \pm 1.9 \\
\{3.4 \pm 2.2\} \\
W / \mathrm{m}^{2}-\mathrm{ACH}\end{array}$ \\
\hline $\begin{array}{l}\% \\
\text { Effective }^{2}\end{array}$ & $\begin{array}{c}26.5 \% \\
\{26.6 \%\}\end{array}$ & $\begin{array}{c}27.3 \% \\
\{27.7 \%\}\end{array}$ & $\begin{array}{c}27.3 \% \\
\{27.7 \%\}\end{array}$ & $\begin{array}{c}27.3 \% \\
\{27.7 \%\}\end{array}$ & $\begin{array}{c}26 \\
\text { (79 days) } \\
\{26 \%) \\
\text { (80 days) } \\
\end{array}$ \\
\hline \multicolumn{4}{|c|}{ Birmingham, AL - ALBIRMNW.WY2 data } & \multicolumn{2}{|c|}{ Hot-Humid-Continental } \\
\hline $\begin{array}{c}\text { Vent. Rate or } \\
\text { Cooling } \\
\text { Potential } \\
\end{array}$ & $\begin{array}{c}1.7 \pm 1.6 \\
\mathrm{ACH}\end{array}$ & $\begin{array}{c}2.6 \pm 2.9 \\
\mathrm{ACH}\end{array}$ & $\begin{array}{c}5.2 \pm 5.9 \\
\mathrm{ACH}\end{array}$ & $10.4+11: 7$ & $\begin{array}{c}5.5 \pm 3.2 \\
W / m^{2}-A C H\end{array}$ \\
\hline $\begin{array}{l}\% \\
\text { Effective }^{2}\end{array}$ & $44.4 \%$ & $63.6 \%$ & $64.4 \%$ & $64.4 \%$ & $\begin{array}{c}51 \% \\
\text { (93 days) }\end{array}$ \\
\hline \multicolumn{4}{|c|}{ Los Angeles, CA - CALOSANW.WY2 data } & \multicolumn{2}{|c|}{ Hot-Arid-Coastal } \\
\hline \begin{tabular}{c|} 
Vent. Rate or \\
Cooling \\
Potential \\
\end{tabular} & $\begin{array}{c}1.5 \pm 1.0 \\
\mathrm{ACH}\end{array}$ & $\begin{array}{c}3.0 \pm 2.1 \\
\mathrm{ACH}\end{array}$ & $\begin{array}{c}5.9 \pm 4.2 \\
\mathrm{ACH}\end{array}$ & $\begin{array}{l}11.8 \pm 8.4 \\
\mathrm{ACH}\end{array}$ & $\begin{array}{c}5.9 \pm 2.3 \\
W / m^{2}-A C H\end{array}$ \\
\hline $\begin{array}{l}\% \\
\text { Effective }^{2}\end{array}$ & $94.9 \%$ & $97.8 \%$ & $97.8 \%$ & $97.8 \%$ & $\begin{array}{c}93 \% \\
\text { (27 days) }\end{array}$ \\
\hline \multicolumn{4}{|c|}{ Phoenix, AZ - AZPHNIXT.WY2 data \{AZPHNIXW.WY2 data $\}$} & \multicolumn{2}{|c|}{ Hot-Arid-Continental } \\
\hline $\begin{array}{l}\text { Vent. Rate or } \\
\text { Cooling } \\
\text { Potential }\end{array}$ & $\begin{array}{c}2.3 \pm 2.4 \\
\{2.2 \pm 2.2\} \\
\mathrm{ACH}\end{array}$ & $\begin{array}{c}3.9 \pm 4.6 \\
\{3.9 \pm 4.2\} \\
\mathrm{ACH}\end{array}$ & $\begin{array}{c}7.9 \pm 9.1 \\
\{7.7 \pm 8.5\} \\
\mathrm{ACH}\end{array}$ & 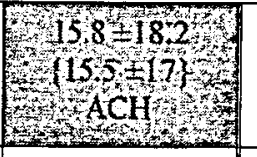 & $\begin{array}{c}3.3 \pm 2.7 \\
\{3.2 \pm 2.7\} \\
\mathrm{W} / \mathrm{m}^{2}-\mathrm{ACH}\end{array}$ \\
\hline $\begin{array}{l}\% \\
\text { Effective }^{2}\end{array}$ & $\begin{array}{c}49.4 \% \\
\{50.3 \%\}\end{array}$ & $\begin{array}{c}59.5 \% \\
\{60.3 \%\}\end{array}$ & $\begin{array}{c}59.5 \% \\
\{60.3 \%\}\end{array}$ & $\begin{array}{c}59.5 \% \\
\{60.3 \%\}\end{array}$ & $\begin{array}{c}70 \% \\
\text { (153 days) } \\
\{67 \%\} \\
\text { (143 days) }\end{array}$ \\
\hline \multicolumn{4}{|c|}{ Seattle, WA - WASEATLT.WY2 data \{WASEATLW.WY2 data\} } & \multicolumn{2}{|c|}{ Temperate-Coastal } \\
\hline $\begin{array}{c}\text { Vent. Rate or } \\
\text { Cooling } \\
\text { Potential }\end{array}$ & $\begin{array}{c}1.4 \pm 1.2 \\
\{1.4 \pm 1.1\} \\
\mathrm{ACH}\end{array}$ & $\begin{array}{c}1.9 \pm 2.0 \\
\{2.0 \pm 1.9\} \\
\mathrm{ACH}\end{array}$ & $\begin{array}{c}3.9 \pm 3.9 \\
\{3.9 \pm 3.8\} \\
\mathrm{ACH}\end{array}$ & $\begin{array}{c}7.8 \pm 7.9 \\
\{7.8 \pm 7.6\} \\
\mathrm{ACH}\end{array}$ & $\begin{array}{c}6.8 \pm 1.6 \\
\{6.6 \pm 1.4\} \\
W / m^{2}-A C H\end{array}$ \\
\hline $\begin{array}{l}\% \\
\text { Effective }^{2}\end{array}$ & $\begin{array}{c}56.1 \% \\
\{55.7 \%\}\end{array}$ & $\begin{array}{c}98.1 \% \\
\{98.0 \%\}\end{array}$ & $\begin{array}{c}98.3 \% \\
\{98.5 \%\}\end{array}$ & $\begin{array}{c}98.3 \% \\
\{98.5 \%\}\end{array}$ & $\begin{array}{c}100 \% \\
(26 \text { days }) \\
\{100 \%\} \\
(21 \text { days })\end{array}$ \\
\hline \multicolumn{4}{|c|}{ Kansas City, MO - MOKANCTW.WY2 data } & \multicolumn{2}{|c|}{ Temperate-Continental } \\
\hline $\begin{array}{l}\text { Vent. Rate or } \\
\text { Cooling }\end{array}$ & $1.9 \pm 1.8$ & $2.6 \pm 3.1$ & $4.8 \pm 6.1$ & $9.7 \pm 12.1$ & $4.5 \pm 3.2$ \\
\hline
\end{tabular}




\begin{tabular}{|c|c|c|c|c|c|}
\hline Potential & $\mathrm{ACH}$ & $\mathrm{ACH}$ & $\mathrm{ACH}$ & $\mathrm{ACH}$ & $\mathrm{W} / \mathrm{m}^{2}-\mathrm{ACH}$ \\
\hline $\begin{array}{l}\% \\
\text { Effective }^{2}\end{array}$ & $37.8 \%$ & $67.4 \%$ & $73.9 \%$ & $73.9 \%$ & $\begin{array}{c}57 \% \\
\text { (81 days) }\end{array}$ \\
\hline \multicolumn{5}{|c|}{ Portland, ME - MEPORTLW.WY2 data } & Cold-Coastal \\
\hline $\begin{array}{c}\text { Vent. Rate or } \\
\text { Cooling } \\
\text { Potential }\end{array}$ & $\begin{array}{c}1.6 \pm 1.3 \\
\mathrm{ACH}\end{array}$ & $\begin{array}{c}2.1 \pm 2.2 \\
\mathrm{ACH}\end{array}$ & $\begin{array}{c}3.7 \pm 4.2 \\
\mathrm{ACH}\end{array}$ & $\begin{array}{c}7.4 \pm 8.4 \\
\mathrm{ACH}\end{array}$ & $\begin{array}{c}7.4 \pm 3.3 \\
W / \mathrm{m}^{2}-\mathrm{ACH}\end{array}$ \\
\hline $\begin{array}{l}\% \\
\text { Effective }^{2}\end{array}$ & $39.1 \%$ & $79.8 \%$ & $92.5 \%$ & $92.5 \%$ & $\begin{array}{c}87 \% \\
\text { (52 days) }\end{array}$ \\
\hline \multicolumn{5}{|c|}{ Madison, WI - WIMADSNT.WY2 data \{WIMADSNW.WY2 data\} } & Cold-Continental \\
\hline $\begin{array}{c}\text { Vent. Rate or } \\
\text { Cooling } \\
\text { Potential }\end{array}$ & $\begin{array}{c}1.8 \pm 1.7 \\
\{1.8 \pm 1.6\} \\
\mathrm{ACH}\end{array}$ & $\begin{array}{c}2.4 \pm 2.8 \\
\{2.2 \pm 2.6\} \\
\mathrm{ACH}\end{array}$ & $\begin{array}{c}4.1 \pm 5.2 \\
\{3.8 \pm 4.8\} \\
\mathrm{ACH}\end{array}$ & $\begin{array}{c}8.2 \pm 10.4 \\
\{7.6 \pm 9.7\} \\
\mathrm{ACH}\end{array}$ & $\begin{array}{c}6.0 \pm 3.0 \\
\{6.3 \pm 3.0\} \\
W / \mathrm{m}^{2}-\mathrm{ACH}\end{array}$ \\
\hline $\begin{array}{l}\% \\
\text { Effective }^{2}\end{array}$ & $\begin{array}{c}39.3 \% \\
\{34.7 \%\}\end{array}$ & $\begin{array}{c}72.4 \% \\
\{71.5 \%\}\end{array}$ & $\begin{array}{c}88.7 \% \\
\{87.4 \%\}\end{array}$ & $\begin{array}{c}88.7 \% \\
\{87.4 \%\}\end{array}$ & $\begin{array}{c}82 \% \\
\text { (68 days) } \\
\{83 \%\} \\
\text { (75 days) }\end{array}$ \\
\hline
\end{tabular}

Night cooling for subsequent days when direct cooling is not effective.

${ }^{2}$ For direct cooling $\%=$ hours effective $\div 8760$ hours; for night cooling $\%=$ days effective $\div$ days needed. white $=0$ to $5 \mathrm{ACH}$

light gray $=5$ to $10 \mathrm{ACH}$

medium gray $=10$ to $15 \mathrm{ACH}$

2ain dark gray $>15 \mathrm{ACH}$

The decision to employ ventilative cooling strategies depends in part on the ventilation rates that will be required to effect the cooling and in part on the relative effectiveness of the strategy. For example, examining the Miami, FL data we see that direct cooling will not only require relatively high ventilation rates for moderate specific internal gains (e.g., 20 to $40 \mathrm{~W} / \mathrm{m}^{2}$ ) but even then it will be useful for only a small fraction of the year. For this U.S. location, nighttime cooling also proves to be relatively marginal demanding relatively high nighttime ventilation rates to offset moderate specific internal gains and then only effective for $26 \%$ of the overheated days of the year.

This particular example points out the critical difference between assessing natural ventilation potential for commercial versus residential applications. Residential (direct) natural ventilation was traditionally used in the Miami area to mitigate overheating. With specific internal gains expected to fall below $10 \mathrm{~W} / \mathrm{m}^{2}$ in residences, the computed results indicate direct cooling will, in fact, be useful in this location if modest levels of natural ventilation can be achieved (i.e., on the order of $3 \mathrm{ACH}$ ). This strategy may be expected to be useful for only $26.5 \%$ of the year and nighttime cooling cannot be expected to mitigate more than $26 \%$ of the remaining overheated days of the year. Thus, as is well known, mechanical air conditioning is commonly used in residences in Miami for overheated periods and natural ventilation for the shoulder seasons. Even this compromise strategy will prove, however, marginal for commercial buildings with higher specific internal gains.

To better facilitate consideration of the level of ventilation needed and relative efficacy of direct cooling the data presented in Table 2.3 has been plotted in the form of bubble plots for the four 
coastal locations and the four continental locations - Figure 2.3 and Figure 2.4. In these plots the center of each bubble locates the average ventilation rate required for each of the four specific internal gain rates considered and the size of the bubble indicates the relative efficacy of direct ventilative cooling. Thus, larger bubbles located lower in the plot indicate direct ventilative cooling is not only feasible (vis a vis ventilation rate required to implement it) but effective.

Examining these plots reveals that direct ventilative cooling may be expected to be most feasible and effective in the cooler locations for moderate to high specific internal gains - a reasonable result that may at first seem unintuitive. Direct cooling will not be particularly feasible or effective in the hot-humid locations for moderate to high specific internal gains.

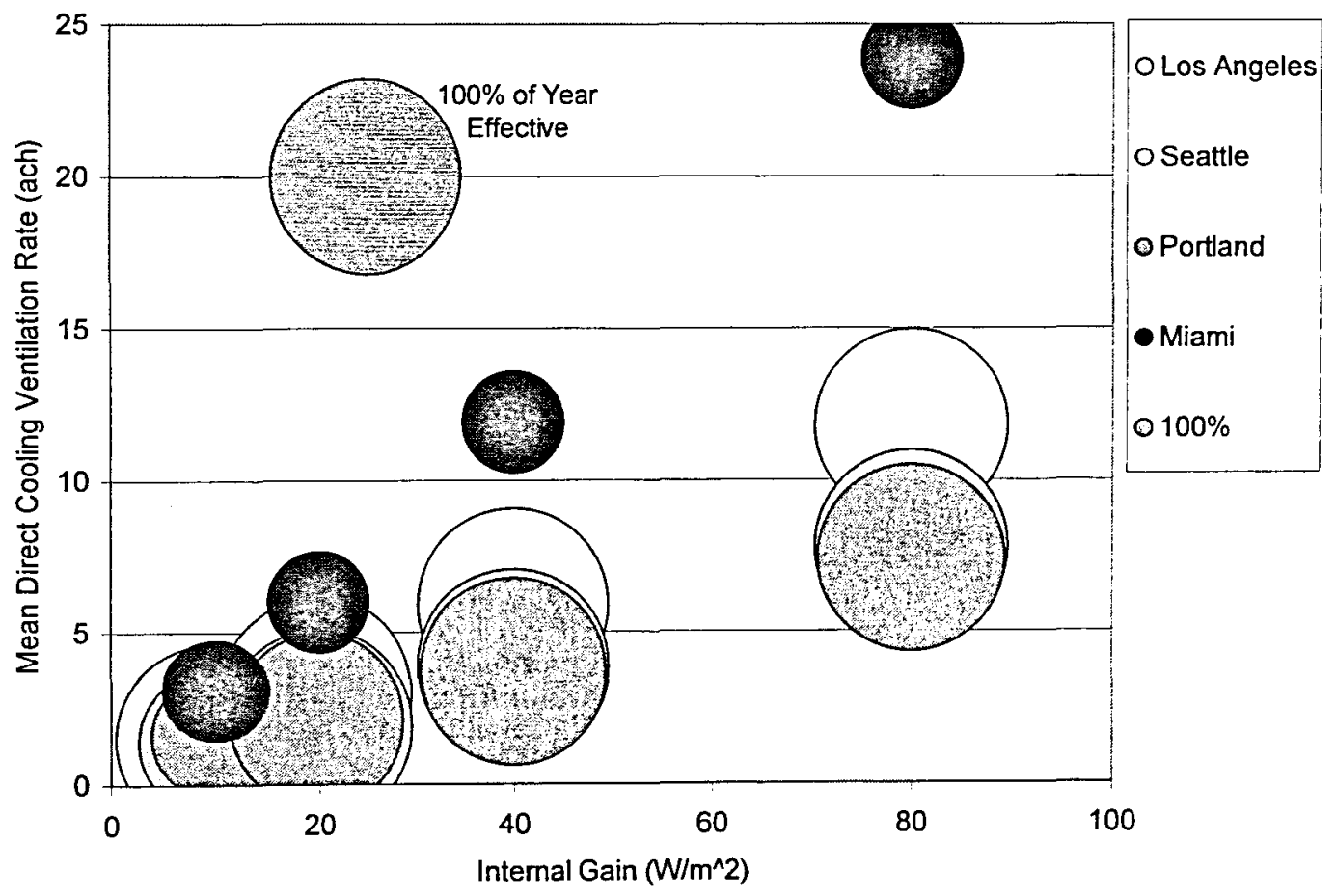

Figure 2.3 Direct ventilative cooling results for the coastal locations. 


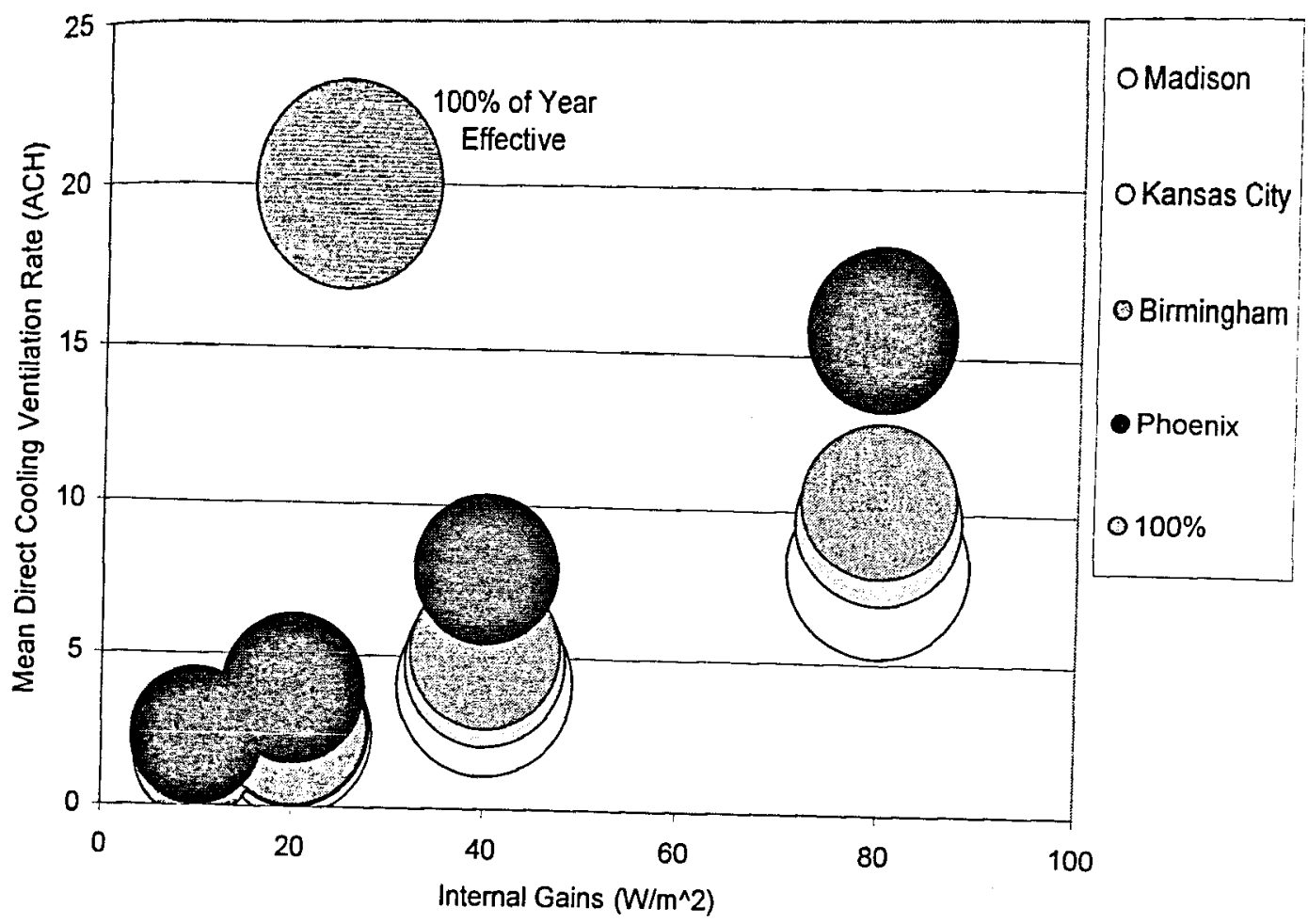

Figure 2.4 Direct ventilative cooling results for the continental locations

\subsection{Discussion}

The proposed method has a rational physical basis and, therefore, should be considered relatively general. The first results of its application indicate that it is able to reveal significant differences between climates - differences that are large relative to the uncertainty in determination for any given climate (i.e., as indicated by the application of the method to two weather records for four of the locations considered). Furthermore, the method has been devised to provide building designers with useful preliminary design guidance relating to the levels of ventilation required to implement the direct and nighttime cooling strategies. These observations suggest that the proposed method may prove to be a practically useful design tool.

The method is not without its faults, however. First, estimates of the internal gains that may be offset by nighttime cooling are based on the assumption that the building has, essentially, infinite thermal mass thus these results may significantly overestimate the benefit of nighttime cooling. This fault could be corrected with a measure of heat transfer efficiency that reflects the anticipated level of thermal mass available in the building, but this correction would require additional research using a dynamic formulation of the building heat transfer.

The assumptions underlying the evaluation of direct ventilative cooling potential are less problematic - i.e., beyond the assumption that commercial building thermal behavior tends to be dominated by internal and solar gains rather than skin losses during warmer weather. The statistical representation of the required ventilation rate to offset a given specific internal gain using a mean rate and the standard deviation about this mean may require reconsideration. Examining the results reported in Table 2.3 reveals that the variation about the mean often 
exceeds the mean. Given the inverse relation between the required ventilation rate and the temperature difference between indoors and out, computed required ventilation rates will not have a simple Gaussian distribution. Thus, alternative statistical characterizations of computed results may prove more useful. This should be investigated in the future.

As presented, the climate suitability analysis tacitly assumed the temperature of the ventilation exhaust was equal to the indoor occupied zone temperature - a condition that would be met if the building zone was well-mixed. The analysis, being based on a control volume approach, need not be limited to a well-mixed zone assumption - the exhaust air temperature should simply reflect the intended operation of the ventilation system being used. If, for example, one seeks to drive ventilation airflows primarily by buoyancy forces then allowing temperature stratification within the building offers some marginal advantages [53-55]. In such a case, exhaust air temperatures could exceed comfort limits (e.g., the indoor cooling set point) by an increment corresponding to that resulting from acceptable or likely stratification, say, $\Delta T_{\text {srrat }}=T_{i-\text { strat }}-T_{i-\text { csp }}$. For direct ventilative cooling, then, the ventilation rate per unit floor area needed to offset a given internal gain (i.e., Equation 1.15) would be modified as:

$$
\dot{m}_{\text {cool }} / A=\frac{q_{i} / A}{c_{p}\left(\Delta T_{\text {strat }}+T_{i-c s p}-T_{o}\right)} \text { when } T_{o-h b p}+\left(T_{i-c s p}-T_{i-h s p}\right)<T_{o} \leq T_{i-c s p}
$$

and analysis would proceed as before. Thus, for example, if a designer feels a $4{ }^{\circ} \mathrm{C}$ stratification increment is acceptable (i.e., if exhaust temperatures can exceed the upper comfort limit by $4{ }^{\circ} \mathrm{C}$ ) then the analysis would proceed with the temperature term of the denominator above increased by $4{ }^{\circ} \mathrm{C}$ thus reducing the ventilation rate needed at any time step during the analysis.

In this way, the reduced ventilation rate benefit of utilizing thermal stratification - in combination with displacement ventilation - may be accounted for. The risk of compromising thermal comfort by radiant exchange from warm ceilings should, however, be considered. For all but the tallest commercial buildings, however, wind forces are likely to play a more important role in natural and hybrid ventilation systems than buoyancy forces - as will be discussed in the next chapter - thus consideration of thermal stratification may not be necessary or appropriate.

The method also presumes direct ventilative cooling should be the strategy of first resort and nighttime ventilative cooling should only be considered as a complement to direct cooling. Conceivably, in some climates or for certain applications nighttime cooling should be considered as the primary strategy. This should also be investigated in the future.

Finally, the method does not directly address questions relating to ambient air quality - outdoor levels of particulates, ozone, volatile organic compounds, carbon monoxide, etc. A complete climate suitability analysis must, of course, consider these and other related problems such as ambient noise levels, the need for security, rain and insect entrainment and the like and seek design solutions to address them. In particularly challenging environments, mechanical ventilation utilizing particulate and even gas-phase filtration may prove necessary. Nevertheless, direct ventilative and nighttime cooling strategies can still be implemented and the "thermal suitability analysis" presented may still be applied. 


\subsection{Conclusion}

A method to evaluate the climate suitability of a given location for direct ventilative cooling and complimentary nighttime ventilative cooling of a building's thermal mass has been presented. Importantly, the method may be applied, in principle, to ventilative cooling achieved by natural, mechanical, or mechanically assisted natural means. This method allows the building designer to evaluate the feasibility and potential effectiveness of ventilative cooling strategies, given knowledge of the likely internal gains in the building, and make first estimates of the ventilation rates required to effect these strategies. 


\section{SYSTEM DESIGN METHODS}

This section of the report will consider the natural ventilation system design methods that have evolved largely from European efforts - specifically the physical design strategies and the computational design tools developed to support them that now define the field of advanced methods of natural ventilation system design. In the brief period of the past decade, these European developments have proceeded through a number of distinct generations moving from early systems that relied exclusively on natural driving forces to the less doctrinaire mechanically-assisted natural ventilation systems, identified here as hybrid ventilation systems, to mix-mode systems that maintain both mechanical and natural ventilation (sub)systems to better handle seasonal variations of a given climate or spatial variations of a given building [56]. Buoyed by successes in new building design and cognizant of the relatively greater importance of building renovation, strategies to adapt these low-energy ventilation strategies to existing buildings are also now beginning to emerge [57].

\subsection{Design Strategies}

The evidence of past yet often unused natural ventilation "systems" - i.e., elements of building configuration and detail - remains visible in many older North American commercial buildings:

- narrow plan configurations and courtyard and atria schemes that increase access to both light and air,

- operable windows or in some instances operable vents in window frames that admit outdoor air and daylight,

- transom openings over doorways that allow air (and light) to flow from offices to hallways,

- relatively open hallways, stairways, and atria that allow air (and light, again) to flow to higher level exhaust vents,

- operable clerestories or skylights above stairways and atria spaces that exhaust stale or warm air and admit daylight to illuminate the circulation paths that they serve.

These, now, archaic systems reveal the three basic elements of natural ventilation systems:

- an appropriate building form: a building form providing access to outdoor air that is sited and shaped to take advantage of prevailing winds and/or to take advantage of buoyancy forces resulting from air temperature differences,

- appropriately sized inlet and outlet openings: most often controllable, inlet and outlet openings sized to admit sufficient outdoor air and to exhaust indoor air to achieve the natural ventilation objective, and

- a relatively unrestricted airflow path from inlet to outlet: natural ventilation inlets and outlets necessarily must be linked by relatively unrestricted paths configured to direct airflow throughout the building.

Importantly, the building form itself - i.e., exterior and interior spatial configuration and detail is inevitably an important, if not in some respects the most important, component of natural ventilation systems. The building form not only determines, to large extent, the magnitude and 
constancy of the natural wind and buoyancy forces that drive the natural ventilation, its interior configuration is most often shaped to complete relatively low-resistance airflow paths from inlet to outlet.

While these traditional natural ventilation systems may well be conceptually reasonable they are not likely to be detailed to achieve the thermal comfort control that we have come to prefer after a half century of mechanically conditioned commercial buildings nor the air quality control and energy efficiency we now require of sustainable building designs. Consequently, a number of design strategies have been developed in recent years to, in most cases, improve upon these and other traditional systems while, in other cases, that present truly new and innovative alternatives.

As suggested by the discussion of the historic precedents presented above, the design of natural and mechanically-assisted ventilation systems logically involves the selection of physical system components and building form given a clear definition of ventilation objective(s) and associated performance criteria for anticipated environmental conditions.

Design is an often overloaded word that must be understood as both a noun and a verb. As suggested by the discussion of the historic precedents presented above, the design of natural and mechanically-assisted ventilation systems - as a noun - logically involves the selection of physical system components and building form for anticipated environmental conditions (design conditions) given a clear definition of ventilation objectives and associated performance criteria (i.e., design requirements). As a verb design must be understood to be the process used to achieve the selection of the ventilation system components and building form.

\section{System Selection - Design as Noun}

The selection of the physical system components and building form involves:

- General Configuration - The selection of the general configuration of the ventilation system and, importantly, building form that will serve it. This will entail decisions relating to outdoor air inlet location(s), stale air outlet location(s), ventilative airflow path(s) through the building from inlet to outlet, and building and site geometry.

- System Topology - The selection of the type and connectivity of the system components needed. This will entail selection of specific hardware for such physical components as inlet vents, ducts, transfer grills, ventilation stacks, stack terminal devices or other outlets, airflow control devices, and the like.

- Component Sizing - The selection of ventilation system component sizes and related details to achieve specific natural ventilation objective(s) for anticipated environmental conditions.

- Control and Operational Strategies - The selection of control and operational strategies to achieve specific natural ventilation objective(s) for anticipated environmental conditions.

\section{Design Process - Design as Verb}

In North America, the building design process and the exchange of design products for design fees commonly unfolds in five distinct steps: 
1. Predesign Programming and Analysis - the definition of the building design program or brief that establishes design objectives and requirements and analytical investigations (e.g., climate and site analyses) needed to define design conditions and requirements.

2. Conceptual or Preliminary Design - the development of the general configuration and topology of the building system often done with little quantitative analysis using intuition, precedents, general guidelines, and rules of thumb.

3. Design Development - the development of system component sizes and details and system control and operational strategies using either empirical or theoretical analytical techniques.

4. Design Performance Evaluation - quantitative evaluation of the thermal, airflow, and air quality performance of the proposed system relative to defined design requirements for the given design conditions.

5. Construction and Commissioning of the Proposed System.

This section of the report will consider design tools intended to serve the first four phases of the design process - i.e., as applied to the design of natural and hybrid ventilation systems.

\section{Performance Criteria - Air Quality Control}

As discussed earlier, natural ventilation may serve one of three primary objectives - air quality control, direct cooling, or indirect cooling via night cooling of building thermal mass. Performance criteria for air quality control are well established. They may be defined prescriptively in terms of minimum ventilation rates (e.g., ASHRAE Standard 62's Ventilation Rate Procedure) or by "restricting the concentration of all known contaminants of concern to some specified acceptable levels" (e.g., ASHRAE Standard 62's Indoor Air Quality Procedure) [51]. Designing for a minimum ventilation rate (e.g., for offices ASHRAE Standard 62-99 stipulates a minimum ventilation rate of $10 \mathrm{~L} / \mathrm{s}$-person) proves to be analytically straightforward yet "provides only an indirect solution to the control of air contaminants" [51]. Designing to restrict air contaminant concentrations is, on the other hand, far more difficult. Consequently, the prescriptive control of minimum ventilation rates is most often the approach taken in the design of natural and mechanical ventilation systems.

In a well-designed, properly insulated and tightly constructed naturally ventilated building, however, winter heat losses are likely to be dominated by ventilation losses when compared to conductive skin losses. Summer cooling by means of natural ventilation, on the other hand, may be implemented without any energy demands thus the energy penalty associated with prescribed minimum ventilation rates may well dominate the energy consumed annually for space conditioning. Thus, use of prescribed minimum ventilation rates for air quality control deserves careful consideration.

In principle, a substantial portion (e.g., up to $90 \%$ ) of the ventilation heat loss could be recovered using heat recovery methods but, as will be discussed below, heat recovery in natural ventilation systems has proven to be difficult to achieve. Here, hybrid systems appear to provide a distinct advantage. Alternatively, one could control minimum ventilation rates using air quality sensors - $\mathrm{CO}_{2}$ demand controlled ventilation represents one common approach used in mechanical ventilation systems - but, again, this has proven to be difficult to achieve in natural ventilation systems. 


\section{Performance Criteria - Ventilative Cooling}

Performance criteria for ventilative cooling are not yet well established, although a number of approaches and even standards have been proposed. Fundamentally, a ventilative cooling system should provide, of course, thermal comfort but the growing evidence that individuals are more likely to adapt to seasonal variations when given the opportunity demands new approaches to the evaluation of thermal comfort $[12,29,31,47,48,58,59]$. Adaptation not only links the range of acceptable temperatures to changes in the outdoor air temperature [48] but to air velocities experienced directly by individuals [12] and the 'adaptive opportunity' provided by occupant control of lighting, shading, and airflow in buildings [40].

Well-designed user-controlled natural and hybrid ventilation systems - especially when combined with user-controlled low-energy shading and lighting systems - offer the 'adaptive opportunity' that may well justify higher indoor air temperatures without compromising comfort. The Brager "adaptive standard for naturally ventilated buildings" establishes an indoor air control temperature comfort zone for office activities (i.e., less than $1.2 \mathrm{met}$ ) that varies from the range of $17^{\circ} \mathrm{C}$ to $22^{\circ} \mathrm{C}$ when outdoor air temperatures are $5^{\circ} \mathrm{C}$ or lower up to a range of $26^{\circ} \mathrm{C}$ to $31^{\circ} \mathrm{C}$ when outdoor air temperatures reach $34^{\circ} \mathrm{C}$ or higher [48]. Beyond these adaptive impacts on comfort, increased air velocities are known to offset higher temperatures when these air velocities are personally controlled. While this additional advantage has yet to be codified into a standard [12], Arens [242] reports comfort may be realized at air temperatures of $31^{\circ} \mathrm{C}$ with air velocities of $1 \mathrm{~m} / \mathrm{s}$ to $1.2 \mathrm{~m} / \mathrm{s}$ for moderate relative humidities supporting $B$ rager's upper limit on the comfort zone for naturally ventilated buildings. Aynsley goes farther and claims upper limit of the comfort zone may be increased by up to $3.7^{\circ} \mathrm{C}$ (above $30^{\circ} \mathrm{C}$ ) for every meter per second of air velocity up to $2.0 \mathrm{~m} / \mathrm{s}$ in hot humid environments [60].

When night cooling of building thermal mass is utilized in a natural or hybrid ventilation system, mean radiant surface temperatures will fall below indoor air temperatures and a thermal comfort benefit will be realized. The benefit realized may be estimated using a temperature comfort index equal to a weighted average of the mean radiant temperature in a room $T_{m r}\left({ }^{\circ} \mathrm{C}\right)$ and the room air temperature $T_{a}\left({ }^{\circ} \mathrm{C}\right)$ - e.g., the operative temperature promoted by ASHRAE [46] or the dry resultant temperature preferred by CIBSE [61]. Here, the CIBSE dry resultant (comfort) temperature $T_{c}\left({ }^{\circ} \mathrm{C}\right)$ is most convenient because it accounts for the impact of air velocity, $u$ $(\mathrm{m} / \mathrm{s})$, on the balance between radiative and convective transfer in a simple manner:

$$
\text { CIBSE Dry Resultant Temperature } \quad T_{c}=\frac{T_{m r}+T_{a} \sqrt{10 u}}{1+\sqrt{10 u}}
$$

For low air velocities on the order of $u \approx 0.1 \mathrm{~m} / \mathrm{s}$ the dry resultant temperature approximates the simple average of the mean radiant temperature and room air temperature $T_{c}=\left(0.5 T_{m r}+0.5 T_{a}\right)$. At relatively high air velocities on the order of $u \approx 2 \mathrm{~m} / \mathrm{s}$ - i.e., that tend to be disruptive in office environments - the weighted average shifts to be dominated by the room air temperature, $T_{c} \approx\left(0.2 T_{m r}+0.8 T_{a}\right)$, reducing the impact of radiant exchange. When night cooling strategies are operative, however, daytime natural ventilation should normally be limited to the minimum rate needed for air quality control to avoid advective over heating of the building, thus air velocities will tend to be minimized and, fortuitously, radiant impact maximized as desired. 
For our purposes here, then, thermal comfort will be defined in terms of the CIBSE dry resultant temperature, Equation 3.1, using Brager's adaptive standard for naturally ventilated buildings as illustrated in Figure 3.1. (A method for evaluating overheating is also schematically illustrated on this figure - after Irving's similar illustration [40] - that will be discussed subsequently. Briefly, the small squares indicate, schematically, representative hourly room air temperatures that exceed the upper limit of the comfort zone, the double headed arrows the corresponding temperature differences, and their integrated sum will be used as a metric of overheating).

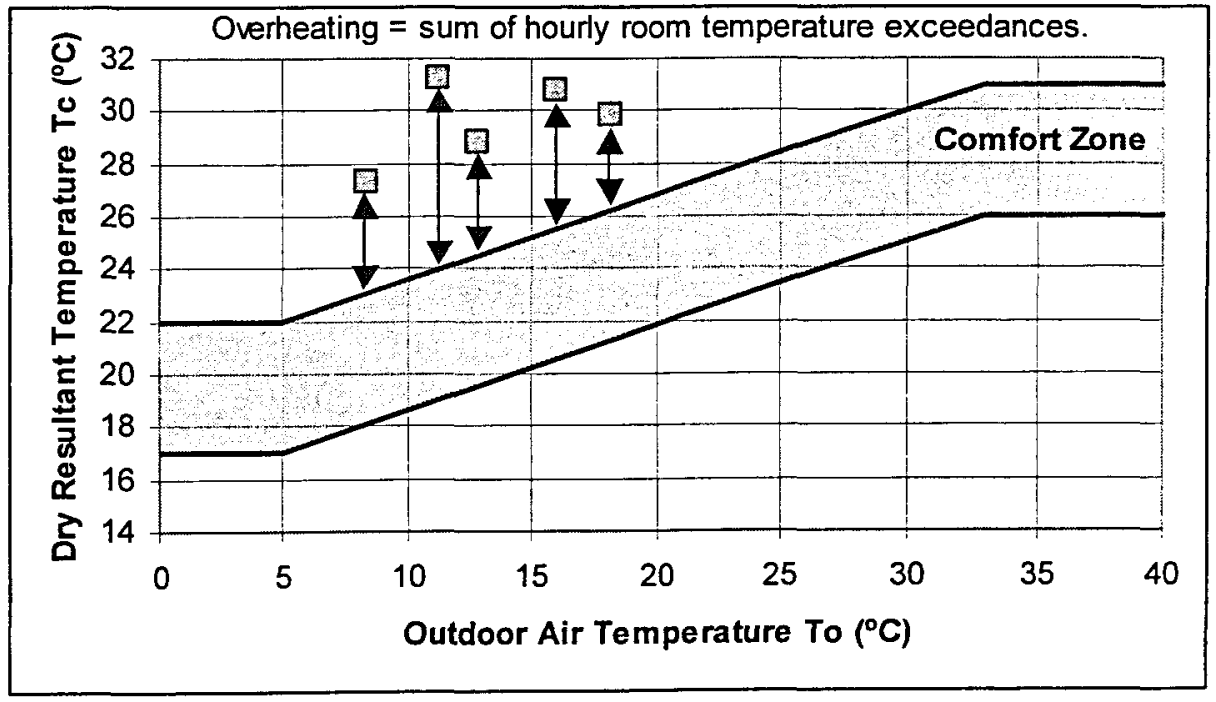

Figure 3.1 Adaptive thermal comfort zone used in subsequent evaluations based on Brager's proposed standard [48] utilizing CIBSE's indoor dry resultant temperature rather than ASHRAE's operative temperature.

When cooling by natural means, the upper limit of the thermal comfort zone may be exceeded from time to time due to the stochastic uncertainty of the natural driving forces. This inevitabile reality must be accepted, within limits, if cooling by natural ventilation is to be pursued. Thus, beyond a well-defined and appropriate description of thermal comfort one must also establish limiting criteria for overheating. Irving reviews a number of proposed standards for assessing and limiting the degree of overheating [40]. The BRE Environmental Design Manual places limits on the mean and standard deviation of summer and indoor air temperatures of $23 \pm 2{ }^{\circ} \mathrm{C}$ for 'formal offices' and $25 \pm 2{ }^{\circ} \mathrm{C}$ for 'informal offices'. In the Netherlands, dry resultant temperatures are not to exceed $25^{\circ} \mathrm{C}$ for more than $5 \%$ of working hours and $28{ }^{\circ} \mathrm{C}$ for more than $1 \%$ of working hours. These and similar absolute approaches do not, however, quantify the degree of overheating. To remedy this shortcoming the 1994 ISO 7730 utilizes a weighted sum of penalty factors for temperatures greater than or equal to $25^{\circ} \mathrm{C}$ with larger penalty factors assigned to the higher temperatures (i.e., a penalty factor of 1.0 for $25^{\circ} \mathrm{C}$ to 4.2 for $30^{\circ} \mathrm{C}$ ) [62]. This approach seems not only arbitrary, it does not directly account for adaptive behavior.

Other standards have been proposed based on an accumulation of hourly temperature exceedances - i.e., the difference between actual or predicted indoor air temperature and a comfort upper limit when the indoor air temperature exceeds that limit - to produce an integrated degree-hour estimate of overheating. Of these, that used in Zurich Switzerland comes closest to accounting for adaptive behavior in that it employs an upper limit to thermal comfort that varies 
with outdoor air temperature. In Zurich, the limit on the integrated temperature exceedance is set at 30 degree hours for a successful natural ventilation system design [40].

Here, overheating will be assessed using a variation of the Zurich method by accumulating the number of temperature exceedance degree hours (i.e., relative to the adapted Brager comfort standard above, Figure 3.1) to evaluate the overheating degree hours $O D H$ that is either observed or predicted for a given building design. The upper limit to the comfort zone in Figure 3.1 may be defined as:

$$
T_{\text {upper }}=\left\{\begin{array}{l}
22^{\circ} \mathrm{C} \text { for }\left(T_{o} \leq 5^{\circ} \mathrm{C}\right) \\
(9 / 28) T_{o}+20.4^{\circ} \mathrm{C} \text { for }\left(5^{\circ} \mathrm{C}<T_{o}<33^{\circ} \mathrm{C}\right) \\
31^{\circ} \mathrm{C} \text { for }\left(T_{o} \geq 33^{\circ} \mathrm{C}\right)
\end{array}\right.
$$

With this limit in hand, the overheating degree hours $O D H$ may then be defined as the integrated sum of the temperature exceedances for the cooling season as:

$$
O D H=\sum_{\text {cooling season }} \max \left\{\left(T_{c}-T_{\text {upper }}\right), 0\right\} \Delta t
$$

where, $\Delta t$ is the time increment for the record of indoor dry resultant temperatures $T_{c}$ (e.g., one hour when using hourly weather records for predictive assessments).

\section{Performance Criteria - Energy Benchmarks}

Beyond air quality control and thermal comfort, the performance of ventilation systems should include an assessment of associated energy consumption and related greenhouse gas emissions. Ventilative cooling, when effective, consumes no energy when natural forces drive the ventilation and only small amounts of energy when fan assistance is employed. Consequently, here we shall be principally concerned with energy consumption during the heating season.

It has become standard practice in Europe to benchmark building systems in terms of annual energy consumed per treated (conditioned) floor area (TFA). The British Research Establishment's Conservation Support Unit (BRECSU), acting on behalf of the U.K.'s Energy Efficient Best Practice Program (EEBPP) publishes representative energy and carbon dioxide emission benchmark values for offices [13]. BRECSU publishes these values for four officebuilding types:

1. naturally ventilated cellular offices,

2. naturally ventilated open-plan offices,

3. air conditioned standard offices, and

4. air-conditioned prestige offices,

distinguishing "good practice" building performance from "typical" building performance. The BRECSU values are published independent of climate, presumably because of the relatively small climatic differences in the more populated regions of the U.K., but indicate best practice naturally ventilated office buildings should be expected to consume less than $80 \mathrm{kWh} / \mathrm{m}^{2}-\mathrm{yr}$ for heating (and hot water) and less than $1 \mathrm{kWh} / \mathrm{m}^{2}$-yr for cooling. The corresponding $\mathrm{CO}_{2}$ 
emissions, expressed in terms of $\mathrm{kg}$ of carbon, are expected to fall below $4.1 \mathrm{kgC} / \mathrm{m}^{2}-\mathrm{yr}$ and 0.1 $\mathrm{kgC} / \mathrm{m}^{2}$-yr, respectively.

A number of European countries have developed building environmental impact assessment point-scoring methods to evaluate the overall ecological performance of specific building designs. Within these methods, points may be accumulated for designs falling below typical practice energy consumption or emission benchmarks [63]. For example, the Pimwag evaluation method prepared by the Helsinki City Council for the Viiki ecological community of Helsinki sets a minimum heating energy standard of $105 \mathrm{kWh} / \mathrm{m}^{2}-\mathrm{yr}$ - estimated to be $34 \%$ below typical levels - and offers 1 point for designs consuming less than $85 \mathrm{kWh} / \mathrm{m}^{2}$-yr and 2 points for those consuming less than $65 \mathrm{kWh} / \mathrm{m}^{2}$-yr. These benchmarks are, presumably, directed primarily to residential buildings although for a climate colder than the more populated regions of the U.K.

Hybrid ventilation systems and low-pressure mechanical ventilation systems utilizing natural driving forces when available - wherein additional fan power consumption is accepted as a means to improve storage heat transfer and control and to effect heat recovery and filtration appear, at this time, to achieve the lowest overall energy consumption in U.K. office buildings $[43,64,65]$. Braham notes a "first generation" naturally-ventilated BRE office building design utilizing massive ceiling soffits reported a measured energy consumption of $67 \mathrm{kWh} / \mathrm{m}^{2}-\mathrm{yr}$ for gas (heating) while a "second generation" example, the BRE Environmental Office of the Future, utilizing cored slabs was expected to consume only $47 \mathrm{kWh} / \mathrm{m}^{2}$-yr for gas. In comparison, the energy consumption reported for the Elizabeth Fry Building utilizing mechanically-driven ventilation and cored slabs, at $43 \mathrm{kWh} / \mathrm{m}^{2}$-year (27 for gas plus 16 for fan power), is "probably the lowest energy usage for any commercial or industrial UK building." Another naturally ventilated building on the same campus designed by the same architect consumed $147 \mathrm{kWh} / \mathrm{m}^{2}$ year for heating. Again, these comparisons are limited to the southern U.K. climate.

Setting energy benchmarks performance criteria is clearly worthwhile, but to be useful in the North American context these benchmarks must be related to climatic conditions. One useful benchmark is the annual energy consumption for heating needed to condition ventilation air alone. If conductive losses are small relative to ventilation losses and internal gains and ventilation heat recovery are not used to offset ventilation losses, then this ventilation heating benchmark would provide a lower-bound estimate for annual heating.

Colliver investigated the energy requirements needed to condition ventilation air for a number of North American and European locations [66]. He reports results in terms of annual energy required $Q$ per unit mass of air conditioned per hour $\dot{m}$ or $(Q / \dot{m})$. In this investigation Colliver distinguished sensible and latent energy transfer required to meet specified design conditions for both heating and cooling with these design conditions defined in terms of heating and cooling dry bulb and wet bulb set point temperatures. Therefore, Colliver's results can be directly used to establish an energy benchmark for heating ventilation air if the ventilation mass flow rate $\dot{m}$ is established.

Table 3.1 presents Colliver's results for two heating set point temperatures and the corresponding ventilation energy benchmarks for the representative minimum ventilation rate used in the climatic suitability studies (i.e., $10 \mathrm{~L} / \mathrm{s}$-person for an occupancy of 7 person $/ 100 \mathrm{~m}^{2}$ or $\dot{m} / A=$ $0.00084 \mathrm{~kg} / \mathrm{s}-\mathrm{m}^{2}$ ). Two locations in England are also included for comparison - the Heathrow site is located near the BRE buildings discussed above and the Norwich site is in East Anglia near the Elizabeth Fry building. 
Table 3.1 Energy requirements and corresponding ventilation benchmark for heating ventilation air at $\dot{m} / A=0.00084 \mathrm{~kg} / \mathrm{s}-\mathrm{m}^{2}$ based on Colliver's results [66] and a degree-day approach.

\begin{tabular}{|c|c|c|c|c|c|c|}
\hline & $\begin{array}{r}\text { Specif } \\
\text { Energy I } \\
(Q / \dot{m})\end{array}$ & $\begin{array}{l}\text { Jeating } \\
\text { uirement } \\
\mathrm{IJ}-\mathrm{h} / \mathrm{kg}\end{array}$ & $\begin{array}{r}\text { Ventil } \\
\text { Benchm } \\
(Q / A\end{array}$ & $\begin{array}{l}\text { Heating } \\
\text { based on } \\
\mathrm{Wh} / \mathrm{m}^{2}\end{array}$ & $\begin{array}{r}\text { Ventil } \\
\text { Benchmark } \\
\text { day } \\
(Q /\end{array}$ & $\begin{array}{l}\text { Jeating } \\
\text { d on degree- } \\
67] \text {. } \\
\mathrm{h} / \mathrm{m}^{2}\end{array}$ \\
\hline Location & $\begin{array}{l}T_{i-h s p} \\
18^{\circ} \mathrm{C}\end{array}$ & $\begin{array}{l}T_{i-h s p} \\
15^{\circ} \mathrm{C}\end{array}$ & $\begin{array}{l}T_{i-h s p} \\
18^{\circ} \mathrm{C}\end{array}$ & $\begin{array}{l}T_{i-h s p} \\
15^{\circ} \mathrm{C}\end{array}$ & $\begin{array}{l}\text { DD65 } \\
18.3^{\circ} \mathrm{C}\end{array}$ & $\begin{array}{l}\text { DD60 } \\
15.5^{\circ} \mathrm{C}\end{array}$ \\
\hline Boston,MA & 77.3 & 58.3 & 64.9 & 49.0 & -- & --- \\
\hline Brownsville,TX & 10.7 & 5.3 & 9.0 & 4.4 & 7.3 & 3.7 \\
\hline Cheyenne, WY & 100.0 & 78.5 & 84.0 & 65.9 & $\cdots$ & -- \\
\hline Ft Worth,TX & 34.9 & 23.6 & 29.3 & 19.8 & 25.8 & 17.4 \\
\hline Lexington, $K Y$ & 64.9 & 48.7 & 54.5 & 40.9 & 53.3 & 40.9 \\
\hline LosAngeles, $\mathrm{CA}$ & 20.9 & 5.6 & 17.5 & 4.7 & 20.5 & 9.6 \\
\hline Miami,FL & 3.3 & 1.0 & 2.7 & 0.8 & 2.3 & 0.6 \\
\hline Omaha,NE & 84.7 & 67.5 & 71.1 & 56.7 & 74.4 & 60.6 \\
\hline Phoenix,AZ & 19.5 & 10.5 & 16.4 & 8.8 & 17.5 & 10.4 \\
\hline SaltLakeCity,UT & 79.2 & 60.9 & 66.5 & 51.2 & 67.4 & 53.2 \\
\hline Seattle,WA & 67.2 & 44.6 & 56.4 & 37.5 & 58.4 & 41.3 \\
\hline Heathrow,UK & 67.6 & 44.4 & 568 & & --- & \\
\hline Norwich,UK & 79.5 & 55.9 & 66.8 & 47.0 & $\ldots$ & --- \\
\hline
\end{tabular}

${ }^{a}$ For a representative office ventilation rate of $0.7 \mathrm{~L} / \mathrm{s}-\mathrm{m}^{2}$ at an occupancy of 7 person $/ 100 \mathrm{~m}^{2}$.

As might be expected, energy requirements for heating ventilation air are sensitive to the assumed heating set point temperature and, of course, the ventilation rate that introduces a degree of uncertainty. Beyond this uncertainty one may achieve energy performance below these benchmarks if a) heat recovery is utilized and b) internal gains are used to offset ventilative losses by, for example, effective and strategic use of thermal mass. Heating a building by internal gains due to lighting and equipment use should, however, be avoided to the extent possible as it is at best equivalent to electric resistance heating and thus represents an inefficient use of primary fuels and carries with it the environmental consequences of electrical power generation.

With these uncertainties and caveats in mind, however, the Heathrow ventilation benchmarks shown in Table 3.1 fall just below the performance of the "first generation" BRE building mentioned above and bracket the performance of the "second generation" BRE building designed with better coupling between ventilation airflow and thermal mass. Likewise, the 
benchmarks based on the Norwich data (i.e., in East Anglia) indicate good performance for the Elizabeth Fry building, presumably, due to the even more effective use of thermal mass.

One may also estimate annual energy consumption for heating ventilation air using a degree-day approach:

$$
Q_{\text {heat }}=\overline{\dot{m}} c_{p} \int_{\substack{\text { heaing } \\ \text { season }}}\left(T_{i-h s p}-T_{o}\right) d t \equiv \overline{\dot{m}} c_{p} D D_{T_{j-h s p}}
$$

where an appropriate mean ventilation rate $\overline{\dot{m}}$ must be used. The integrand of equation 3.4 is evaluated only when positive and, when determined in terms of units of days, is commonly identified as the heating degree-days evaluated for an assumed heating set point temperature or degree-day base. Finally, Equation 3.4 can be normalized by dividing by the total floor area and evaluated for a minimum ventilation rate to obtain an estimate of the ventilation heating benchmark:

$$
\frac{Q_{\text {heat }}}{A} \approx \frac{\dot{m}_{\min }}{A} c_{p} D D_{T_{i-h s p}}
$$

Heating degree days have been published for a range of base temperatures including values for $18.3^{\circ} \mathrm{C}\left(65^{\circ} \mathrm{F}\right)$ or $D D 65$ and $15.5^{\circ} \mathrm{C}\left(60^{\circ} \mathrm{F}\right)$ or $D D 60$ for a variety of North American locations. Using values reported by Stein and Reynolds [67], heating ventilation benchmark values were computed for the representative minimum ventilation rate used in the climatic suitability studies for a variety of U.S. locations. These results are also included in Table 3.1 where it can be seen that they are comparable to those based on Colliver's data.

\section{Anticipated Environmental Conditions}

Given the discussion of performance criteria presented above, it should be clear that a rigorous assessment of the overheating potential, and thus success, of a natural or hybrid ventilation design proposal will demand detailed - reasonably hourly - predictions of indoor air conditions for the entire cooling season. Consequently, these predictions will necessarily have to be based on hourly weather records of outdoor air temperature, wind speed, wind direction, relative humidity, and solar insolation. Representative average or, alternatively, extreme hourly weather data could be used for this purpose. Levermore argues that extreme hourly weather data be used, although this he proposes to do so in conjunction with the Dutch absolute limit on system performance discussed above [52]. When evaluating overheating potential quantitatively, as proposed here, the use of representative average weather data is logically more consistent. Three sources provide typical year weather data for North America (see Chapter 26 of [46]):

- WYEC2 Data: Weather Year for Energy Calculations version 2 data is available from ASHRAE for 77 North American locations [44]. This data was used for the climate suitability method introduced in Chapter 2 and will be used for subsequent modeling studies presented in Chapter 4 of this report.

- TMY2 Data: Typical Meteorological Year version 2 is available from the U.S. National Renewable Energy Laboratory [68].

- CWYEC Data: Canadian Weather Year for Energy Calculations data from the Atmospheric Environment Service, Ontario. 


\subsubsection{Natural Ventilation for Direct Cooling \& Air Quality Control}

The variety and diversity of natural ventilations systems that have been proposed in recent years is staggering $[8,9,11,39,40,69,70]$. Hybrid variations of many of these systems add yet another level of complication [71]. Nevertheless, both natural and hybrid systems are invariably conceived as variants of three fundamental but idealized approaches to natural ventilation - each based on a distinct driving mechanism:

- cross ventilation based on wind-driven pressure differences,

- stack ventilation based on buoyancy-induced pressure differences, and

- single-sided ventilation induced largely by flow momentum due to turbulence.

Airflow in any real natural (or hybrid) ventilation system will be driven by combinations of wind, buoyancy and momentum effects, but it is useful to consider first these idealized systems before moving on to the full complexity of real systems and recent innovative proposals.

\section{Wind-Driven Cross Ventilation}

Wind-driven cross ventilation is, perhaps, the most familiar approach to natural ventilation. Wind airflow over a building tends to induce positive (inward acting) pressures on windward surfaces and negative (outward acting) pressures on leeward surfaces thereby creating a net pressure difference across the section of the building that drives cross ventilation airflows, Figure 3.2. Qualitatively, then, the mechanism driving this airflow is quite straightforward. To gain a deeper understanding of this approach, however, it is useful to consider some fundamental theory.

The positive windward pressure $\Delta p_{w w}$ and the negative leeward pressure $\Delta p_{l w}$ are, in fact, pressure differences from the ambient air pressure of the free-field airflow. While these pressure differences often vary rapidly with time, due to turbulence in the wind airflows, and position, due to the aerodynamic affects of building form and detail, on average they may be related to a reference time-averaged approach wind velocity $U_{\text {ref }}$ :

$$
\Delta p_{w w}=C_{p-w w}\left(\frac{\rho U_{r e f}^{2}}{2}\right) \text { and } \Delta p_{l w}=C_{p-l w}\left(\frac{\rho U_{r e f}^{2}}{2}\right)
$$

where $\rho$ is the density of the air, $\rho U_{r e f}^{2} / 2$ is the kinetic energy per unit volume ${ }^{1}$ of the reference wind velocity, and $C_{p-w w}$, a positive value, and $C_{p-i w}$, a negative value, are the socalled wind pressure coefficients of the windward and leeward surface locations under consideration. The reference wind velocity is most commonly (but not always) taken as the time-averaged wind velocity at the building height.

\footnotetext{
'If a parcel of the approach wind is brought to a standstill, this kinetic energy per unit volume will be converted, by Bernoulli's law, into an equal increase in pressure. Consequently, the quantity $\rho U_{r e f}^{2} / 2$ is often called the stagnation or dynamic pressure of the approach wind. Even among specialist in the field, this results in confusion between this dynamic pressure and the actual pressure of the fluid, which, then, is identified as the static pressure. To avoid this confusion it is important to accept the kinetic energy per unit volume as a measure of the potential of the moving fluid to increase or decrease fluid pressure as it impinges on building surfaces and not a pressure in its own right. The wind pressure coefficient $C_{p}$ quantifies this potential.
} 


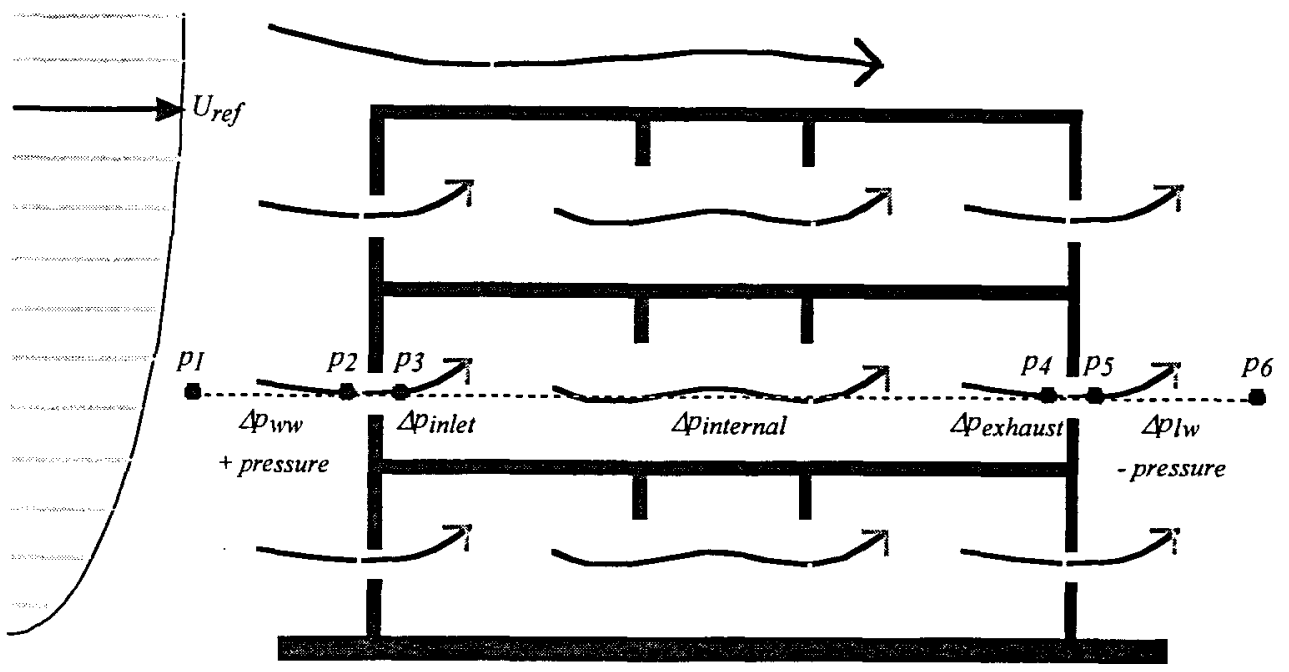

Wind-driven Cross Ventilation

Figure 3.2 Pressure drops associated with wind-driven cross ventilation.

Consider the details of the pressure changes along a given cross-ventilation airflow path, for example, from the ambient air node pressure $p_{1}$ on the windward side of the building of Figure 3.2 to the ambient node pressure $p_{6}$ on the leeward side. The pressure change from node 1 to 2 will be positive, while that from node 5 to 6 will be negative, due to action of the wind. The resistances offered by the inlet vent, internal obstructions, and exhaust vents will, on the other hand, produce negative changes in pressure, $\Delta p_{\text {inlet }}, \Delta p_{\text {intemal }}$, and $\Delta p_{\text {exhaust }}$, respectively. Given nodes 1 and 6 are in the free-field and, thus, must be ambient air pressure we may demand:

$$
p_{6}-p_{1}=\Delta p_{w w}-\Delta p_{\text {inlet }}-\Delta p_{\text {intemal }}-\Delta p_{\text {exhaust }}-\Delta p_{l w}=0
$$

or:

substituting Equation 3.6 and defining a new term the wind-driven pressure difference:

$$
\Delta p_{w}=\left(C_{p-w w}-C_{p-l w}\right) \frac{\rho U_{r e f}^{2}}{2}
$$

we obtain:

$$
\left(\Delta p_{\text {inlet }}+\Delta p_{\text {intemal }}+\Delta p_{\text {cxhaust }}\right)=\Delta p_{w}
$$

(The sum of pressure losses due to flow resistance.) $=$ (The driving wind pressure difference.)

Thus, quite reasonably, the sum of the pressure losses due to resistance to airflow must equal the driving wind pressure difference $\Delta p_{w}$. For typical design conditions the reference wind velocity is around $4 \mathrm{~m} / \mathrm{s}$, windward wind pressure coefficients are typically around +0.5 , leeward wind pressure coefficients around -0.5 , and the density of air will be approximately $1.2 \mathrm{~kg} / \mathrm{m}^{3}$ thus we may expect the driving wind pressure for cross-ventilation to be approximately $10 \mathrm{~Pa}$ : 


$$
\Delta p_{w}=\left(C_{p-w w}-C_{p-l w}\right) \frac{\rho U_{r e f}^{2}}{2} \approx((+0.5)-(-0.5)) \frac{1.2 \mathrm{~kg} / \mathrm{m}^{3}(4 \mathrm{~m} / \mathrm{s})^{2}}{2}=9.6 \mathrm{~Pa}
$$

A $10 \mathrm{~Pa}$ driving pressure is small relative to typical fan-driven pressure differences, thus to achieve similar ventilation rates the resistance offered by the natural ventilation system will have to be small relative to ducted mechanical ventilation systems.

It is important to note that the driving wind pressure is independent of the resistance to airflow along the ventilation airflow path. If this resistance is large, then the flow along this path will be relatively low; if this resistance is small, the flow will be relatively large; in either case, the pressure losses due to this resistance must equal that of the driving wind pressure. Given the relatively small driving pressure that may be expected, it is often strategic to minimize the resistances to airflow. To control the rate of airflow one key resistance, most commonly the inlet resistance, is designed to be limiting while the other resistances are minimized, although this is not universally done.

In the design of natural ventilation systems it is important to consider details of the relation between airflow (e.g., expressed as a volumetric flow rate $\dot{V} \mathrm{~m}^{3} / \mathrm{s}$ or mass flow rate $\dot{m} \mathrm{~kg} / \mathrm{s}$ ) and pressure drop across a given flow resistance $\Delta p$. In general, functional notation, the airflow rate will depend on the pressure drop and some characteristic design parameter or size $\phi$ of a given flow resistance:

$$
\dot{m}=f(\Delta p, \phi) \quad \text { or } \quad \dot{V}=g(\Delta p, \phi)
$$

or, equivalently the pressure drop will depend on the airflow rate and the characteristic design parameter - the so-called inverse functions of those presented in Equation 3.11:

$$
\Delta p=f^{\prime}(\dot{m}, \phi) \quad \text { or } \quad \Delta p=g^{\prime}(\dot{V}, \phi)
$$

Specific flow relations will be considered subsequently. Suffice it to say here, when ventilation airflow rates are intended to be constant by design, it will be useful to use a limiting flow resistance that maintains relatively constant airflow rates for large variations of the driving wind pressures since these wind pressures will inevitably vary with time. Simple openings do not achieve this objective. Self-regulating inlet vents, on the other hand, do and thus have become indispensable to reliable performance in natural ventilation systems [20-22, 24].

This simple natural ventilation scheme suffers a critical shortcoming - as wind directions change so do the wind pressure coefficients. Consequently, the driving wind pressure may drop to low values even when windy conditions prevail and thus natural ventilation airflow rates will drop in turn. Self-regulating inlet vents may help to mitigate this problem, but ideally, one would prefer a system that is less sensitive to wind direction than that presented above unless, of course, a prevailing wind of constant direction is available at the building site.

When wind speeds drop to low values, again the driving wind pressure will diminish and ventilation airflows will subside regardless of wind direction. This "zero-wind" design condition is often put forward as a critical case, yet some limited studies indicate "zero-wind" conditions are not only unlikely at many locations but they may well be short-lived [72-75].

In spite of these shortcomings, simple wind-driven cross ventilation has been employed in some recently built non-residential buildings although its use is uncommon. Examples include the 
machine shop wing of the Queen's Building of De Montfort University, Leicester, England designed by Short Fort Associates architects and Max Fordham Associates environmental engineers [9, 76-78] and a number of skyscrapers designed by architect Ken Yeang of TR Hamzah \& Yeang Sdn Bhd, Malayasia [77, 79-81].

The analysis of wind-driven cross ventilation presented above is commonly used as the basis of both design and analysis methods for these and related systems yet it is based on time-averaged conditions of wind-driven airflow rather than actual instantaneous considerations. Wind turbulence, and the rapidly varying pressures that result from it, can significantly increase ventilation rates above those predicted by the time-averaged steady formulation of the theory. Girault reports this error may be on the order of $20 \%$ while Saraiva indicates both under- and overestimation of ventilation rates by as much as 30 to $40 \%$ may result [82,83]. Yet, turbulence is seldom accounted for even though models are available to do so [84].

Even within the time-averaged modeling assumptions there are significant sources of uncertainty that should be kept in mind. For one, wind pressure coefficients $C_{p}$ are seldom known with certainty - they vary from position to position over the building envelope being sensitive to small details of form, they are altered significantly by the shelter offered by other buildings, they vary with wind direction, and are affected by building porosity $[60,85]$. Wind characteristics are generally known with certainty only for regional airports where detailed records are maintained. Consequently, evaluation of the reference wind speed and direction for a given site is always problematic and subject to error. Finally, empirical coefficients associated with flow resistance models introduce another source of uncertainty, although perhaps not as significant as that due to wind uncertainties [86-89].

\section{Buoyancy-Driven Stack Ventilation}

Buoyancy-driven stack ventilation is also familiar although the mechanism driving it is subtle. In qualitative terms, warm air within a building will tend to rise and flow out of upper level exhausts while cooler outdoor air will tend to flow in through lower inlets to replace it, Figure 3.2. If the internal air temperature $T_{i}$ is greater than the outdoor air temperature $T_{o}$ then internal air density $\rho_{i}$ will be less than the outdoor air density $\rho_{o}$. The difference between the weight of a column of air indoors and a corresponding column outdoors will therefore create a pressure difference (e.g., between $p_{2}$ and $p_{3}$ of Figure 3.2) that will drive the airflow.

Again, it will be useful to analyze this mode of ventilation more theoretically. Consider, then, the buoyancy-driven airflow path from pressure node $p_{1}$ to $p_{5}$ via nodes $p_{2}, p_{3}$ and $p_{4}$ of Figure 3.3. This time, consider the changes of pressure as proceeding from node to node and returning to node $p_{1}$ to complete a so-called pressure loop. The algebraic sum of the pressure changes around a loop must necessarily be zero.

If the airflow is relatively quiescent, then pressure changes resulting from elevation changes $\Delta z$ may be approximated by the hydrostatic equation:

$$
\Delta p=\rho g \Delta z
$$

where $\rho$ is the density of the air and $g$ is the acceleration of gravity (i.e., $9.8 \mathrm{~m} / \mathrm{s}^{2}$ ). The density of dry air may be estimated from knowledge of its temperature using the ideal gas law. 
Recognizing ambient air pressures of practical building problems will be close to standard atmospheric pressure (e.g., 101,325 Pa) we obtain:

$$
\rho=\frac{352.6 \mathrm{~kg}-{ }^{\circ} \mathrm{K} / \mathrm{m}^{3}}{\left(T\left({ }^{\circ} \mathrm{C}\right)+273.15\right)^{\circ} \mathrm{K}}
$$

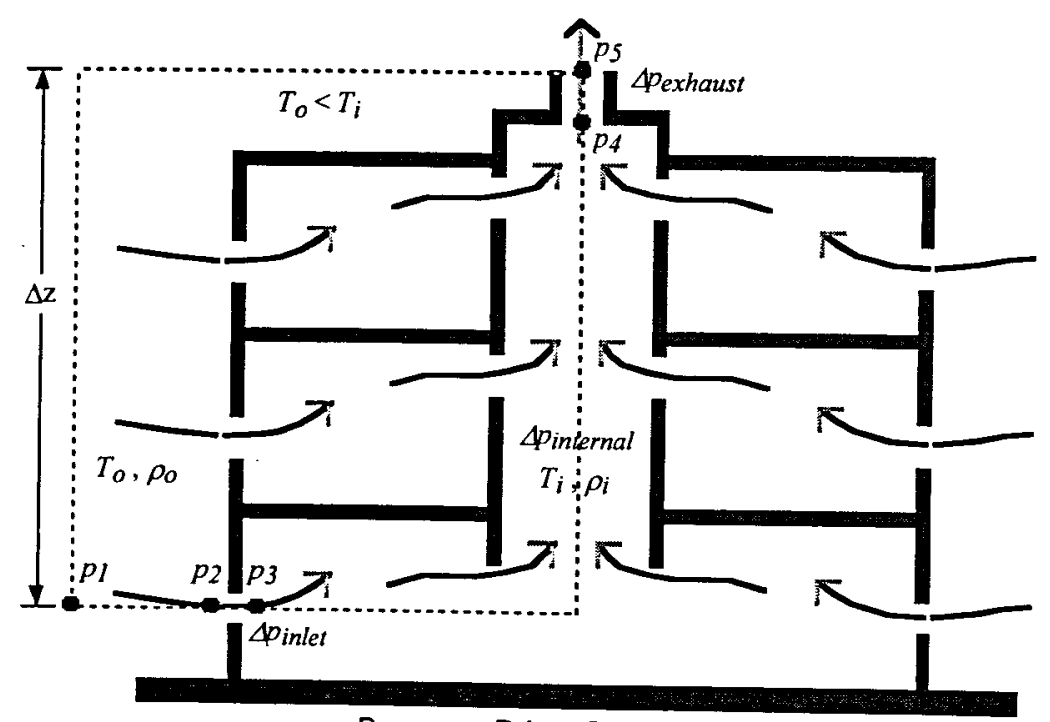

Buoyancy-Driven Stack Ventilation

Figure 3.3 Pressure drops associated with buoyancy-driven stack ventilation.

Applying Equations 3.13 and 3.14 to the pressure loop shown in Figure 3.3 we obtain:

$$
-\Delta p_{\text {inlet }}-\Delta p_{\text {imemal }}-\rho_{i} g \Delta z-\Delta p_{\text {exhaust }}+\rho_{o} g \Delta z=0
$$

or, by defining a new term the buoyancy-driven stack pressure difference as:

$$
\Delta p_{s}=\left(\rho_{o}-\rho_{i}\right) g \Delta z
$$

we obtain the final result:

$$
\left(\Delta p_{\text {inlet }}+\Delta p_{\text {incmal }}+\Delta p_{\text {cxhaust }}\right)=\Delta p_{s}
$$

(The sum of pressure losses due to flow resistance.) = (The driving stack pressure difference.)

To achieve the approximately $10 \mathrm{~Pa}$ pressure difference computed above for typical wind-driven conditions for a relatively warm indoor air temperature of $23^{\circ} \mathrm{C}$, the outdoor air temperature for the three-story stack (i.e., approximately $10 \mathrm{~m}$ ) shown in Figure 3.3 would have to be close to the freezing point of $0^{\circ} \mathrm{C}$ :

$$
\Delta p_{s}=\left(\frac{352.6}{\left(0^{\circ} \mathrm{C}+273.15\right)}-\frac{352.6}{\left(23^{\circ} \mathrm{C}+273.15\right)} \frac{\mathrm{kg}}{\mathrm{m}^{3}}\right)\left(9.8 \frac{\mathrm{m}}{\mathrm{s}^{2}}\right)(10 \mathrm{~m})=9.8 \mathrm{~Pa}
$$

Consequently, during warm periods as outdoor temperatures approach indoor air temperatures, the stack pressure differences that may be developed for all but very tall multi-story stacks may be expected to be small relative to typical wind-driven pressure differences. Furthermore, for 
higher floors the stack pressure difference available to drive natural airflows will be proportionately smaller. For this reason buoyancy-driven stack ventilation alone cannot be expected to be a very effective strategy for cooling. For wintertime air quality control, on the other hand, when large indoor-to-outdoor temperature differences may be expected, buoyancydriven stack ventilation may be expected to be effective although differences of air distribution with story level must be accounted for by proper sizing of inlet vents.

This simple and fundamentally based observation is not well known. Consequently, buoyancydriven stack ventilation is often over-rated as a cooling strategy. Indeed, in practice stack configurations have often achieved acceptable ventilation rate but this is due to the fact that wind forces will also drive flow in stack ventilation systems thus complicating the system behavior which, apparently, has led to the general confusion about stack ventilation system. Given low wind conditions may be unlikely and short-lived at most locations [72-74], simple buoyancydriven stack flow is not likely to occur often in practice. Thus combined wind plus buoyancydriven stack ventilation should be considered instead.

\section{Combined Wind + Buoyancy-driven Stack Ventilation}

Stack ventilation systems have proven very effective and, thus, popular. There are a number of reasons for this but foremost among them is that stack ventilation systems can, when properly designed, make effective use of both wind and buoyancy-driven pressure differences. This may be readily appreciated through a theoretical analysis of their behavior - an analysis that combines the results of the analyses presented above.

Consider now a stack ventilation system under the combined influence of wind and buoyancy differences, Figure 3.4. This system is similar to that illustrated in Figure 3.3 with a stack terminal device added that can respond to the prevailing wind direction to maximize the negative pressure induced by the wind (e.g., operable louvers, rotating cowls, etc.).

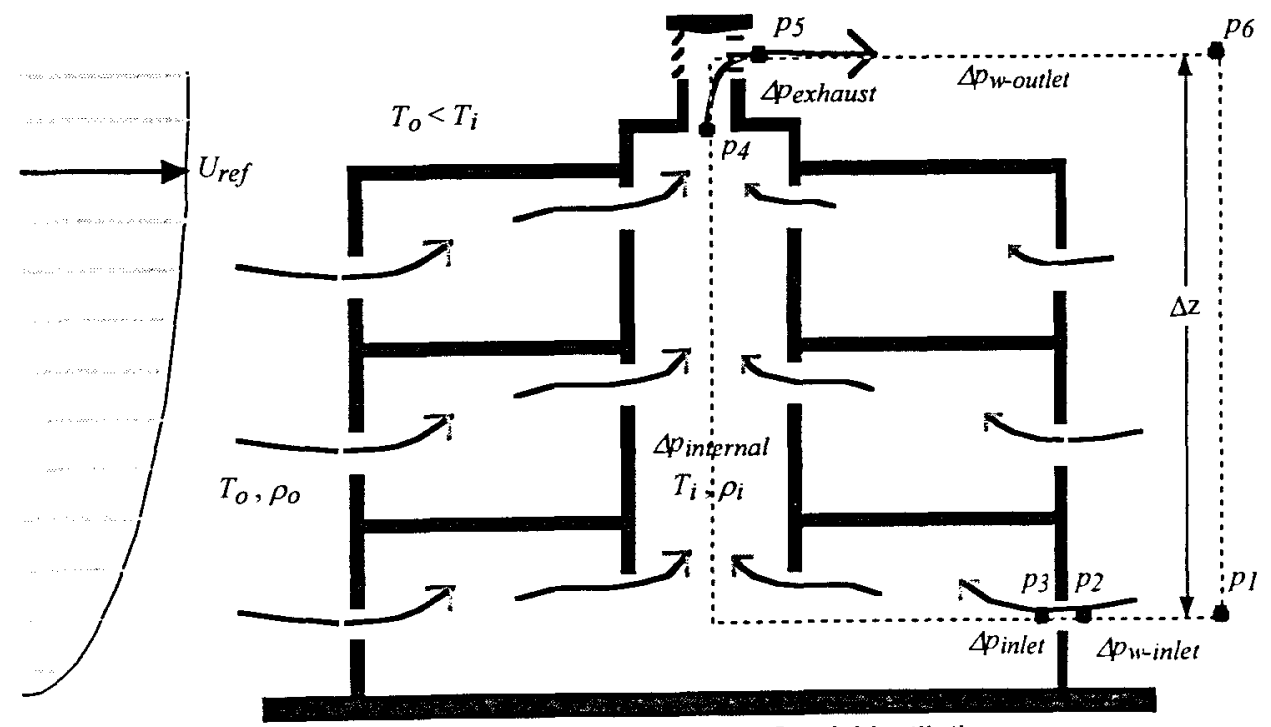

Wind+Buoyancy-Driven Stack Ventilation

Figure 3.4 Pressure drops associated with wind + buoyancy-driven stack ventilation. 
A consideration of a representative pressure loop - e.g., loop $p_{1}-p_{2}-p_{3}-p_{4}-p_{5}-p_{6}-p_{1}$ will now include both buoyancy-driven and wind-driven pressure differences that appear as a simple sum:

$$
\left(\Delta p_{\text {inlet }}+\Delta p_{\text {intemal }}+\Delta p_{\text {exhaust }}\right)=\Delta p_{s}+\Delta p_{w}
$$

where, for the present case:

$$
\begin{gathered}
\Delta p_{s}=\left(\rho_{o}-\rho_{i}\right) g \Delta z \\
\Delta p_{w}=\left(C_{p-\text { inlet }}-C_{p-\text { exhoust }}\right) \frac{\rho U_{\text {ref }}^{2}}{2}
\end{gathered}
$$

Again the driving pressure difference - now the sum of buoyancy and wind contributions - is independent of the resistance to airflow provided by the components of the natural ventilation system. Pressure loop equations for each of the additional five ventilation loops of Figure 3.4 will assume the same general form as given in Equation 3.19 although the values of the various parameters will change.

For the pressure loop shown in Figure 3.4, both the inlet wind pressure coefficient $C_{p \text {-inlet }}$ and the exhaust wind pressure coefficient $C_{p-\text { exhaust }}$ are likely to be negative as both are on the leeward side of the building. Consequently, the wind-driven pressure difference will act to cause flow in the direction indicated only if the absolute value of the exhaust value is greater than the inlet value. For this reason, driving wind pressure differences for the leeward rooms of stack ventilation systems tend to be smaller than those of the windward rooms. As a result, unless inlet vents are designed accordingly, ventilation rates may be expected to be lower in these rooms and may actually reverse under certain conditions. Self-regulating vents can serve to maintain design-level ventilation rates and thereby mitigate this problem but can not inhibit flow reversals or provide flow when the net driving pressure $\Delta p_{s}+\Delta p_{w}$ drops to zero.

The stack pressure contribution $\Delta p_{s}$ will act to compensate for low or reverse wind pressures but again this contribution must be expected to be smaller for the upper floors of the building. Consequently, upper leeward rooms tend to experience the lowest driving pressures and thus lower ventilation rates (i.e., as indicated diagrammatically in Figure 3.4).

Ventilation stacks that extend above nearby roofs, especially when equipped with properly designed stack terminal devices, tend to create negative (suction) pressures that are relatively independent of wind direction. Thus, stack systems serve to overcome the major limitation of simple cross-ventilation systems identified above while providing similar airflows in individual rooms of the building. As a result of these advantages, stack ventilation systems - perhaps, most often using a central slot atria as a shared stack - have become the most popular natural ventilation system used in commercial buildings in recent years and a number of manufacturers have responded to this popularity with the development of specialized system components to serve these systems.

Stack ventilation systems provide ventilation to the building as a whole and depend critically on external building form and internal layout - that is to say, they provide a global ventilation solution. Cross ventilation systems provide ventilation, typically, local to a floor of a building. When ventilation is needed for individual rooms, single-sided ventilation, the most localized of all natural ventilation strategies may be the only choice available. 


\section{Turbulence-Induced Single-Sided Ventilation}

Often when one talks of natural ventilation, the uninitiated often thinks of simply opening a window to allow outdoor air to flow indoors. This approach to natural ventilation is the simplest form of so-called single-sided ventilation and, in comparison to the approaches considered so far the least effective means of natural ventilation.

To better understand this and more reasonable forms of single-sided ventilation consider the building cross-section illustrated in Figure 3.5.

Single-sided ventilation through a single opening is illustrated at the lowest floor level. The macroscopic approach to analysis used for the stack and cross ventilation cases above does not provide an explanation for this ventilation strategy. Time-averaged wind pressures acting on the inflow and outflow paths may be expected to be of similar magnitude and direction, therefore, they can not alone account for single-sided ventilation airflows. Large opening flow models developed for macroscopic analysis can be useful [5, 90-92] but, as the essential character of the airflow is microscopic, zonal $[93,94]$ or computational fluid dynamic (CFD) methods $[95,96]$ that can resolve these details may be needed.

While the nature of single-sided ventilation has yet to be fully described theoretically, it is clear that the turbulence superimposed on the mean flow, illustrated schematically in Figure 3.5, can induce small differences in envelope pressures that can drive the airflow. Detailed flow visualization studies reveal that small-scale turbulence may have sufficient momentum to force airflow in through one area of an open window while continuity of flow forces air out of another area [97]. Both of these driving mechanism may be expected to be highly variable and yet not particularly effective.

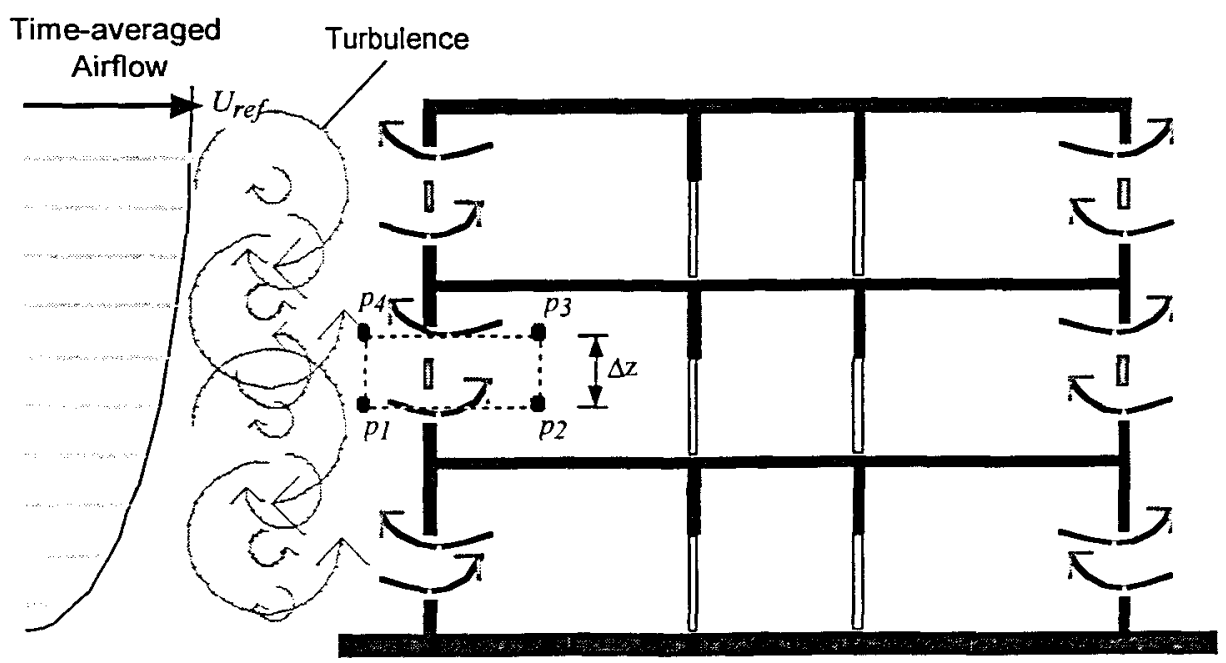

Single-Sided Ventilation

Figure 3.5 Single-sided ventilation driven, primarily, by turbulence-induced effects.

Single-sided ventilation may be improved if two or more openings are used. One may apply loop analysis to multiple-opening single-sided ventilation (e.g., as illustrated on the second level of Figure 3.5) although wind pressures acting on the envelope surfaces must now be considered 
instantaneous values. If the openings are placed at different elevations, buoyancy-induced pressure differences can act to enhance the ventilation flow rate although given the relatively small elevation differences possible these pressure-differences must be expected to be slight. Widely spaced multiple openings, especially if detailed appropriately, will also increase the likelihood that envelope pressures acting on the inflow and outflow paths will differ and thus drive airflow. Again, however, the pressure differences generated must be expected to be small in comparison with wind-driven stack or cross-ventilation.

Consequently, compared to the other alternatives considered so far, single-sided ventilation offers the least attractive ventilative cooling solution during warm weather periods but, nevertheless, a solution that can serve individual rooms. When outdoor air temperatures are low and buoyancy effects play a greater role, opening windows provides an intuitively direct and often rapid means to "air" individual rooms as cooler more dense air flows in as a gravity current across the floor forcing hotter air out through the upper portions of windows. Traditional and often required "airings" of European public schools has been shown to be more effective than mechanical ventilation in one case [32] and remain an area of active research [93, 94].

\section{Elaborations of the Fundamental Strategies}

Most built examples employ elaborations of the fundamental natural ventilation schemes discussed above. In some instances, all three schemes have been used concurrently in single buildings to handle a variety of ventilation needs as illustrated in Figure 3.6. The most notable example of such an approach is found in the Queen's Building of De Montfort University in Leicester, England, Figure 3.7 - a building that has proven to be the most influential of the first generation of the newer naturally ventilated buildings $[9,76-78]$.

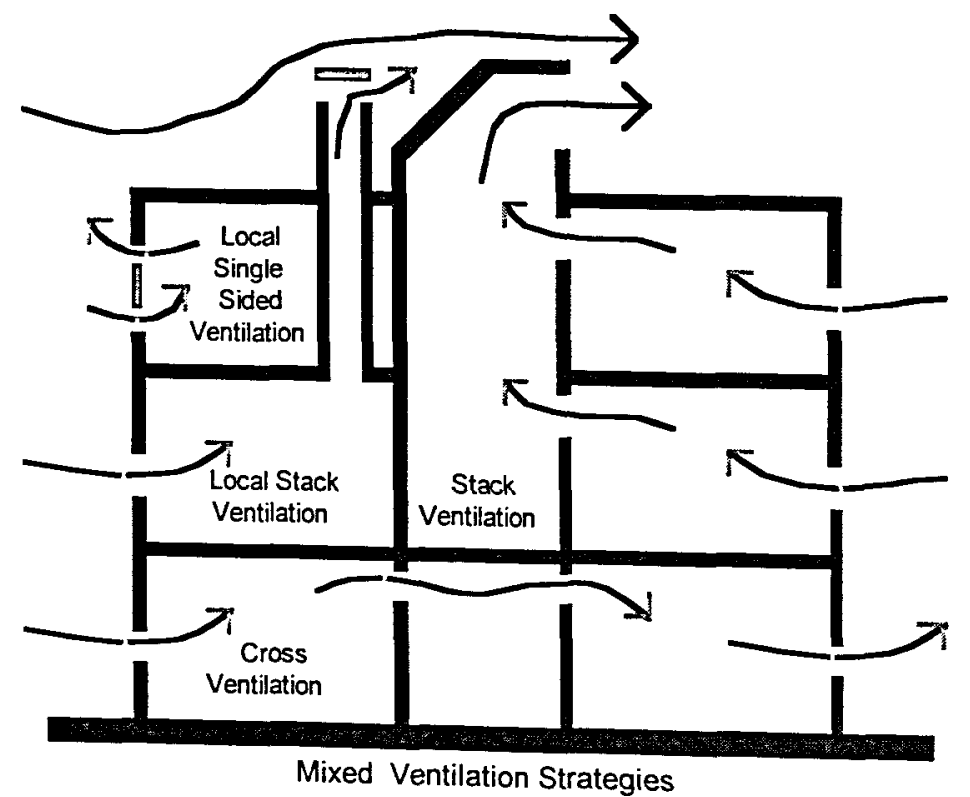

Figure 3.6 Mixed natural ventilation strategies in a single building to satisfy local and global ventilation needs. 


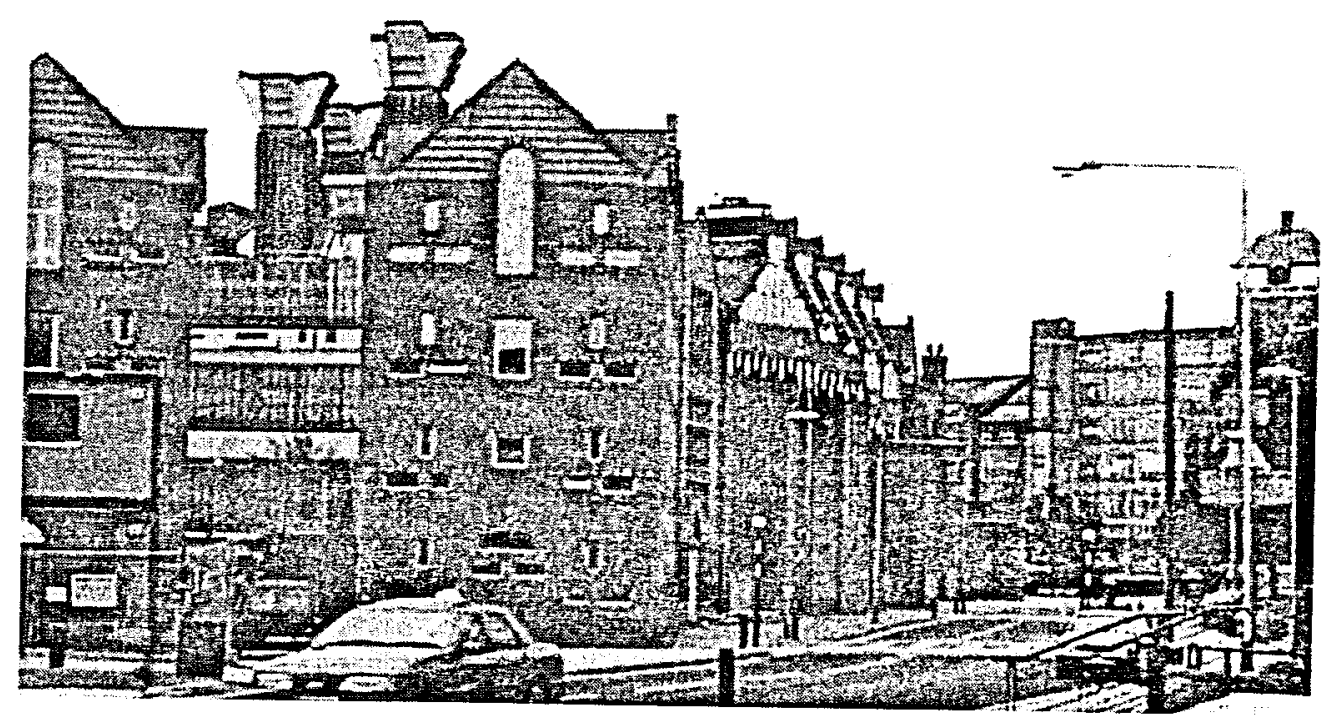

Figure 3.7 The Queen's Building of De Montfort University, Leicester, England.

In other instances, the elaboration resides in the details of inlet, exhaust, and distribution tactics. One common approach involves the use of in-slab or access-floor distribution of fresh air to provide greater control of air distribution across the building section and to temper incoming air to prevent cold drafts, Figure 3.8. This particular means of fresh air distribution is similar to displacement ventilation most commonly implemented mechanically and offers similar benefits - i.e., use of thermal plumes generated by equipment and occupants to assist the airflow and improved air quality in the occupied zone of rooms.

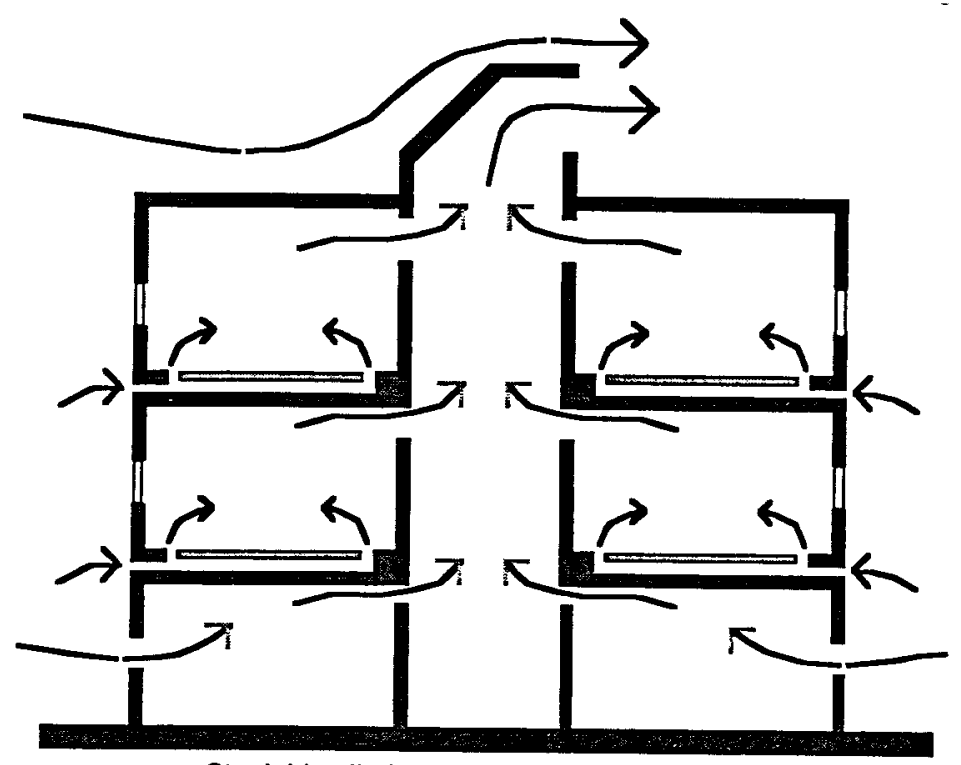

Stack Ventilation w/ Sub-slab Distribution

Figure 3.8 Diagrammatic representation of combined wind and buoyancy-driven stack ventilated building with sub-slab or access-floor distribution of fresh air. 
The variations and elaborations of these basic ventilation strategies are practically equal to the number of naturally ventilated buildings built in recent years - each to a greater or lesser degree is unique. The more notable projects and references to case studies of these projects are listed at the end of this chapter. The reader is therefore advised to consult these more detailed case studies so that our attention can be turned to recent innovative proposals that appear to hold promise.

\section{Recent Innovations}

The growing interest in naturally ventilated buildings has fueled a seemingly endless series of innovative proposals in recent years. Some of these proposals are based on reconsiderations and new analyses of older, even ancient, strategies while others appear to be completely fresh. Most of the innovations considered in this section have yet to be fully developed technically, but appear to offer promise.

\section{Solar Assisted Stack Ventilation}

Buoyancy-driven stack ventilation, as established above, depends on both temperature differences and stack height. One may in principle, then, increase buoyancy-driven pressure differences by heating air in the ventilation stack. During the $19^{\text {th }}$ century this was done with purpose-provided gas burners placed directly into the chimneys of the House of Parliament in London and indirectly using exhaust stacks of kitchen stoves in some innovative homes [1]. More recently, ventilation stacks have been fitted with solar air collectors to increase stack temperature.

An early example of this approach can be found in the Canning Crescent Health Centre, London designed by architects MacCormac Jamieson Prichard with environmental engineer Patrick Bellew of Atelier Ten, London [9, 11, 78, 98, 99]. Sections of this extensive L-shaped building are divided by sets of approximately three-story stacks that serve individual rooms and extend above adjacent roofs. Each stack is fitted with $1.5 \mathrm{~m}$ glass inserts at their tops to collect solar energy.

More recently, Rodrigues has presented a single-story, vertical solar air collector that fits into southern walls of buildings to preheat incoming air in winter mode and acts to boost exhaust air in summer mode. A simplified model based on integral equations derived from boundary layer theory is presented by Rodrigues for this system that is compared to CFD studies [100].

Sandberg recently investigated the use of photovoltaics to both generate electricity and heat air to assist natural ventilation [101]. Although maximum flow rates resulting from such a system occur when solar gains and thus when ventilation needs are greatest, the conversion of solar to airflow kinetic energy is typically very low (i.e., $0.033 \%$ in the example considered) - low compared even to photovoltaic conversion efficiencies (e.g., 5 to $15 \%$ ). Nevertheless, the efficiency of photovoltaic cells can be improved by the cooling that results from the induced natural ventilation. Thus by combining technologies, ventilation assist, improved photovoltaic performance, and, of course, photovoltaic-generated electricity is gained.

Progress has been made in developing analytical models of solar-assisted natural ventilation that provide the means to optimize this approach for building applications $[102,103]$. The success of a $50 \mathrm{~kW}$ solar chimney electric power generator prototype constructed and operated in 
Manzanares, Spain provides some indication of the potential of this approach when used at sufficiently large scale, although, here, not in a building application [104].

\section{Top-Down or Balanced Stack Ventilation}

Urban and similar densely populated environments present a special challenge for natural ventilation systems that rely on low-level inlets since outdoor air at these low levels may well be contaminated and inlets will be shielded from winds. Consequently, a number of ancient Middle Eastern strategies using both roof level inlets and exhausts - including the traditional Iranian wind towers or bagdir and the Arabian and Eastern Asian wind catchers or malkaf [7, 8]- are being reconsidered for broader application and technical refinement.

In these top-down or balanced stack ventilation schemes, air is supplied in a cold stack (i.e., with air temperatures maintained close to outdoor conditions through proper insulation of the stack) and exhausted through a warm stack, Figure 3.9.

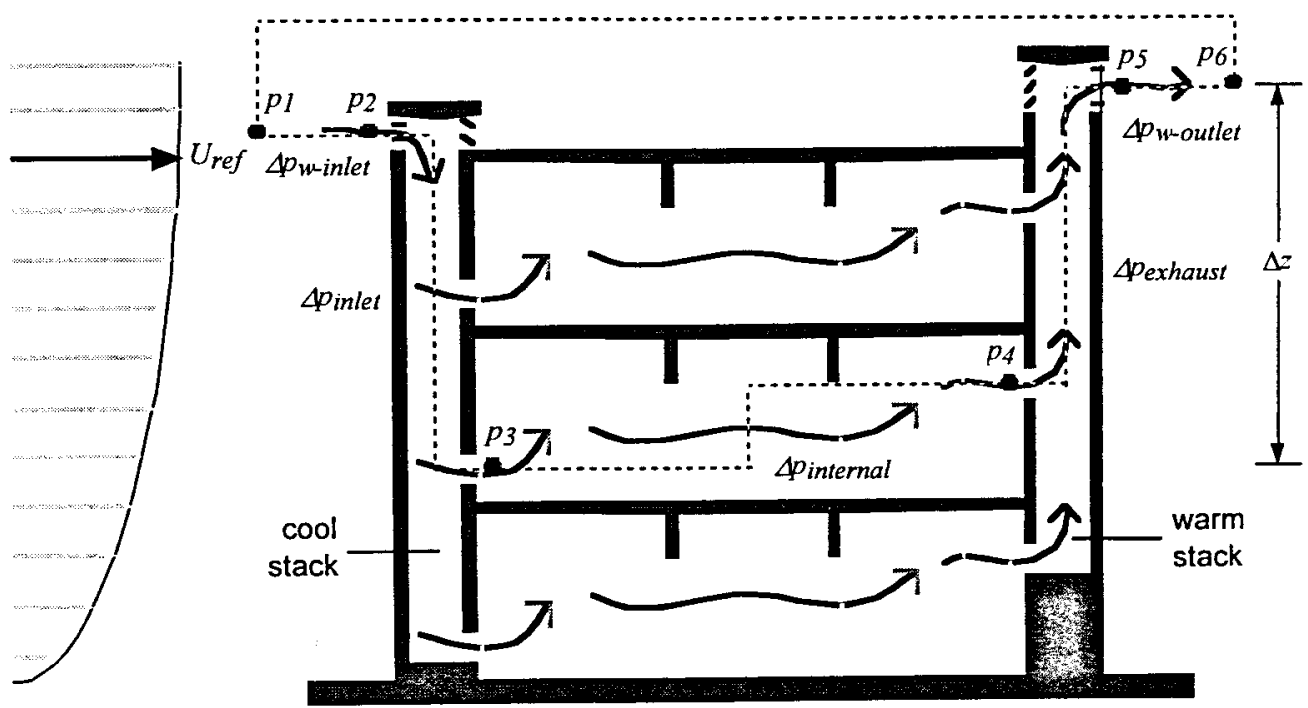

Top-Down or Balanced Stack Ventilation

Figure 3.9 Top-down or balanced stack natural ventilation systems use high level supply inlets to a) access less contaminated air and b) place both inlet and outlets in higher wind velocity exposures.

The loop analysis approach can be directly applied to this scheme. Consider, for example, the loop through the second level of Figure 3.9 - the resulting loop equation governing (timeaveraged) airflow will be identical in form to those derived for the combined wind and buoyancy-driven stack ventilation scheme above, Equation 3.19. The driving buoyancy pressure is, as before, determined by the indoor-to-outdoor air density (air temperature) difference and the height difference from the stack exhaust and the floor level inlet locations $\Delta p_{s}=\left(\rho_{o}-\rho_{1}\right) g \Delta z$ if air temperatures within the cold stack can be maintained close to outdoor levels. Airflow through each floor level will, therefore, be identical to that expected in the simpler single stack scheme of Figure 3.4 provided the resistance to airflow provided by the supply stack (and its inlet and outlet devices) is similar to that provided by the air inlet devices of Figure 3.4. 
The driving wind pressure is, as before, determined by the difference between inlet and exhaust wind pressure coefficients and the kinetic energy content of the approach wind velocity $\Delta p_{w}=\left(C_{p-\text { inlet }}-C_{p \text {-exhoust }}\right) \rho U_{r e f}^{2} / 2$, but, in this case, the high location of the inlet assures a relatively high inlet wind pressure coefficient and wind direction insensitivity if the inlet stack is detailed carefully. This, combined with the potential of a wind-direction insensitive exhaust stack, makes this scheme particularly attractive for urban environments.

The success of the balanced stack ventilation system depends critically on the sizing of the system components - i.e., the inlet stack openings, details, and geometry, the room inlet details, internal resistances, and the outlet stack openings, details, and geometry. The potential advantages of this approach may be completely lost if these resistances become too great. It will be seen that the loop method introduced in this section may be applied to achieve these sizing objectives.

It is important to stress here that this approach is not hypothetical - balanced stack systems have been commercially available in the UK for, apparently, over a century [105] although these commercially available systems have, until recently, been designed to serve single rooms rather than whole buildings. The Windcatcher natural ventilation systems distributed by Monodraught Limited in the U.K. offer air change rates as high as five air changes per hour under relatively low wind conditions $(3 \mathrm{~m} / \mathrm{s})$ [106]. These systems may also be supplied with co-axial fans to provide mechanical assistance during extreme weather conditions and integrated daylighting light tubes. Due to increased interests in recent years, the Monodraught company has expanded their product line to serve larger spaces and multiple floors. They are also engaged in research and development efforts with the British Research Establishment, the University of Nottingham, and the Bartlett School of Architecture in England to use solar assist, microprocessor controlled dampers for better wind control, built-in cooling coils, and winter-time heat recovery.

As the first central supply natural ventilation system considered in this section (i.e., as opposed to the distributed supply cross, stack, and single-sided ventilation schemes) low-pressure devices such as electrostatic filters and large surface area air cooling coils may be added to improve and extend the performance of the system for the more challenging urban environments of North America [107, 108]. In cold conditions, it may also be possible to achieve ventilation air heat recovery with top-down schemes by either using coaxial supply and exhaust chimneys or runaround heat recovery methods that circulate a heat transfer fluid between heat exchangers in supply and exhaust flow paths [75]. This will be discussed below.

Finally, modeling studies of top-down ventilation schemes indicate internal gains due to occupants and equipment characteristic of office environments may serve to drive displacement ventilation airflows within rooms of top-down ventilated offices thus adding yet another potential advantage of this approach $[107,109]$.

\section{Passive Downdraught Evaporative Cooling (PDEC) Stack Ventilation}

A closely related natural ventilation strategy also based on ancient Middle Eastern and Eastern Asian strategies adds evaporative cooling to the supply stack of a top-down or balanced stack ventilation system. In the traditional form of this scheme, evaporative cooling was introduced through the placement of water-filled porous pots within the supply air stream or the use of a pool of water at the base of the supply stack $[7,8]$. In the more recent developments of this approach, water is injected high into the supply air stream as a fine spray cooling the air stream 
via evaporation and simultaneously increasing the supply air density thereby increasing the buoyancy induced pressure differences that drive airflow [110].

The loop analysis of this so-called passive downdraught evaporative cooling (PDEC) scheme is similar to that of the balanced-stack scheme presented above but now the buoyancy effects of the increased moisture content must be accounted for psychrometrically. Consider the representative diagram of such a system shown in Figure 3.10 where two height differences must now be distinguished - $\Delta z_{a}$ the height of the moist column of air in the supply stack above the room inlet location and $\Delta z_{b}$ the height of the exhaust above this moist column.

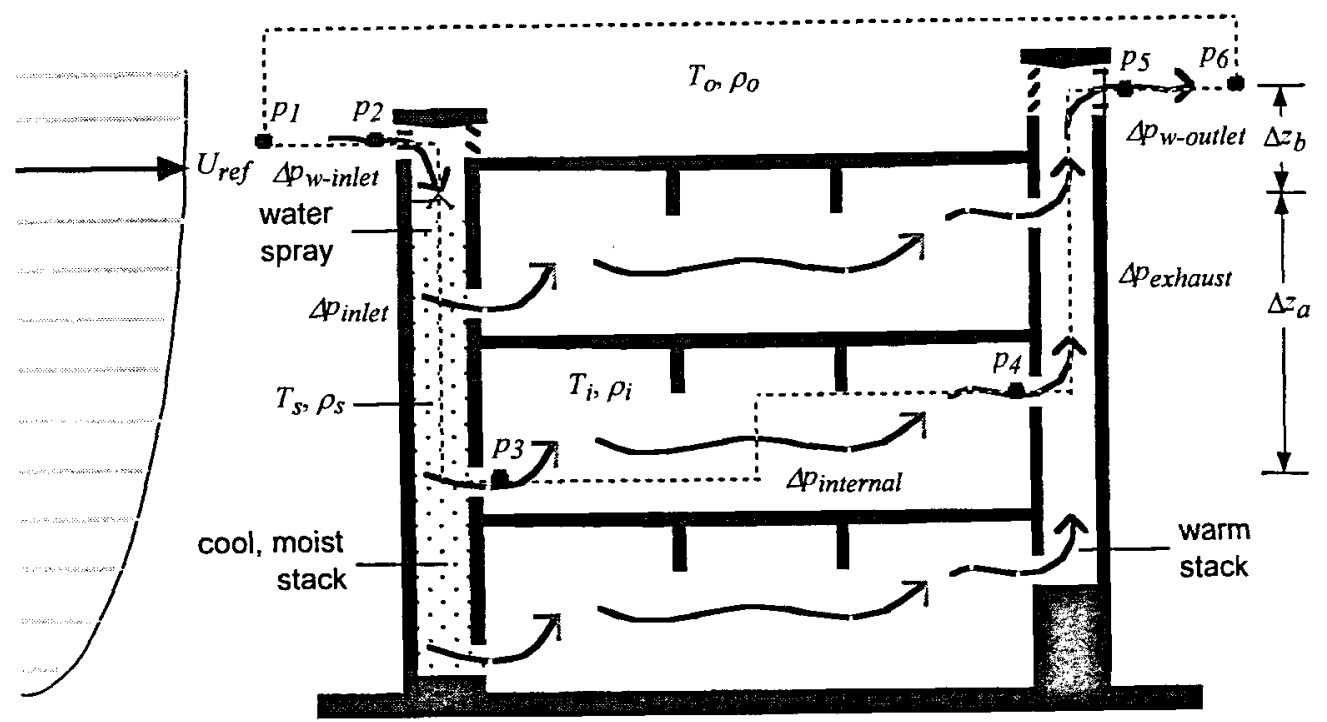

Passive Downdraught Evaporative Cooling Stack Ventilation

Figure 3.10 Passive downdraught evaporative cooling (PDEC) stack ventilation.

The density of the air $\rho_{s}$ in the moist air supply column will approach the saturation density corresponding to the outdoor air wet bulb temperature - more specifically, experiments indicate these supply air conditions will be within $2^{\circ} \mathrm{C}$ of this wet bulb temperature. Hence the loop equation governing the (time-averaged) ventilation airflow in this system becomes:

$$
\left(\Delta p_{\text {inlet }}+\Delta p_{\text {intermal }}+\Delta p_{\text {exhaust }}\right)=\Delta p_{s}+\Delta p_{w}
$$

where, now:

$$
\begin{gathered}
\Delta p_{s}=\left(\rho_{o} \Delta z_{b}+\rho_{s} \Delta z_{a}-\rho_{i}\left(\Delta z_{a}+\Delta z_{b}\right)\right) g \\
\Delta p_{w}=\left(C_{p-\text { inlet }}-C_{p-\text { cxhaust }}\right) \frac{\rho U_{r e f}^{2}}{2}
\end{gathered}
$$

To place quantitative scale on the impact of this PDEC strategy, consider a case similar to that discussed above with the cool moist column height approaching the stack height of $10 \mathrm{~m}$ (i.e., $\Delta z_{a} \approx 0$ and $\Delta z_{b} \approx 10 \mathrm{~m}$ ). If outdoor air at $25{ }^{\circ} \mathrm{C}$ and $20 \% \mathrm{RH}$ (i.e., with a density of approximately $1.18 \mathrm{~kg} / \mathrm{m}^{3}$ ) is evaporatively cooled to within $2{ }^{\circ} \mathrm{C}$ of its wet bulb temperature $\left(12.5^{\circ} \mathrm{C}\right)$, its dry bulb temperature will drop to $14.5^{\circ} \mathrm{C}$ while its density will increase to 
approximately $1.21 \mathrm{~kg} / \mathrm{m}^{3}$ and relative humidity to $77 \%$. If internal conditions are kept just within the thermal comfort zone for these outdoor conditions (i.e., $28^{\circ} \mathrm{C}$ and $60 \% \mathrm{RH}$ ), using an appropriate ventilation flow rate given internal gains, then internal air density will be approximately $1.15 \mathrm{~kg} / \mathrm{m}^{3}$. Consequently the buoyancy pressure difference that will result will be:

$$
\Delta p_{s}=\left(1.18 \frac{\mathrm{kg}}{\mathrm{m}^{3}}(0 \mathrm{~m})+1.21 \frac{\mathrm{kg}}{\mathrm{m}^{3}}(10 \mathrm{~m})-1.15 \frac{\mathrm{kg}}{\mathrm{m}^{3}}(0+10 \mathrm{~m})\right) 9.8 \frac{\mathrm{m}}{\mathrm{s}^{2}}=6.4 \mathrm{~Pa}
$$

Without the evaporative cooling (i.e., with $\Delta z_{a} \approx 10$ and $\Delta z_{b} \approx 0 \mathrm{~m}$ ), on the other hand:

$$
\Delta p_{s}=\left(1.18 \frac{\mathrm{kg}}{\mathrm{m}^{3}}(10 \mathrm{~m})+1.21 \frac{\mathrm{kg}}{\mathrm{m}^{3}}(0 \mathrm{~m})-1.15 \frac{\mathrm{kg}}{\mathrm{m}^{3}}(10+0 \mathrm{~m})\right) 9.8 \frac{\mathrm{m}}{\mathrm{s}^{2}}=2.9 \mathrm{~Pa}
$$

Thus, in this representative example, evaporative cooling more than doubles the buoyancy pressure difference while, at the same time, providing "free" (i.e., adiabatic) cooling.

Recent developments of this very attractive approach for hot arid climates provide sizing methods, additional technical detail, modeling studies, and references to built examples $[30,110$, $111]$.

\section{Heat Recovery - Air-to-Air \& Air-to-Fabric}

As discussed above, air-to-air heat recovery may be readily implemented in mechanical ventilation systems - a significant advantage they offer $[112,113]$. In natural ventilation systems, on the other hand, air-to-air heat recovery has proven more difficult to achieve for three. primary reasons. First, air-to-air heat recovery necessarily reduces buoyancy forces that may be needed to drive the naturally ventilated airflows. Second, common air-to-air heat recovery systems pass supply air and exhaust air through one of several different types of heat and/or enthalphy exchangers. Thus proximity of supply and exhaust airstreams is needed - distributed inlet natural ventilation systems make this difficult. Third, common air-to-air heat recovery systems, especially those system that prove most effective, offer significant resistance to airflow and thus are inherently incompatible with low-pressure natural ventilation systems.

For cold weather applications, when heat recovery is most beneficial, a slight loss of buoyancy force may not be critical especially if wind-driven pressures play a key role in the system. Furthermore, coaxial balanced stacks both solve the proximity problem and offer the possibility of large surface areas needed for heat exchange in low-pressure air-to-air heat recovery. Consequently, recent reports indicate air-to-air heat recovery is possible in coaxial balanced stack systems - although, so far only at the residential scale - provided they are matched by airtight building construction [114]. Additionally, the use of heat pipes to enhance heat transfer without inducing large pressure losses has been investigated as one tactic to improve this heat recovery strategy $[115,116]$.

To overcome the proximity requirement so-called run-around heat recovery systems may be used. These systems circulate a heat transfer fluid between heat exchangers placed in supply and exhaust flow paths. An innovative German environmental engineering firm, Transsolar Energietechnik of Stuttgart, recently used a run-around system for a larger naturally ventilated building in Gross Gerau, Germany. The thermal storage strategies used in this building will be 
discussed below - here it is useful to consider some of the details of the run-around heat recovery system, Figure 3.11 .

In this building outdoor air is admitted at a basement level, circulated through the building via cored slabs to rooms at five upper levels, and is exhausted from each level through one of two stacks with rather elaborate stack terminal units (see Figure 3.12). Run-around system heat exchangers are logically placed at the supply inlet location and just below the stack terminal cowl and two simple fluid piping loops with pumps connect the two stack heat exchangers with the supply heat exchanger. By placing heat exchangers close to the top of the exhaust stack only the last meter or so of the stack is affected, thus practically the full height of the stack can contribute to develop the driving buoyancy forces. In addition, the stack terminal units are fitted with glazed solar collector panels just downstream of the stack heat exchangers to augment the heat recovery with solar gain when available. The run-around heat exchangers are used in a fan assist mode in colder conditions and are positioned in both the supply and stack locations so that they can be bypassed during warmer weather conditions when natural forces alone can drive airflows (i.e., without the resistance provided by the run-around heat exchangers).

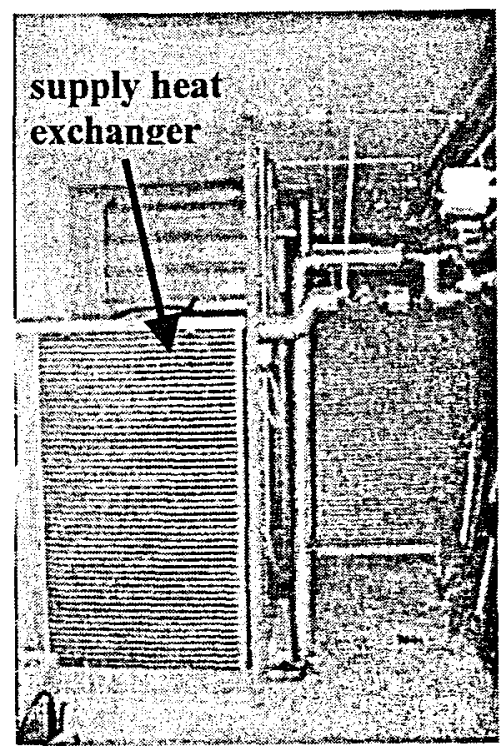

Outdoor Air Supply Inlet

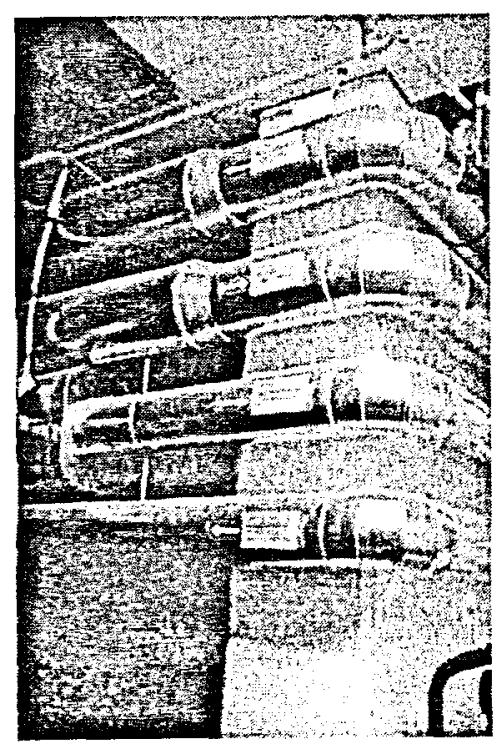

Linking Pipes

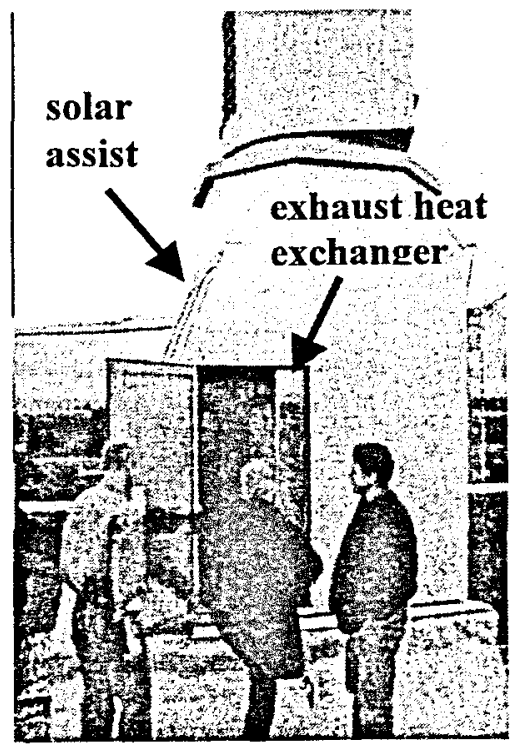

Exhaust Stack Terminal Unit

Figure 3.11 The run-around heat recovery system used in the Gross Gerau building by design engineers Transsolar Engietechnik, Stuttgart, Germany (www.transsolar.com).

For warm weather conditions, supply and exhaust heat exchangers linked by a heat pump have been proposed [108]. In this case, the hot coil of the heat pump system would logically be placed low in the exhaust stack to enhance buoyancy forces while the cold coil would be placed in the supply air stream to cool the incoming air. One wonders if a more efficient system would result by simply using fan-assistance and ground-coupling the heat pump instead.

In another approach, large rotary heat recovery wheels have been used in hybrid variants of the balanced stack system - specifically in the New Parliamentary Building in London and several buildings of the New (Jubilee) Campus of the University of Nottingham designed by architects Michael Hopkins \& Partners and environmental engineers Ove Arup \& Partners $[65,117]$. In 
these systems, the hybrid balance stacks are configured to bring supply and exhaust airstreams within the radius of oversized rotary heat exchangers. However, these heat exchangers present significant resistance (i.e., $60 \mathrm{~Pa}$ in operating modes utilizing them) so natural forces only augment fans when these heat exchangers are in operation. In the New Campus buildings, however, the exhaust stack is configured so that the rotary heat exchangers can be bypassed during warmer conditions when heat recovery is not beneficial to allow the system to operate in a natural ventilation mode.

Air-to-air heat recovery is, however, just one mode of heat recovery being investigated. A number of strategies that together could be identified as air-to-fabric heat recovery are also being considered. In these strategies ventilation heat flows operating counter to conductive heat flows act to simultaneously precondition incoming air (and "decondition" outgoing air) while reducing conductive exchanges through the building envelope. Unintended infiltration through building construction is known to provide this dynamic insulation heat recovery benefit, although this benefit is seldom accounted for in practice [118-120]. Etheridge presents a promising study of purpose-provided dynamic insulation using porous masonry units [121]: " They indicate that dynamic insulation and natural ventilation are compatible and that there is a strong synergy between dynamic insulation and wind energy which could lead to significant reductions in energy consumption of buildings."

Double façade or double skin systems achieve the same end as dynamic insulation and, due to their current popularity, are far less speculative and better understood than purpose-provided dynamic insulation [122-125]. By directing ventilation airflows between glazed layers, these systems also precondition these airflows, reduce conductive losses, and thereby affect a type of heat recovery. When the ventilation airflow is not needed, however, double-skin systems may be little more than expensive envelope components with limited thermal resistance. However, these systems are often designed to achieve multiple objectives beyond simply reducing conductive losses via convective heat exchange with ventilating airflows, including solar control, glare control, and acoustical separation while providing access for maintenance. Thus, their value must be judged ultimately in terms of these multiple objectives.

\section{Passive-Mechanical}

One familiar and generally ineffective stack terminal device is the rotating cowl often used on flue gas stacks of smaller gas burner appliances (e.g., boilers, furnaces, space heaters, hot water heaters, etc.) [126-129]. The traditional rotating cowl might be classified as an aero-mechanical device that serves to transform wind power into mechanical motion to drive a fan device. Etheridge at the University of Nottingham has initiated a study of a more effective aeromechanical device using a vertical turbine [121] that may well become a useful addition to the collection of devices being used in natural ventilation systems.

Graham and Jenkins discuss the potential of extracting energy from the wind using generators incorporated in the structure of tall buildings. Their results, based in part on wind tunnel studies, indicate up to $50 \%$ of the artificial lighting power required can be generated in this manner. They also discuss the possibility of applying this power to assist natural ventilation [130].

Another, better established, approach to power fans passively using naturally available energy sources involves the use of photovoltaic cells to generate electrical power that then is used to drive fans in ventilation systems. Photovoltaic ventilators have been used in recreational boats for more than two decades offering the obvious advantage of being able to more effectively drive 
airflows during sunny conditions when below-deck temperatures tend to be higher. Spurred on by a variety of tax incentives and installation discounts, photovoltaic systems are finding broader application in buildings - clearly some of the power they generate could be directly or indirectly used to drive fans to assist natural ventilation.

One particularly interesting application of photovoltaic generation to serve the ventilation needs of larger buildings is the AIRLIT-PV building envelope unit being developed by a consortium of European Union countries. "The intention of the European Union AIRLIT-PV project is to develop a prototype for a cost competitive building facade unit, which in application would strongly diminish the necessity for mechanical cooling. ... This unit integrates natural ventilation, daylighting, solar protection, intelligent control, and photovoltaic power and is being designed to perform optimally in energy efficient buildings. ..." [131, 132]. This unit is designed to provide well-controlled ventilation for winter air quality control and summer direct cooling as well as night cooling when appropriate.

\subsubsection{Natural Ventilation for Indirect Cooling - Night Cooling Strategies}

In many climates, extreme summer daytime temperatures are matched by moderate nighttime temperatures. It is therefore reasonable, in these situations, to consider indirectly cooling building interiors by precooling thermally massive components of the building fabric or a purpose-provided thermal storage chamber with cool nighttime outdoor air. Night cooling strategies provide the means of extending the utility of direct ventilative cooling strategies to the more extreme summer conditions by simply, in many situations, activating the thermal mass that is inherent in any large building structure. Consequently, many if not most naturally ventilated buildings are now designed to make effective use of night cooling.

Extending Braham's distinction of first-and second-generation night cooling strategies [64], it is useful to distinguish zeroth-, first-, second-, and third-generation night cooling strategies. Many early, even ancient, naturally ventilated buildings of masonry construction contained sufficient thermal mass to attenuate diurnal, weekly, and even longer outdoor temperature variations to, in effect, provide a type of unintentional night cooling. In Mediterranean regions, vernacular residential traditions included operational strategies for managing ventilation to purposely enhance night cooling by increased natural ventilation and to reduce daytime ventilative gains by reduced natural ventilation. Thus, zeroth-generation night cooling strategies are those early design strategies that implemented night cooling via ventilation control alone hoping sufficient thermal mass was available to make the effort worthwhile.

First-generation night cooling examples, in contrast, sought to improve the heat transfer to available thermal mass contained within the building fabric by simply making sure this thermal mass remained exposed to room air (e.g., was not covered by suspended ceilings or carpeting) and sought to maximize thermally massive building components. These buildings are characterized by massive exposed ceilings ("ceiling soffits"), the use of masonry walls, and/or brick and tile finishes for nonstructural partitions. The Queen's Building at De Montfort University is the premier example of a first-generation approach [9, 76-78].

Second-generation examples take a more aggressive approach to activating available thermal mass within the building structure by directing ventilation airflow through hollow or access floor construction, increasing ceiling soffit surface area through the use of so-called wave-form precast concrete floor planks, and the like. Recognizing only the first few inches of concrete 
construction participate in diurnal storage strategies, it became clear that increasing surface area was an effective strategy to make the most of available massive construction. The BRE Low Energy (Environmental) Office Building, Watford and the Inland Revenue Building, Nottingham in the U.K. are two examples of the early phase of these second-generation buildings $[9,78]$. A later phase of this second-generation use small diameter (e.g., approximately 8 to $10 \mathrm{~cm}$ ) cored slabs that are ventilated at higher velocities to improve heat transfer, albeit at greater pressure losses, to further activate more available mass. The proprietary Termodek precast, pretensioned, cored concrete floor plank system is widely used in Scandinavia and the U.K. [133]. This system has been used in a number of projects completed by the innovative environmental engineering firm Atelier Ten in London for this purpose [134-137]. In Germany where the Termodek system cannot be used for minor code reasons, on the other hand, cores are cast in place to achieve the same end [138].

Finally, third-generation methods isolate the thermal mass from the occupied spaces of the building to allow greater control of heat exchange with the thermal mass store and often use a mechanical assist hybrid approach. The labyrinth schemes promoted by Atelier Ten of London which were originally inspired by earlier German precedents and much earlier Roman hypocaust methods - provide the most conspicuous example of this third-generation approach [139-142]. The mass-plenum scheme investigated by Jones is similar [143]. In the labyrinth schemes, a literal labyrinth of concrete walls is placed beneath the building or site and cool nighttime air is used to "charge" the labyrinth for subsequent use as needed. In the case of the Federation Square project in Melbourne, Australia the labyrinth walls were formed with a corrugated surface to further increase surface area.

It is interesting to note this evolution from first to third-generation systems parallel a similar evolution in the development of residential passive solar heating methods in North America during the 70's and 80's. The most complex passive solar systems also isolate the thermal mass to achieve greater control over thermal comfort and, importantly, overheating. In night cooling both overheating and overcooling are concerns but control strategies developed for secondgeneration methods appear to be sufficient to avoid these problems [78, 99, 144-149]. Consequently, it appears that third-generation methods are best limited to special climates or circumstances that warrant their use.

A very recent proposal to use phase change materials (PCM) in lieu of thermal mass for night cooling also parallels developments in passive solar heating. A research team at the University of Nottingham have investigated coupling PCMs to indoor air via heat pipes using a slow-speed propeller fan to force airflow over the heat pipes and, thus, improve heat transfer for both night cooling of the PCM and daytime cooling of the space. When compared to conventional night cooling methods:

"The present system has been compared with the well-known passive cooling system whereby a concrete slab of high thermal mass is cooled by night ventilation, and/or chilled water is passed through pipes embedded within the slab. A concrete slab of 5 tonnes (which would be very difficult to retrofit) would be needed to provide the same cooling rate as the present system with 10 heat pipe units $(116 \mathrm{~kg}$... of PCM). Moreover, with the present system there is no risk of condensation whereas reduction of the concrete temperature below the dew point of the ambient air can occur with 
chilled-ceilings. The current units therefore provide a much more weight- and installation-efficient system than the chilled ceiling option." [150]

As experience has been gained with second-generation approaches, designers have increasingly made use of the thermal mass to store internal gains generated within the building during cooler periods of the year to minimize auxiliary heating energy consumption. As noted in the first section of this chapter, hybrid systems utilizing thermal mass storage strategies have achieved the lowest energy consumption of all office buildings in the U.K. [43]. One must, however, balance the advantages of storing excess energy due to equipment and lighting to reduce auxiliary heating energy consumption against the relatively high primary energy penalty associated with electrical energy consumption in the first place.

Curiously, even though thermal mass is central to night cooling methods, quantitative metrics to characterize the amount of thermal mass needed are seldom used. Researchers and practitioners alike commonly make qualitative distinctions between "light", "medium", and "heavy construction" (e.g., see [78, 144, 149]. Two exceptions to this rule should be noted. Van Paassen characterizes these three as providing $M=50 \mathrm{~kg} / \mathrm{m}^{2}, 75 \mathrm{~kg} / \mathrm{m}^{2}$ and $100 \mathrm{~kg} / \mathrm{m}^{2}$ of thermal mass, respectively, where $M$ is "the sum of half the weight of the side walls, back wall, floor, ceiling, and the entire weight of the façade divided by the total inner room area" [148]. Svensson and Aggerholm introduce the concept of active thermal capacity (Wh/K- $\mathrm{m}^{2}$ ) and define it as "the thermal mass per gross floor area" without giving any guidance on how it is to be evaluated in general [151, 152]. They do provide, however a table of representative values that is reproduced here, Table 3.2. Note that these values apply, in essence, to first generation night cooling - active thermal mass for second generation approaches must be expected to be even greater.

Table 3.2 Active thermal capacity per $\mathrm{m}^{2}$ gross floor area (taken from [151]).

\begin{tabular}{llc}
\hline Description & Internal Construction & $\begin{array}{c}\text { Active Thermal Capaciy } \\
\text { Wh/K-m }\end{array}$ \\
\hline Very Light & $\begin{array}{l}\text { Light walls, floors and ceilings, e.g. skeleton with } \\
\text { boards, without any heavy structures }\end{array}$ & 40 \\
Light & $\begin{array}{l}\text { Some heavy structure, e.g. concrete slab with } \\
\text { wooden floor or light-weight concrete walls. }\end{array}$ & 80 \\
Heavy & $\begin{array}{l}\text { Several heavy structures, e.g. concrete slab with } \\
\text { clinker and brick or clinker concrete walls. }\end{array}$ & 120 \\
Very Heavy & $\begin{array}{l}\text { Heavy walls, floor and ceiling made by concrete, } \\
\text { brick or clinker. }\end{array}$ & 160 \\
\hline
\end{tabular}

An examination of the algorithm used in the NatVent ${ }^{\mathrm{TM}}$ program reveals that the active thermal mass is the effective thermal mass participating in the dynamic thermal response of the building assuming the temperature of the thermal mass remains spatially uniform - a thermal mass modeling sometimes identified as quick mass in the passive solar literature [151]. While the active thermal capacity represents a beginning, a more rigorously defined and practically useful thermal mass metric is needed. It may be helpful to research the building thermal simulation literature for approaches to do this. 
The number of variants of first-and second-generation night cooling ventilation schemes is large and, thus a classification and enumeration of these schemes is beyond the scope of this report. A list of case studies of innovative buildings is appended to this report that the reader may want to look into. To make these strategies more concrete, however, one second-generation example building will be described next and a typical first-generation example will be presented in Chapter 4.

\section{Transsolar's Gross Gerau Building}

Transsolar Energietechnik GmbH of Stuttgart, Germany recently completed construction of a five-story office building in the town of Gross Gerau just south of Frankfurt, Germany that utilizes mechanically-assisted natural ventilation with cored-slabs to achieve both night cooling during extreme summer periods and to more optimally use internal gains during the heating season. In this building outdoor air is admitted at a basement level, circulated centrally up to each floor level then outward to the building perimeter via cored slabs to room perimeters at each level - see white arrows in Figure 3.12 and details in Figure 3.13. From the rooms, ventilation airflows move through corridors to one of two stacks where they are exhausted through selfvaning cowls, Figure 3.13, designed to maximize the suction provided by winds and yet remain insensitive to wind direction. Outdoor air is admitted, heated and fan assisted as required in the basement inlet room and ultimately exhausted through the stack terminal units, Figure 3.13.

Conceptually straightforward, the success of this building depends entirely on the proper sizing of system components. It should come as no surprise, then, that Transsolar develops computational modeling tools in addition to providing design services for innovative low-energy natural and hybrid ventilated buildings. First-, second- and third-generation naturally ventilated buildings may be distinguished from the zeroth-generation prototypes by the engineering analysis used to support the former.
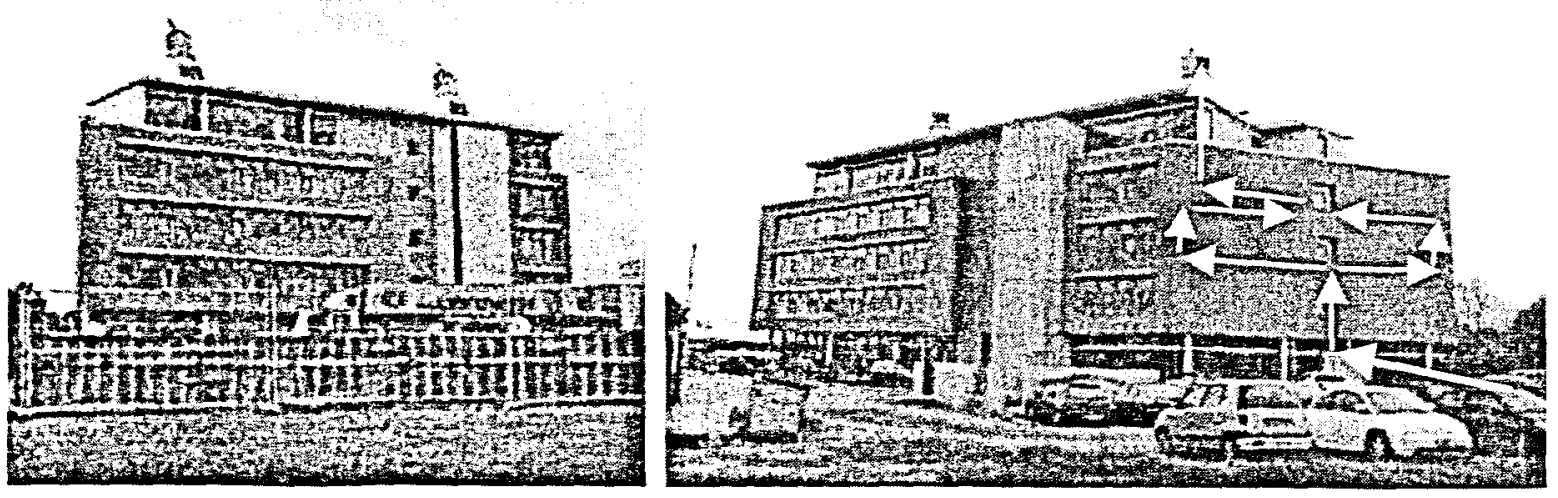

Figure 3.12 The Gross Gerau building designed by Transsolar Energietechnik, GmbH with two dominant stacks fitted with large self-vaning cowls. White arrows indicate, schematically, the ventilation airflow paths. 

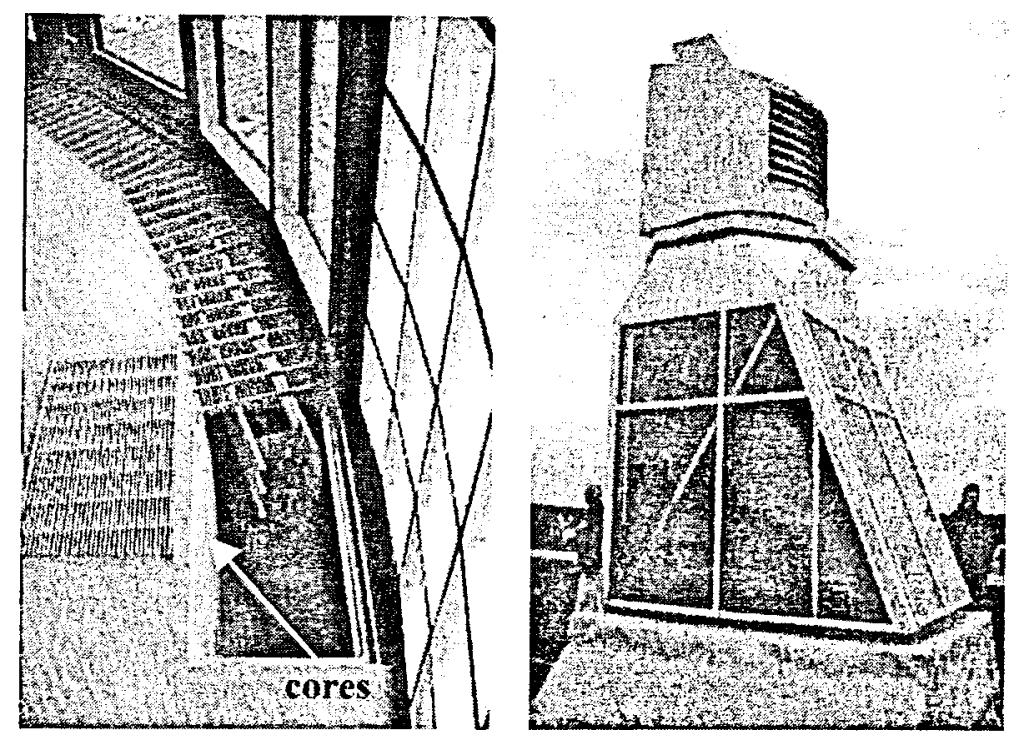

Figure 3.13 Air diffuser detail of the Gross Gerau building designed by Transsolar

Energietechnik, GmbH showing one of the cores used to direct ventilation airflows to the building perimeter. Stack terminal unit showing glazed solar assist panels and self-vaning cowl.

\subsubsection{Natural Ventilation System Components}

A number of specialized components - e.g., operable and automatically controlled windows, specialized inlet vents, automatic and self-regulating vents, stack terminal devices, etc. - have been developed specifically for natural ventilation systems. These specialized components are invariably combined with more familiar components - e.g., ducts and standard duct fittings, fans (for fan-assisted natural ventilation), conventional doors, windows, and the like - in the design development and construction of natural ventilation systems. Here, a number of references will be cited that provide more detailed information about the specialized components and mathematical models for modeling these and the more familiar components will be presented.

Specialized window systems, including some that are operable under occupant control during the day yet automatically controlled by the building management system at night, are described in several design guidelines $[39,40,146]$. These design guidelines also provide an introduction to the range of actuators that are available to control window openings. Trickle ventilators, intended to provide background ventilation for air quality control, have been used in residential applications for perhaps a century in the U.K. In recent years, manufacturers have developed a large variety of these devices, some intended for commercial building applications, including trickle ventilators integrated into window systems [39, 40, 146, 149, 153].

For a number of years research has been directed toward the development of self-regulating inlet vents in the hopes of developing completely passively controlled natural ventilation systems. These devices have been designed to increase or decrease airflow rates in response to sensed wind speed, air temperatures, relative humidity, occupant presence, pressure differences, etc. [20, $21,24,154-156]$. Of these devices, those that regulate airflow rates to remain constant over a relatively broad and suitable range of pressure differences across the device (i.e., from $5 \mathrm{~Pa}$ to 25 $\mathrm{Pa}$ ) have proven most useful as they can effectively provide reasonably constant airflow rates for 
variable wind conditions. Indeed, the success of many natural ventilation systems depends critically on the efficacy of these pressure-driven self-regulating components.

Stack terminal devices are also critical to the success of many natural ventilation systems and, consequently, have been the subject of some but not yet exhaustive research efforts. In most applications wind direction insensitive terminal designs are strongly favored, again to provide relatively constant control over ventilation rates. Wind-direction insensitivity is invariably achieved with vertically axisymmetric designs with the stack terminal extending above adjacent roof areas, Figure 3.14. In addition, stack terminal designs that maintain relatively large suction pressures (i.e., negative wind pressure coefficients) and are resistant to short term reverse flow due to wind turbulence are preferred as they are more likely to maintain the ventilation airflow direction desired. This is commonly achieved using baffles or so-called "H-pot" configurations or more aggressively with rotating self-vaning cowls (see [65] or the Gross Gerau stack terminal in Figure 3.13). A number of investigations by the British Research Establishment and the Dutch research institute TNO on stack terminal devices used, primarily, for gas combustion exhaust systems essentially establish the state-of-knowledge in this specialized area [126-129, 157, 158]. Some limited wind tunnel measurements of stack terminal devices for natural ventilation systems have, however, complemented this body of knowledge [65, 159-161].

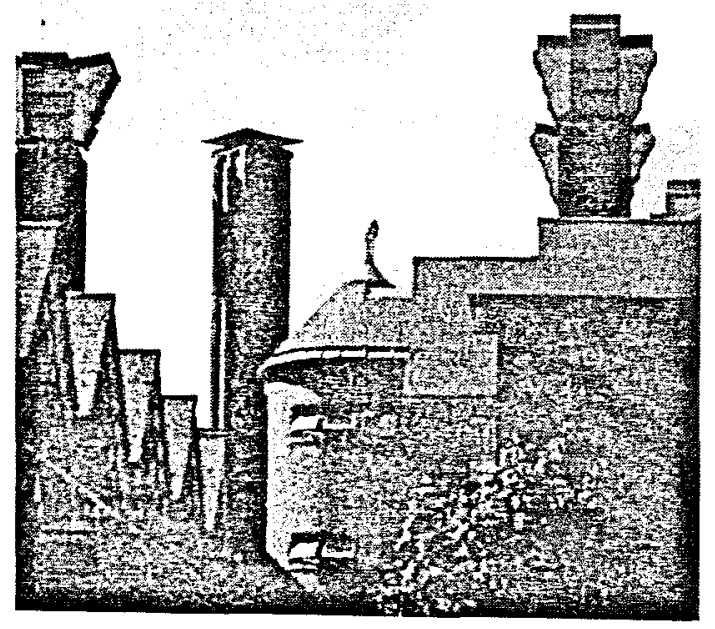

Figure 3.14 Stack terminals used in the Queen's Building De Monfort University, Leicester, England showing a simple square stack and more complex baffled axisymmetric stacks and a small self-vaning cowl (center).

\section{Component Flow Relations}

Mathematical models are needed to rationally size components of natural ventilation systems. As established above, these flow relations may be developed in forward or inverse form (i.e., Equations 3.11 and 3.12). Multizone airflow analysis programs, including the CONTAM and COMIS family of programs offer libraries of forward flow component relations. The underlying theory for these elements is presented in the manuals that accompany these programs [162-166].

Here, a library of inverse flow component relations that may be directly used in the pressure loop equations introduced above will be enumerated. In general, these mathematical models relate the 
pressure drop $\Delta p_{l}$ in a component $l$ to the volumetric flow rate $\dot{V}_{l}$ through the component and a design (e.g., size) parameter $\phi_{1}$. These inverse relations may be directly derived from the wellestablished forward flow relations (see [72] for details and additional models).

Two semi-empirical models - the power-law model and the effective leakage area model - are commonly used to model a variety of flow components including windows, doors, trickle vents, cracks and joints in building construction, etc. Specific input data for these models have been published by ASHRAE, NIST, and AIVC [46, 89, 167].

Power Law Component: Two model parameters define the power law component relation - a dimensionless exponent $n_{l}$ which is reasonably assumed constant for a given class of flow components and a flow coefficient $C_{l}\left(\mathrm{~m}^{3} / \mathrm{s}-\mathrm{Pa}^{-\mathrm{n}}\right)$. For this component the design parameter will be taken as $\phi_{l}=C_{l}^{1 / n_{l}}$ :

$$
\Delta p_{l}=\frac{\dot{V}_{l}^{1 / n_{l}}}{\phi_{l}} \text { where } \phi_{l}=C_{l}^{1 / n_{l}}
$$

Effective Leakage Area Component: The effective leakage area model, based in form on the classical orifice relation, relates the behavior of the flow component to a physically consistent but approximate effective leakage area $A_{e f f-I}$ and the density of the air flowing through the component $\rho$. For this component the design parameter will be taken as $\phi_{l}=A_{e f f-l}^{2}$ :

$$
\Delta p_{l}=\frac{\rho \dot{V}_{l}^{2}}{2 \phi_{l}} \text { where } \phi_{l}=A_{e f f-l}^{2}
$$

Orifice Component: The classic orifice equation is a theoretically rigorous model calibrated with an empirically determined dimensionless parameter - the so-called discharge coefficient $C_{d}$ that is reasonably applied to openings such as open windows, doors, and the like. It relates the behavior of the component to its cross-sectional area $A_{l}$ and the density of the air flowing through the component $\rho$. For this component the design parameter will be taken as $\phi_{l}=A_{l}^{2}$ :

$$
\Delta p_{l}=\frac{\rho \dot{V}_{l}^{2}}{2 C_{d}^{2} \phi_{l}} \text { where } \phi_{l} \equiv A_{l}^{2}
$$

Duct Component: Flow relations for ducts and duct networks made up of duct segments and duct fittings of a variety of types are well established. Here we will limit consideration to the classical form of the duct relation and the most common semi-empirical relation for duct fittings. The behavior of a duct segment may be defined in terms of the duct length $L(\mathrm{~m})$, the so-called hydraulic diameter $D_{h}(\mathrm{~m})$ of the duct equal to the area of the cross-section divided by its perimeter, the cross-sectional area of the duct $A_{t}\left(\mathrm{~m}^{2}\right)$, and a dimensionless friction factor $f$. For duct segments the design parameter will be taken as $\phi_{l}=D_{h} A_{l}^{2}$ :

$$
\Delta p_{l}=\frac{f L}{2} \frac{\rho \dot{V}_{l}^{2}}{\phi_{l}} \text { where } \phi_{l} \equiv D_{h} A_{l}^{2}
$$


Airflow in natural ventilation systems is likely to fall within the so-called transitional or turbulent regime. Consequently, for preliminary sizing calculations the friction factor may be expected to fall within the range of 0.01 to 0.05 .

Duct Fitting Component: Pressure losses in duct fittings are related to the kinetic energy content of the airflow in the duct via a dimensionless fitting loss coefficient $C_{l}$, that is analogous to the wind pressure coefficient introduced above, and a characteristic cross-sectional area $A_{l}$ of the fitting. For this component the design parameter will be taken as $\phi_{l}=A_{l}^{2}$ :

$$
\Delta p_{l}=\frac{\rho C_{l} \dot{V}_{l}^{2}}{2 \phi_{l}} \text { where } \phi_{l}=A_{l}^{2}
$$

Self-Regulating Vent Component: As noted above, self-regulating vents have proven to be critical to the success of natural ventilation system yet, ironically, flow relations have yet to be developed for these essential components. The author has proposed two models for these important components - a logarithmic model with physically consistent parameters and a loworder power law model.

The low-order power law model will be used in the modeling studies reported in Chapter 4 . It is simply the power law expression above, Equation 3.23, with an exponent of $n_{l}=0.10$ fitted to measured data for a specific self-regulating vent (e.g., see Equation 4.3). Figure 4.5 compares a specific application of this model to a related power-law relation using an exponent of 0.5 revealing the near-constancy of the low-order power law model for the range of pressure differences likely to be encountered in practice - i.e., the ability of the self-regulating vent to maintain nearly constant airflow rates.

The logarithmic model describes the behavior of self-regulating vents in terms of a threshold pressure difference $\Delta p_{o}$ - the pressure difference at which regulation effectively begins - and the nominal self-regulated volumetric flow rate $\dot{V}_{a}$ :

$$
\Delta p_{l l}=-\Delta p_{o} \ln \left(1-\frac{\dot{V}_{l}}{\dot{V}_{o}}\right) \text { where } \phi_{l} \equiv \dot{V}_{o}
$$

This proposed model was fitted to measured data for both Dutch and French self-regulating vent data [21]. Figure 3.15 illustrates the results of this exercise comparing the proposed empirical model to both measured data and the orifice model for the $4,000 \mathrm{~mm}^{2}$ and $8,000 \mathrm{~mm}^{2}$ inlet vents recommended for residential passive stack ventilation systems. Again, the constancy of flow provided by these self-regulating vents is evident. 


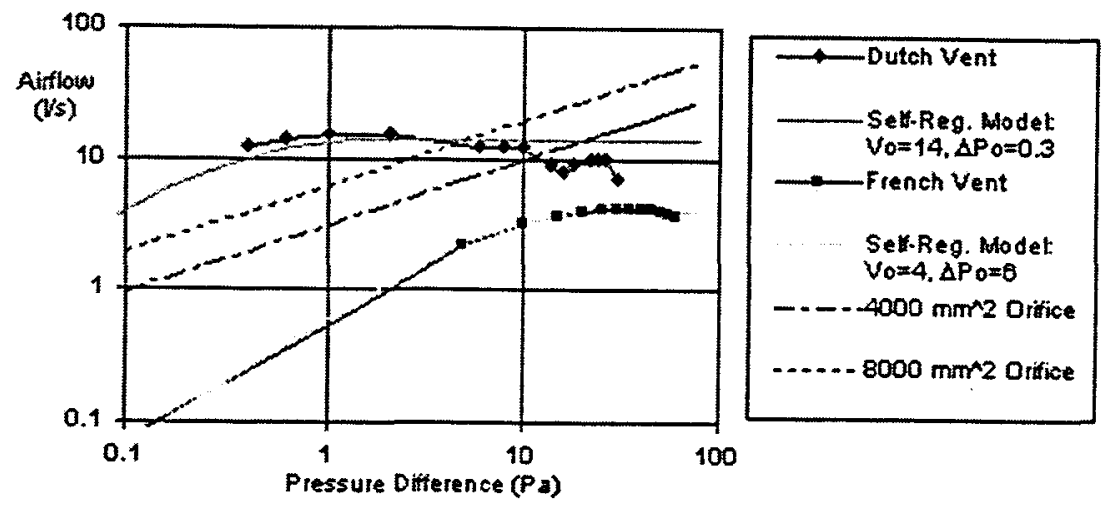

Figure 3.15 Comparison of proposed logarithmic self-regulating vent model, Equation 3.28, with measured data [21] and orifice models for the $4,000 \mathrm{~mm}^{2}$ and $8,000 \mathrm{~mm}^{2}$ inlet vents.

A method for sizing components in natural ventilation systems will be presented that is based on pressure loop equations using these flow component relations.

\subsubsection{Hybrid \& Mixed-Mode Ventilation Strategies}

In the past decade, natural ventilation strategies began to demonstrate their ability to conserve energy without significant first and operational cost penalties while providing greater occupant control over indoor environmental conditions and improved air quality. In comparison, mechanical ventilation systems "combined with heating and cooling, humidity control and filtration ... \{demanding\} ... significant fan power consumption ... became associated with profligate use of energy, ... poor air quality, ... ineffective air distribution, ... re-circulation of exhaust air, ... problems of maintaining and operating, ... sick building syndrome, \{and $\ldots$... health and comfort complaints" [56]. Recognizing the advantages mechanical systems offered including (potentially) better comfort and air quality control and heat recovery, building mechanical engineers devised new systems that reduced fan power through the use of more efficient and variable speed fans, low pressure designs, and ventilation-only air systems. These innovations were made possible, in part, by improved solar control, reduced internal gains, chilled beams and radiant ceilings, thermal mass, and displacement as well as demand-controlled ventilation methods. Simultaneously, building "environmental engineers" accepted the need to rely on mechanically-assisted ventilation when natural driving forces were insufficient and turned to minimum power mechanical systems to implement some heat recovery strategies (i.e., run-around and oversized rotary heat recovery devices).

Inevitably, these trends merged to create the important emerging trend of hybrid and mix-mode ventilation systems. Here hybrid systems are ones that combine mechanical and natural systems that operate integrally to minimize energy consumption while maintaining acceptable thermal comfort and air quality. Mix-mode systems, on the other hand, are designed to allow natural systems to operate independently when effective otherwise mechanical systems take over. Practically all built "natural ventilation" systems include mechanical devices to control the systems (e.g., operable openings or dampers, sensors, actuators, and control processors) and fans to assist natural flows when necessary - thus are technically hybrid systems. Even the symbolic flagship of naturally ventilated buildings, the Queen's Building of De Montfort University, uses low-speed "Calcutta" fans in its paired stacks to inhibit top-down convective flows and a variety 
of mechanically operated openings. Likewise, the "independent" mechanical subsystems of mixmode systems are configured to make use of natural driving forces and could, therefore, be said to be naturally-assisted (e.g., see $[65,117,168,169])$.

"So, if we look to the future, buildings are more likely to have some form of hybrid ventilation system and there will be less prejudice for choosing either a natural or mechanical solution independent of building and site consideration" [56]. An International Energy Agency research "annex", Annex 35 HybVent, with fifteen participating countries is presently developing control strategies, performance analysis methods, and measurement methods to promote "energy- and cost-effective hybrid ventilation systems" for office and educational buildings $[15,16,41,170]$.

An interesting but presently exceptional approach to hybrid ventilation is the COOL POOL system implemented by Aynsley, and a similar strategy proposed by Kato, to provide a pool of mechanically cooled air within a larger space that is otherwise naturally ventilated [171-173]. When faced with the problem of air conditioning a large two-story space within a historic $19^{\text {th }}$ century customs building in the Australian tropics, Aynsley chose to maintain a pool of mechanically cooled air within the relatively small unenclosed office area bounded by three walls and a high counter rather than cooling the entire two-story volume. To moderate temperatures in the larger enclosing volume natural ventilation was maintained. Bellew used a similar strategy on a much larger scale by providing a cool air pool within a large atrium space in the Federation Square project, Melbourne, but in this case the air was cooled naturally using a night-cooled labyrinth [174].

\subsubsection{Operation \& Control}

Reflecting the three potential purposes of natural ventilation, three distinct control regimes should be considered in the operation of natural and hybrid ventilation systems:

1. control of ventilation rates and air distribution to maintain acceptable indoor air quality,

2. control of ventilation rates and air distribution for direct ventilative cooling when appropriate, and

3. control of ventilation rates and air distribution for night cooling when required.

It is important to stress that control of both rates and air distribution must be considered.

Typically, minimal ventilation rates for air quality control (i.e., on the order of $1 \mathrm{ACH}$ during building occupancy) will be less than those required for direct ventilative cooling (i.e., on the order of 5 to $10 \mathrm{ACH}$ ), thus air quality control will normally not be an issue during direct ventilative cooling. Likewise, typical ventilation rates for night cooling (e.g., on the order of 5 to $15 \mathrm{ACH}$ ) will exceed minimal rates needed for air quality control, which during unoccupied hours may fall well below $1 \mathrm{ACH}$, thus again air quality control - other than moisture control will normally not need to be considered during night cooling. As direct ventilative cooling and night cooling are operational strategies that do not occur concurrently, control for each of these three modes of ventilation are mutually exclusive and can be considered independently.

The minimal ventilation required to maintain acceptable air quality - so-called background ventilation - is reasonably controlled automatically as personal detection of air quality conditions is generally too subtle to be considered. This control is critical in winter conditions when overventilation can have significant energy consequences. In a naturally ventilated building this is 
achieved at a coarse level through building configuration and proper design of the topology of the natural ventilation system and at a fine level through the proper sizing of the components used in this system and the regulation of key component openings [40]. Pressure responsive selfregulating vents achieve this fine-tuning automatically in a passive manner (i.e., without the need for sensors, actuators, and control processors) thus they have become indispensable to state-ofthe-art natural ventilation design $[20,21]$ and are gradually replacing conventional trickle ventilators intended to achieve the same end but lacking automatic self-regulation. To maintain pressure differences across these self-regulating vents within their operable range they may have to be complemented with manually or mechanically regulated coarser-control components. For example, hydraulically actuated large stack caps used in the Inland Revenue Building of Nottingham can be adjusted daily to "coarse" tune the natural ventilation system for windy or calm day conditions as necessary [40]. Pressure loop equations may be applied to the task of sizing components for this and other ventilation strategies and developing the specific opening requirements for such "coarse" tuning. An example application of this approach for the Inland Revenue Building is presented in [175].

Control of ventilation for direct cooling may best be left to building occupants as occupant control appears to be strongly related to productivity [40], occupants will accept wider thermal comfort bands when occupant control is available [12, 47, 59], and is generally preferred by occupants. In fact, some circumstantial evidence indicates occupants may provide better control than more complex automatic systems. Gunnarsen notes for one recent school renovation project where occupant control replaced mechanical control: "The school users were as good, or better, at obtaining comfortable temperature and air quality as the poorly maintained mechanical ventilation system with central automation" [32].

This may well be due to the fact that occupant control can be a robust form of control. Leyten defines robustness as the ability of a system to perform well even when operational conditions violate design assumptions and argues simpler, more comprehensible technology, including occupant controlled natural ventilation, are inherently more robust [19]. Irving notes, however, this demands ventilation controls be associated with the space they control, be intuitively obvious to use, and be readily accessible [40].

Nevertheless, there are some obvious pitfalls with occupant control including problems of windows left open unintentionally and the need to limit daytime ventilation when night cooling operation is active. Thus, operable windows with mechanical over-rides may have to be used in practice.

Tall buildings present special but not insurmountable challenges for occupant controlled openings as they are subject to high wind pressures and often large buoyancy pressures induced by tall elevator, stair, and utility shafts. Architects Sir Norman Foster in the Commerzebank. Stuttgart, Germany and Ken Yeang in both built and proposed designs mitigate the high wind problem by allowing operable windows to open on partially enclosed "sky courts" placed strategically at various heights on the building perimeter or into a protected layer of double-skin facades. To reduce the impact of buoyancy pressures both architects subdivide their towers into independent segments using glazed diaphragms in tall atria spaces, discontinuous elevator shafts, and linked partially-conditioned "sky courts" [40, 80, 81, 123].

In hybrid (and mechanically ventilated) buildings, most mechanical systems pressurize the building. Even a slight pressurization may defeat natural ventilation by operable openings, thus 
special strategies to allow occupant controlled ventilation in hybrid buildings will need to be developed [45]. Low-pressure mechanical systems configured to be assisted by natural driving forces may provide one logical strategy to overcome this problem.

Table 3.3 Recommended night cooling control strategies from three different investigations.

\begin{tabular}{|c|c|c|}
\hline $\begin{array}{c}\text { Kolokotroni } \\
{[149]}\end{array}$ & Martin \& Fletcher & van Paassen et al \\
\hline
\end{tabular}

Enable Night Cool Criteria

- if peak zone temp. $>23^{\circ} \mathrm{C}$ or,

- if average daytime zone temp. $>22{ }^{\circ} \mathrm{C}$ or,

- if average afternoon outside air temp. $>23^{\circ} \mathrm{C}$ or,

- if slab temp. $>23^{\circ} \mathrm{C}$.
- if peak zone temp. $>23^{\circ} \mathrm{C}$ or,

- if average daytime zone temp. $>22^{\circ} \mathrm{C}$ or,

- if average afternoon outside air temp. $>20^{\circ} \mathrm{C}$ or,
- Opt. A: if peak zone temp. > $24^{\circ} \mathrm{C}$ and,

- Opt A: if daytime zone degree hours, base $21^{\circ} \mathrm{C}$ is positive or,

- Opt B: if average afternoon outside air temp. $>18^{\circ} \mathrm{C}$ or,

- Opt. C: if slab temp. $>23^{\circ} \mathrm{C}$.

- Opt. D: PI vent control on peak zone temp. to (1822) ${ }^{\circ} \mathrm{C}$ or,

- Opt. E: manual control based on weather forecast.

\section{Operate Night Cool Criteria}

- if zone temp. > outdoor temp. and

- if outside air temp. $>12^{\circ} \mathrm{C}$ and

- if zone temp. > zone heating setpoint.
- if zone temp. > outdoor temp. $+2{ }^{\circ} \mathrm{C}$ and

- if outside air temp. $>12{ }^{\circ} \mathrm{C}$ and

- if zone temp. > zone heating setpoint.

\section{Operation Period}

- enable operation 7 days a week

- enable operation during entire non-occupied period
- enable operation 7 days a week

- enable operation during entire non-occupied period

- continue operation two additional nights when activation \& operation criteria are no longer satisfied if operated for 5 or more consecutive nights.
- if zone temp. > outdoor temp. and

- if outside air temp. $>12^{\circ} \mathrm{C}$.

${ }^{a}$ The PI control set point in this option is set to $\max \left\{\left(22^{\circ} \mathrm{C}-n\left(2{ }^{\circ} \mathrm{C}\right)\right), 18^{\circ} \mathrm{C}\right\}$ where $n$ is the number of consecutive days night cooling has been operational.

Control of ventilation for night cooling represents a far greater challenge, in part, due to the dynamic nature of night ventilation and the need to anticipate future conditions it is difficult to achieve and often counter intuitive and, in part, due to the consequences of improper night ventilation. Improper night ventilation can lead to overheating, overcooling, and moisture entrainment. Consequently, night ventilation is best controlied automatically. 
A number of research efforts have been directed to the problem of developing effective night cooling control strategies and the hardware to support these strategies [40, 78, 146-149]. Three recommended control strategies will be compared here - those proposed by Martin, Kolokotroni, and van Paassen, Table 3.3. The reader is directed to these references for more specific information regarding the control hardware.

Martin and his colleagues based their recommended control strategy on site monitoring studies of four buildings and matching simulation studies. Kolokotroni, likewise based her recommended control strategy on monitoring and simulation studies. Van Paassen investigated five different control strategies (here, labeled A, B, C, D \& E) using a detailed coupled thermal/airflow model for a representative section of a typical office building floor (i.e., two exterior offices separated by a corridor). Although van Paassen did not explicitly recommend any one control strategy he concluded: "The control strategies show more or less the same performance."

Upon comparison, there is very little difference between these control strategies, although van Paassen et al's control strategies Opt. D and Opt. E are predictive strategies and they did not include the practically important operational criteria that night cooling should be terminated when indoor air temperatures fall below the indoor heating setpoint temperature (i.e., to avoid overcooling that would demand a morning preheating period). Given the similarity of these results, the observation by the van Paassen group that, in essence, variants of Martin's and Kolokotroni's control schemes may well be equally effective, and the fact that sampling a representative slab temperature may be practically difficult to achieve, Kolokotroni's scheme without the slab temperature condition would seem to suffice. In practice one should fine tune the actual set points used in any event using design development simulation studies or as part of the commissioning of the building.

\subsection{Design Tools}

Until very recently, natural ventilation systems were designed based on local or regional traditions, limited empirical studies, and fundamental but incomplete theoretical models similar to those presented in Chapter 25 of the 1997 ASHRAE Handbook of Fundamentals [46]. By the early 1990's, as the rapid spread of air conditioning systems across Europe and the electrical power consumption associated with them began to compromise efforts to limit greenhouse gas emissions, a number of European research programs were initiated to develop natural ventilation as an energy saving alternative to building air conditioning and mechanical ventilation. Three early programs, the European Union (EU) SAVE program [7], the International Energy Agency (IEA) PASCOOL program [5, 6, 176, 177], and the IEA Annex 28 Low Energy Cooling Systems project [178] were quickly followed by the NatVent ${ }^{\mathrm{TM}}$ European JOULE project, undertaken by a consortium of nine research groups in seven European Countries [3, 4, 11], and, most recently, the IEA Annex 35 Hybrid Ventilation project $[15,16,41,170]$.

Impatient to implement natural and hybrid ventilation systems in commercial and institutional projects, a number of leading architects and environmental \{building\} engineers - a term that emerged during this period - proceeded to devise and build a series of naturally ventilated buildings of increasingly ambitious design. Indeed, case study investigations of these innovative building systems became a major part of the European research programs as researchers, in essence, struggled to keep up with advances in the profession. 
This section of the report will present a review of design tools that have resulted from these and other research projects - tools that include predesign tools, descriptive guidelines, manual and computational analysis tools for preliminary design, and computational simulation and physical modeling tools for performance evaluation. However, it must be emphasized at the outset that these tools fall well short of what is needed to reliably size and configure natural ventilation systems and their components, in general. Specifically the descriptive guidelines are limited to overly simplistic system configurations and the analytical tools are often limited to climates similar to that of southern England and northern continental Europe and are invariably based on incomplete models of building systems - e.g., single-zone models of buildings that ignore internal resistances to airflow altogether.

Most importantly, it appears that not one of these models properly accounts for the airflow characteristics of the self-regulating vents that have become so central to the success of natural ventilation systems and very few account for the coupled thermal/airflow interactions that govern natural ventilation system behavior. Indeed, Heiselberg's observation regarding hybrid ventilation, below, applies equally well to the design of natural ventilation systems:

"Suitable methods as we know them from mechanical systems are
not available for hybrid ventilation systems yet. Valid methods
would give architects and engineers the necessary confidence in
system performance which in many cases is the decisive factor for
choice of system design. As the hybrid ventilation process and the
thermal behaviour of the building are linked the development of
design methods for hybrid ventilation must take both aspects into
consideration at the same time and include efficient iteration
schemes. This is the case for all types of methods from simple
decision tools, analytical methods, zonal and multizone methods to
detailed CFD analysis methods. A model that combines a thermal
simulation model with a multizone air flow model will allow the
thermal dynamics of the building to be taken into account and will
improve the prediction of the performance of hybrid ventilation
considerably. Such a model will be capable of predicting the yearly
energy consumption for hybrid ventilation and will therefore be the
most important design tool for hybrid ventilation systems." [16]

Consequently, this section of the report will quickly review the range of modeling tools that have been developed over the past decade or so, pointing to key references, and move on to describe the most recent tools in somewhat greater detail.

To set the stage for this discussion, however, it will be useful to establish the broad framework into which these tools fit - tools for the design and analysis of natural ventilation systems. In the present discussion, analysis refers to the process of predicting building response given building system characteristics and driving forces (i.e., wind, buoyancy, and mechanical driving forces) while design refers to the inverse problem of determining building system characteristics (e.g., the size of a ventilation opening) given desired building response - the design requirements and expected driving forces. Mathematical models, based on physical idealizations of building systems, often represented by diagrammatic models, are necessarily common to both analysis and design tools. Two broad classes of models may be distinguished: 
- macroscopic models (e.g., multi-zone building models) based on physical idealizations of building systems as collections of control volumes whose behavior may be described by algebraic or ordinary differential equations, and

- microscopic models (e.g., computational fluid dynamics or CFD models) based on numerically approximate solutions of systems of partial differential equations (e.g., the Navier-Stokes equations for fluid flow) wherein the physical domain of the "system" is subdivided into a relatively fine mesh.

As analysis tools may be used to design in an iterative, trial and error manner to search for acceptable building characteristics, the distinction between a design and analysis tool is not often made. In this discussion, however, a sharp distinction will be maintained.

Microscopic airflow analysis is presently limited to the analysis of single enclosed spaces of usually relatively simple geometry. Consequently, its application has been more or less limited to studies of single-sided and cross ventilation of single rooms or floors of larger building systems. Macroscopic analysis is well suited to studies of whole, multi-zone building systems of complex configuration - even though it has been more often applied to more limited single-zone idealizations of these buildings - consequently, most of the modeling tools put forward have been based on macroscopic theory.

\subsubsection{Predesign Tools}

The climate suitability method introduced in Chapter 2 of this report represents one example of a predesign tool - a tool that can be used to identify approaches to natural ventilation that may be suitable for a given site and, ideally, offer some rough initial quantitative guidance.

As a part of the NatVent ${ }^{\mathrm{TM}}$ project, Van Paassen and his colleagues at the Delft University of Technology, developed a predesign tool for night ventilation based on detailed simulations of a three-zone office building model - two exterior offices separated by an interior corridor allowing either single-sided, cross, or stack ventilation. This tool allows the designer to select ventilation system type and rough dimensions for ventilation openings given anticipated internal loads, solar gains, and thermal mass characteristics "without any knowledge of building physics" [148]. Application of the tool to a specific building design and the resulting performance of the building is presented in a companion publication [155]. Unfortunately, the tool produced is based on simulations for the Dutch climate and thus must be limited to similar climates in use. It is also tied to the three, relatively simple, natural ventilation systems investigated and may be limited to their use as well. Nevertheless, the innovative organization and layout of the design tool - which is presented on a single sheet - could be used as a template for similar tools for other climates and system types.

The NatVent ${ }^{\mathrm{TM}}$ project also produced another predesign tool, the NiteCool ${ }^{\mathrm{TM}}$ program intended to predict the cooling potential and performance of both mechanical and natural ventilation systems:

"The NiteCool Night Cooling Pre-Design Tool was developed as part of the DoE EnREI research programme focusing on simplified calculation methods for assessing night cooling strategies. The program can be used to produce design curves which show the effects of variations in building design on the peak room temperatures. It is intended to be used at early stages in the design 
process to help the designer of the building to make informed decisions on the construction, configuration and operation of the building.

The Pre-Design Tool was designed especially for the assessment of a range of night cooling strategies. The program is configured to analyse a $10 \mathrm{~m} \times 6 \mathrm{~m} \times 3 \mathrm{~m}$ cell of a typical office building." [11]

The NiteCool ${ }^{\mathrm{TM}}$ program is based on a simplified coupled thermal/airflow model that is not well documented but appears to be a single zone model, with inlet, exhaust and internal resistances accounted for in cross- and stack-ventilation modes, based on BRE's "3TC" room algorithm that models room behavior using three time constants. Specifically NiteCool ${ }^{\mathrm{TM}}$ models a single office that is operated during representative seven-day periods of selected months in South East England using a night ventilation control strategy similar to those presented above in Table 3.3 but allowing the user to specify specific control setpoints. Importantly, it models both natural and mechanical ventilation alternatives, accounting for fan power consumption, so that useful comparisons may be made. Although it use is limited (presently) to climates similar to that of South East England and its validity uncertain, it provides a useful example upon which predesign tools might be based.

(An apparently related and similar tool based on the APACHE program has also been developed that may appear in a future commercial version. This program has been used to generate design graphs similar to those produced by NiteCool ${ }^{\mathrm{TM}}$ that have been published for predesign purposes as well $[144,149,179]$.)

\subsubsection{Conceptual Design Guidelines \& The Role of Trend-Setting Buildings}

Design guidelines provide general guidance (i.e., short of analysis) relating to the selection of system type, system configuration, component selection, system control, operational strategies, and resolution of related problems such as those due to acoustic isolation, outdoor air quality, solar control, internal gains, lighting, fire safety, and security. They also invariably include a number of case studies of actual, trend-setting built projects. The CIBSE Applications Manual AM10: 1997 - Natural Ventilation in Non-domestic Buildings [40] is far and away the most comprehensive of these guides. An earlier but complementary guide is the BSRIA Technical Note TN 11/95 - Control of Natural Ventilation that offer far more guidance than that needed solely for the control of natural ventilation and includes a number of reasonably detailed case studies [78]. The BSIRA Guidance Note GN 7/2000 - Making Natural Ventilation Work adds another complement to these two earlier guides as it addresses common problems one is likely to encounter in natural ventilation systems and provides detailed solutions [39] - it also includes a number of case studies. The earlier BRE Digest, provides a useful summary of key issues that should be considered, provides specific design recommendations, and includes case studies of a number of buildings [70].

Beyond these three comprehensive and complementary guidelines a number of more limited guides have been published as individual flyers, within introductory textbooks, and as collections of building case studies, for example see $[8,63,70,76,180,181]$.

Ironically, the case studies included with these guides invariably present more complex natural and hybrid ventilation systems than are addressed directly within the body of the guides. This is due, in part, to the fact that natural ventilation systems are by necessity integrated with other 
systems to reduce solar and internal gains, enhance daylighting and its distribution, address acoustical and air quality problems, etc. and, in part, because developments in natural and hybrid ventilation are being driven by professional innovation rather than research at this moment in time. Consequently, design professionals turn to symposia of trend-setting buildings, wherein practitioners present the most recent innovative building ventilation solutions, to seek physical design strategies and design methods to advance the state-of-the-art. The importance of trendsetting buildings must not be undervalued and ignored even though documents of these building seldom end up in archival journals.

\subsubsection{Design Development Tools}

Design development tools are used to size ventilation system components (e.g., the size of a ventilation opening) given the general configuration of the building ventilation system, desired building response - the design requirements, and expected driving forces - the design conditions. A number of manual and simple computational tools achieve this objective but only partially. Most are based on simplistic single-zone models of building systems that, most often, ignore the relatively complex problem of coupled thermal/airflow behavior, some are limited to specific climates, and few account for internal resistances to ventilation airflows. One approach to sizing components, the inverse solution method promoted in the CIBSE Application Manual Natural Ventilation in Non-Domestic Buildings [40, 182, 183], however, has been generalized to size internal as well as envelope components of multi-zone ventilation systems of arbitrary complexity. This loop design method, based on pressure loop equations, will be presented in greater detail.

A number of handbooks and textbooks present equations based on fundamental principles for simple building configurations intended for manual calculation of wind-driven cross-ventilation and buoyancy-driven stack ventilation under steady conditions (e.g., see $[7,8,46,67,76,184]$ ). Aynsley provides some general guidance regarding the application of these methods [184] and the ASHRAE Handbook of Fundamentals provides an ad hoc procedure for combining wind and buoyancy driven results [46].

In the passive solar technology literature, a number of design methods were developed based on correlation relations, or simply graphs, generated using more complete and detailed models. Simplified design charts and, in some cases, design correlations have been developed for the design of natural ventilation systems as well. For example, van Paassen presents simple correlation equations intended for manual calculation that allow the designer to estimate ventilation openings for single-sided, cross-, and fan-assisted cross-ventilation of offices given internal gains, solar gains, and thermal mass characteristics of a common office building configuration consisting of two exterior offices separated by an interior corridor [148].

British researchers have long favored presenting these types of correlation relations graphically. One standard British publication, the BRE Environmental Design Manual [185], "presents a method for assessing the effect of window size and type, the kind of construction and the rate of ventilation on summertime comfort conditions and daylighting in offices in the British Isles" using some 48 design graphs. Not only is this method limited to the British Isles it applies only to single "rooms with one external wall, primarily offices." Etheridge continues this tradition through the introduction of non-dimensional graphs for commercial scale multistory buildings with limiting flow resistances at inlet locations in the building envelope (i.e., with negligible internal resistances). 
To ease the burden of manual calculation both fundamental and correlation-based design relations may be implemented as design development tools in standard spreadsheet programs. Arisoy provides an example of the former to evaluate monthly potential airflow rates provided by a wind-driven cross-ventilation system in an Istanbul high rise and the resulting annual savings in fan power provided [186]. Potangaroa presents an example of the later - a spreadsheet design development tool for natural ventilation of high rise buildings in the tropics using on wind tunnel and CFD-based correlation relations [187].

The simple relations presented in handbooks, textbooks, and the like, being fundamental and thus general, may be directly applied for "back of the envelope" calculations in North American and other locations. The utility of correlation design relations and design graphs is marginal at best and may well be misleading. Not only are they limited to specific climates and simplistic building models they may well be in error as they are not fully validated. Etheridge's nondimensional design graphs may be an exception, but they too are limited to a relatively simplistic model of noncommercial buildings. Furthermore, these manual techniques may simply be more difficult to use than more complete and general computational tools.

The NiteCool ${ }^{\mathrm{TM}}$ program offers such a computational convenience when used in the "design" operational mode [11]. This mode computes ventilation openings for specified flow rates and design conditions and requirements for single-sided-, cross-, and stack-ventilation systems using the inverse solution method described in the CIBSE Application Manual - Natural Ventilation in Non-Domestic Buildings $[40,182,183]$. For the latter two cases, the user is also able to specify an internal resistance opening area as well. Again, NiteCool ${ }^{\mathrm{TM}}$ program is presently limited to climates similar to that of South East England and to relatively simple system configurations but presumably the former could be changed with little effort to handle a range of North American and other climates.

\section{The Loop Design Method}

In developing tools to size ventilation components, two types of design problems may be distinguished. A so-called first-order design problem is one wherein design requirements are defined in terms of required ventilation rates while a second-order design problem is defined in terms of either thermal or air quality design requirements. Suffice it to say, first-order design problems are more readily defined and solved than second-order problems - indeed most often in practice ventilation design is approached as a first-order problem whether this is done directly or iteratively.

The author has presented a general approach to the first-order design problem that is based on the same theory currently used in general-purpose multi-zone airflow analysis programs like CONTAM and COMIS $[163,164,188,189]$. This method is based on the pressure loop equations presented above for ventilation loops that follow a ventilation flow path from inlet to exhaust and back to the inlet again. The loop design method allows for direct sizing of airflow components; accounts rigorously for both buoyancy and wind-induced airflow and their combination; and can be applied to multi-zone building idealizations of arbitrary configuration (e.g., accounting for all details of internal resistance). Furthermore, this approach may be applied using statistical representations of environmental conditions for specific locations to better account for local climatic conditions. The method may be applied manually or, since it shares the same theoretical base, it may be implemented within the interface of existing multizone program [72, 175, 190-192]. 
The loop design method is a systematic procedure that may be outlined as follows

i. Layout the global geometry and topology (i.e., flow component types and connectivity) of the ventilation flow loops to be considered. This is typically done in a building sectional drawing.

ii. Identify an ambient pressure node and additional pressure nodes at entries and exits of each flow component along each loop.

iii. Establish design conditions: envelope node wind pressure coefficients, design outdoor temperature, wind speed and direction, desired interior temperature conditions, and evaluate ambient and interior air densities (e.g., using Equation 3.14).

iv. Establish the design criteria, here, a design ventilation rate for each inlet and by applying continuity determine the objective design flow rates required for each flow component.

v. Form the pressure loop equations for each loop selected in i. above by systematically accounting for all pressure changes while traversing the loop. Pressure changes due to component resistances will be expressed in terms of the component design (size) parameters. (It is useful here to keep the stack and wind pressure contributions separate so that with-wind and without-wind cases can be more easily evaluated.)

vi. Determine the minimum feasible sizes for each of the flow components by evaluating the asymptotic limits of each component design (size) parameter for the loop equation. (Again it is useful to compute these limits for the with-wind and without-wind cases separately.)

vii. Develop and apply a sufficient number of technical or non-technical design rules or constraints to transform the under-determined design problem defined by each loop equation into a determined problem.

viii. Develop an appropriate operational strategy to accommodate the regulation of the ventilation system for variations in design conditions (e.g., for the with-wind and withoutwind cases).

Each pressure loop equation will be defined in terms of a number of unknown design (size) parameters equal to the number of components along that loop that are to be sized. That is to say, the loop equations as design equations are under-determined and, therefore, do not have a unique solution - many feasible solutions to the design problem may be formulated. Thus the designer must impose design rules, constraints, and operational strategies to transform each loop equation into a determined problem with a final solution - i.e., one of the many feasible solutions possible.

Defining design rules, design constraints, and operational strategies may seem to be the most elusive part of this methodology. It is important to emphasize that this is not a flaw in the methodology but intrinsic to the design of natural ventilation systems - systems that inevitably may be designed in a number of different ways. The methodology offers and supports the designer's need to introduce practical design considerations (e.g., off-the shelf component sizes, an architectural constraint that all windows be of certain sizes, etc.) that necessarily constrain design in the real world. In a more complex application, these design rules could define, for example, objective functions to be minimized in search of a design solution. 


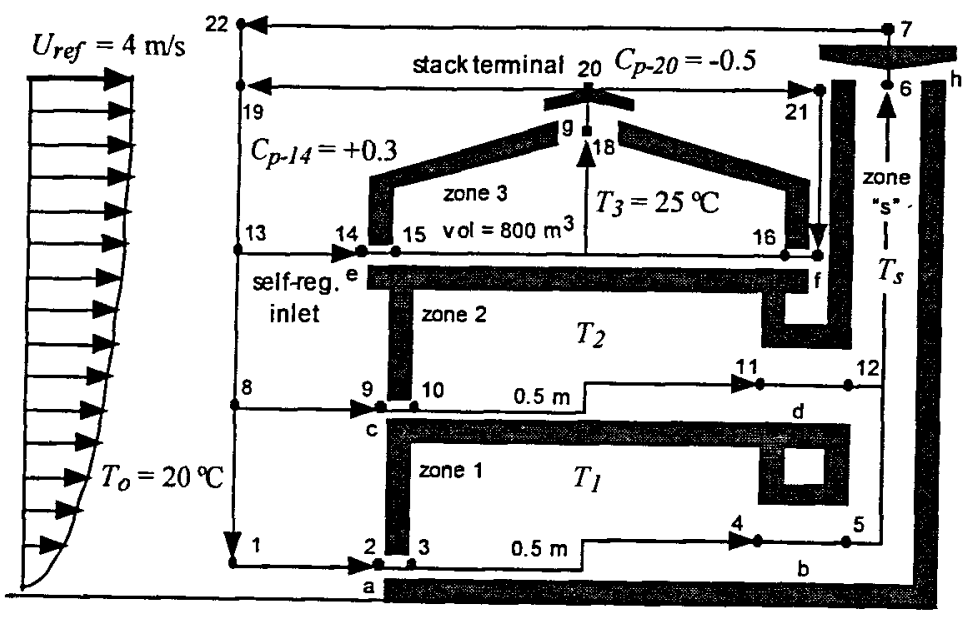

Figure 3.16 Global geometry, topology, and pressure nodes for the ventilation flow loops of a first design example based on the Inland Revenue Building, England (after [40]).

In the example building section shown in Figure 3.16, based on the Inland Revenue Building, England (after [40]), four loops are relevant. Here, we'll consider the design of the ventilation components along the upper left loop passing through the ambient pressure node 13 to the surface node 14 and on through nodes $15,18,20$, and 19 back to node 13 . This particular loop is independent of the lower two loops, but not the upper right loop, and involves only two components - a self-regulating inlet vent and a stack terminal device. The design of the slightly more challenging lower loop components is presented in [175]. To proceed we will simply follow the steps outlined above:

i. Layout the global geometry and topology: See Figure 3.16.

ii. Identify pressure nodes: See Figure 3.16.

iii. Establish design conditions: For the purposes of this example, the design conditions will be representative conditions for a summer day - an approach wind velocity of $U_{\text {ref }}=4 \mathrm{~m} / \mathrm{s}$ and an outdoor air temperature of $T_{o}=20^{\circ} \mathrm{C}$ and desired indoor air temperature of $T_{3}=25$ ${ }^{\circ} \mathrm{C}$. Applying Equation 3.14, the corresponding air densities are $\rho_{o}=1.20 \mathrm{~kg} / \mathrm{m}^{3}$ and $\rho_{3}=$ $1.18 \mathrm{~kg} / \mathrm{m}^{3}$. (To design for actual time-varying climatic conditions see [175].)

iv. Establish the design criteria: For the purposes of this example, the design objective will be to provide a room ventilation rate of $5 \mathrm{ACH}$ (e.g., based on a thermal analysis to maintain indoor air temperatures at the desired $T_{3}=25^{\circ} \mathrm{C}$ ). For the given room volume of $800 \mathrm{~m}^{3}$ we would then need a room ventilation rate of $5 \times 800 \mathrm{~m}^{3} / \mathrm{h}$ or $1.10 \mathrm{~m}^{3} / \mathrm{s}$. To maintain a uniform distribution of this supply air it would be reasonable to admit half this flow rate through the leftmost inlets and halt through the right. Consequently the volumetric flow rate through the self-regulating inlet $e$ would have to be $\dot{V}_{e}=0.55 \mathrm{~m}^{3} / \mathrm{s}$ while that through the stack exhaust $g$, by continuity, would have to be $\dot{V}_{g}=1.10 \mathrm{~m}^{3} / \mathrm{s}$

v. Form the pressure loop equations: 


$$
\left(\Delta p_{e}+\Delta p_{g}\right)=\Delta p_{s}+\Delta p_{w}
$$

where, for the present case:

$$
\begin{aligned}
& \Delta p_{s}=\left(\rho_{o}-\rho_{i}\right) g \Delta z=\left(1.2028-1.1826 \frac{\mathrm{kg}}{\mathrm{m}^{3}}\right)\left(9.8 \frac{\mathrm{m}}{\mathrm{s}^{2}}\right)(3.5 \mathrm{~m})=0.69 \mathrm{~Pa} \\
& \Delta p_{w}=\left(C_{p-14}-C_{p-20}\right) \frac{\rho U_{r e f}^{2}}{2}=(0.30+0.5) \frac{\left(1.2028 \frac{\mathrm{kg}}{\mathrm{m}^{3}}\right)\left(4 \frac{\mathrm{m}}{\mathrm{s}}\right)^{2}}{2}=7.70 \mathrm{~Pa}
\end{aligned}
$$

Here the inlet will be modeled with the low order power law relation (i.e., with $n=0.10$ ) and the stack terminal with the classic orifice relation:

$$
\begin{gathered}
\Delta p_{e}=\frac{\dot{V}_{e}^{1 / n_{t}}}{C_{e}^{1 / n_{1}}}=\frac{\left(0.55 \mathrm{~m}^{3} / \mathrm{s}\right)^{1 / 0.10}}{C_{e}^{1 / 0.10}}=\frac{0.002533}{C_{e}^{10}} \\
\Delta p_{g}=\frac{\rho \dot{V}_{g}^{2}}{2 C_{d}{ }^{2} A_{g}{ }^{2}}=\frac{\left(1.1826 \mathrm{~kg} / \mathrm{m}^{3}\right)\left(1.10 \mathrm{~m}^{3} / \mathrm{s}\right)^{2}}{2(0.6)^{2} A_{g}{ }^{2}}=\frac{1.9874}{A_{g}{ }^{2}}
\end{gathered}
$$

Substituting these results into Equation 3.29a yields the loop equation that defines feasible combinations of the component design (size) parameters:

$$
\left(\frac{0.02533}{C_{e}^{10}}+\frac{1.9874}{A_{g}^{2}}\right)=\underset{\text { without -wind }}{0.69} \underset{\text { with-wind }}{(0.69+7.70) \mathrm{Pa}}
$$

vi. Determine the minimum feasible sizes (i.e., asymptotic limits): Here, we simply consider the limit of Equation 3.30 as we allow all but one denominator of the left hand side approach large values and solve for the remaining denominator (i.e., design parameter):

$$
\lim _{A_{\varepsilon}^{2} \rightarrow \infty}\left(\frac{0.02533}{C_{e}^{10}}+\frac{1.9874}{A_{g}^{2}}\right)=\frac{0.02533}{C_{e}^{10}} \leq \underset{\text { without-wind }}{0.69} \text { or } \underset{\text { with-wind }}{(0.69+7.70) \mathrm{Pa}}
$$

or,

$$
C_{e} \geq \underset{\text { without-wind }}{0.72} \text { or } \underset{\text { with-wind }}{0.56}
$$

and,

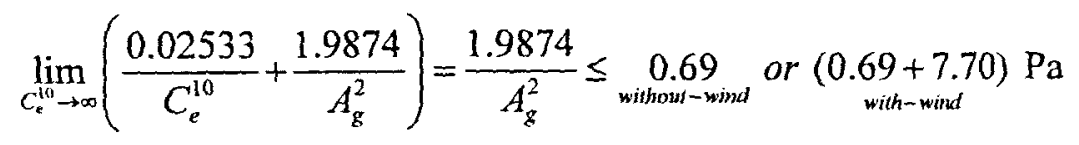

or,

$$
A_{g} \geq \underset{\text { without-wind }}{1.70} \text { or } \underset{\text { with-wind }}{0.49} \mathrm{~m}^{2}
$$

Thus the designer may conclude that the exhaust opening must be greater than $1.70 \mathrm{~m}^{2}$ for the without-wind case and $0.49 \mathrm{~m}^{2}$ for the with-wind case. 
vii. Develop and apply design constraints: For example, let's assume an operable exhaust terminal is available with a maximum opening of $0.50 \mathrm{~m}^{2}$. Four of these terminals could be used providing a maximum total opening of $A_{g}=2.00 \mathrm{~m}^{2}$ for the without-wind case (i.e., providing a total opening greater than the minimum required of $1.70 \mathrm{~m}^{2}$ ). Substituting this design constraint into the governing loop equation determines the inlet vent size for the without-wind case:

$$
\left(\frac{0.02533}{C_{e}^{10}}+\frac{1.9874}{A_{g}^{2}}\right)=\left(\frac{0.02533}{C_{e}^{10}}+\frac{1.9874}{2.0^{2}}\right)=\underset{\text { without-wind }}{0.69} \mathrm{~Pa}
$$

or,

$$
C_{e}=0.82 \mathrm{~m}^{3} / s-P a^{0.10}
$$

While the self-regulating vent size parameter may not be particularly intuitive it can be directly determined from vent manufactures' literature and, thereby, an appropriate vent (or set of vents) may be selected.

viii. Develop operational strategy: In this case it is reasonable to reduce the exhaust opening for the with-wind case while maintaining the same self-regulating inlet vent conditions. This operational strategy is actually used in the Inland Revenue Building where exhaust openings are adjusted daily for prevailing wind conditions. To determine the with-wind exhaust opening, we again simply substitute into the governing loop design equation, now using $C_{e}=0.82 \mathrm{~m}^{3} / s-P a^{0.10}$ :

$$
\left(\frac{0.02533}{C_{e}^{10}}+\frac{1.9874}{A_{g}^{2}}\right)=\left(\frac{0.02533}{0.82^{10}}+\frac{1.9874}{A_{g}^{2}}\right)=\underset{\text { wih-wind }}{(0.69+7.70) \mathrm{Pa}}
$$

or,

$$
A_{g}=\underset{\text { with-wind }}{0.49} \mathrm{~m}^{2}
$$

Thus, one feasible final design "solution" would be realized if the total stack opening were designed to be adjustable from $0.49 \mathrm{~m}^{2}$ to $2.0 \mathrm{~m}^{2}$ for a self-regulating inlet vent with a characteristic size of $C_{e}=0.82 \mathrm{~m}^{3} / \mathrm{s}-P a^{0.10}$. At this point, the designer may then turn to the task of sizing components for the rightmost loop at the third level (i.e., remembering to use the stack opening size just determined as the stack is shared by both third level loops) and the lower two loops (see [175] for details).

It is important to stress the design "solution" determined above is just one of many feasible possibilities. In general, natural and hybrid ventilation system design is a physically underdetermined problem with many feasible solutions possible. Within the loop method, the designer is able to, actually must, introduce additional nonphysical constraints to completely specify a feasible solution to the problem. From another perspective, the loop design method does not unnecessarily constrain the designer - the designer maintains full freedom of choice possible within the physics of the problem. The sizing algorithms used in the NiteCool ${ }^{\mathrm{TM}}$ program [11], which are based in essence on a limited case of the loop method introduced by Irving $[40,182$, 183], unnecessarily impose additional constraints arbitrarily to provide a single solution. 
Examples of the application of this method to both residential and non-residential buildings are presented in [72, 175, 190-192]. The method can, with difficulty, be applied by hand or, more readily, be carried out using spreadsheet or symbolic mathematical analysis software. Even better, the method could be implemented within available general-purpose multizone programs as it shares the same theoretical base and diagrammatic (i.e., interface) conventions.

The "loop method", in its current formulation, is based on multizone airflow analysis theory that assumes, in effect, steady conditions of airflow prevail. It, therefore, does not account for unsteady airflow phenomena nor does it account directly for unsteady coupled airflow and thermal interactions. The former shortcoming is commonly believed to be minor, although due to this shortcoming the application of the loop method to single-sided ventilation and backdrafting phenomena would be misguided. The latter shortcoming is likely to be more important as the loop method's application to the important night cooling natural ventilation strategy is very limited. Extending the method to account for coupled thermal/airflow interactions is, however, not out of the question and should be considered.

\subsubsection{Macroscopic Tools for System Performance Evaluation}

Now as in the past, natural ventilation systems can provide ventilation to control air quality and thermal comfort but presently design requirements demand more reliable and precise control than in the past while at the same time avoiding unnecessary energy consumption and the green house gas emissions associated with it. Thus building performance evaluation is now commonly part of commercial building design and has become central to innovative low-energy design efforts. This involves the macroscopic simulation of the performance of the proposed building system to evaluate both the temporal and spatial variation of air quality and thermal comfort provided and the energy consumption required (e.g., to condition ventilation air) and is, therefore, most reasonably achieved using one of a number of simulation tools that are currently available.

Much of the air quality and ventilation research of the past two decades has been directed toward the development of these simulation tools. Consequently, not only has a vast body of theory and methods been amassed but a large number of computer programs have been developed based on this work. Beyond the number of programs available, several programs have evolved through multiple generations over the years gaining in capabilities and complexity (e.g., the CONTAM and COMIS program families [163-165, 188, 189, 193-195]). Consequently, a detailed review of these simulation methods is beyond the scope of this report - instead a broad overview of these tools will be presented and then attention will be placed on those few programs that simulate the coupled thermal/airflow interactions that govern the behavior of natural ventilation systems. For more complete reviews of these simulation tools and the theory underlying them see references $[8,72,170,196]$.

The simpler simulation tools are invariably based on single zone models of building systems that ignore internal resistances to airflow and seldom account completely for the coupled thermal/airflow interactions that are characteristic of natural ventilation airflow systems. In principal, the former shortcoming can be accepted because, properly, internal resistances to airflow should be minimized by design, but without supporting analysis, the designer may not know whether this objective has been realized. In some wind-driven natural ventilation systems, the coupled thermal airflow interactions may not be critical, but in most systems, especially when used for cooling, these interactions are all important and must be considered. 
More complete and detailed performance evaluation is possible using one of the many multizone simulation tools. Broadly speaking, these tools are based on either fixed-configuration or general-configuration models of building systems. The former often model the buildings using two or three well-mixed zones and, possibly, a mechanical ventilation system serving these zones, and allow the user to specify envelope and internal flow resistances, wind conditions and pressure coefficients, and thermal characteristics. A common three-zone approach used for simulation studies of natural ventilation systems in offices models a typical floor of an office building using two exterior office zones and an internal corridor zone, Figure 3.17. This particular model is used in the NaVIAQ performance evaluation program and by van Paassen and his colleagues for the night cooling control investigations completed within the NatVent ${ }^{\mathrm{rM}}$ project [11]. This model and a similar two-zone typical floor model was also employed by Barnard and Kolokotroni in the studies discussed above [144, 149, 179] and the NiteCool ${ }^{\mathrm{TM}}$ program developed within the NatVent ${ }^{\mathrm{TM}}$ project [11].

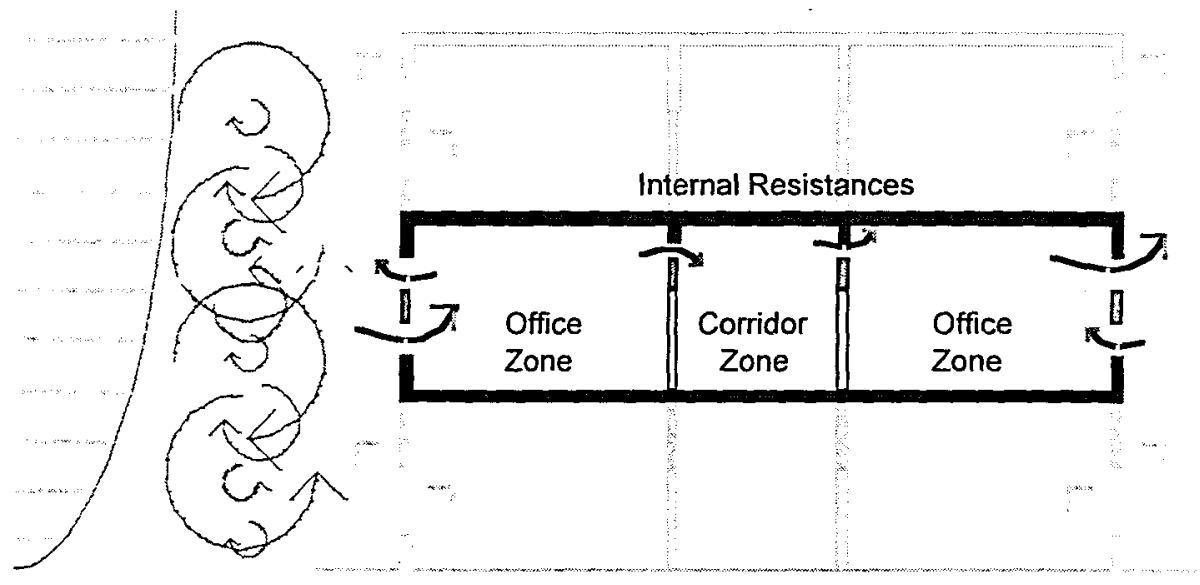

Common 3-Zone Model of an Office Floor

Figure 3.17 A common three-zone model of a typical floor for a centrally loaded office building used for design simulation studies.

The most flexible general-configuration multizone models are based on component- or elementassembly techniques $[197,198]$ that allow the user to construct multizone models of building systems of arbitrary complexity. Within these programs, users define the number of zones and their layout, the types of flow components that link these zones (e.g., doors, windows, selfregulating vents, cracks, stacks, etc.), design conditions (wind speed, wind direction, outdoor temperatures, contaminant emission rates, etc.) and their variation with time, as well as - in the more complete programs - mechanical systems (e.g., duct networks, fans, diffusers, etc.) used to serve the building zones. In addition, thermal characteristics may also be defined in a general and open manner for the very few programs that tackle the coupled thermal/airflow problem. The most complete airflow and air quality analysis programs in this class of programs can provide annual simulations of the building system response to hourly weather records specific to a given climate (e.g., the programs BREEZE, COMIS, CONTAM96 and CONTAMW provide this capability $[163,165,188,189,199])$.

These general-configuration multizone - or, more precisely, macroscopic component-assembly programs provide the modeling flexibility required to simulate the performance of practically all 
existing natural and hybrid ventilation systems and, presumably, new system proposal that may be expected to be put forward in the future. In the hands of an informed analyst, but not necessarily a modeling specialist, they may be used to model systems simply (e.g., as single zone idealizations) or in exacting detail accounting not only for all ventilation system components but also building infiltration characteristics and unrelated mechanical systems. Consequently, macroscopic component-assembly programs are the simulation tool of choice for system-level (e.g., whole-building) simulation studies. However, the programs noted do not model the coupled thermal/airflow interactions that should be considered in natural and hybrid ventilation system analysis.

The macroscopic theory for addressing the coupled thermal/airflow problem has been in place [200-202] and a program, ESPmfs, based in part on this theory have been available for over a decade [203-208]. Yet funding agencies have been reluctant to sponsor continued development of these coupled thermal/airflow analysis tools, presumably, because the need for them was not entirely apparent. The emergence of natural and hybrid ventilation systems as energyconserving alternatives to mechanical systems has made this need eminently clear consequently a number of simulation tools are beginning to appear to answer this need.

The NiteCool ${ }^{\mathrm{TM}}$ program discussed above and a program developed by Mathews are based on single-zone thermal models of buildings complemented by simple, but fundamentally-based, airflow components $[11,209]$. The NatVent ${ }^{\mathrm{TM}}$ computer program, developed within the NatVent ${ }^{\mathrm{TM}}$ project, is also based on a single-zone idealization of a building but appears to offer greater capabilities, can be applied to multistory buildings, and has a well-documented theoretical base $[151,152]$.

The AIOLOS program falls between a multizone and single zone model in that it provides multizone modeling of building airflows integrated with a single-zone thermal model [8, 210]. Moving on to multizone programs, one study, developed within the European project TIP-VENT (JOULE) investigated the impact of ventilation air flow rates upon the energy needs of typical buildings using two newer coupled thermal/airflow analysis codes, ESPr and Enervent4 [211]. Another multizone coupled thermal/airflow analysis program, CHEMIX, is being developed by $\mathrm{Li}$ [212]. In addition, projects are underway to link the component-assembly multizone airflow and air quality program COMIS with the U.S. DOE's new energy analysis program ENERGY+ via data passing strategies [213], although the limited experience gained in coupled thermal/airflow analysis would suggest data passing will not be sufficiently fast to produce an effective tool. The multi-zone analysis tools, COMIS and CONTAM, have also been integrated with another thermal analysis tool, TRNSYS. TRNSYS is a modular environment that enables independently developed modules to be integrated into an already very powerful analysis system. COMIS and CONTAM modules have been created and implemented within the TRNSYS environment to incorporate the energy requirements due to air infiltration [241].

Chapter 4 of this report will present modeling studies of a five story fan-assisted stack-ventilated building using an unreleased version of the NIST program CONTAM that is internally identified as CONTAM97R [214]. This general-purpose, component-assembly macroscopic simulation tool models coupled thermal/airflow interaction and air contaminant dispersal in idealizations of multizone building systems of arbitrary complexity. In many respects CONTAM97R is at the edge of the state-of-the-art. However, in its current internal research form it is difficult to use due to the limitations of its interface, the need for the user to edit output files and run the component programs CONTAM97 and CONTAMX sequentially, and convergence problems 
that are far more likely to occur than in uncoupled airflow simulation. Nevertheless, results obtained in its application presented in Chapter 4 clearly reveal the critical value of coupled thermal/airflow simulation for natural ventilation system design.

CONTAM97R also optionally models nontrace contaminant dispersal enabling the program to account for buoyancy effects due to moisture changes, for example, in natural ventilation systems utilizing evaporative cooling to both drive airflow and cool outdoor supply air. With regard to buoyancy forces due to moisture changes Woloszyn notes:

\begin{abstract}
"Indeed, the airflow values are very sensitive to air density modifications induced by even small changes in the temperature or the moisture content values. ... In practice, some of the links between different phenomena are often removed in order to enable numerical computations. In such situations, we can no longer talk about truly coupled modeling." [215]
\end{abstract}

The programs discussed above have all been developed as application-specific, special purpose tools (i.e., for building applications). Alternatively, coupled thermal/airflow simulation tools may, in principle, be developed within so-called general-purpose simulation environments. Special purpose simulation tools can be developed to take advantage of the specific characteristics of the systems being modeled consequently they can, in principle, provide more rapid simulations. General-purpose simulation environments, on the other hand, provide the means to develop simulation tools rapidly and can offer more sophisticated solution algorithms that often compensate for the lack of consideration of a problem's special characteristics. Examples of this approach warrant mention.

A general purpose dynamic systems simulation environment SIMULINK $®$ that operates within

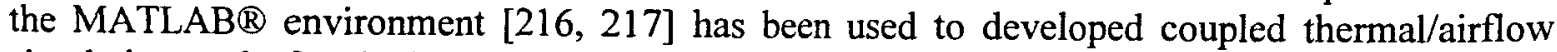
simulation tools for double skin facades [122] and for the AIRLIT-PV façade unit discussed above [132]. The IDA simulation environment has been applied to develop a general-purpose component assembly simulation tool for the uncoupled airflow and associated contaminant dispersal simulation problem [218] and is presently being used to develop a similar simulation tool for the coupled thermal/airflow problem $[116,219]$.

\title{
3.2.5 Microscopic Tools for Room Performance Evaluation
}

Macroscopic methods do not presently provide simulation detail at the room level, although socalled zonal models currently under development may be able to add this capability in the near future [190, 220-224]. Two options are available to investigate this detail: computational fluid dynamics - CFD programs and physical scale modeling tools. A discussion of CFD methods and their application is beyond the scope of this report, but physical modeling tools will be briefly discussed.

Swainson provides a rigorous overview of the issues that must be considered when using physical modeling of room airflows and some of the methods that may be used to achieve this modeling using wind tunnels and gas and liquid models [225]. The former more commonly applied to exterior flow conditions associated with natural ventilation and the latter two applied to interior flow studies. 
Boundary layer wind tunnels have been used to test the performance of small and large stack terminal devices $[65,128,158,226,227]$. Alexander, Jones and colleagues have reported on a number of wind tunnel studies "... to investigate the effect of wind on natural ventilation performance in commercial buildings ..." that have led to improved designs for natural ventilation inlets and exhausts [159-161, 228]. Addressing the special ventilation problems posed by urban sites, a number of wind tunnel investigations have investigated traditional and current courtyard and wind tower ventilation schemes [229-231]. While less common, perhaps, wind tunnels have also been used to study details of room airflow in single-sided- and crossventilation schemes.

Salt bath modeling techniques wherein dyed salt solutions are injected into building models submerged in salt solutions of a different density to simulate buoyancy induced flows have proven particularly useful in the study of the details of time-dependent gravity flows in natural ventilation systems [54, 109, 111, 232, 233]. Riffat provides some theoretical background for the use of salt baths and comparisons of measured and experimental data that validate the use of salt baths [234]. Finally, another water bath technique utilizing fine bubbles has recently been developed by Li and his colleagues [103, 235].

\subsection{Appendix - Notable Projects}

In Europe innovation in the design of natural and hybrid ventilation systems is driven largely through the example of innovative built projects. Indeed, the lively competition to achieve extreme low-energy building designs economically among building designers appears, presently, to be a more important impetus for innovation than even the aggressive European research activities. Some information relating to these innovative building projects is found in case studies published in archival technical publications - a number of these case studies are listed below. Professional symposia and publication in architectural design journals, along with personal visits to these buildings, together play an equally important role in driving this competition.

Practically all the buildings listed not only combine mechanical assistance of one sort or another with natural ventilation systems but these systems are complemented by comprehensive daylighting, solar control systems, state-of-the-art artificial lighting systems, and low-energy equipment to minimize internal gains and energy-efficient mechanical systems and often energy storage systems to further reduce energy consumption and associated greenhouse gas emissions.

\section{New Construction}

- Atlantis Paper Company, East London; Paul Hyett architects; Max Fordham and Partners, environmental engineers [70]

- B\&O Headquarters, Struer, Denmark; KHR A/S, architects, Birch \& Krogboe A/S, environmental engineers [16]

- Barclaycard Building, Northhampton, U. K. [149]

- BBRI PROBE Building, Limelette, Belgium; Y. Wauthy, architects; Belgium Building Research Institute BBRI, environmental engineers [16]

- BRE Low Energy Office, Watford, UK 1981 [9]

- BRE Environmental Office of the Future, Watford, UK [64]

- Bodyshop HQ, Littlehampton, UK [70] 
- Cable \& Wireless College, Coventry, UK; McCormac Jamieson Prichard, architects; Ove Arup \& Partners, environmental ngineers [70, 78]

- Channing Crescent Health Centre, London; MacCormac Jamieson Prichard, architects; Atelier Ten, environmental engineers $[9,78]$

- C. K. Choi Building, University of British Columbia, Vancouver, Canada [236]

- Canterbury Law Courts, Canterbury, UK [78]

- Elizabeth Fry Building at the University of East Anglia, UK [43, 64]

- Faculty Offices of the (Jubilee) New Campus at the University of Nottingham; Michael Hopkins \& Partners, architects; Ove Arup, environmental engineers [65]

- Inland Revenue Building, Durrington, UK [9, 78, 149]

- Inland Revenue Building, Nottingham, UK; Michael Hopkins \& Partners, architects; Ove Arup, environmental engineers [78, 149]

- Ionica Headquarters, Cambridge, UK; RH Partnership, architects; Battle McCarthy, environmental engineers $[9,78,149]$

- John Cabot City Technology College, Bristol, UK; Fleiden Clegg, architects; Buro Happold, environmental engineers [70]

- Learning Resources Center, Anglia Polytechnic University, Chelmsford, UK; ECD (Energy Conscious Design) Architects; Ove Arup \& Partners, environmental ngineers $[70,78]$

- Liberty Tower, Meiji University, Tokyo, Japan; Nikken Sekkei Ltd., architects and engineers $[16,168]$

- Longman's Offices, Harlow, U.K.: Powergen HQ, Coventry, UK; Bennetts Associates, architecgts; Ernest Griffiths \& Sons, environmental engineers [9, 78, 149]

- Media School, Grong, Norway; Letnes Arkitekter, architects; SINTEF and NTNU, environmental engineers [16]

- New Parlimentary Building, Westminster, London, UK; Michael Hopkins \& Partners, architects; Ove Arup \& Partners, environmental engineers [117]

- Powergen HQ, Coventry, U.K. (Bennetts Associates w/ Ernest Griffiths \& Sons): mentioned by [149];

- Queens Building, De Monfort University, Leicester, UK; Short Ford Associates, architects; Max Fordham \& Partners, environmental engineers; [9, 76, 78, 149]

- Torrent Pharmaceutical Company, Ahmedabad, India; Abhikram with Short Ford Associates, architects [110]

\section{Renovation}

- Good Practice Case Study 308, UK; BRESCU and BRE, research groups [149]

- Regent House, Weston-super-Mare, UK [149] 


\section{MODELING STUDIES}

The project set out originally to evaluate the annual performance of a representative commercial building using both mechanical and natural ventilation systems through a series of computational modeling studies using an unreleased version of the CONTAM family of programs, CONTAM97R [214]. This multizone dynamic analysis program supports modeling of coupled thermal/airflow interactions and ventilation control logic, both central to the behavior of natural ventilation systems. As designed, CONTAM97R may be used, in principle, to evaluate key performance characteristics including:

- annual and peak energy demands,

- indoor air temperature extremes during natural ventilation system operation (e.g., the overheating degree hours defined by Equation 3.3 as well as the number of hours temperatures exceed $25.6^{\circ} \mathrm{C}$ and $29.4^{\circ} \mathrm{C}$ ),

- time histories and statistical analyses of whole building outdoor air change rates achieved during periods of natural ventilation,

- indoor air pollution levels due to occupant-generated $\mathrm{CO}_{2}$ evaluated in terms of time histories and statistical analyses of zone $\mathrm{CO}_{2}$ concentration levels (i.e., for realistic occupancy schedules and distributions),

- air distribution evaluated in terms of time histories and statistical analyses of zoneevaluated age of air, and

- indoor moisture levels due to occupant-generated water vapor evaluated in terms of time histories and statistical analyses of zone moisture levels (i.e., for realistic occupancy schedules and recorded outdoor humidities).

However, in its current state not all modeling capabilities are operational, output processing is not directly provided, and use of the program is complicated by the need to resolve programming bugs as they arise. Consequently, the scope of the modeling studies had to be abridged. In place of the original annual performance evaluation studies two related studies were undertaken:

- Calibration Study - a calibration study that served to validate the application of CONTAM97R to a specific building analysis through the comparison of measured and predicted response results and

- Night Cooling Design Development Study - a modeling study intended to provide an example of the use of detailed performance evaluation in the design development of a night cooling system for two specific climates where night cooling should be considered - Los Angeles and Fresno, CA. These studies also provide a first evaluation of the feasibility of night cooling by natural means in these two climates.

A state-of-the-art low-energy commercial building - the Tax Office of Enschede, Netherlands [10] - was used as the basis for the modeling studies. This five story, $4,300 \mathrm{~m}^{2}$ building, even though European, is similar in plan and organization to many mid-sized U.S. commercial buildings. It utilizes a natural ventilation system based on operable windows, self-regulating trickle ventilators, and a central slot atrium with passive stacks and mechanical-assist fans that could be readily built in the U.S. at this time. As constructed, the natural ventilation system may be operated in a direct or indirect (i.e., nighttime cooling) mode, thus, this particular building 
may be used directly, without modification, to investigate two of the three building configurations that are to be studied.

\subsection{Description of Building Models}

The plan of the Enschede Tax Office is organized around an elongated east-west slot atrium, Figure 4.1. Offices and meeting rooms are distributed along the southern and northern sides of the building along corridors that, on the north, separate the offices from the atrium and, on the south, separate the offices from a row of utility spaces that flank the atrium volume - a stairway, file rooms, toilets, and storage rooms.

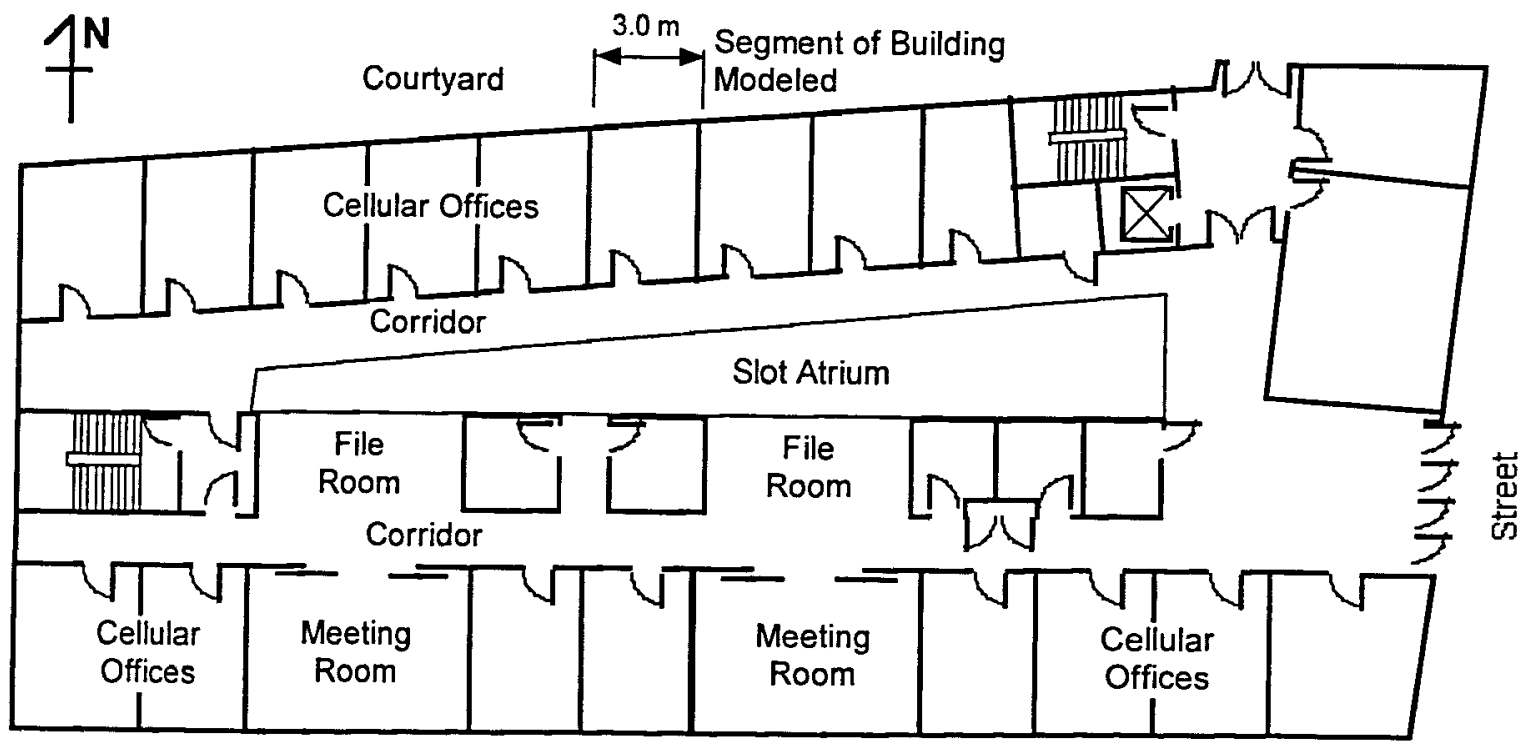

Street \& Railway

Figure 4.1 Plan of the Enschede Tax Office showing the section of the building modeled.

In section, five levels of offices are placed above ground level parking on the south side of the building and above utility rooms on the north, Figure 4.2 . The basic natural ventilation strategy is clearly revealed in this section. Driven by the combined effects of buoyancy forces and wind, air enters individual offices through self-regulating inlet vents, mixes within the offices and flows out of the offices, on the north side, through transfer grills and, on the south side, over the corridor and utility spaces through purpose-provided transfer ducts to the central atrium. This air then flows up through the atrium space to ventilation stacks and out. In the event that the natural driving forces are insufficient, assist fans are provided which exhaust air from the atrium space on the north side roof level. 


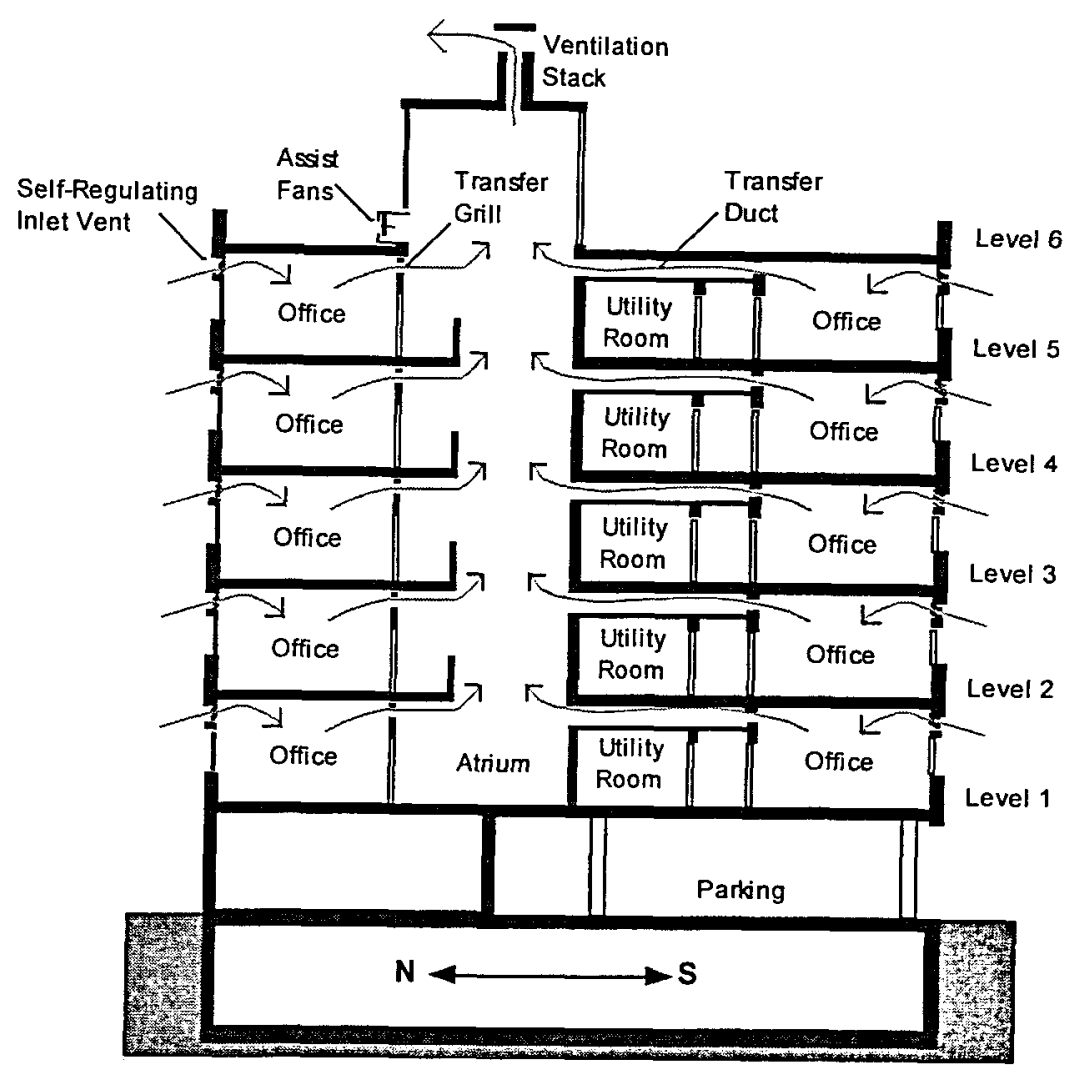

Figure 4.2 Representative section of the Enschede Tax Office illustrating natural ventilation airflow paths.

Slot atria schemes, like the Enschede Tax Office, are one of a number of common schemes used in office buildings in both Europe and North America. They offer obvious daylighting and ventilating advantages and through their open section create a workplace that encourages communication and participation of individual employees in the larger office society. From a technical point of view, slot atria schemes may reasonably be modeled by limiting consideration to a representative segment of the building as the influence of airflows through the narrow end walls may be expected to be slight, especially for more elongated plans. Here, a representative segment of the building equal to one office bay in width, Figure 4.1, and passing through the full height of the building was chosen for the basis of all modeling studies (i.e., with the section shown in Figure 4.2).

Two models of this representative building segment were constructed using the airflow and air quality simulation tool CONTAM:

- Simplified Single-Zone Model: a simplified single-zone model of the building in which only ventilation system components were modeled - i.e., self-regulating inlet vents, stack exhausts, and stack assist fans were modeled Figure 4.3. The simplified model used to study the natural ventilation system alternatives is similar to simplified envelope models commonly used for preliminary analysis of natural ventilation systems that ignore internal resistances to air flow. 


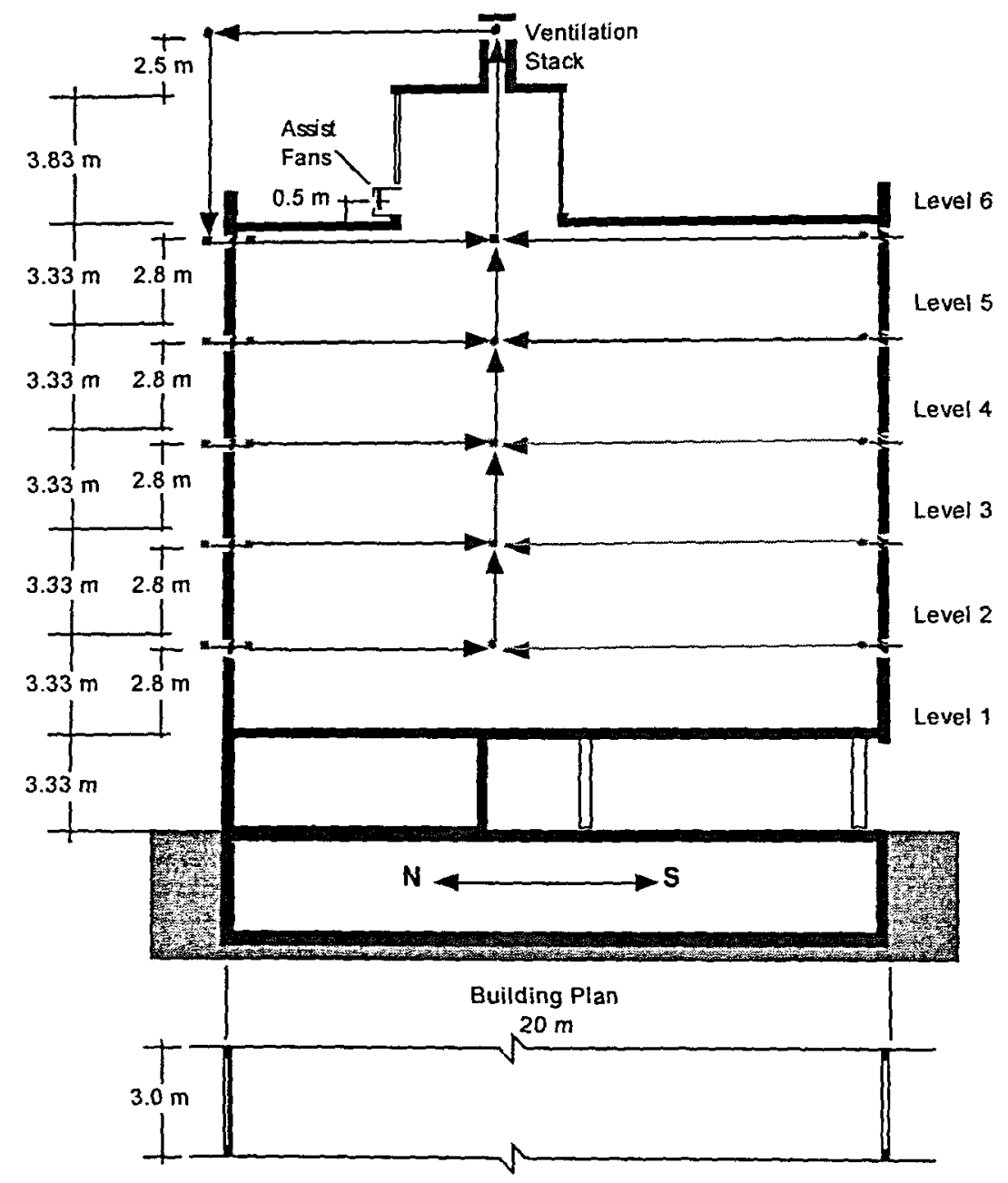

Figure 4.3 Plan and section of the simplified single-zone model of a representative segment of the Enschede Tax Office building corresponding to envelope models commonly used for preliminary analysis of natural ventilation systems. Solid dots and linking arrows indicate, diagrammatically, pressure nodes and airflow paths that will be used in subsequent loop analysis to size components for specific climatic conditions.

- Detailed Multi-Zone Model: a multizone model of the building in which all important flow paths through the envelope and within the interior of the section were modeled in detail Thus, in addition to the flow paths considered in the simplified single-zone model, transfer grills and duct components of the natural ventilation system and wall, window, and door leakage are included for each of twenty one zones corresponding to the ten offices, five corridors, five utility rooms, and the central atrium shown in Figure 4.4. 


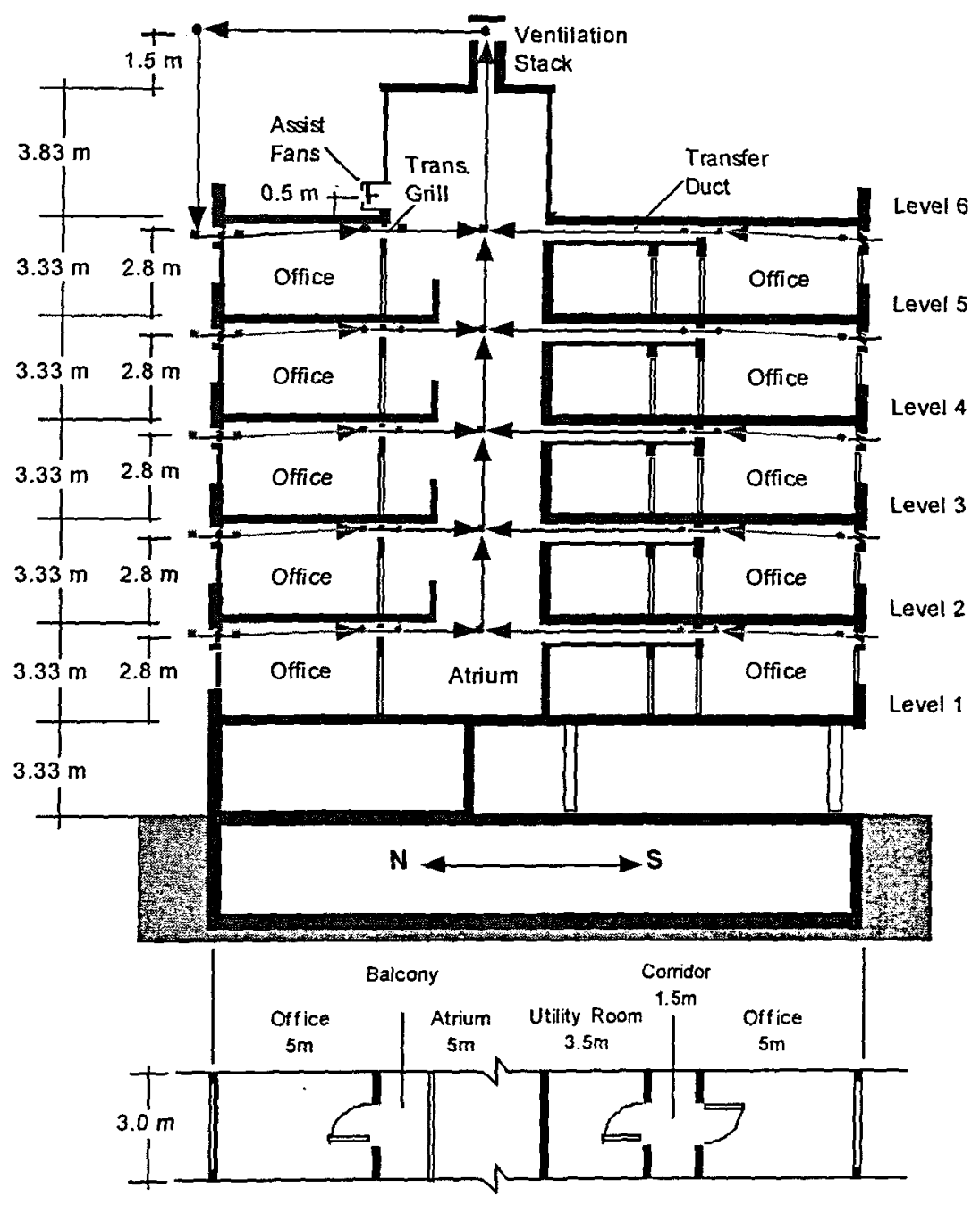

Figure 4.4 Plan and section of the detailed multizone model of a representative segment of the Enschede Tax Office building. Solid dots and linking arrows indicate, diagrammatically, pressure nodes and airflow paths that will be used in subsequent loop analysis to size components for specific climatic conditions.

The relevant geometry of both models is shown on the figures. Floor-to-floor heights were assumed to be $3.33 \mathrm{~m}$ with an effective floor-to-ceiling height of $3.0 \mathrm{~m}$ based on published information [11]. Self-regulating inlet vents in the Enschede Tax Office were located close to the ceiling to take advantage of the coanda effect during cold outdoor conditions - here their location was assumed centered $2.8 \mathrm{~m}$ above the floor level in all offices. Finally, the actual dimensions of the monitor at the top of the atrium, the ventilation stack height, and the location of the assist fans were estimated from photographs of the Enschede Tax Office [11]. 


\subsubsection{Wind Pressures}

Wind pressures $p_{w}$ acting on envelope openings of the building were modeled in the usual manner using the kinetic energy per volume of the reference approach wind velocity $1 / 2 \rho U_{r e f}^{2}$ modified by empirically determined wind pressure coefficients $C_{P}$ :

$$
p_{w}=C_{p} \frac{1}{2} \rho U_{r e f}^{2}
$$

where $\rho\left(\mathrm{kg} / \mathrm{m}^{3}\right)$ is the air density of the approach wind and $U_{\text {ref }}(\mathrm{m} / \mathrm{s})$ is the reference wind velocity taken at the height of the building. Utilizing the capabilities of the program CONTAM to account for terrain and elevation effects $[163,189]$, reference wind velocities were modeled for an assumed urban location using airport wind speed data for all model studies except the calibration studies. The calibration studies, discussed below, used actual wind speeds measured at the site of Enschede Tax Office for the reference wind velocity.

The variation of wind pressure coefficients $C_{p}$ with wind direction $\phi$ was modeled using the Walker/Wilson model [237]:

$$
\begin{aligned}
C_{p}(\varphi) & =\frac{1}{2}\left[\left(C_{p}\left(0^{\circ}\right)+C_{p}\left(180^{\circ}\right)\right)\left(\cos (\phi)^{2}\right)^{1 / 4}+\left(C_{p}\left(0^{\circ}\right)-C_{p}\left(180^{\circ}\right)\right) \cos (\phi)|\cos (\phi)|^{1 / 4}\right. \\
& \left.+\left(C_{p}\left(90^{\circ}\right)+C_{p}\left(270^{\circ}\right)\right) \sin (\phi)^{2}+\left(C_{p}\left(90^{\circ}\right)-C_{p}\left(270^{\circ}\right)\right) \sin (\phi)\right]
\end{aligned}
$$

The spatial variation of these wind pressures coefficients over the height of the building were based on published wind pressure coefficient data for a five-story building of simple rectangular geometry, Table 4.1 [89].

Table 4.1 Spatial variation of wind pressure coefficients used in all modeling studies, after Orme and Welsh $[89,128]$.

\begin{tabular}{|c|c|c|c|c|}
\cline { 2 - 5 } \multicolumn{1}{c|}{} & \multicolumn{4}{c|}{ Wind Pressure Coefficients $C_{P}$} \\
\cline { 2 - 5 } & $C_{p}\left(0^{\circ}\right)$ & $C_{p}\left(90^{\circ}\right)$ & $C_{p}\left(180^{\circ}\right)$ & $C_{p}\left(270^{\circ}\right)$ \\
\hline $\begin{array}{c}\text { Stack } \\
\text { Terminal }\end{array}$ & -0.60 & -0.60 & -0.60 & -0.60 \\
\hline Level 6 & 0.70 & -0.58 & -0.36 & -0.58 \\
\hline Level 5 & 0.70 & -0.58 & -0.36 & -0.58 \\
\hline Level 4 & 0.72 & -0.55 & -0.35 & -0.55 \\
\hline Level 3 & 0.58 & -0.48 & -0.34 & -0.48 \\
\hline Level 2 & 0.41 & -0.38 & -0.29 & -0.38 \\
\hline Level 1 & 0.44 & -0.17 & -0.28 & -0.17 \\
\hline
\end{tabular}


Due to the central importance of the ventilation stack in natural ventilation system design, it is important to select stacks that a) are relatively insensitive to wind direction and b) provide relatively large suction pressures (i.e., to maintain control authority over the natural ventilation airflow rates and direction). Stacks terminating above nearby roofs and having a more-or-less axisymmetric configuration tend to provide wind direction insensitivity. Wind pressure coefficients between -0.5 to -0.7 or even greater may be realized with properly configured and detailed stack terminal devices [126-129, 157, 158, 226, 238]. As indicated in Table 4.1, the stack wind pressure coefficient was assumed to be -0.60 for all modeling studies.

\subsubsection{Natural Ventilation System}

Natural ventilation systems involve both the physical assembly of ventilation system components and the logical control of these components to achieve one or more ventilation objectives. From a modeling point of view, five component types are used in the natural ventilation system of the Enschede Tax Office:

1. self-regulating inlet vents

2. the ventilation stack

3. the assist fan

4. transfer grills used to link the north offices to the atrium, and

5. transfer ducts used to link the south offices to the atrium.

Component types 1 and 2 were included in the simplified single-zone model while all five components were included in the detailed multizone model of the Enschede Tax Office.

In addition, control strategies were formulated for winter and summer conditions that were modeled as discussed below.

\section{Self-Regulating Inlet Vents \& Design}

Self-regulating inlet vents, a relatively new but essential technology for effective natural ventilation system control $[22,24,154,239,240]$, provide relatively constant airflow rates over the range of air pressure differences likely to be encountered across the inlet vent device. Consequently, they provide the means to achieve controlled design airflow rates for the stochastically varying natural driven conditions that must be expected in the field. However, they cannot sustain design airflow rates when wind and buoyancy forces drop to negligible values.

The self-regulating inlet vents used in the Enschede Tax Office were designed to provide a constant flow rate of $50 \mathrm{~m}^{3} / \mathrm{h}$ for driving pressure differences between $1 \mathrm{~Pa}$ and $25 \mathrm{~Pa}$ at their lowest setting and $100 \mathrm{~m}^{3} / \mathrm{h}$ at their highest setting. Two of these vents, each approximately 0.3 $\mathrm{m}$ wide and $0.1 \mathrm{~m}$ high, were installed at near-ceiling locations in each of the offices. Consequently, by setting both of these vents at the lowest ventilating position an airflow rate of $100 \mathrm{~m}^{3} / \mathrm{h}$ could be achieved - this rate was the design airflow rate specified for air quality control in the Enschede Tax Office. By setting both vents to the highest setting an airflow rate of $200 \mathrm{~m}^{3} / \mathrm{h}$ could be achieved (i.e., when driving forces were sufficient) - this rate was the design airflow rate specified for night cooling ventilation in the Tax Office. 
The following power-law component relation using an unusually-low exponent of $n=0.1$ was used to model one of the two vents placed in the offices set at its lowest setting:

$$
\dot{V}=38.84 \Delta p^{0.10}\left(\mathrm{~m}^{3} / \mathrm{h}\right)
$$

where $\dot{V}\left(\mathrm{~m}^{3} / \mathrm{h}\right)$ is the volumetric airflow rate through the component and $\Delta p(\mathrm{~Pa})$ is the pressure difference across the component. It is instructive to compare this pressure-flow relation to the more commonly applied power-law relation with flow exponent of $n=0.5$, here, adjusted to provide the same design airflow rate of $50 \mathrm{~m}^{3} / \mathrm{h}$ as Equation 4.3 for a pressure difference midrange of the pressure differences expected to be encountered in the field, i.e., for $\Delta p=12.5 \mathrm{~Pa}$ :

$$
\dot{V}=14.14 \Delta p^{0.5}\left(\mathrm{~m}^{3} / \mathrm{h}\right)
$$

These relations, Equations 4.3 and 4.4, are compared in Figure 4.5. Relative to the power law model using an exponent of $n=0.5$ that is commonly used to model simple openings in building envelopes, the relation chosen to model the self-regulating inlet vents, Equation 4.3 , is seen to provide a fairly constant airflow rate over a range of pressure differences likely to be encountered in practice (i.e., from $0 \mathrm{~Pa}$ to $25 \mathrm{~Pa}$ ). Other pressure-flow models have been proposed for modeling self-regulating vents that offer mathematical and numerical advantages [72], but this particular model was selected because it is currently supported in CONTAM97R [214].

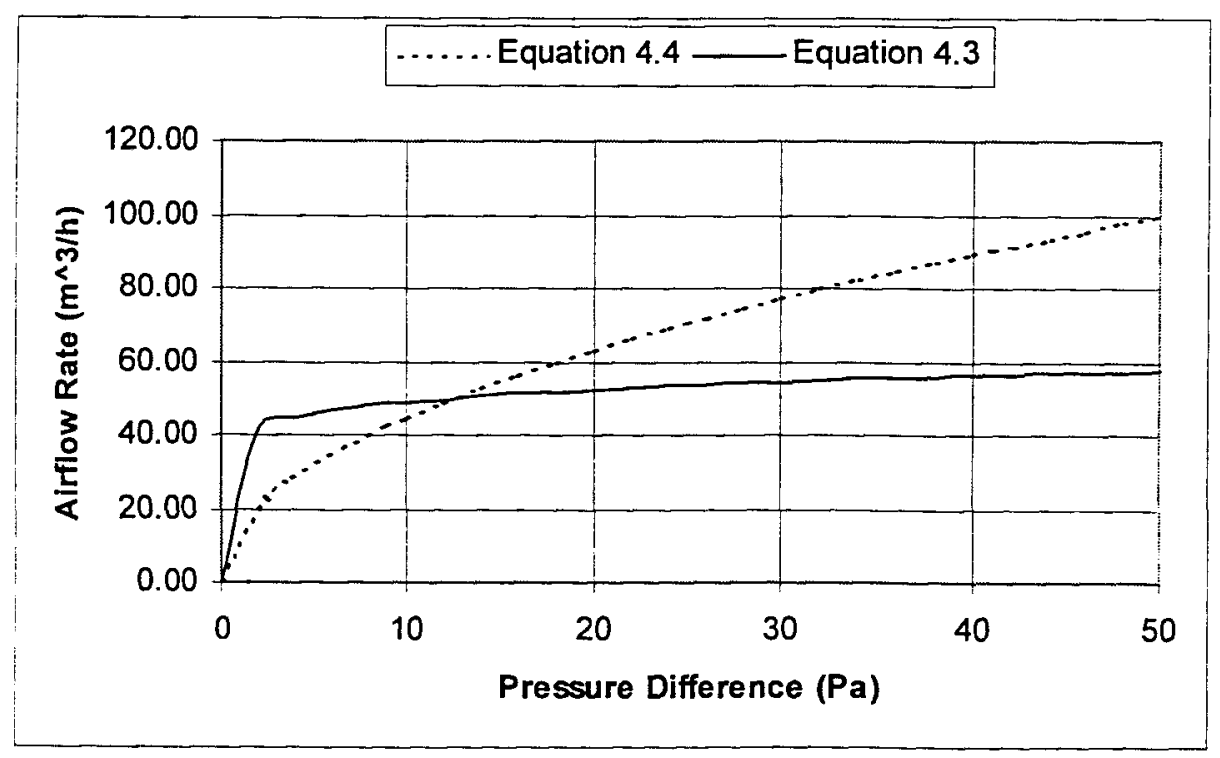

Figure 4.5 Comparison of power law models with exponent $n=0.5$, Equation 4.4, and the relation chosen to model the self-regulating inlet vents with exponent $n=0.1$, Equation $4.3-$ both adjusted to provide the same airflow rate of $50 \mathrm{~m}^{3} / \mathrm{h}$ at a pressure difference of $12.5 \mathrm{~Pa}$.

During winter operation, then, when the design airflow rate of $100 \mathrm{~m}^{3} / \mathrm{h}$ is the ventilation objective, the component relation defined by Equation 4.3 will be scaled by 2.0 for modeling the combined use of both vents at their lowest setting - i.e., $\dot{V}=2(38.84) \Delta p^{0.10}=77.68 \Delta p^{0.10}$. 
Similarly, for night cooling operation inlet vents will be modeled by Equation 4.3 scaled by 4.0 -i.e., $\dot{V}=4(38.84) \Delta p^{0.10}=155.36 \Delta p^{0.10}$.

\section{Ventilation Stack}

Unfortunately, the pressure-flow characteristics of the stack used in the Enschede Tax Office Building are not available. Consequently, the performance of the stack had to be modeled based on a reasonable design strategy that the self-regulating inlet vents maintain authority over the natural ventilation airflow rates as they were intended to be the controlling flow component. To ensure that these vents do, indeed, limit flow one may examine pressure drops around each of ten airflow loops passing through each office, to the atria, up the stack and back again to the inlet vents. Of these ten loops, the loop passing through the upper office, shown as a linked series of black arrows and nodes in Figures 4.3 and 4.4, provides the critical case, as pressure differences in this loop due to buoyancy will be smallest in comparison to all other loops.

As discussed in Chapter 3, design loop equations may be directly formulated once mathematical models are selected for each of the flow components in a ventilation loop [72, 175, 190, 192]. The self-regulating inlet vent model may be taken as the inverse form of Equation 4.3, (with the coefficient adjusted to units of seconds):

$$
\begin{aligned}
& \text { AQ Control Mode: } \Delta p_{\text {inlet }}=\left(\frac{\dot{V}_{\text {inlet }}}{77.68 / 3600}\right)^{10}=\left(\frac{\dot{V}_{\text {incet }}}{0.02158}\right)^{10} \\
& \text { Night Cool Mode: } \Delta p_{\text {intet }}=\left(\frac{\dot{V}_{\text {inlet }}}{155.4 / 3600}\right)^{10}=\left(\frac{\dot{V}_{\text {inlet }}}{0.04316}\right)^{10}
\end{aligned}
$$

Limiting consideration to the simplified model of the building, we may model the stack terminal pressure losses using a simple orifice model as:

$$
\Delta P_{\text {stack }}=\frac{\rho \dot{V}_{\text {stack }}^{2}}{2 C_{d}^{2} A_{\text {stack }}^{2}} \approx \frac{1.2 \mathrm{~kg} / \mathrm{m}^{3} \dot{V}_{\text {stack }}^{2}}{2(0.6)^{2} A_{\text {stack }}^{2}}
$$

where $A_{\text {stack }}$ is the opening free area of the stack terminal device, $C_{d}$ is the discharge coefficient that typically has a value approximately equal to 0.6 , and $\rho$ is the density of air which is approximately equal to $1.2 \mathrm{~kg} / \mathrm{m}^{3}$.

The sum of the pressure losses in the inlet and the stack terminal device must be equal to the driving stack and wind pressures, $\Delta p_{s}$ and $\Delta p_{w}$ accumulated on proceeding around the loop or:

$$
\begin{aligned}
& \text { AQ Control Mode: }\left(\frac{\dot{V}_{\text {.llet }}}{0.02158}\right)^{10}+\frac{1.2 \mathrm{~kg} / \mathrm{m}^{3} \dot{V}_{\text {stack }}^{2}}{2(0.6)^{2} A_{\text {stack }}^{2}}=\Delta p_{s}+\Delta p_{w} \\
& \text { Night Cool Mode: }\left(\frac{\dot{V}_{\text {inlet }}}{0.04316}\right)^{10}+\frac{1.2 \mathrm{~kg} / \mathrm{m}^{3} \dot{V}_{\text {stack }}^{2}}{2(0.6)^{2} A_{\text {sack }}^{2}}=\Delta p_{s}+\Delta p_{w}
\end{aligned}
$$

Demanding continuity, for design airflow conditions, the stack airflow rate must be equal to the sum of the inlet design airflow rates or $\dot{V}_{\text {stack }}=10 \dot{V}_{\text {imlet }}$ as the stack serves ten offices. Two design 
airflow rates - winter air quality control at $100 \mathrm{~m}^{3} / \mathrm{h}\left(0.0278 \mathrm{~m}^{3} / \mathrm{s}\right)$ and summer night cooling at $200 \mathrm{~m}^{3} / \mathrm{h}\left(0.0556 \mathrm{~m}^{3} / \mathrm{s}\right)$ - establish the limiting conditions that need to be considered. Substituting these values in Equation 4.7 and simplifying we obtain:

$$
\begin{aligned}
& \text { AQ Control Mode: }\left(\frac{0.0278}{0.02158}\right)^{10}+\frac{1.2 \mathrm{~kg} / \mathrm{m}^{3}(0.278)^{2}}{2(0.6)^{2} A_{\text {stack }}^{2}}=12.5+\frac{0.129}{A_{\text {stack }}^{2}}=\Delta p_{s}+\Delta p_{w} \\
& \text { Night Cool Mode: }\left(\frac{0.0556}{0.04316}\right)^{10}+\frac{1.2 \mathrm{~kg} / \mathrm{m}^{3}(0.556)^{2}}{2(0.6)^{2} A_{\text {stack }}^{2}}=12.5+\frac{0.515}{A_{\text {stack }}^{2}}=\Delta p_{s}+\Delta p_{w}
\end{aligned}
$$

Finally, if the loss in the stack terminal device is to be small relative to that of the inlet vent (i.e., so the inlet vent maintains control authority), then we must demand the second terms of Equations $4.8 \mathrm{a}$ and $4.8 \mathrm{~b}$ be small relative to the first terms. If, say, we set the relative difference to a ten-fold difference we obtain:

$$
\begin{aligned}
& \text { AQ Control Mode: } A_{\text {stack }} \geq \sqrt{0.129 / 1.25}=0.32 \mathrm{~m}^{2} \\
& \text { Night Cool Mode: } A_{\text {stack }} \geq \sqrt{0.515 / 1.25}=0.64 \mathrm{~m}^{2}
\end{aligned}
$$

A five-fold difference would require that $A_{\text {stack }}$ be greater than $0.23 \mathrm{~m}^{2}$ for the air quality control mode and greater than $0.46 \mathrm{~m}^{2}$ for the night cool mode.

Based on these rather elusive, but reasonable, limiting arguments for sizing the stack terminal device the stack terminal will be modeled as an orifice with a free opening area of $0.50 \mathrm{~m}^{2}$ as (the constant 3600 term converts from units of seconds to hours):

$$
\dot{V}_{\text {stack }}=(3600) C_{d} A_{\text {stack }} \sqrt{\frac{2 \Delta p}{\rho}}=(3600)(0.6)(0.5) \sqrt{\frac{2 \Delta p}{\rho}}[=] \mathrm{m}^{3} / \mathrm{h}
$$

For room air temperatures, the density of air is approximately $\rho \approx 1.20 \mathrm{~kg} / \mathrm{m}^{3}$ thus this flow relation becomes $\dot{V}_{\text {stack }} \approx 1390 \Delta P^{0.5} \mathrm{~m}^{3} / \mathrm{h}$. (Subsequent calibration studies, discussed below, were used to refine this estimate. As a result, the stack terminal free area was increased to $1.0 \mathrm{~m}^{2}$ to insure that the inlet vents maintained authority over ventilation flow rates.)

As discussed in Chapter 3, the stack and wind-driven pressure differences must be evaluated for each individual pressure loop (greater detail may be found in [72]. For the simplified singlezone model (i.e., with indoor air temperatures assumed to be uniform), these terms assume particularly simple forms:

$$
\begin{gathered}
\Delta p_{B}=\left(\rho_{\text {in }}-\rho_{\text {out }}\right) g \Delta z \\
\Delta p_{w}=\Delta C_{p} \frac{\rho U_{r e f}^{2}}{2}
\end{gathered}
$$

where $\left(\rho_{m}-\rho_{\text {out }}\right)$ is the difference between indoor and outdoor air densities, $g$ is the acceleration of gravity (i.e., $9.8 \mathrm{~m} / \mathrm{s}^{2}$ ), $\Delta z$ is the elevation difference between inlet and stack terminal exhaust, and $\Delta C_{p}$ is the algebraic difference between inlet and stack terminal wind pressure coefficients. 
Air densities were estimated using the ideal gas relation for dry air, Equation 3.14, for all model studies considered in this report.

\section{Assist Fans}

A single assist fan was included in the building model. The fan modeled as a CONTAM variable flow fan with a fan performance curve represented by a cubic polynomial adjusted to provide the maximum design ventilation flow rate at a low-pressure difference (i.e., $200 \mathrm{~m}^{3} / \mathrm{h}$ for each of the ten offices included in the model or $2,000 \mathrm{~m}^{3} / \mathrm{h}$ ), Figure 4.6 .

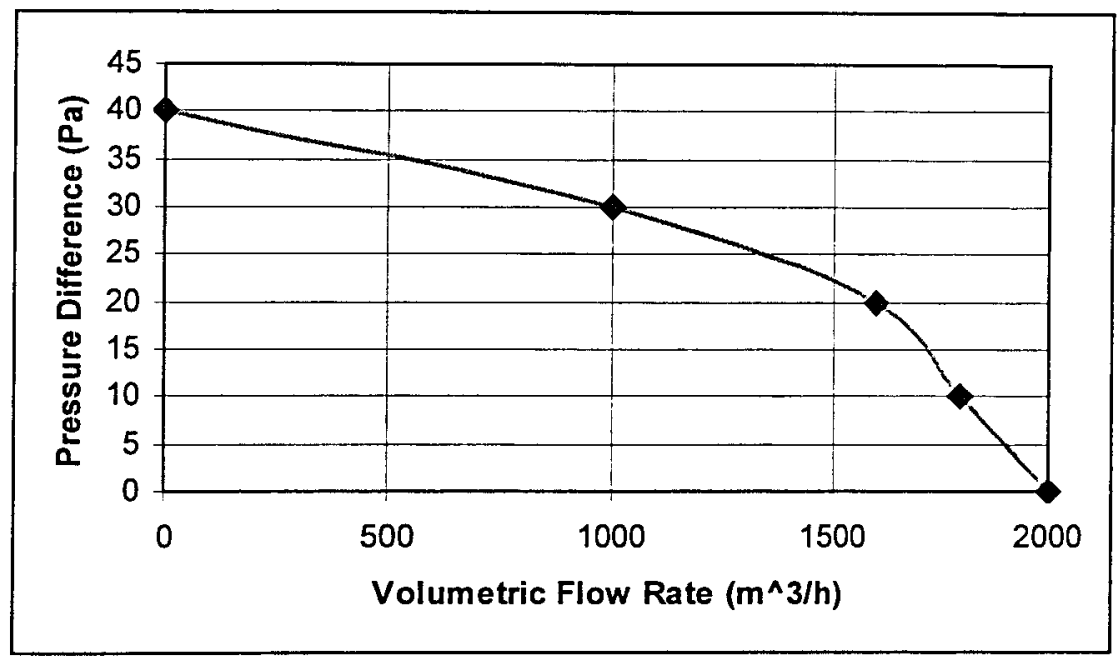

Figure 4.6 Fan performance curve used to model assist-fan for fan-assisted natural ventilation for night cooling.

\section{Natural Ventilation Control}

Building occupants in the Enschede Tax Office were given direct control of their environmental conditions although automatic control of lighting and external shading was provided that occupants could choose to override. A graphic chart - a so-called desk map - was placed at each work station within the Tax Office that provided specific instructions for ventilation, heating, lighting, and internal and external shade operation. These instructions were organized for winter and summer conditions with distinct instructions given for operations during and outside of office hours. The objectives of the control were quite simple and logical:

- maximize the use of daylight throughout the year to offset electrical energy consumption associated with artificial lighting and, due to the relatively high efficacy of the admitted daylight, to minimize thermal gains during overheated periods of the year - this was achieved, primarily, through the use of higher daylight windows with light shelves and integrated fluorescent light fixtures controlled by light cells,

- control solar gains, with external shades on lower view windows, during the overheated periods of the year,

- provide at least a minimum natural ventilation rate of $100 \mathrm{~m}^{3} / \mathrm{h}$ for each office (approximately $2 \mathrm{ACH}$ ) throughout the year for air quality control during occupied hours - 
occupants were encouraged to increase this during overheated periods when outdoor air temperatures were low enough to provide direct cooling,

- limit natural ventilation outside of office hours during winter conditions, and

- provide a maximum natural ventilation rate of $200 \mathrm{~m}^{3} / \mathrm{h}$ for each office (approximately 4 $\mathrm{ACH}$ ) outside of office hours during heat waves to effect night cooling of the building thermal mass.

For night ventilation during summer hot periods, building occupants were instructed to set the self-regulating inlet vents to the maximum setting " 2 " (i.e., intended to provide $200 \mathrm{~m}^{3} / \mathrm{h}$ for each office) at the end of the workday. At other times they were to set the inlet vents to the minimal airflow setting " 1 " (i.e., intended to provide $100 \mathrm{~m}^{3} / \mathrm{h}$ for each office). With the workday assumed to be from 8:00 am to $5: 00 \mathrm{pm}$ during weekdays, this night ventilation control strategy was modeled using a simple schedule for weekdays and weekends as illustrated in Figure 4.7. To introduce a more realistic operating schedule (and to avoid abrupt changes in operating conditions that are difficult to capture numerically), it may be seen that changes in the self-regulating ventilation settings were assumed to occur over a 15-minute time interval.

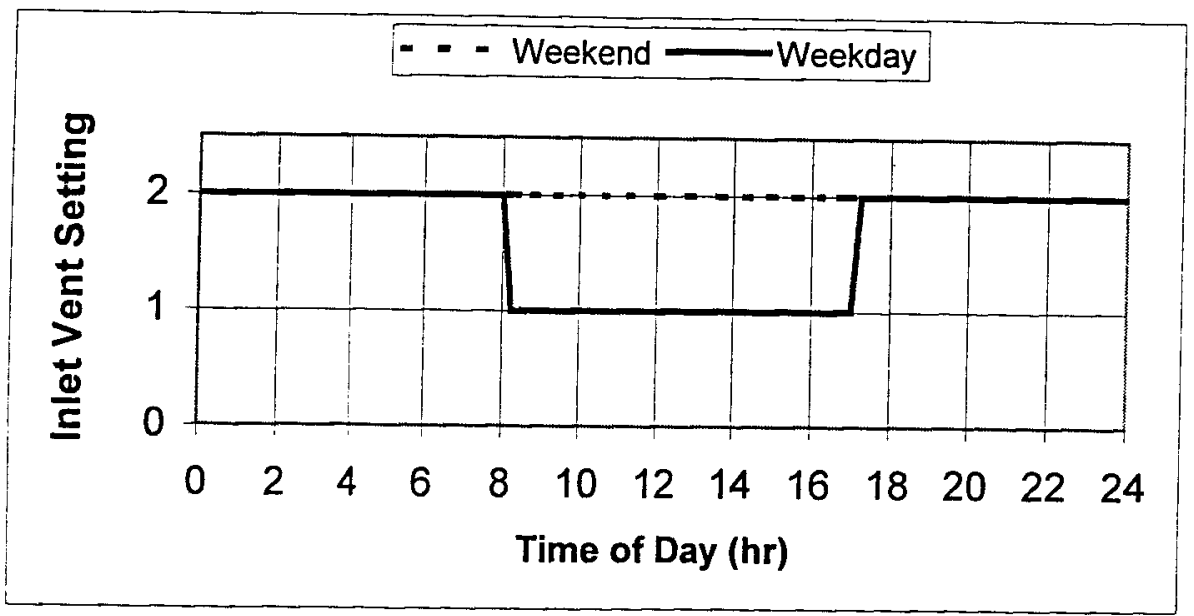

Figure 4.7 Schedule for self-regulating inlet vent used to model the night ventilating control strategy implemented in the Enschede Tax Office building (i.e., minimal setting " 1 " during work hours and maximal setting " 2 " thereafter).

Ideally, night ventilation should be controlled in response to thermal conditions (i.e., specifically when outdoor air temperatures fall below indoor air temperatures and moisture content is not excessive) rather than by a time-of-day schedule. Consequently, one should expect the control strategy used in the Enschede Tax Office to be less than optimal - computed results of the calibration studies presented below indicate this was the case.

\section{Detailed Multi-Zone Model Assumptions}

In addition to the modeling assumptions enumerated above, that were common to both the simplified single-zone model and the detailed multi-zone model, additional flow paths and flow resistances were included in the multi-zone model.

Leakage was modeled using the guidelines and data published by NIST [167]. 
- Envelope Leakage: Envelope leakage through both windows and walls was modeled using an effective leakage area of $1.0 \mathrm{~cm}^{2} / \mathrm{m}^{2}$ of window or wall surface area for tight construction and $10.0 \mathrm{~cm}^{2} / \mathrm{m}^{2}$ for loose construction.

- Interior Walls: Interior walls were modeled using an effective leakage area of 1.0 $\mathrm{cm}^{2} / \mathrm{m}^{2}$.

- Doors: Doors between offices and corridors were assumed closed and not undercut. Doors to the utility rooms were assumed closed and undercut. Doors linking the southern corridor with the atrium were assumed opened and modeled using the orifice element model with opening area equal to $0.9 \mathrm{~m} \mathrm{x} 2.1 \mathrm{~m}$ and a discharge coefficient of 0.6 . Closed interior doors without a ventilation undercut were modeled with a leakage area of $100 \mathrm{~cm}^{2}$ per door. Closed interior doors with a ventilation undercut were modeled with a leakage area of $250 \mathrm{~cm}^{2}$ per door.

Transfer ducts between the southern offices and atrium and transfer grills between the northern offices and atrium were both modeled with $150 \mathrm{~mm}(6 \mathrm{in})$ round ducts using the CONTAM Darcey-Colebrook duct modeling element. The transfer duct was modeled as a $5 \mathrm{~m}$ long duct and the transfer grill as a $150 \mathrm{~mm}$ long duct. The resistances of both proved to be small relative to other flow resistances along the natural ventilation flow paths and thus had little impact on the ventilation flow rates - i.e., they were amply sized for their intended purpose.

Finally, stack exhaust airflow was modeled using the variable flow fan model described above with an off flow resistance defined by the orifice equation with a free area of $1 \mathrm{~m}^{2}$. This modeling tactic allowed the control of fan-assisted stack ventilation to be modeled. For those studies utilizing fan-assisted stack ventilation for night ventilation, the assist fan was activated outside of occupied hours when two conditions were satisfied:

- the slot atrium temperaure exceeded outdoor air temperature, $\left(\mathrm{T}_{\text {atr }}>\mathrm{T}_{\text {out }}\right) \underline{\text { and }}$

- the slot atrium temperature was greater than $24^{\circ} \mathrm{C},\left(\mathrm{T}_{\text {atr }}>24^{\circ} \mathrm{C}\right)$.

At all other times, the stack exhaust was modeled as an orifice with a free area of $1 \mathrm{~m}^{2}$.

\subsubsection{Thermal Characteristics}

The unreleased research version of the CONTAM family of programs, CONTAM97R [214] may be used to model the interaction of the natural (and mechanical) airflow and thermal systems of multizone building models - that is to say it provides coupled thermal/airflow analysis. Presently it provides thermal components to model:

1. dynamic 1D conductive heat transfer components (i.e., accounting for both conductivity and heat capacity in multi-layer construction assemblies) that may be used to model heat transfer through the building envelope and between zones of multizone idealizations of building systems,

2. dynamic 1D thermal storage heat transfer components (i.e., accounting for both conductivity and heat capacity in multi-layer construction assemblies with an adiabatic boundary) that may be used to model thermal mass placed internally to building zones,

3. advective heat transfer due to the airflow from zone-to-zone through the airflow components used in the associated airflow model of multizone building models, and 
4. heat gains internal to zones that may be used to model internal gains due to occupants and equipment, solar gains, and heat delivered to or removed from individual zones for purposes of heating or cooling.

Advective heat transfer is automatically modeled using the airflows computed for the airflow system modeling. The present version of CONTM97R does not directly account for radiative transfer through glazed portions of the building envelope and does not yet correctly account for air spaces in glazed or opaque wall constructions although much of the program code is in place to implement these capabilities.

Conductive heat transfer, internal thermal mass, and heat gain components were used to model the physical components of the Enschede Tax Office thermal system and the scheduling capabilities of CONTAM97R were used to model the control of heat gains internal to building zones. Some but not all details of building construction were available so a number of relatively minor assumptions had to be made to build a model of the building. Details of these modeling assumptions are enumerated below.

Thermal properties for all materials were taken from the 1997 ASHRAE Handbook of Fundamentals [46]. Table 4.2 presents a summary of the materials used for modeling purposes and their assumed thermal properties.

Table 4.2 Materials and their thermal properties used in the modeling studies.

\begin{tabular}{|l|c|c|c|c|}
\hline Material & $\begin{array}{c}\text { Density } \\
\left(\mathrm{kg} / \mathrm{m}^{3}\right)\end{array}$ & $\begin{array}{c}\text { Conductivity } \\
\left(\mathrm{W} / \mathrm{m}-{ }^{\circ} \mathrm{K}\right)\end{array}$ & $\begin{array}{c}\text { Heat Capacity } \\
\left(\mathrm{J} / \mathrm{kg}^{-} \mathrm{K}\right)\end{array}$ & $\begin{array}{c}\text { Surface } \\
\text { Emissivity }\end{array}$ \\
\hline Brick (Tile) & 1970 & 0.70 & 800 & 0.90 \\
\hline Concrete & 2300 & 0.93 & 653 & 0.90 \\
\hline Fiberglass Insul. & 100 & 0.036 & 960 & --- \\
\hline Glass & 2230 & 1.00 & 840 & 0.20 \\
\hline Gypsum Board & 800 & 0.17 & 1090 & 0.90 \\
\hline Plywood & 540 & 0.12 & 1210 & 0.90 \\
\hline
\end{tabular}

\section{Envelope Resistances}

Opaque roof and wall surfaces were modeled by a multilayer construction consisting of $25 \mathrm{~mm}$ (1 in) of brick tile, $20 \mathrm{~mm}$ ( $3 / 4 \mathrm{in})$ of plywood, $150 \mathrm{~mm}$ (6 in) of fiberglass insulation, and 13 $\mathrm{mm}(1 / 2$ in) of gypsum wallboard. Given the current limitation of CONTAM97R, solar absorption to outer surfaces of these constructions were not directly modeled thus heat transfer was limited to conductive and surface convective transfer due to temperature differences between zones and between zones and the outdoor ambient air temperature. For the $3.0 \mathrm{~m}$ section of the building modeled, the total opaque envelope surface area modeled was $155.4 \mathrm{~m}^{2}-$ $60 \mathrm{~m}^{2}$ of roof area, $55 \mathrm{~m}^{2}$ of wall surface, and $40.5 \mathrm{~m}^{2}$ of an exposed floor area above a ground level parking area (see Figure 4.2).

Glazed wall surfaces included higher daylight windows, that were estimated to be $0.5 \mathrm{~m}$ tall and $3.0 \mathrm{~m}$ wide, and lower view windows, that were estimated to be $1.0 \mathrm{~m}$ tall and 3.0 meter wide, that together provided $4.5 \mathrm{~m}^{2}$ of glazed area per office. This area amounted to $45 \%$ of the nominal exterior wall area of each office (i.e., $3 \mathrm{~m} \times 3.33 \mathrm{~m}$ or $10 \mathrm{~m}^{2}$ ). Thus for the ten offices included in the $3.0 \mathrm{~m}$ section of the building modeled, $45 \mathrm{~m}^{2}$ of these windows were accounted for. 
These windows were assumed double-glazed with relatively efficient low-e glazing. Given the current limitations of CONTAM97R, however, the internal air space of this double-glazed system could not be directly modeled. Instead, these windows were modeled as a multilayer construction of $3 \mathrm{~mm}(1 / 8 \mathrm{in})$ of glass, $10 \mathrm{~mm}$ (3/8 in) fiberglass insulation, and $3 \mathrm{~mm}(1 / 8 \mathrm{in})$ of glass with both inside and outside surfaces of the double-glazed system modeled with long wave emissivities of 0.20 . As noted above, solar gain through these windows was not directly modeled.

Finally, windows that flanked the north and south sides of the atrium extension were also modeled using the same double-glazed construction. For the assumed $3.83 \mathrm{~m}$ height of this extension, an area of glazing of $3 \mathrm{~m} \times 3.83 \mathrm{~m}=11.49 \mathrm{~m}^{2}$ on each side of the extension or 22.98 $\mathrm{m}^{2}$ total was accounted for.

\section{Internal Thermal Mass}

The Enschede Tax Office was constructed to allow the massive floor construction used to be exposed on both upper and lower surfaces to room air. The effect of this "high" thermal mass was modeled using $150 \mathrm{~mm}$ (6 in) of concrete (i.e., with an assumed adiabatic inner surface) for both floor and ceiling surfaces. Given the geometry illustrated in Figure 4.2, the total internal mass surface area was estimated to be $516 \mathrm{~m}^{2}$. Night ventilation strategies depend critically on the amount of thermal mass present and its participation in the dynamic thermal response of the building which depends on the exposed surface area of the thermal mass, on its thermal characteristics, and on the dynamic character of the thermal excitation. For the spans involved in the Tax Office, an effective participating thickness of concrete of $15 \mathrm{~cm}$ is reasonable. The estimated surface area was based on the assumption of a flat ceiling surface - perhaps a conservative assumption given concrete joist or waffle slab systems commonly used for this type of construction would result in larger ceiling surface areas. Finally, while other materials such as masonry floor tiles may have more desirable thermal properties, massive concrete construction is not too dissimilar.

The modeling assumptions used here certainly correspond to a relatively "high" thermal mass building yet using more effective materials and a floor construction designed to increase surface area (e.g., cored slab, waffle slab, or even concrete joist floor system) an even higher thermal mass could have been provided. Consequently, the model assumptions made are believed to be reasonable.

\section{Internal and Solar Gains}

Natural ventilation cooling strategies must be complemented by effective and comprehensive control of solar and internal gains. In the Enschede Tax Office this was achieved with a relatively high resistance envelope construction to control solar gains admitted by conduction, automatic control of external shades to control solar gain admitted by radiative transmission, and automatic control of artificial lighting coupled with optimally designed day lighting systems to offset heat gains due to electrical lighting with higher efficacy daylight. Combined internal gains for lighting, equipment and occupants (i.e., at two people per $20 \mathrm{~m}^{2}$ office) during summer operation of the building were reported to be $27.5 \mathrm{~W} / \mathrm{m}^{2}$ net office floor area. Of this, $8 \mathrm{~W} / \mathrm{m}^{2}$ could be attributed to occupants and the remaining $19.5 \mathrm{~W} / \mathrm{m}^{2}$ to lighting and equipment [11]. 
Estimates of internal gains due to equipment in offices vary considerably from $4 \mathrm{~W} / \mathrm{m}^{2}$ to 20 $\mathrm{W} / \mathrm{m}^{2}$ with intensive computational facilities approaching $30 \mathrm{~W} / \mathrm{m}^{2}$ (see, for example, [46] Chapter 28 , or $[49,50])$. State-of-the-art lighting systems may be expected to add another 5 $\mathrm{W} / \mathrm{m}^{2}$ to $10 \mathrm{~W} / \mathrm{m}^{2}$ (see, for example, [75]). Thus, combined with an occupant load $8 \mathrm{~W} / \mathrm{m}^{2}$, internal gains in offices may be expected to range from $17 \mathrm{~W} / \mathrm{m}^{2}$ to $38 \mathrm{~W} / \mathrm{m}^{2}$ for typical uses.

Ideally, in an optimally designed low-energy building, solar gains during the summer period should be limited to just that necessary to provide sufficient day lighting (i.e., to offset artificial lighting of lower efficacy). If this ideal is achieved the combined solar and internal gain during sunny periods should fall below that of the internal gains alone required during overcast conditions. In any event, in a properly designed low-energy building the solar gains may, arguably, fall within the uncertainty of the internal gains due to occupants, equipment and artificial lighting alone. Thus, rather than modeling solar gains directly - which is not presently supported by CONTAM97R anyway - dynamic thermal studies were completed for a range of assumed combined internal and solar gains.

Specifically, modeling studies were completed for $20.0 \mathrm{~W} / \mathrm{m}^{2}, 27.5 \mathrm{~W} / \mathrm{m}^{2}$ and $35.0 \mathrm{~W} / \mathrm{m}^{2}$ combined internal gains for office areas and $5.0 \mathrm{~W} / \mathrm{m}^{2}$ (i.e., for lighting loads alone) for corridor, atrium, and utility room areas - during occupied hours. These areas were estimated to total 150 $\mathrm{m}^{2}$ for offices and $108 \mathrm{~m}^{2}$ for the other areas for the $3.0 \mathrm{~m}$ section of the building modeled. Averaged over the floor area of the building model, these modeling assumptions correspond to combined internal loads of $13.7 \mathrm{~W} / \mathrm{m}^{2}, 18.1 \mathrm{~W} / \mathrm{m}^{2}$, and $22.4 \mathrm{~W} / \mathrm{m}^{2}$ of gross floor area respectively. Internal and solar gains were assumed to be negligible during nighttime hours and were assumed to be maintained at $5.0 \mathrm{~W} / \mathrm{m}^{2}$ during daytime hours on week ends.

\subsection{Modeling Studies Investigated}

Two general types of modeling studies were considered:

- Calibration Studies - The Enschede Tax Office building has been the subject of detailed field measurements within the NatVent ${ }^{\circledR}$ Project [10] consequently its measured performance was used to calibrate both the simplified single-zone and the detailed multizone models to quantify the reliability and accuracy of the simulation model and thereby characterize the uncertainty of computed results.

- Night Cooling Design Development Study - The performance of a night ventilated version of the detailed multi-zone model of the Enschede Tax Office placed in two representative hot-arid U.S. climates - Los Angeles and Fresno, CA - was investigated to illustrate the use of detailed performance evaluation to refine a preliminary natural ventilation system proposal.

\section{Calibration Studies Data}

Both winter and summer field measurements are available that were used for calibration studies. They include:

- March 1997 - the ventilation rate was measured for selected offices for the following conditions: 
o indoor air temperatures: $20^{\circ} \mathrm{C}-21^{\circ} \mathrm{C}$ - for analysis, indoor air temperature was assumed to be $20.5^{\circ} \mathrm{C}$,

o outdoor air temperature: $9^{\circ} \mathrm{C}-12^{\circ} \mathrm{C}$, - for analysis, outdoor air temperature was assumed to be $10.5^{\circ} \mathrm{C}$,

o wind speed: $2 \mathrm{~m} / \mathrm{s}-3 \mathrm{~m} / \mathrm{s}$ - for analysis, wind speed was assumed to be $2.5 \mathrm{~m} / \mathrm{s}$, and

o wind direction: from the North.

- June, 1997 - the ventilation rate was measured for selected offices for the following conditions:

o indoor air temperatures: $21^{\circ} \mathrm{C}-23^{\circ} \mathrm{C}$ - for analysis, indoor air temperature was assumed to be $22{ }^{\circ} \mathrm{C}$,

- outdoor air temperature: $16^{\circ} \mathrm{C}$,

o wind speed: $3 \mathrm{~m} / \mathrm{s}-4 \mathrm{~m} / \mathrm{s}$ - for analysis, wind speed was assumed to be $3.5 \mathrm{~m} / \mathrm{s}$, and

o wind direction: from the South West.

- August, 1997 - indoor air temperatures were measured for selected offices and the atrium for a four-day period for the following conditions:

o internal gains in offices during occupancy (i.e., two people per office) of approximately $8 \mathrm{~W} / \mathrm{m}^{2}$ for occupants and $19.5 \mathrm{~W} / \mathrm{m}^{2}$ for office equipment and lighting combined and

- measured outdoor air temperatures varying diurnally from a minimum of $17^{\circ} \mathrm{C}$ to a maximum of $31^{\circ} \mathrm{C}$ over the four-day period

Unfortunately, wind speed and direction were not reported for this series of measurements. Consequently, calibration analyses were based on a four-day heat wave extracted from the WYEC2 MABOSTNT weather record for Boston [44] that has a similar, but slightly more extreme, outdoor temperature time history.

\section{Night Cooling Design Development Study}

Los Angeles and Fresno, CA were selected for the design development studies. Both climates may be considered hot-arid climates but Los Angeles' climate is moderated by its coastal location and Fresno, being located within California's Central Valley, has more extreme summer temperatures, Figure 4.8 .

Histogram of the summer wind speed data for these locations reveal that Los Angeles experiences higher wind speeds more frequently but very low wind speeds (i.e., less than $2 \mathrm{~m} / \mathrm{s}$ ) seldom occur in either location, Figure 4.9. The average summer wind speed for Fresno is 3.05 $\mathrm{m} / \mathrm{s}$ while that of Los Angeles is $3.86 \mathrm{~m} / \mathrm{s}$. On this basis, then, a nominal design wind speed for Fresno would reasonably be set at $3 \mathrm{~m} / \mathrm{s}$ while that for Los Angeles $4 \mathrm{~m} / \mathrm{s}$ would be more appropriate. 

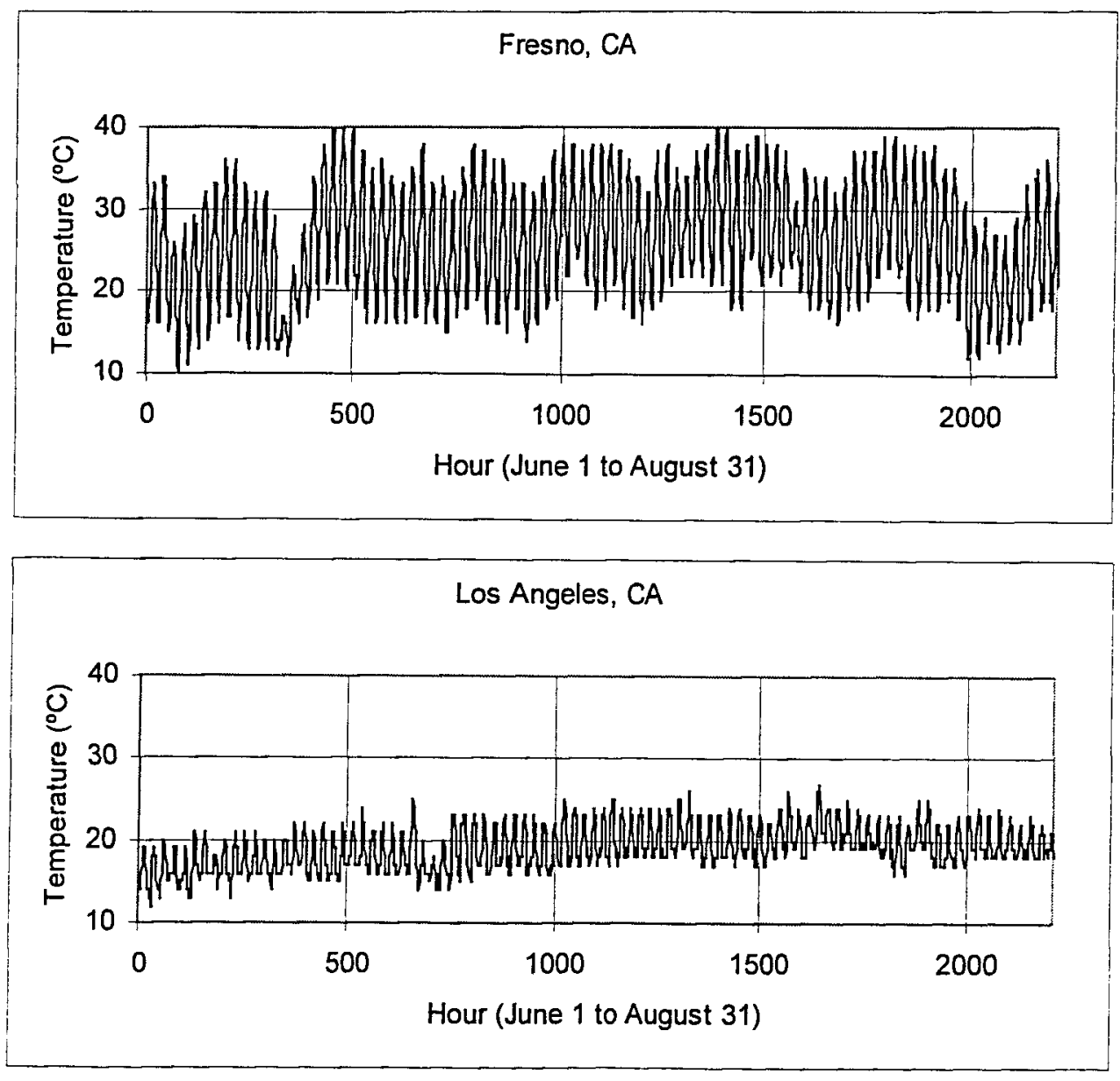

Figure 4.8 Summertime outdoor temperatures time histories for Fresno and Los Angeles, CA used for modeling studies - extracted from WYEC2 data [44].

Table 4.3 presents results of the climatic suitability analysis for Los Angles and Fresno. These results indicate it will be more difficult to cool buildings with natural ventilation systems, in general, in Fresno than in Los Angeles. More specifically, higher ventilation rates will be required for direct ventilative cooling yet this strategy will be less effective annually. Likewise, night cooling will offset smaller levels of daytime internal gain in Fresno than in Los Angeles (i.e., $4.9 \pm 3.0 \mathrm{~W} / \mathrm{m}^{2}-\mathrm{ACH}$ versus $5.9 \pm 2.3 \mathrm{~W} / \mathrm{m}^{2}-\mathrm{ACH}$ ) and will be required in Fresno for 174 days of the year versus only 27 in Los Angeles. For example, to offset a daytime internal gain of $27.5 \mathrm{~W} / \mathrm{m}^{2}$ - the representative internal gain that will be used in subsequent modeling design exercises - a nighttime ventilation rate of $5.6 \mathrm{ACH}$ on average and up to $14.4 \mathrm{ACH}$ may be required in Fresno. For Los Angeles, on the other hand, only 4.7 ACH on average and up to 7.6 $\mathrm{ACH}$ may be required. 


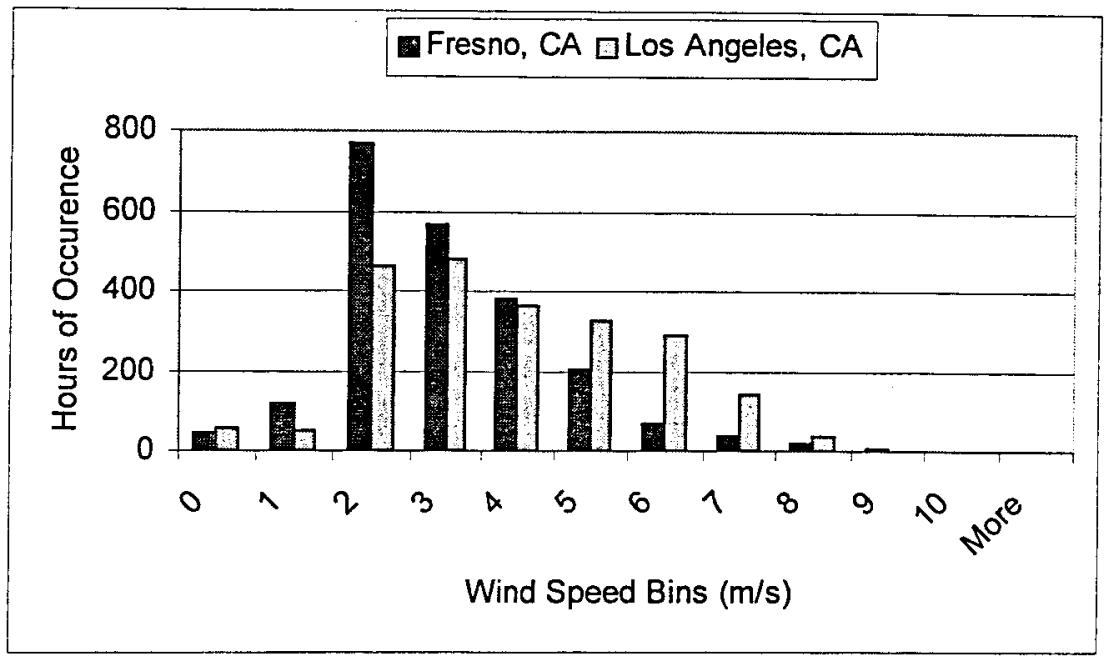

Figure 4.9 Histograms of summertime wind speed data for Fresno and Los Angeles, CA used for modeling studies - based on WYEC2 data [44].

Table 4.3 Climate suitability results for Los Angeles and Fresno CA based on WYEC2 data sets (CALOSANW.WY2 and CAFRESNT.WY2) [42].

\begin{tabular}{|c|c|c|c|c|c|}
\hline & \multicolumn{4}{|c|}{ Direct Cooling } & \multirow[t]{2}{*}{ Night Cooling' } \\
\hline & $10 \mathrm{~W} / \mathrm{m}^{2}$ & $20 \mathrm{~W} / \mathrm{m}^{2}$ & $40 \mathrm{~W} / \mathrm{m}^{2}$ & $80 \mathrm{~W} / \mathrm{m}^{2}$ & \\
\hline \multicolumn{6}{|c|}{ Los Angeles, CA - CALOSANW.WY2 data } \\
\hline $\begin{array}{c}\text { Vent. Rate or } \\
\text { Cooling } \\
\text { Potential }\end{array}$ & $\begin{array}{c}1.5 \pm 1.0 \\
\mathrm{ACH}\end{array}$ & $\begin{array}{c}3.0 \pm 2.1 \\
\mathrm{ACH}\end{array}$ & $\begin{array}{c}5.9 \pm 4.2 \\
\mathrm{ACH}\end{array}$ & $\begin{array}{c}11.8+8.4 \\
\text { ACH }\end{array}$ & $\begin{array}{c}5.9 \pm 2.3 \\
W / m^{2}-A C H\end{array}$ \\
\hline$\%$ Effective $^{2}$ & $95 \%$ & $98 \%$ & $98 \%$ & $98 \%$ & $\begin{array}{c}93 \% \\
\text { (27 days) }\end{array}$ \\
\hline \multicolumn{4}{|c|}{ Fresno, CA - CAFRESNT.WY2 data } & \multicolumn{2}{|c|}{ Hot-Arid-Continental } \\
\hline $\begin{array}{c}\text { Vent. Rate or } \\
\text { Cooling } \\
\text { Potential }\end{array}$ & $\begin{array}{c}2.1 \pm 2.2 \\
\mathrm{ACH}\end{array}$ & $\begin{array}{c}3.3 \pm 4.1 \\
\mathrm{ACH}\end{array}$ & $\begin{array}{c}6.6 \pm 8.2 \\
\mathrm{ACH}\end{array}$ & $\begin{array}{r}132+165 \\
\mathrm{ACH} \\
\mathrm{S}\end{array}$ & $\begin{array}{c}4.9 \pm 3.0 \\
W / m^{2}-A C H\end{array}$ \\
\hline$\%$ Effective $^{2}$ & $58 \%$ & $80 \%$ & $80 \%$ & $80 \%$ & $\begin{array}{c}100 \% \\
\text { (174 days) }\end{array}$ \\
\hline
\end{tabular}

Tight cooling for subsequent days when direct cooling is not effective.

${ }^{2}$ For direct cooling $\%=$ hours effective $\div 8760$ hours; for night cooling $\%=$ days effective $\div$ days needed. white $=0$ to $5 \mathrm{ACH}$ light gray $=5$ to $10 \mathrm{ACH}$ (2) 3 medium gray $=10$ to $15 \mathrm{ACH}$

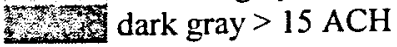




\subsection{Modeling Results}

This section will present and discuss the implications of computed results for both the calibration and U.S. climate modeling studies.

\section{Calibration Studies Results}

Computed results for both the simplified single-zone and the detailed multi-zone model of the Enschede Tax Office Building are considered in this section. As should be expected, the simplified single-zone model predicted general aspects of the building response that were in good agreement with that predicted by the detailed model.

\section{March 1997 \& June 1997 Results: Simplified Single-Zone Building Model}

Computed ventilation rates based on the simplified single-zone model for the Winter (March,1997) and Summer (June, 1997) calibration data sets are presented in Table 4.4 along with the computed pressure differences at each of the ten inlet vents.

Table 4.4 Comparison of computed and measured ventilation rates for assumed stack terminal free area of $0.5 \mathrm{~m}^{2}$ for the simplified single-zone model of the Tax Office.

\begin{tabular}{|c|c|c|c|c|c|c|c|c|}
\hline \multirow[b]{3}{*}{ Level } & \multicolumn{4}{|c|}{$\begin{array}{c}\text { Winter Conditions } \\
\left(T_{\text {out }}=10.5^{\circ} \mathrm{C} ; V_{H}=2.5 \mathrm{~m} / \mathrm{s} ; \phi=\mathrm{N} ; T_{\text {in }}=20.5^{\circ} \mathrm{C}\right)\end{array}$} & \multicolumn{4}{|c|}{$\begin{array}{c}\text { Summer Conditions } \\
\left(T_{\text {out }}=16^{\circ} \mathrm{C} ; V_{H}=3.5 \mathrm{~m} / \mathrm{s} ; \phi=\mathrm{SW} ; T_{\text {in }}=22^{\circ} \mathrm{C}\right)\end{array}$} \\
\hline & \multicolumn{2}{|c|}{$\begin{array}{l}\text { Computed } Q\left(\mathrm{~m}^{3} / \mathrm{h}\right) \\
\{\Delta P(\mathrm{~Pa})\}\end{array}$} & \multicolumn{2}{|c|}{ Measured $^{\mathrm{a}} Q\left(\mathrm{~m}^{3} / \mathrm{h}\right)$} & \multicolumn{2}{|c|}{$\begin{array}{l}\text { Computed } Q\left(\mathrm{~m}^{3} / \mathrm{h}\right) \\
\{\Delta P(\mathrm{~Pa})\}\end{array}$} & \multicolumn{2}{|c|}{ Measured $^{\mathrm{a}} Q\left(\mathrm{~m}^{3} / \mathrm{h}\right)$} \\
\hline & North & South & North & South & North & South & North & South \\
\hline Stack & \multicolumn{2}{|c|}{$\begin{array}{c}971 \\
\{0.48\}\end{array}$} & \multicolumn{2}{|c|}{-} & \multicolumn{2}{|c|}{$\begin{array}{c}1500 \\
\{1.16\}\end{array}$} & \multicolumn{2}{|c|}{--} \\
\hline 5 & $\begin{array}{c}95 \\
\{5.33\}\end{array}$ & $\begin{array}{c}90 \\
\{2.95\}\end{array}$ & 97 & 110 & $\begin{array}{c}-90 \\
\{-0.004\}\end{array}$ & $\begin{array}{c}176 \\
\{2.98\}\end{array}$ & 93 & 146 \\
\hline 4 & $\begin{array}{c}98 \\
\{6.78\}\end{array}$ & $\begin{array}{c}93 \\
\{4.37\}\end{array}$ & $\cdots$ & -- & $\begin{array}{c}157 \\
\{0.91\}\end{array}$ & $\begin{array}{c}181 \\
\{3.89\}\end{array}$ & -- & $\cdots$ \\
\hline 3 & $\begin{array}{c}99 \\
\{7.87\}\end{array}$ & $\begin{array}{c}96 \\
\{5.80\}\end{array}$ & 96 & 90 & $\begin{array}{c}167 \\
\{1.78\}\end{array}$ & $\begin{array}{c}183 \\
\{4.38\}\end{array}$ & 101 & 192 \\
\hline 2 & $\begin{array}{c}100 \\
\{8.89\}\end{array}$ & $\begin{array}{c}98 \\
\{7.31\}\end{array}$ & -- & -- & $\begin{array}{c}175 \\
\{2.82\}\end{array}$ & $\begin{array}{c}185 \\
\{4.77\}\end{array}$ & -- & -- \\
\hline 1 & $\begin{array}{c}102 \\
\{10.29\}\end{array}$ & $\begin{array}{c}100 \\
\{8.74\}\end{array}$ & $126^{b}$ & $160^{6}$ & $\begin{array}{c}180 \\
\{3.65\}\end{array}$ & $\begin{array}{c}189 \\
\{5.94\}\end{array}$ & 133 & 209 \\
\hline
\end{tabular}

${ }^{a}$ Measured data reported in by the European NatVent ${ }^{\circledR}$ Project [11].

"The unexpectedly high ventilation rates measured at the $1^{\text {st }}$ level were attributed to "excessive air leakage" [11].

The natural ventilation system of the Enschede Tax Office was configured to provide ventilation rates of $100 \mathrm{~m}^{3} / \mathrm{h}$ for winter conditions and $200 \mathrm{~m}^{3} / \mathrm{h}$ for summer conditions for each office served by the system.

Given the inherent uncertainty in wind speed, wind direction, and wind pressure coefficients characterizing the impact of these winds on the building, the computed ventilation flow rates compare reasonably well to the reported measured results. For the winter conditions the computed ventilation rates at the $3^{\text {rd }}$ and $5^{\text {th }}$ levels are within $18 \%$ of the measured values. At the 
$1^{\text {st }}$ level greater difterences are observed but the measured ventilation rates were reported to be excessively high (i.e., relative to the winter design objective of $100 \mathrm{~m}^{3} / \mathrm{h}$ ) due to unintended air leakage - air leakage not accounted for in the simplified single-zone model. As computed, the winter ventilation rates fall within $10 \%$ of the winter design objective of $100 \mathrm{~m}^{3} / \mathrm{h}$, exhibiting slightly greater ventilation rates on the windward (North) side of the building and for the lower offices where buoyancy pressures $\Delta P_{B}$ play a greater role.

Computed summer ventilation rates are within $27 \%$ of the measured values with the significant exception of the $5^{\text {th }}$ level North office where the computed ventilation direction was opposite of that measured. For the given SW wind and the relatively small difference between indoor and outdoor temperatures, wind suction pressures acting on this office were able to overcome buoyancy pressures to produce a net outward rather than inward airflow. This is a characteristic problem for upper rooms on the leeward side of naturally ventilated buildings [72]. All other airflows approached but fell short of the summer design objective of $200 \mathrm{~m}^{3} / \mathrm{h}$ - providing, on the average, only $150 \mathrm{~m}^{3} / \mathrm{h}$ (i.e., the stack exhaust rate divided by the number of offices, ten). An examination of the pressure differences computed for each of the inlet ventilation devices and the stack suggests an explanation.

For winter operation (i.e., self regulating inlet vents set to provide $100 \mathrm{~m}^{3} / \mathrm{h}$ at the first setting) the computed pressure drop across the stack terminal $(0.48 \mathrm{~Pa})$ proved to be an order of magnitude smaller than pressure drops computed for all inlet vents which ranged from 2.95 to $10.29 \mathrm{~Pa}$. Thus, as intended, the inlet vents acted to limit and thus control ventilation airflow rates as intended. For summer operation (i.e., self regulating inlet vents set to provide $200 \mathrm{~m}^{3} / \mathrm{h}$ at the second setting) this design objective was not, however, realized the computed pressure drop across the stack terminal $(1.16 \mathrm{~Pa}$ ) proved to be smaller but of the same order of magnitude as the pressure drops across the inlet vents. Consequently, ventilation flow rates were not limited and thus not controlled so clearly by the inlet vents. To achieve better control the free area of the stack terminal would have to be increased - this refinement will be examined below.

Before considering the modification to the stack terminal, it is useful to note another subtlety of the computed results. Computed inlet vent pressure differences proved to be relatively small for both the summer and winter conditions, all falling below 10.29 Pa. Examining the form of the self-regulating inlet flow model Equation 4.3 shown in Figure 4.5 reveals that below about $3 \mathrm{~Pa}$ (i.e., below the knee of the flow model curve) self-regulation is not realized. This behavior is inevitable and is observed for real self-regulating ventilating devices - i.e., as driving pressures approach zero ventilation rates necessarily must drop.

Based on the observations discussed above all results were recomputed using an increased free area of the stack terminal, increasing this area from $0.5 \mathrm{~m}^{2}$ to $1.0 \mathrm{~m}^{2}$. The results tabulated below clearly reveal improved control of the ventilation flow rates - i.e., all ventilation flow rates now more closely approach the design ventilation flow rates of $100 \mathrm{~m}^{3} / \mathrm{h}$ for winter conditions and $200 \mathrm{~m}^{3} / \mathrm{h}$ for summer conditions. As expected the impact of the increased stack free area was slight, but beneficial, for the winter operation and conditions but significant for the summer - importantly, the problematic flow reversal at the upper floor leeward office has been mitigated. The computed results show higher ventilation flow rates for the windward (i.e., due to higher wind pressures) and lower offices (i.e., due to greater buoyancy pressures) as is to be expected. Curiously, the winter measured data does not reveal these effects even though these trends are more pronounced in the measured summer data than in the computed. 
Table 4.5 Comparison of computed and measured ventilation rates for an increased stack terminal free area of $1.0 \mathrm{~m}^{2}$ for the simplified single-zone model of the Tax Office.

\begin{tabular}{|c|c|c|c|c|c|c|c|c|}
\hline \multirow[b]{3}{*}{ Level } & \multicolumn{4}{|c|}{$\begin{array}{c}\text { Winter Conditions } \\
\left(T_{\text {ow }}=10.5^{\circ} \mathrm{C} ; V_{H}=2.5 \mathrm{~m} / \mathrm{s} ; \phi=\mathrm{N} ; T_{i n}=20.5^{\circ} \mathrm{C}\right)\end{array}$} & \multicolumn{4}{|c|}{$\begin{array}{c}\text { Summer Conditions } \\
\left(T_{\text {out }}=16^{\circ} \mathrm{C} ; V_{H}=3.5 \mathrm{~m} / \mathrm{s} ; \phi=\mathrm{SW} ; T_{\text {in }}=22^{\circ} \mathrm{C}\right)\end{array}$} \\
\hline & \multicolumn{2}{|c|}{$\begin{array}{c}\text { Computed } Q\left(\mathrm{~m}^{3} / \mathrm{h}\right) \\
\{\Delta P(\mathrm{~Pa})\}\end{array}$} & \multicolumn{2}{|c|}{ Measured $^{\mathrm{a}} Q\left(\mathrm{~m}^{3} / \mathrm{h}\right)$} & \multicolumn{2}{|c|}{$\begin{array}{c}\text { Computed } Q\left(\mathrm{~m}^{3} / \mathrm{h}\right) \\
\{\Delta P(\mathrm{~Pa})\}\end{array}$} & \multicolumn{2}{|c|}{ Measured $^{\mathrm{a}} Q\left(\mathrm{~m}^{3} / \mathrm{h}\right)$} \\
\hline & North & South & North & South & North & South & North & South \\
\hline Stack & \multicolumn{2}{|c|}{$\begin{array}{c}977 \\
\{0.12\}\end{array}$} & \multicolumn{2}{|c|}{--} & \multicolumn{2}{|c|}{$\begin{array}{c}1863 \\
\{0.45\}\end{array}$} & \multicolumn{2}{|c|}{--- } \\
\hline 5 & $\begin{array}{c}96 \\
\{5.69\}\end{array}$ & $\begin{array}{c}91 \\
\{3.31\}\end{array}$ & 97 & 110 & $\begin{array}{c}172 \\
\{2.34\}\end{array}$ & $\begin{array}{c}187 \\
\{5.32\}\end{array}$ & 93 & 146 \\
\hline 4 & $\begin{array}{c}98 \\
\{7.14\}\end{array}$ & $\begin{array}{c}94 \\
44.73\}\end{array}$ & -- & -- & $\begin{array}{c}178 \\
\{3.25\}\end{array}$ & $\begin{array}{c}190 \\
\{6.24\}\end{array}$ & -- & -- \\
\hline 3 & $\begin{array}{c}99 \\
\{8.23\}\end{array}$ & $\begin{array}{c}97 \\
\{6.16\}\end{array}$ & 96 & 90 & $\begin{array}{c}182 \\
44.13\}\end{array}$ & $\begin{array}{c}190 \\
\{6.72\}\end{array}$ & 101 & 192 \\
\hline 2 & $\begin{array}{c}101 \\
\{9.25\}\end{array}$ & $\begin{array}{c}99 \\
\{7.67\}\end{array}$ & - & -- & $\begin{array}{c}186 \\
\{5.17\}\end{array}$ & $\begin{array}{c}192 \\
\{7.12\}\end{array}$ & - & -- \\
\hline 1 & $\begin{array}{c}102 \\
\{10.65\}\end{array}$ & $\begin{array}{c}100 \\
\{9.10\}\end{array}$ & $126^{6}$ & $160^{6}$ & $\begin{array}{c}189 \\
\{6.00\}\end{array}$ & $\begin{array}{c}195 \\
\{8.29\}\end{array}$ & 133 & 209 \\
\hline
\end{tabular}

Measured data reported in by the European NatVent(B) Project [11].

b The unexpectedly high ventilation rates measured at the $1^{\text {st }}$ level were attributed to "excessive air leakage" [11].

This single adjustment to the stack terminal area appeared to be sufficient to calibrate the simplified single-zone model to achieve computed results that well-approximated measured results within the inherent uncertainty of airflow modeling. All subsequent analyses were then based on the simplified single-zone model with a stack terminal free area of $1.0 \mathrm{~m}^{2}$ and all other parameters as established above.

March 1997 \& June 1997 Results: Detailed Multi-Zone Building Model

Computed ventilation rates based on the detailed multi-zone model for the Winter (March,1997) and Summer (June, 1997) calibration data sets are compared to measured results below. In contrast to the results reported above for the simplified single-zone model, however, ventilation flow rates into each office are now the sum of contributions from the self-regulating inlet vent and leakage through the windows and walls. Data are presented for both assumed tight envelope construction, with leakage areas of $0.10 \mathrm{~cm}^{2} / \mathrm{m}^{2}$, and loose envelope construction, with leakage areas of $1.0 \mathrm{~cm}^{2} / \mathrm{m}^{2}$. 
Table 4.6 Comparison of computed and measured ventilation rates for the detailed multi-zone models of the Tax Office with assumed tight envelope construction with leakage areas of 1.0 $\mathrm{cm}^{2} / \mathrm{m}^{2}$. Results are presented separately for each ventilation contribution as: inlet vent + window + wall. (Additional results for loose envelope construction with leakage areas of 10.0 $\mathrm{cm}^{2} / \mathrm{m}^{2}$ are included in brackets.)

\begin{tabular}{|c|c|c|c|c|c|c|c|c|}
\hline \multirow{3}{*}{ Level } & \multicolumn{4}{|c|}{$\begin{array}{c}\text { Winter Conditions } \\
\left(T_{\text {out }}=10.5^{\circ} \mathrm{C} ; V_{H}=2.5 \mathrm{~m} / \mathrm{s} ; \phi=\mathrm{N} ; T_{\text {in }}=20.5^{\circ} \mathrm{C}\right)\end{array}$} & \multicolumn{4}{|c|}{$\begin{array}{c}\text { Summer Conditions } \\
\left(T_{\text {out }}=16^{\circ} \mathrm{C} ; V_{H}=3.5 \mathrm{~m} / \mathrm{s} ; \phi=\mathrm{SW} ; T_{m n}=22^{\circ} \mathrm{C}\right)\end{array}$} \\
\hline & \multicolumn{2}{|c|}{$\begin{array}{c}\text { Computed } Q\left(\mathrm{~m}^{3} / \mathrm{h}\right) \\
\text { \{values for loose envelope\} }\end{array}$} & \multicolumn{2}{|c|}{ Measured $^{\mathrm{a}} \overline{Q\left(\mathrm{~m}^{3} / \mathrm{h}\right)}$} & \multicolumn{2}{|c|}{$\begin{array}{c}\text { Computed } Q\left(\mathrm{~m}^{3} / \mathrm{h}\right) \\
\{\text { values for loose envelope }\end{array}$} & \multicolumn{2}{|c|}{$\begin{array}{c}\text { Measured } d^{\mathrm{a}} Q \\
\left(\mathrm{~m}^{3} / \mathrm{h}\right)\end{array}$} \\
\hline & North & South & North & South & North & South & North & South \\
\hline Stack & \multicolumn{2}{|c|}{$\begin{array}{c}1100 \\
\{2151\}\end{array}$} & \multicolumn{2}{|c|}{--} & \multicolumn{2}{|c|}{$\begin{array}{c}1778 \\
\{2156\}\end{array}$} & \multicolumn{2}{|c|}{--} \\
\hline 5 & $\begin{array}{c}95+5+6 \\
\{94+47+57\}\end{array}$ & $\begin{array}{c}87+3+4 \\
\{83+21+25\}\end{array}$ & 97 & 110 & $\begin{array}{c}143+1+1 \\
\{133+5+7\}\end{array}$ & $\begin{array}{c}168+2+3 \\
\{165+18+22\}\end{array}$ & 93 & 146 \\
\hline 4 & $\begin{array}{c}97+6+7 \\
\{96+55+68\}\end{array}$ & $\begin{array}{c}91+4+5 \\
\{88+30+37\}\end{array}$ & -- & $-\cdots$ & $\begin{array}{c}162+2+2 \\
\{159+17+21\}\end{array}$ & $\begin{array}{c}174+3+4 \\
\{166+23+29\}\end{array}$ & $\overline{--}$ & $\cdots$ \\
\hline 3 & $\begin{array}{c}99+6+8 \\
\{98+62+75\}\end{array}$ & $\begin{array}{c}95+5+6 \\
\{91+38+47\}\end{array}$ & 96 & 90 & $\begin{array}{c}170+3+3 \\
\{168+26+31\}\end{array}$ & $\begin{array}{c}176+3+4 \\
\{169+26+32\}\end{array}$ & 101 & 192 \\
\hline 2 & $\begin{array}{c}100+7+9 \\
\{99+67+82\}\end{array}$ & $\begin{array}{c}97+6+7 \\
\{94+46+57\}\end{array}$ & $-\cdots$ & -- & $\begin{array}{c}177+4+4 \\
\{176+34+42\}\end{array}$ & $\begin{array}{c}178+4+5 \\
\{171+28+34\}\end{array}$ & $\cdots$ & $\cdots$ \\
\hline 1 & $\begin{array}{c}102+8+10 \\
\{101+75+91\}\end{array}$ & $\begin{array}{c}99+7+8 \\
\{96+53+65\}\end{array}$ & $126^{6}$ & $160^{6}$ & $\begin{array}{c}183+4+5 \\
\{181+42+51\}\end{array}$ & $\begin{array}{c}183+4+5 \\
\{176+34+42\}\end{array}$ & 133 & 209 \\
\hline
\end{tabular}

${ }^{a}$ Measured data reported in by the European NatVent ${ }^{8}$ Project [11].

${ }^{b}$ The unexpectedly high ventilation rates measured at the $1^{\text {st }}$ level were attributed to "excessive air leakage" [11].

Comparing these results with those presented earlier, multi-zone inlet vent airflow rates are seen to be very close but consistently smaller than those results obtained with the simplified singlezone model. The impact of the additional internal flow resistances is thus slight. This is as it should be if the natural ventilation system is designed properly - i.e., so that the self-regulating inlet vents offer the controlling resistances to airflow. The infiltration ventilation contribution through windows and walls while relatively small proved to be significant at 1 to $18 \%$, for tight construction (i.e., with effective leakage areas of $1.0 \mathrm{~cm}^{2} / \mathrm{m}^{2}$ ) and overwhelming at $9 \%$ to $164 \%$ for loose construction.

The lesson here is quite clear. One may not expect to realize effective natural ventilation control unless the envelope construction is relatively tight. The credo "build tight and ventilate right" applies equally well to effective mechanical and natural ventilation system design.

The comparison with measured results is again within any reasonable measure of expected uncertainty in prediction for the computed results and in measurement for the measured results. However, the ventilation flow rate for the tight construction assumption, on average, fell below the summer design objective $-178 \mathrm{~m}^{3} / \mathrm{h}$ instead of $200 \mathrm{~m}^{3} / \mathrm{h}$ for the summer condition. By increasing the maximum setting of the self-regulating inlet vent $25 \%$ for summer conditions the ventilation flow rate for the tight construction assumption increased, on average, to $214 \mathrm{~m}^{3} / \mathrm{h}$ with the upper floors under-ventilated by as much as $17 \%$ and the lower floors over-ventilated by 
as much as $18 \%$. Accepting these variations as practically inevitable, this increase for summer ventilation appeared to be sufficient to calibrate the multi-zone model to achieve the design objective of $200 \mathrm{~m}^{3} / \mathrm{h}$ per office. Therefore, a $25 \%$ increase in the effective opening area of the self-regulating vents for the maximum ventilation setting was applied in all subsequent analyses.

\section{August 1997 Results: Simplified Single-Zone Building Model}

The March and June 1997 calibration data were reported for relatively steady environmental conditions and could, therefore, be modeled using the standard versions of the CONTAM program - CONTAM96 or CONTAMW $[163,189]$ - that may be familiar to the reader. However, the August 1997 calibration data of measured indoor air temperature time histories were collected for transient environmental conditions that can not be directly modeled using the standard versions of CONTAM. Consequently, the research version of CONTAM CONTAM97R [214] - which models the coupled interactions between airflow and thermal exchanges, was employed. This version of CONTAM allows the user to add thermal components to a building idealization to augment the flow components available in the standard versions of CONTAM and, thus, define the coupled thermal/airflow system to be analyzed.

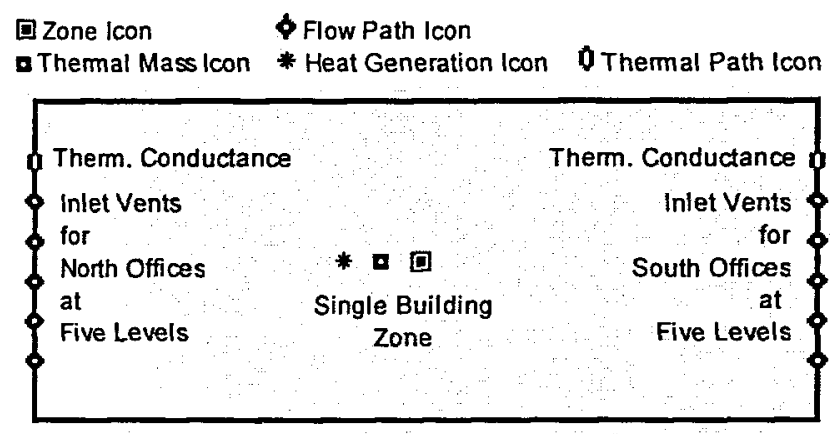

Figure 4.10 Simplified single-zone CONTAM97R model of the Enschede Tax Office used for modeling the transient coupled thermal/airflow response for a four-day August heat wave.

The simplified coupled thermal/airflow model generated within CONTAM97R used for this study is illustrated in Figure 4.10. In this case, the combined thermal conductance of walls, windows, roofs and floors of the building envelope was lumped in two thermal conductance components placed on the north and south walls respectively. Internal thermal mass and combined heat gains due to solar, occupants, lighting, and equipment were each modeled with single components placed within the single zone representation of the building. The flow components shown in this figure correspond to the self-regulating inlet vents for each of the five levels on the north and south side of the building, respectively. Two additional components, one for the stack airflow path and the other for the assist fan appear in the CONTAM sketchpad level above this level and, thus, are not shown.

Measured indoor air temperatures for the August 1997 four-day heat wave are compared to outdoor air temperatures in Figure 4.11. Internal gains in the offices of the Enschede Tax Office were estimated to be $27.5 \mathrm{~W} / \mathrm{m}^{2}$ during working hours for this period [11]. 


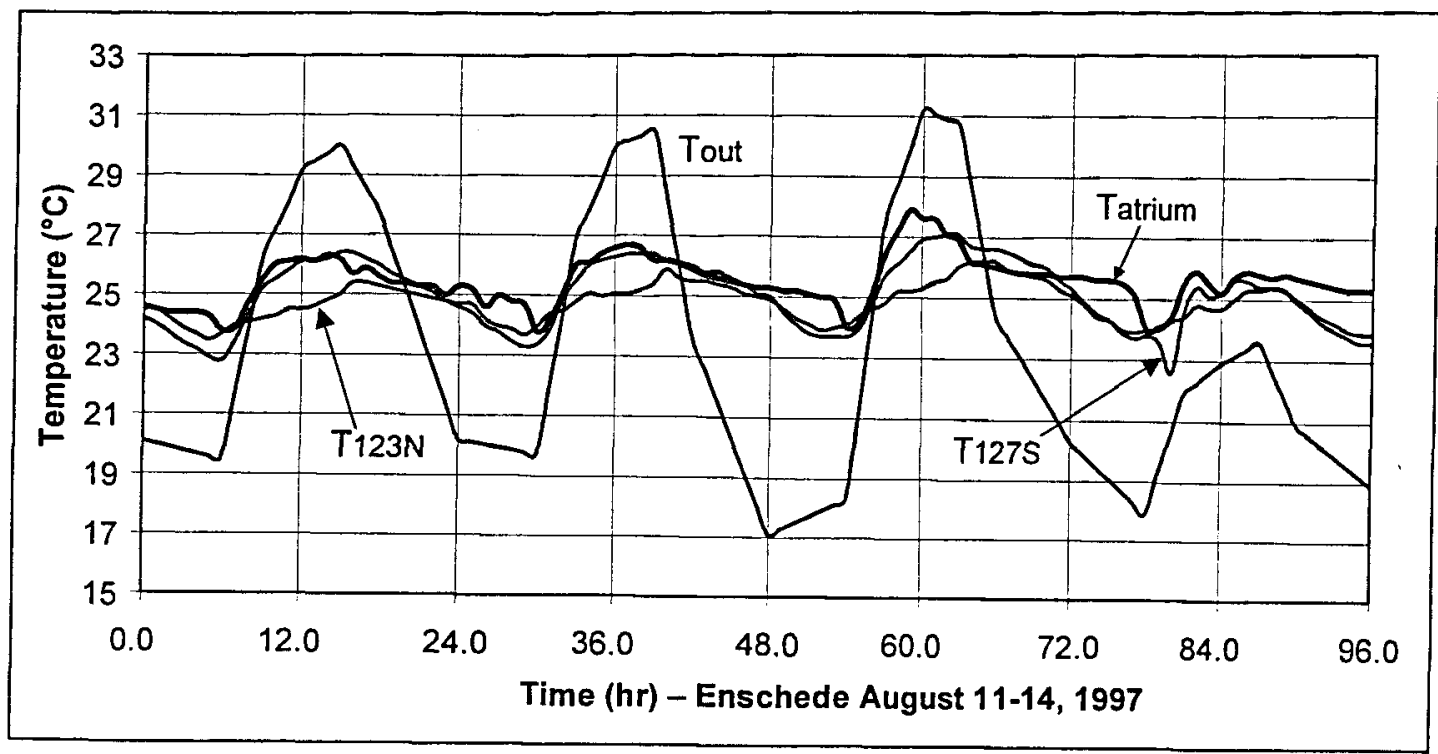

Figure 4.11 Measured indoor and outdoor temperatures for the August 1997 four-day heat wave (from [11]). Atrium temperatures, $\mathrm{T}_{\text {atrium, }}$, and first floor room temperatures on the north and

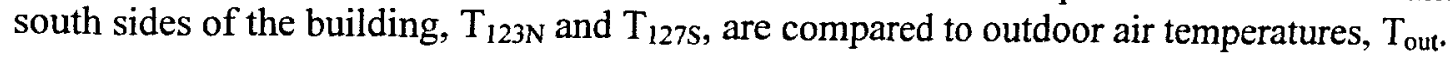

Computed results based on the simplified single-zone model of the Tax Office for a similar fourday outdoor air temperature record taken from the WYEC2 Boston weather data set MABOSTNT [44] are plotted in Figure 4.12. These results were computed for three assumed combined solar and internal gains in offices of $20.0 \mathrm{~W} / \mathrm{m}^{2}, 27.5 \mathrm{~W} / \mathrm{m}^{2}$ and $35.0 \mathrm{~W} / \mathrm{m}^{2}-$ a range covering typical gains that may be expected in optimally designed office buildings - and internal gains of $5 \mathrm{~W} / \mathrm{m}^{2}$ in corridors, utility rooms, and atrium corresponding to the minimal lighting needed in these areas.

In both the modeled response and measured response indoor air temperature swings are attenuated by the high thermal mass available although the measured attenuation is approximately $40 \%$ while that of the computed results is on the order of $50 \%$ suggesting thermal mass was slightly underestimated in the model. In both cases the impact of heat gains during office hours is revealed by the rapid rise in indoor air temperatures during these periods with, in the computed results, higher heat gains resulting in proportionately greater indoor air temperature increases. Conversely, the impact of night cooling is revealed by a subtle but evident decrease in slope of the temperature time histories that occurs as outdoor air temperatures fall below indoor values.

Peak indoor air temperatures in the computed results occur at the end of the workday (i.e., at $5: 00 \mathrm{pm}$ ) as internal gains drop to negligible values. Similar peaks are observed for the offices in the measured data but not for the atrium. Given the ventilation control strategy used - i.e., occupants were to set the inlet vents at their maximum setting at the end of the work day - night ventilation was initiated long before outdoor air temperatures fell below indoor air temperatures in both measured and computed results. Consequently, the full benefit of night ventilation may have been compromised. Finally, for these very similar outdoor air temperature records, indoor air temperatures climbed gradually over the four-day period, staying marginally within an extended comfort zone of $28{ }^{\circ} \mathrm{C}$. Yet on the fourth day, indoor temperatures climbed to exceed or equal outdoor air temperatures for the measured case and the high internal gain case - a 
problem that could conceivably be mitigated with a more optimal night cooling schedule, increased thermal mass, and/or better control of heat gains.

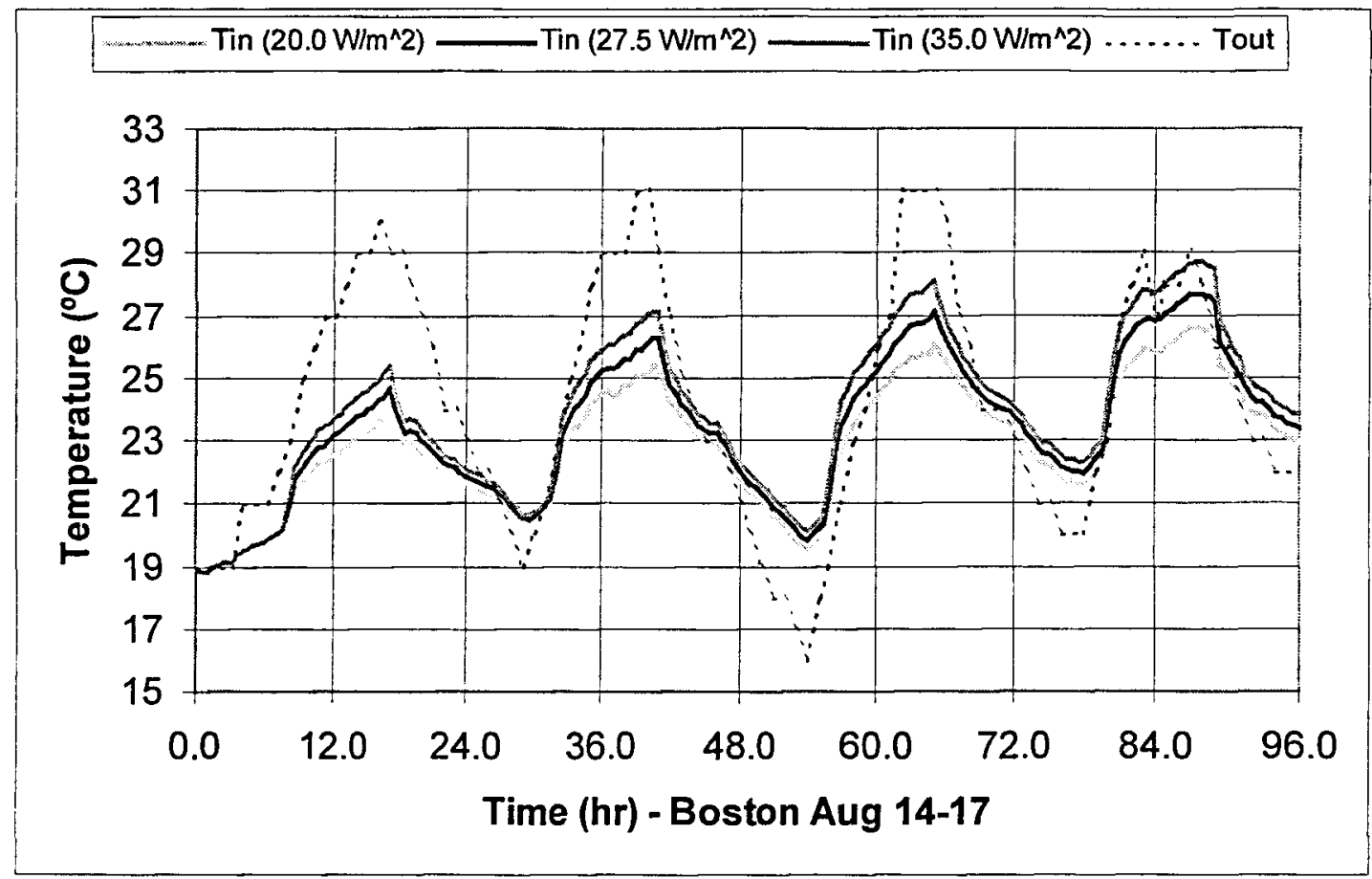

Figure 4.12 Computed indoor and outdoor temperatures using the single-zone model for a fourday heat wave taken from the WYEC2 Boston weather data set MABOSTNT [44] for office heat gains of $20.0 \mathrm{~W} / \mathrm{m}^{2}, 27.5 \mathrm{~W} / \mathrm{m}^{2}$ and $35.0 \mathrm{~W} / \mathrm{m}^{2}$.

Overall, the modeled and measured results appear to be very similar. The model allows, however, more detailed analysis of system behavior. Figure 4.13 compares wind speeds to the natural ventilation airflow rate passing through the atrium stack, expressed in terms of office air volumes exchanged per hour ACHoff. Somewhat surprisingly, effective control of night ventilation rates is achieved only on the third and fourth days of the heat wave, although at approximately $3.5 \mathrm{ACHoff}$ this control falls below the 4 ACHoff control objective. Night ventilation control for the first and second days and daytime ventilation control for all but the fourth day appears to be poor, although the daytime control objective of $2 \mathrm{ACHoff}$ is erratically reached on the second, third, and fourth days. Indeed, stack airflow reverses several times during the four-day period flowing down the stack into the building. Comparing this plot to the plot of indoor and outdoor temperatures presented in Figure 4.12 it is seen that periods of poor control correspond to periods when outdoor air temperatures exceed indoor and better control is achieved when indoor air temperatures exceed outdoor values.

Apparently, when stack pressures oppose wind-driven pressures poor flow control, and reverse flow at times, is observed. This is to be expected if the net driving pressure falls below the minimal pressure difference needed by the self-regulating inlet vents to maintain effective control (i.e., approximately $3 \mathrm{~Pa}$ for the self-regulating vent model used, see Figure 4.5) or indeed becomes negative. 


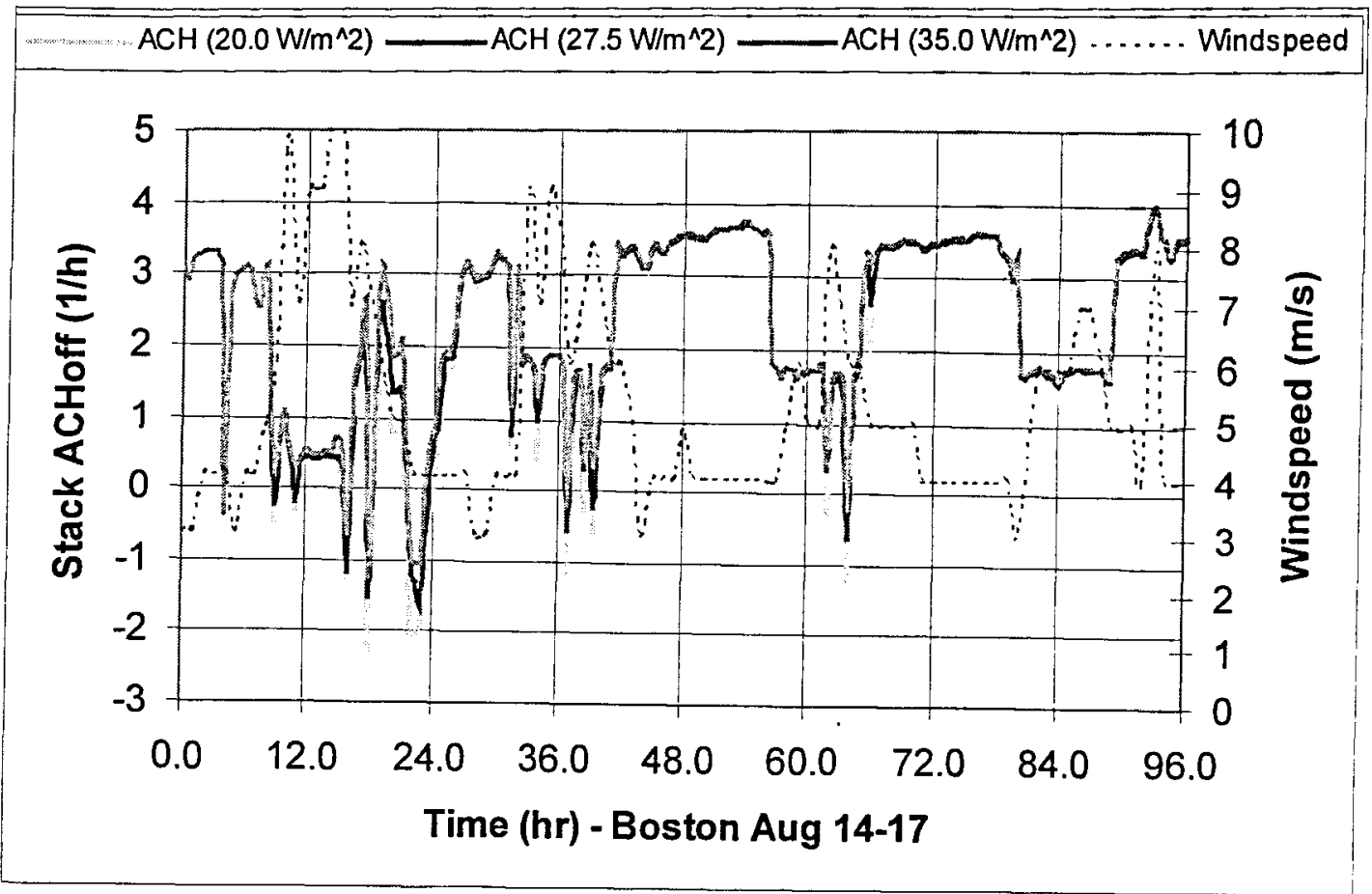

Figure 4.13 Computed stack airflow rates, expressed in terms of office air volumes exchanged per hour (ACHoff), using the single-zone model for a four-day heat wave taken from the WYEC2 Boston weather data set MABOSTNT [44] for office heat gains of $20.0 \mathrm{~W} / \mathrm{m}^{2}, 27.5$ $\mathrm{W} / \mathrm{m}^{2}$ and $35.0 \mathrm{~W} / \mathrm{m}^{2}$.

To investigate this problematic flow behavior further, natural ventilation air flow rates for the first, third and fifth level offices on the north side of the building are plotted in Figure 4.14. On close examination, it may be seen that during the problematic first and second days of the heat wave air flows, at times, into the lower offices and out of the upper fifth floor office, at times, out of all offices, and, at other times, into the fifth floor office and out of the lower offices as the subtle balances between stack and wind-driven pressure differences shift. Thus, the erratic behavior is seen to be more complex than suggested by the stack flow behavior alone yet in all cases buoyancy pressures acting in opposition to wind pressure differences is at play.

The erratic ventilation behavior observed during this four-day heat wave represents a general problem that needs to be addressed if night cooling of thermal mass is to become a successful method. Assist fans may well serve to mitigate this problem, without incurring a significant additional energy expense; if they can be activated when net driving pressures become inadequate. As the net driving pressures result from the combination of stack and wind-driven pressures, inadequacy may result from:

- small driving pressures: combinations of low wind conditions and small positive insideto-outside temperature differences or

- opposing driving pressures: combinations of moderate to low wind conditions and negative inside-to-outside temperature differences. 
Assist fans were installed in the Enschede Tax Office but they were controlled to be activated only when wind speeds fell below $2 \mathrm{~m} / \mathrm{s}$ - a condition that was never realized for the Boston weather record used in these modeling studies. In effect, these fans were controlled for the first possibility above while they should have ideally been controlled for both possibilities.

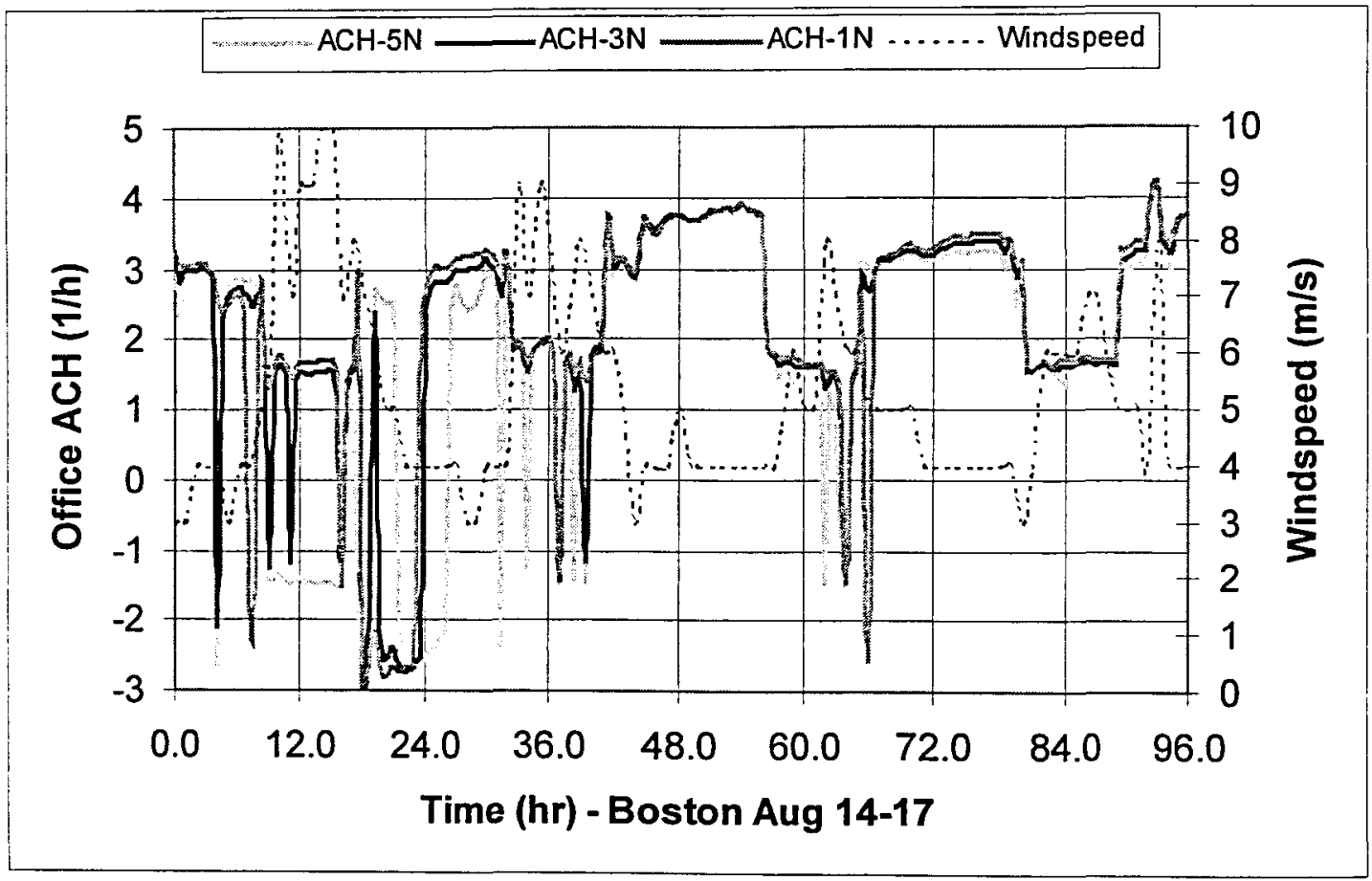

Figure 4.14 Computed office airflow exchange rates for offices on the first, third, and fifth levels, north side of the modeled Tax Office using the single-zone model for a four-day heat wave taken from the WYEC2 Boston weather data set MABOSTNT [44] for office heat gains of $27.5 \mathrm{~W} / \mathrm{m}^{2}$.

This erratic flow behavior also proved to lead to convergence problems in computational analysis. Quite reasonably, quasi-stable physical flow conditions lead to quasi-stable numerical solutions. Consequently, the accuracy of computed flows during such erratic behavior should be held suspect. The multi-zone model of the Tax Office by adding additional flow resistances within the building will further shift the subtle pressure differences that drive flows under these minimal driving pressure conditions and thus may well produce results different from those obtained with the single-zone model. In either case, the analyst must be alert to erratic behavior and, when observed numerically, treat analytical results with cautious suspicion.

As a final exercise in this particular calibration study three additional analyses were completed:

1. $150 \%$ Thermal Mass: The thermal mass included in the single-zone model was increased $50 \%$ and the indoor air temperature response was recomputed for the nominal heat gain in the offices of $27.5 \mathrm{~W} / \mathrm{m}^{2}$. 
2. $150 \%$ Thermal Mass + New Night Vent Schedule: In addition to the increase in thermal mass the night ventilation scheduled was modified so that the higher ventilation setting would be set two hours after the end of the work day instead of at the end of the work day and again the response was computed for $27.5 \mathrm{~W} / \mathrm{m}^{2}$.

3. 150\% Thermal Mass + New Night Vent Schedule + Assist Fan: In addition to increased thermal mass and a revised ventilation schedule an assist fan was operated during the night ventilation period to better maintain ventilation close to the $4.0 \mathrm{ACHoff}$ objective.

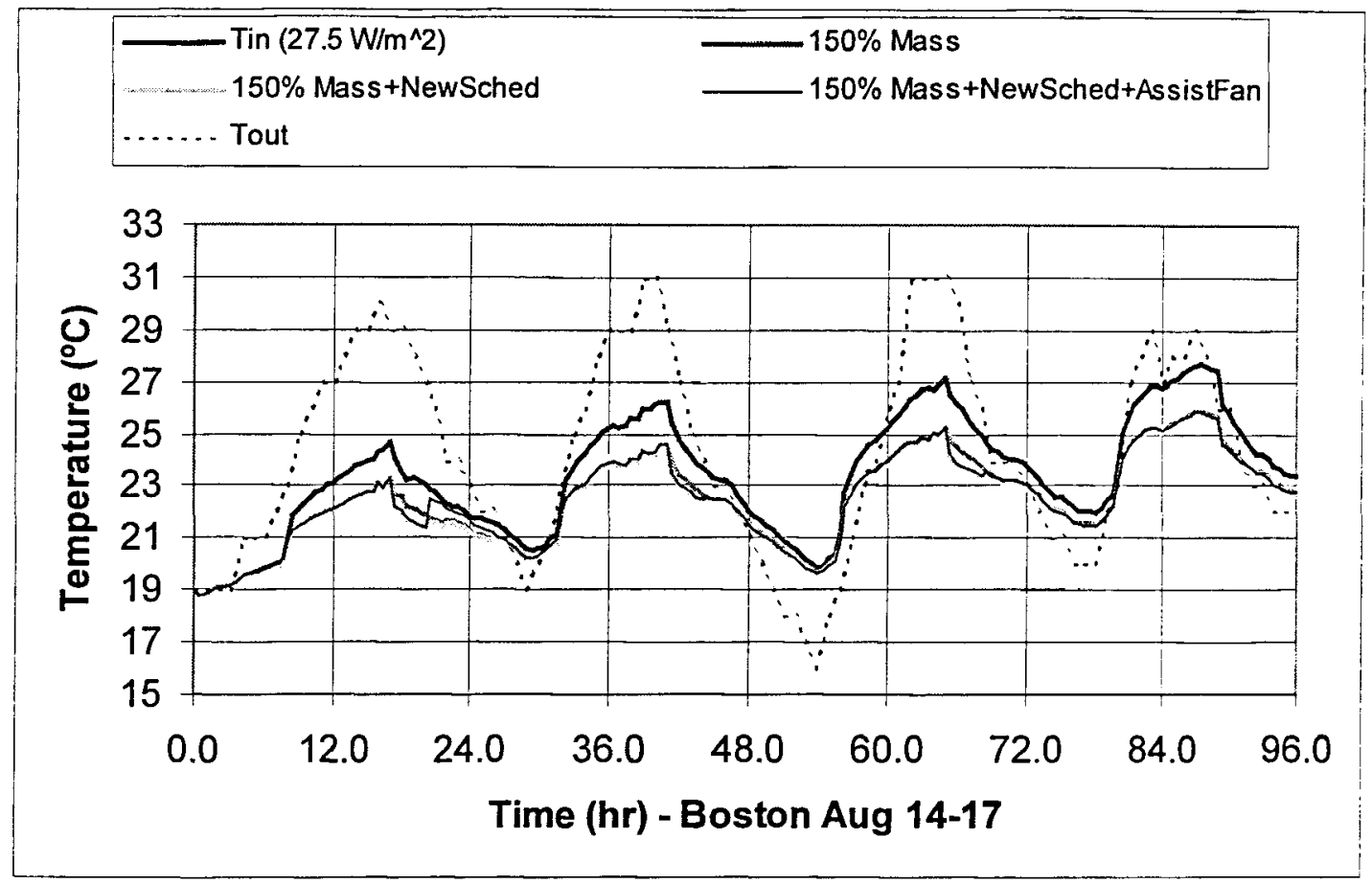

Figure 4.15 Computed indoor and outdoor temperatures for a four-day heat wave taken from the WYEC2 Boston weather data set MABOSTNT [44] using the single-zone model for office heat gains of $27.5 \mathrm{~W} / \mathrm{m}^{2}$ for the original and three additional system strategies.

The results of these additional analyses are presented in Figure 4.15. In this particular case, the impact of additional thermal mass is greatest and significant. Indeed, the $50 \%$ increase in thermal mass appears to create a response that better simulates the attenuation observed in reality (i.e., in Figure 4.11). Consequently, this increased thermal mass will be employed in all additional studies. Practically, a 50\% increase in thermal mass may be realized by either increased surface area provided by, for example, cored slabs or waffle slabs or by thermally more effective surface materials such as masonry tiles.

The improved night ventilation schedule provided some slight benefit but the difference was not significant. The assist fans produced essentially the same response that was achieved with natural ventilation alone although during the first day the assist fans actually compromised the response. The assist fans were operating on the same schedule as the inlet vents, consequently they acted to increase indoor air temperatures during a period when outdoor air temperatures exceeded indoor air temperatures. We may conclude, for this case, that a) the response of the thermal mass was rapid enough that premature night ventilation had little effect on the 
performance of the system, and b) the natural ventilation system alone provided ventilation rates sufficiently close to the design ventilation rates to achieve the cooling objective without the need of assist fans. (A fourth study investigated the impact of using an assist fan to drive the ventilation rate at $8 \mathrm{ACHoff}$ rather than $4 \mathrm{ACHoff}$, but again the impact on daytime temperatures was marginal.)

\section{August 1997 Results: Detailed Multi-Zone Building Model}

As noted above, the research version of CONTAM, CONTAM97R, was required to simulate the interactions between airflow and thermal exchanges that governed the response of the building to the four-day August heat wave. A representative floor of the detailed multi-zone coupled thermal/airflow model generated within CONTAM97R used for this study is illustrated in Figure 4.16. In this case:

- separate zones were modeled for each room, corridor, hall, and the six levels of the atrium - a total of 31 separate zone,

- airflow components for self-regulating vents; wall, window and door leakages; open hall doors and atrium shaft resistances modeled the discrete physical flow paths between zones and between zones and the outdoor environment,

- duct components modeled transfer airflow paths between offices and the atrium, and

- thermal conductance, mass, and heat generation components modeled the distribution of these thermal processes as they actually occurred in the building.

$\begin{array}{lll}\text { 口Zne Icon } & \text { \$ Flow Path Icon } & \text { Duct Inlet/Outlet Icon } \\ \text { a Thermal Mass Icon } & \text { * Heat Generation Icon } & \mathbf{0} \text { Thermal Path Icon }\end{array}$

Transfer Grill

Transfer Duct

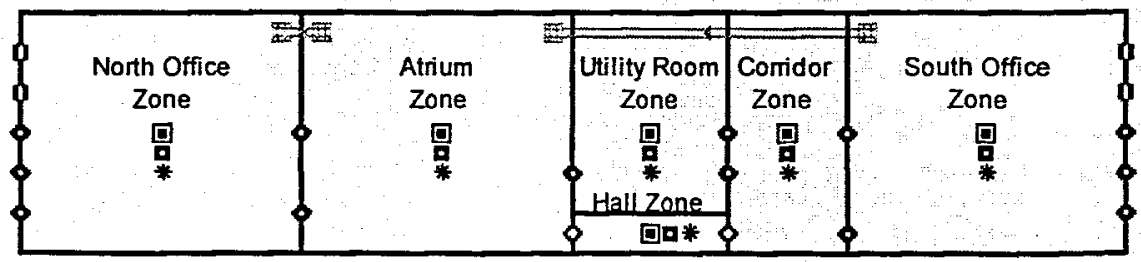

Figure 4.16 Representative floor of the detailed multi-zone CONTAM97R model of the Enschede Tax Office used for modeling the transient coupled thermal/airflow response for a four-day August heat wave.

Computed temperature results based on this detailed multi-zone model of the Tax Office for the WYEC2 Boston weather data set MABOSTNT are compared to the results obtained using the simplified single-zone model in Figures 4.17 and 4.18. These results were computed for assumed combined solar and internal gains in offices of $27.5 \mathrm{~W} / \mathrm{m}^{2}$, internal gains of $5 \mathrm{~W} / \mathrm{m}^{2}$ in corridors, utility rooms, and atrium corresponding to the minimal lighting needed in these areas, and the $50 \%$ increase in thermal mass established as a calibration correction above. The atrium temperature response at three different levels, Figure 4.17, are practically identical to each other and the results obtained with the simplified single-zone model. The relatively small upward perturbations from the average response illustrated in the upper level of the atrium, $T_{\text {mzsat }}$, result from short-term reverse stack flows that will be considered below. 


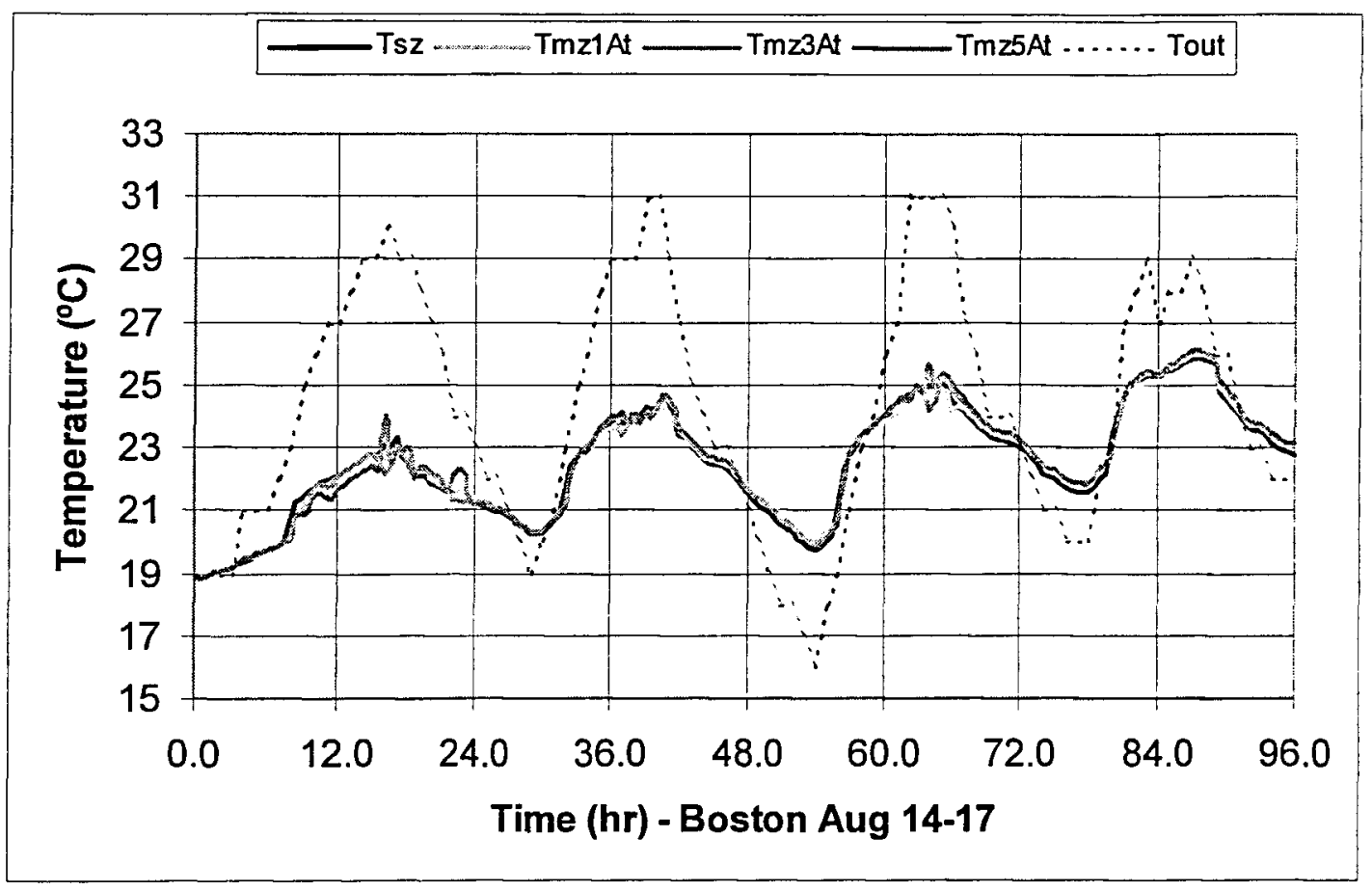

Figure 4.17 Computed atrium and outdoor temperatures for a four-day heat wave taken from the WYEC2 Boston weather data set MABOSTNT [44] using the multi-zone model for office heat gains of $27.5 \mathrm{~W} / \mathrm{m}^{2}$. (Single-zone temperature: $\mathrm{T}_{\mathrm{sz}}$, multi-zone level 1 atrium temperature: $\mathrm{T}_{\mathrm{mzlAt}}$; multi-zone level 3 atrium temperature: $\mathrm{T}_{\mathrm{mz} 3 \mathrm{At}}$; and multi-zone level 5 atrium temperature: $T_{\text {mz5At }}$ )

In contrast, the office temperature response at three different levels, Figure 4.18, are similar to each other but are generally greater than the simplified single-zone model temperature response. This is a direct result of the fact that heat gains in the office zones were modeled (realistically) at $27.5 \mathrm{~W} / \mathrm{m}^{2}$ and in other zones of the building at $5 \mathrm{~W} / \mathrm{m}^{2}$ in the detailed multi-zone model while an area-weighted average was used in the simplified single-zone model. This is, of course, the advantage of the multi-zone model - it provides details of system response that cannot be provided by the simplified single-zone model. Again, the perturbations seen and the few instances where computed office temperatures are similar to that predicted by the single-zone model are related to reverse-flow episodes.

On the whole, then, the computed multi-zone temperature time histories not only compare favorably to the measured response for the similar heat wave event in Enschede, Figure 4.11, and the single-zone response, their variation from these response time histories is physically consistent. That is to say, these results suggest that the multi-zone model may well predict the response details needed to comprehensively evaluate the performance of a proposed natural ventilation system in relatively complex office buildings. 


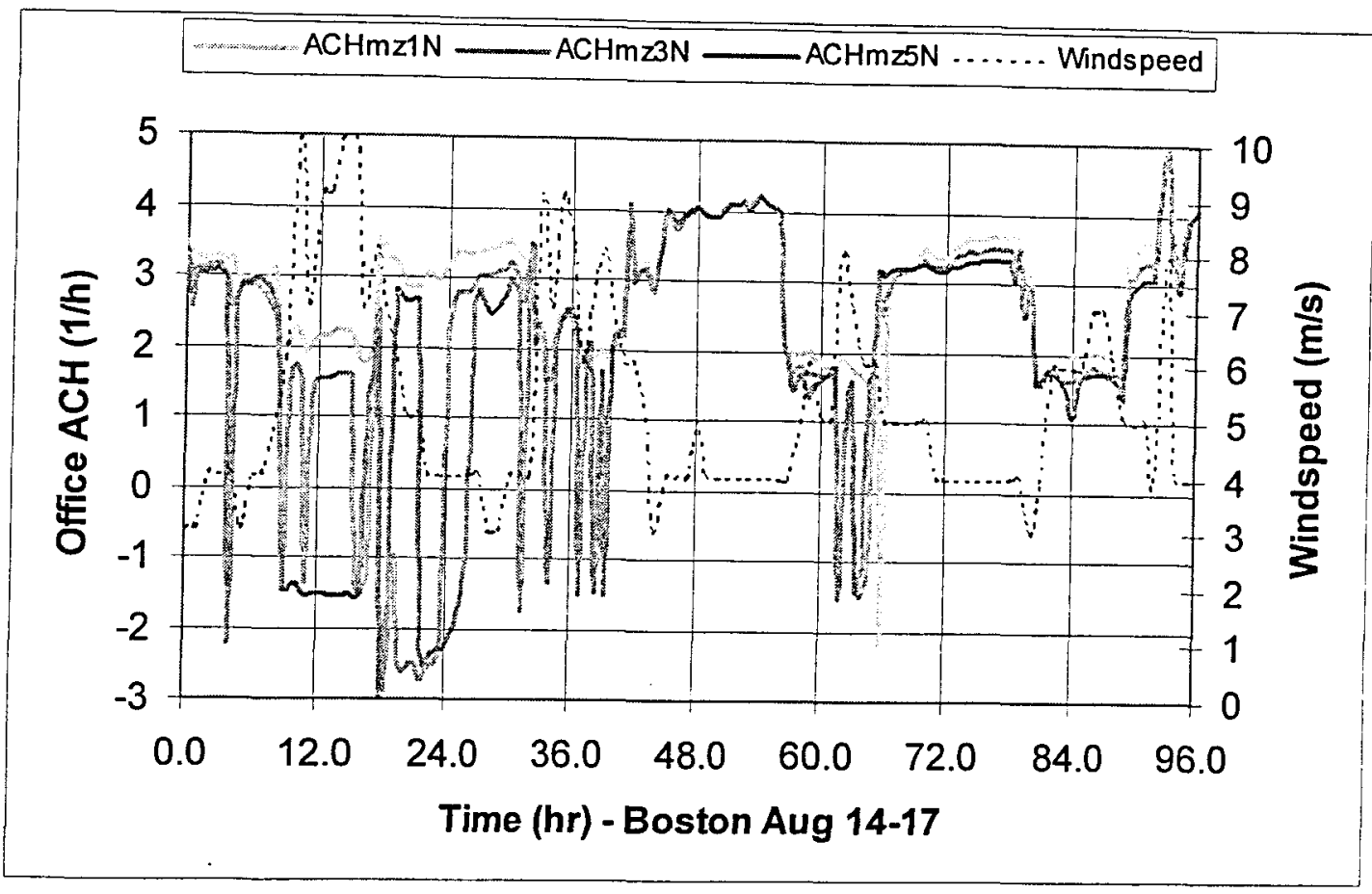

Figure 4.19 Computed office air change rates for a four-day heat wave taken from the WYEC2 Boston weather data set MABOSTNT [44] using the multi-zone model for office heat gains of $27.5 \mathrm{~W} / \mathrm{m}^{2}$. (Multi-zone level 1 north office: $\mathrm{ACH}_{\mathrm{mzlN}}$; multi-zone level 3 north office: $\mathrm{ACH}_{\mathrm{mz} 3 \mathrm{~N}}$; and multi-zone level 5 north office: $\mathrm{ACH}_{\mathrm{mzSN}}$ )

As noted above, there was a clear association between opposing stack and wind pressures (that naturally lead to physical instabilities in the flow) with these numerical problems. Thus, the distinct reverse-flow perturbations shown in Figure 4.19 most often correspond to the very times when numerical convergence was not achieved. The accuracy of these perturbations must be therefore considered suspect.

A more general comment about convergence is in order. CONTAM97R does not analyze the complete dynamic coupled thermal/airflow problem. Instead, it analyses what may be called a semi-dynamic problem wherein thermal response is modeled dynamically (i.e., as an initial value problem defined by a system of ordinary differential equations) but the airflow response is not. For each iteration within each time step the airflow problem is defined as a steady problem defined in terms of a system of algebraic equations rather than a dynamic problem that accounts for flow inertia and mass accumulation. Convergence within a time step simply assures the flow solution and thermal solution are physically consistent. Violation of convergence at any time step places the flow solution into question but may not have a lasting impact on the thermal solution since subsequent building thermal system response is not, typically, sensitive to current conditions. Consequently, isolated or limited convergence failures may be expected to be significant only at that time and soon thereafter.

Nevertheless, convergence failures cannot be accepted for the longer-period U.S. climate studies yet to be considered simply because general conclusions about the efficacy of natural ventilation 
demand reliable hourly data for the entire period. Consequently, an alternative multi-zone model was developed that proved more reliable.

\section{Summary of Calibration Modifications}

A multi-zone model that proved to be less sensitive to convergence problems was developed by combining the interior zones of the atrium, utility room, corridor, and hall of the model discussed above (see Figure 4.16), for all levels, into a single combined zone, Figure 4.20. This created a model of sufficient detail to capture individual office response time histories yet one where the number of flow components was greatly reduced in number. Importantly, from a numerical point of view, the remaining flow components did not vary as widely in the resistances they offered to flow as the components' of the more detailed model did.

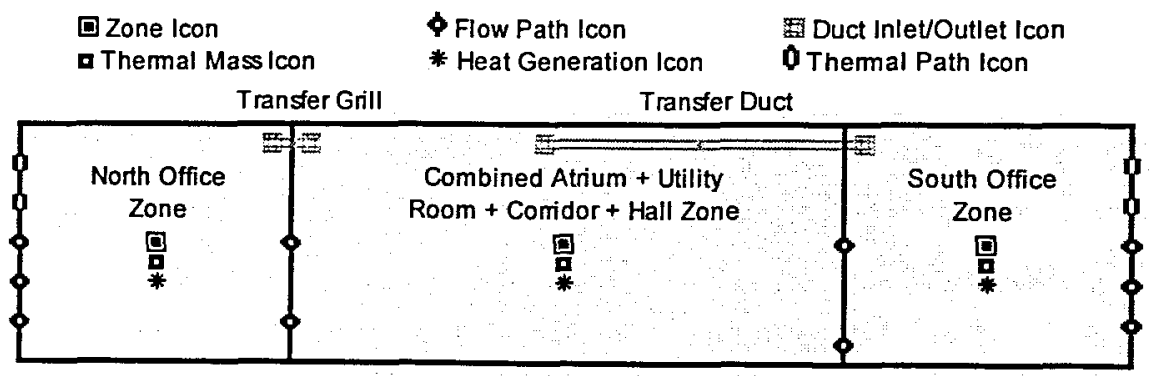

Figure 4.20 Representative floor of the simplified multi-zone CONTAM97R model of the Enschede Tax Office with a combined central zone that proved to be less sensitive to convergence problems.

When applied to the task of computing the four-day August heat wave calibration response, this multi-zone model produced office temperature and airflow time histories very similar to those reported above, Figures 4.16 and 4.17 with only three convergence violations in 576 simulation time steps. The single combined internal zone temperature time history and those of the offices bracketed the single-zone response results, as one would expect, as shown in Figure 4.21.

This simplified multi-zone model will be used for all subsequent modeling studies. In addition to its simplified topology, it includes the calibration modifications identified as part of the calibration exercises discussed above - specifically:

- the stack terminal device opening was set to $1 \mathrm{~m}^{2}$,

- the self-regulating inlet vents were set to provide a maximum setting equal to 2.5 times the minimum setting to realize approximately $2 \mathrm{ACH}$ at the lower setting and $4 \mathrm{ACH}$ at the higher setting, and

- thermal mass was modeled using $150 \mathrm{~mm}$ concrete construction with an exposed surface area equal to the $150 \%$ of the nominal combined surface area of ceilings and floors. 


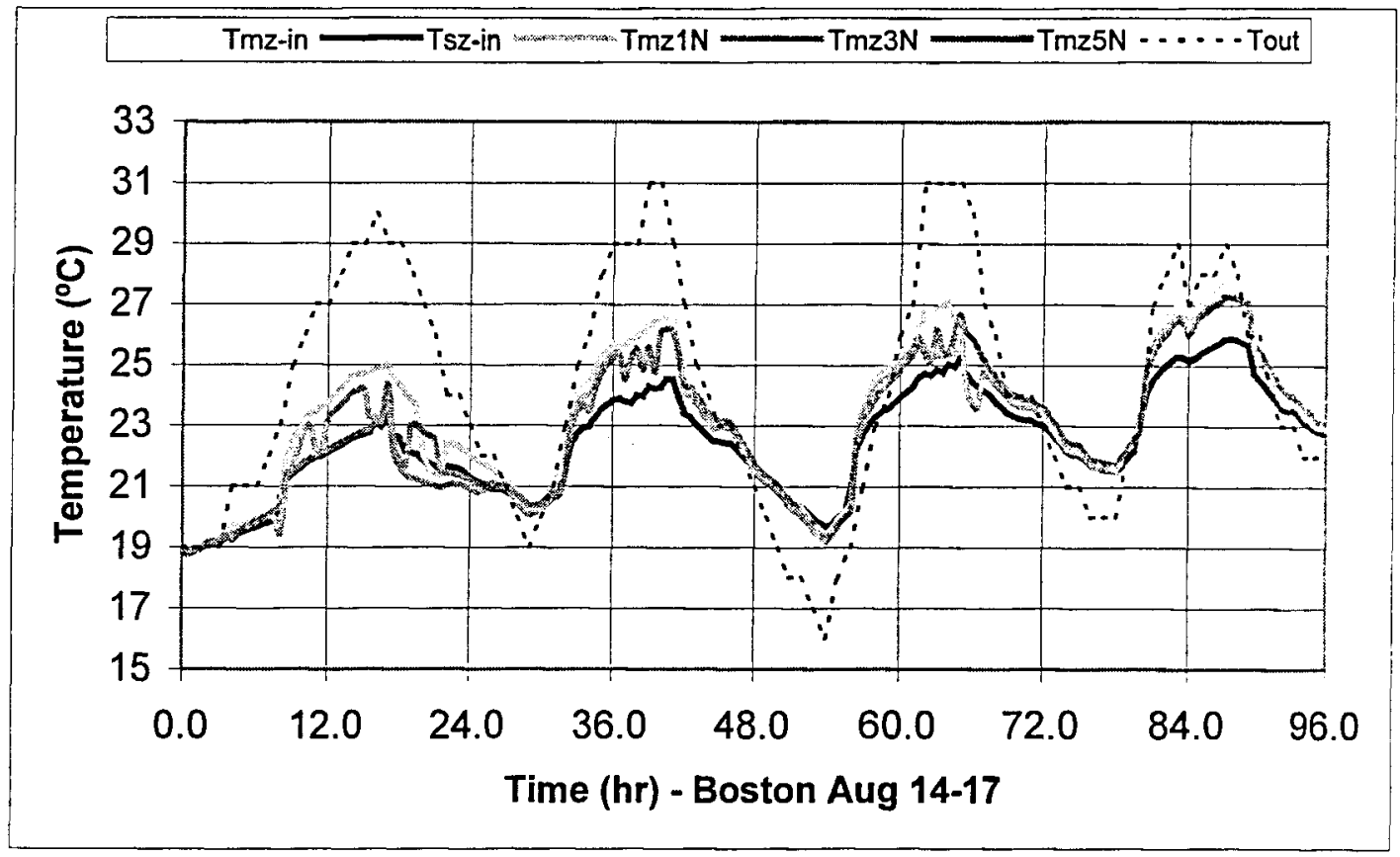

Figure 4.21 Computed office and combined internal zone temperature responses for a four-day heat wave taken from the WYEC2 Boston weather data set MABOSTNT [44] using the simplified multi-zone model for office heat gains of $27.5 \mathrm{~W} / \mathrm{m}^{2}$. (Single-zone interior temperature: $\mathrm{T}_{\mathrm{sz}-\mathrm{in}}$, multi-zone internal zone temperature: $\mathrm{T}_{\mathrm{mz}-\mathrm{in}}$; multi-zone level 1 north office temperature: $T_{m z I N}$; multi-zone level 3 north office temperature: $T_{m z 3 N}$; and multi-zone level 5 north office temperature: $T_{m z 5 N}$ )

\section{Night Cooling Design Development Study Results}

To explore the application of detailed performance evaluation to the design development of natural ventilation systems, the detailed multizone model of the Enschede Tax Office was configured to operate in a night cooling mode and subjected to the three-month (i.e., June 1 to August 31) weather records for Los Angeles and Fresno California discussed above. Ideally, outdoor air inlet vents should have been controlled to simulate the actual occupant control strategy used in the Enschede Tax Office but this proved difficult to model given CONTAM97R's current limitations. Consequently, the inlet vent operation for all offices was controlled to a fixed schedule to be set at the minimum airflow rate (i.e., $100 \mathrm{~m}^{3} / \mathrm{h}$ per office) during office hours and the maximum design airflow rate (i.e., $200 \mathrm{~m}^{3} / \mathrm{h}$ per office) after office hours and through the night. For the particularly hot Fresno weather record this control strategy is reasonable - for the Los Angeles record, on the other hand, daytime ventilation rates often could have been higher to make more optimal use of direct ventilative cooling.

\section{Design Development of the Night Cooling System for Los Angeles, California}

The Enschede Tax Office performed well as-designed in the Los Angeles, CA climate. Figure 4.22 shows the dynamic response results for the slot atrium temperature (i.e., modeled as a single well-mixed zone in the detailed multizone model of the building). Even for the relatively high combined solar and internal gain rate of $30 \mathrm{~W} / \mathrm{m}^{2}$ atrium temperatures seldom exceeded $25^{\circ} \mathrm{C}$. 
Consequently, the evaluation of the overheating degree hours (ODH) performance criteria, defined by Equation 3.3, for all assumed combined gain rates (i.e., $20 \mathrm{~W} / \mathrm{m}^{2}, 27.5 \mathrm{~W} / \mathrm{m}^{2}$ and 30 $\mathrm{W} / \mathrm{m}^{2}$ ) yielded zero results. Thus, in this case, the building as-designed would be considered a success and further design development performance evaluation would not be needed.

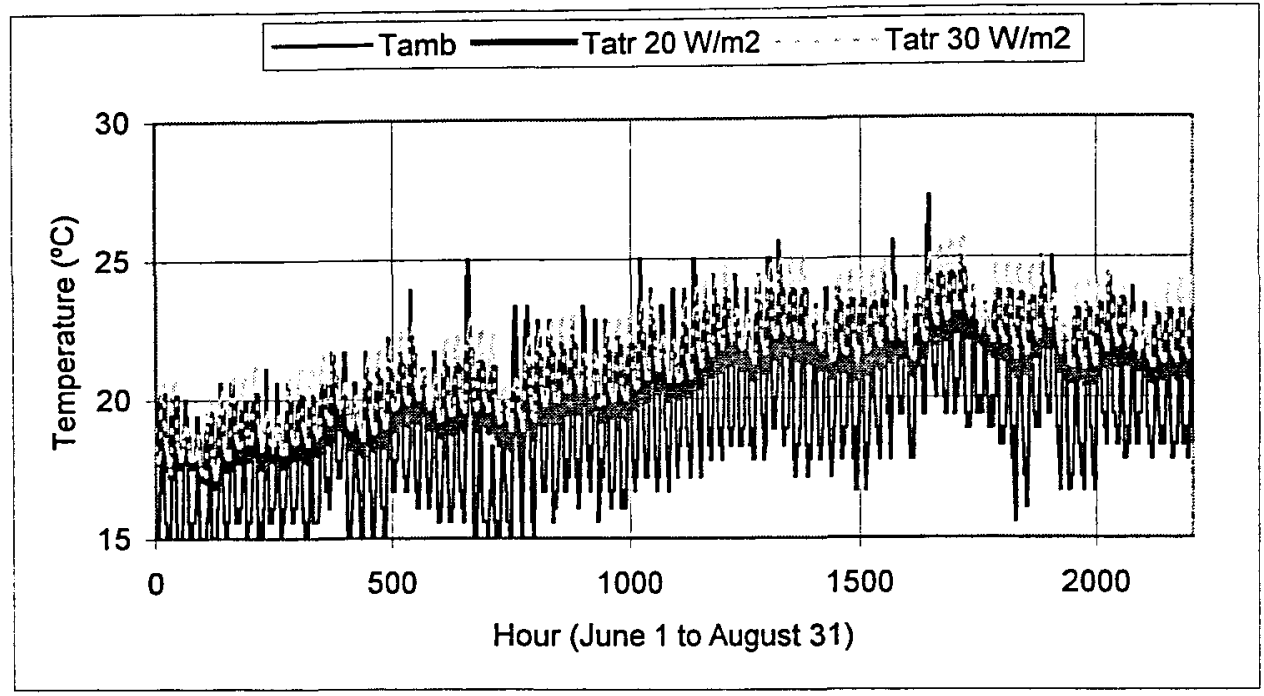

Figure 4.22 Atrium temperature response for the Enschede Tax Office building to Los Angeles' summer conditions operated in a natural night cooling mode. Results plotted for two assumed combined solar and internal gains $-20 \mathrm{~W} / \mathrm{m}^{2}$ and $30 \mathrm{~W} / \mathrm{m}^{2}$ - compared to ambient conditions.

Nevertheless, it is instructive to look at the details of the system response to better appreciate the behavior of the building as a system. Figure 4.23 isolates the stack airflow rate response for the hottest period of this record and Figure 4.24 shows the corresponding atrium temperature responses. The natural ventilation system with the self-regulating inlet vents is seen to provide reasonably good control of ventilation rates as desired (i.e., ten offices at $200 \mathrm{~m}^{3} / \mathrm{h}$ per office in night-cool mode and $100 \mathrm{~m}^{3} / \mathrm{h}$ per office in direct-cool mode during occupancy), although there is some variation about these objective ventilation rates. A couple of reverse-flow events are observed when indoor air temperatures fall below outdoor air temperatures that appear to have had a relatively minor impact on system response. 


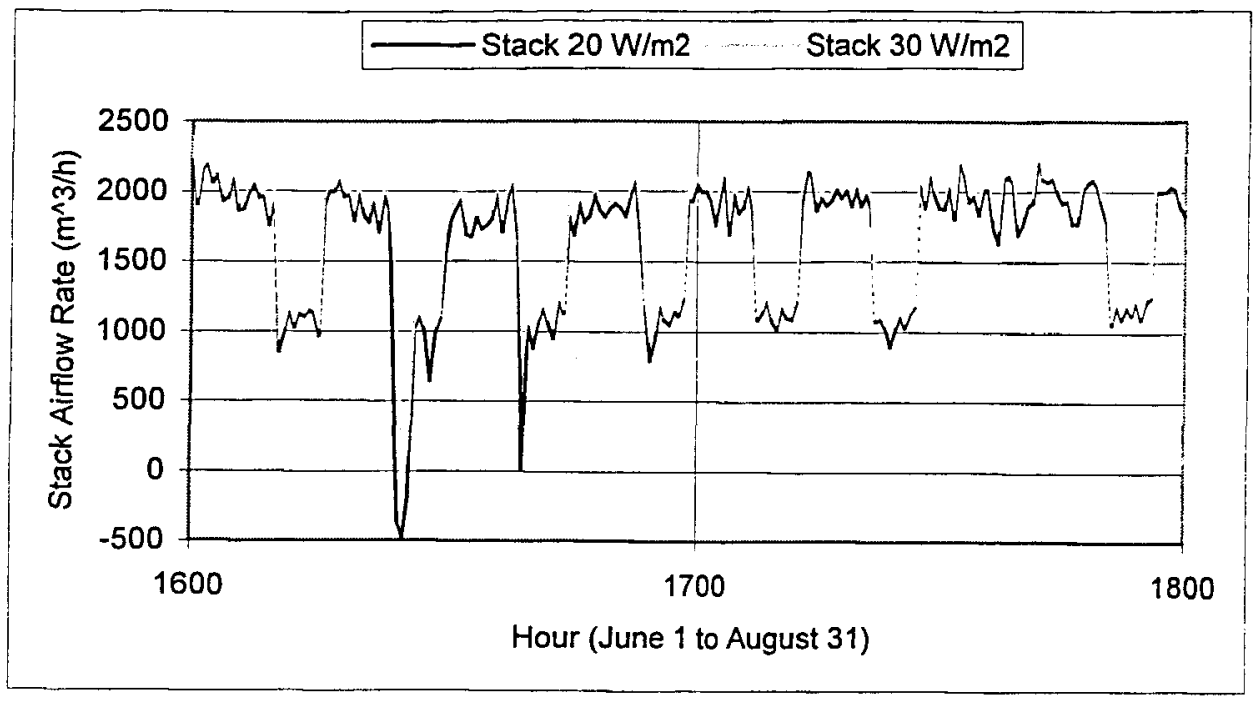

Figure 4.23 Detailed stack airflow rate response for the Enschede Tax Office building to Los Angeles' summer conditions operated in a natural night cooling mode. Results plotted for two assumed combined solar and internal gains $-20 \mathrm{~W} / \mathrm{m}^{2}$ and $30 \mathrm{~W} / \mathrm{m}^{2}$.

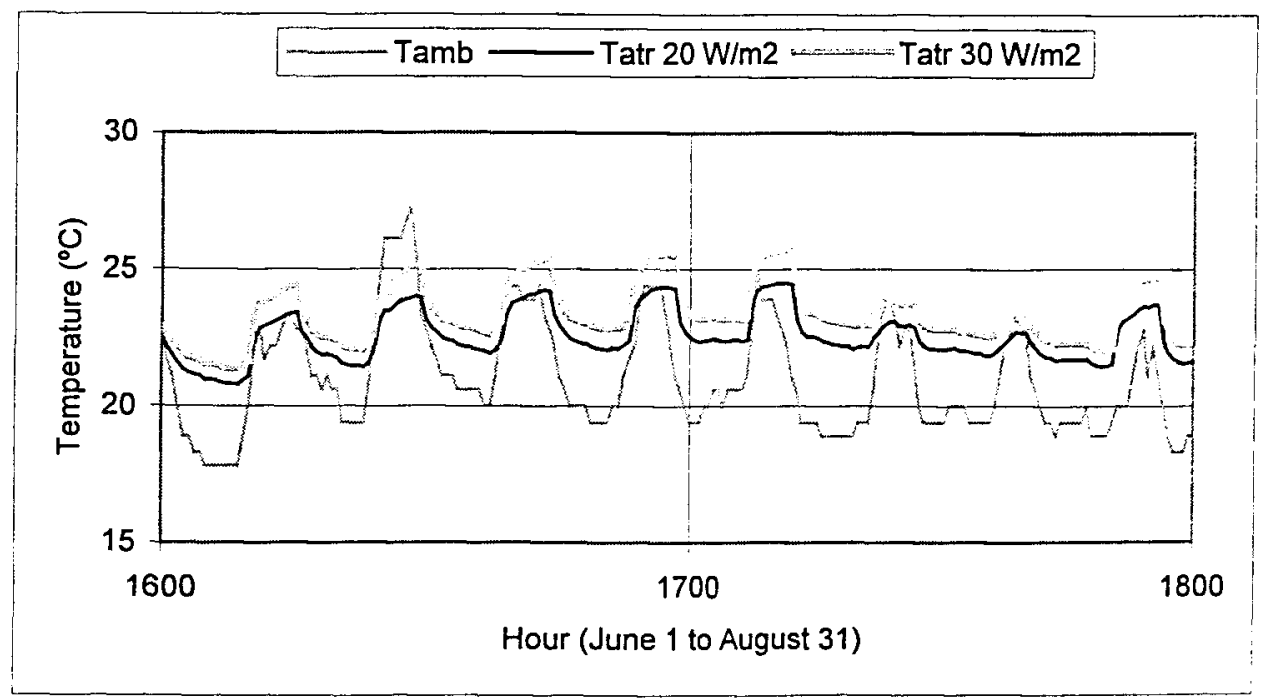

Figure 4.24 Detailed atrium temperature response for the Enschede Tax Office building to Los Angeles' summer conditions operated in a natural night cooling mode. Results plotted for two assumed combined solar and internal gains $-20 \mathrm{~W} / \mathrm{m}^{2}$ and $30 \mathrm{~W} / \mathrm{m}^{2}$.

Importantly, indoor air temperatures appear to have a minor impact on stack airflow rates indicating this airflow is driven primarily by wind, as desired.

Turning now to distribution of ventilation airflows and its impact on individual office thermal response, consider Figures 4.25 and 4.26 which illustrate inlet ventilation rates and indoor air temperatures, respectively, for offices at the $1^{\text {st }}, 3^{\text {rd }}$ and $5^{\text {th }}$ levels of the south side of the building. For these offices, inlet ventilation rates fall below design objectives with the upper levels being most under ventilated indicating buoyancy forces are at play here. Nevertheless. 
office temperatures are relatively uniform from office-to-office but consistently higher than the atrium temperatures on the warmer days. This last observation is to be expected since combined gains in the offices is greater than the atrium (i.e., $27.5 \mathrm{~W} / \mathrm{m}^{2}$ versus $5 \mathrm{~W} / \mathrm{m}^{2}$ ) during office hours and both areas have the benefit of thermal mass.

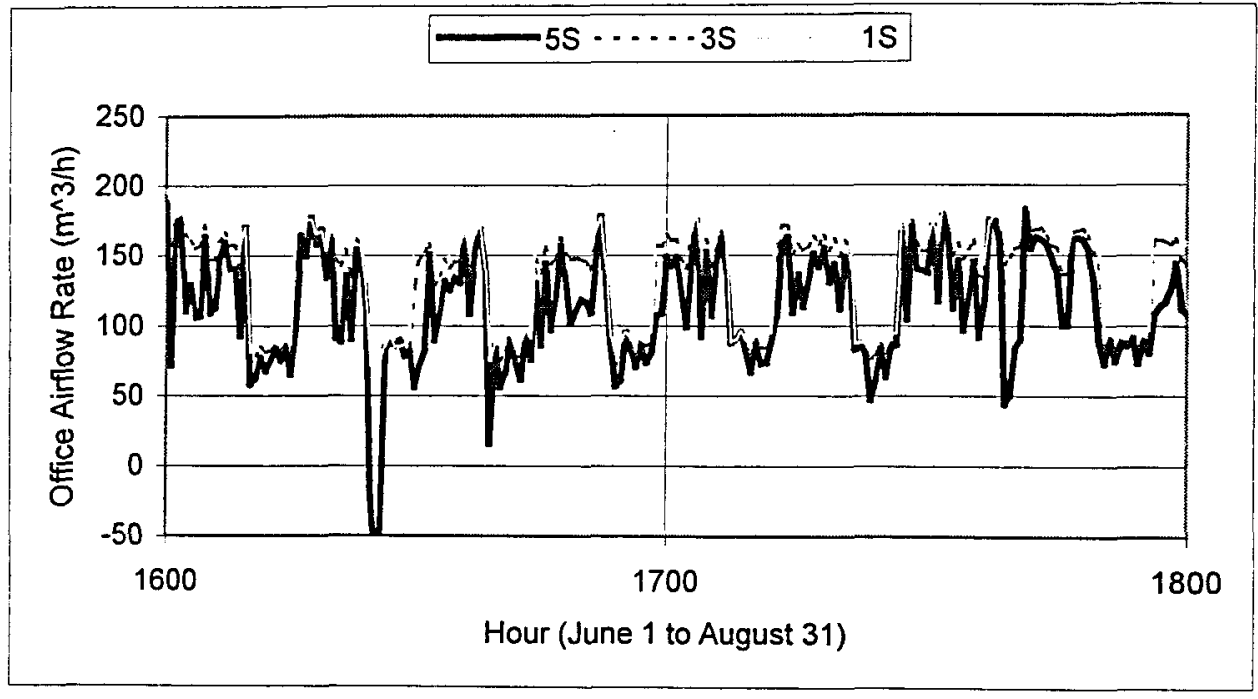

Figure 4.25 Detailed office inlet airflow rate responses for the Enschede Tax Office building to Los Angeles' summer conditions operated in a natural night cooling mode. Results plotted for assumed combined solar and internal gain of $27.5 \mathrm{~W} / \mathrm{m}^{2}$ for south offices at levels 1,3 and 5 .

From these results it is clear that coupled thermal/airflow analysis can provide detailed dynamic response results that can be used to evaluate both the general aspect of system performance and detailed air distribution and temperature response - both essential to system performance evaluation. Not readily evident but clear at the time of constructing these models and reviewing response results is the fact that direct ventilative cooling will inevitably engage the thermal mass of the building - to advantage when outdoor air temperatures fall below indoor and disadvantage otherwise. Thus from a dynamic analysis point of view, the distinction between night cooling and direct ventilative cooling is artificial. Indeed, to optimize cooling system performance inlet vents should be controlled using "night-cooling" strategies (e.g., as discussed in Chapter 3) throughout the day during warm periods. 


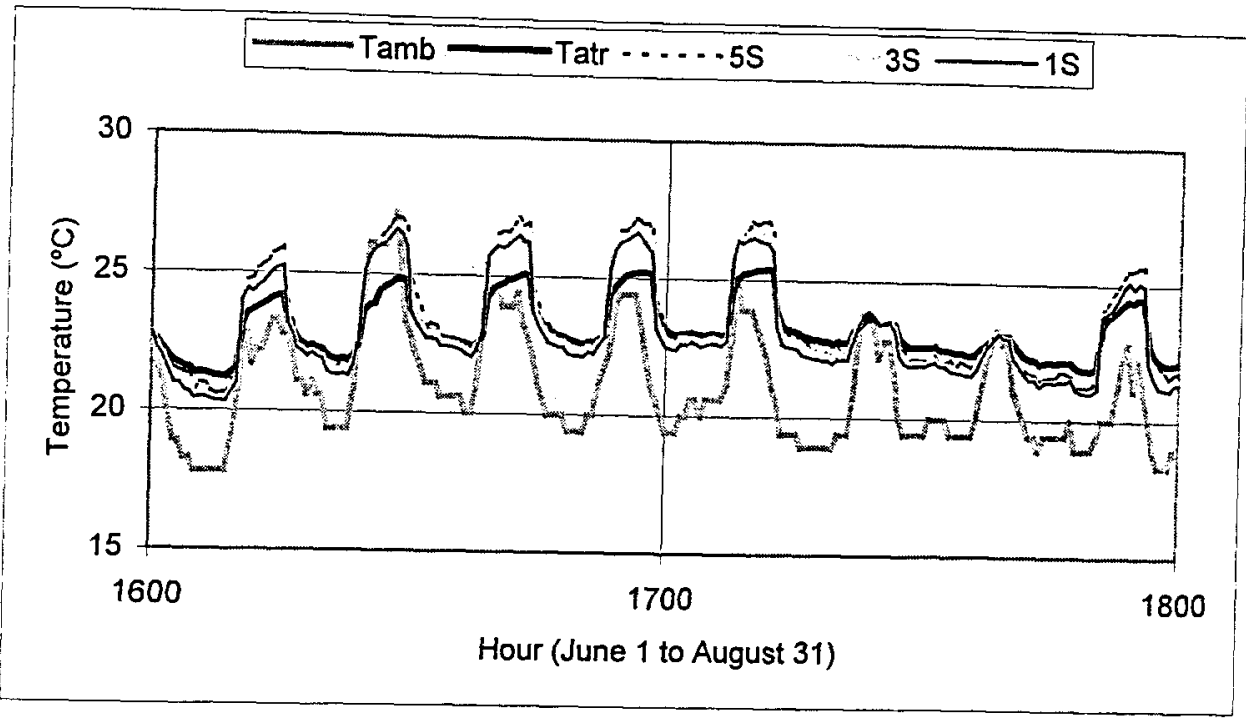

Figure 4.26 Detailed office temperature responses for the Enschede Tax Office building to Los Angeles' summer conditions operated in a natural night cooling mode. Results plotted for assumed combined solar and internal gain of $27.5 \mathrm{~W} / \mathrm{m}^{2}$ for south offices at levels 1,3 and 5 , atrium, and ambient.

\section{Design Development of the Night Cooling System for Fresno, California}

The Enschede Tax Office did not performed well as designed in the Fresno, CA climate. Figure 4.27 shows the dynamic response results for the slot atrium temperature for two combined solar and internal gain rates. While the atrium response was moderated in comparison to ambient conditions, atrium temperatures frequently exceeded comfort levels during the three-month period and were consistently uncomfortable during a relatively long hot spell.

Again, an examination of the detailed response during this hot spell is instructive. Figure 4.28 isolates the stack airflow rate response for this period and Figure 4.29 shows the corresponding atrium temperature responses. The natural ventilation system with the self-regulating inlet vents is seen to provide reasonably good control of ventilation rates as desired (i.e., ten offices at 200 $\mathrm{m}^{3} / \mathrm{h}$ per office in night-cool mode and $100 \mathrm{~m}^{3} / \mathrm{h}$ per office in direct-cool mode during occupancy), although daytime ventilation is marked by reverse flows. Due to the self-regulation model used, however, these reverse flows also approach the design ventilation rate of $1000 \mathrm{~m}^{3} / \mathrm{h}$ as desired. Reverse flows may be unexpected but they do, nevertheless, provide the minimum ventilation required for air quality control. 


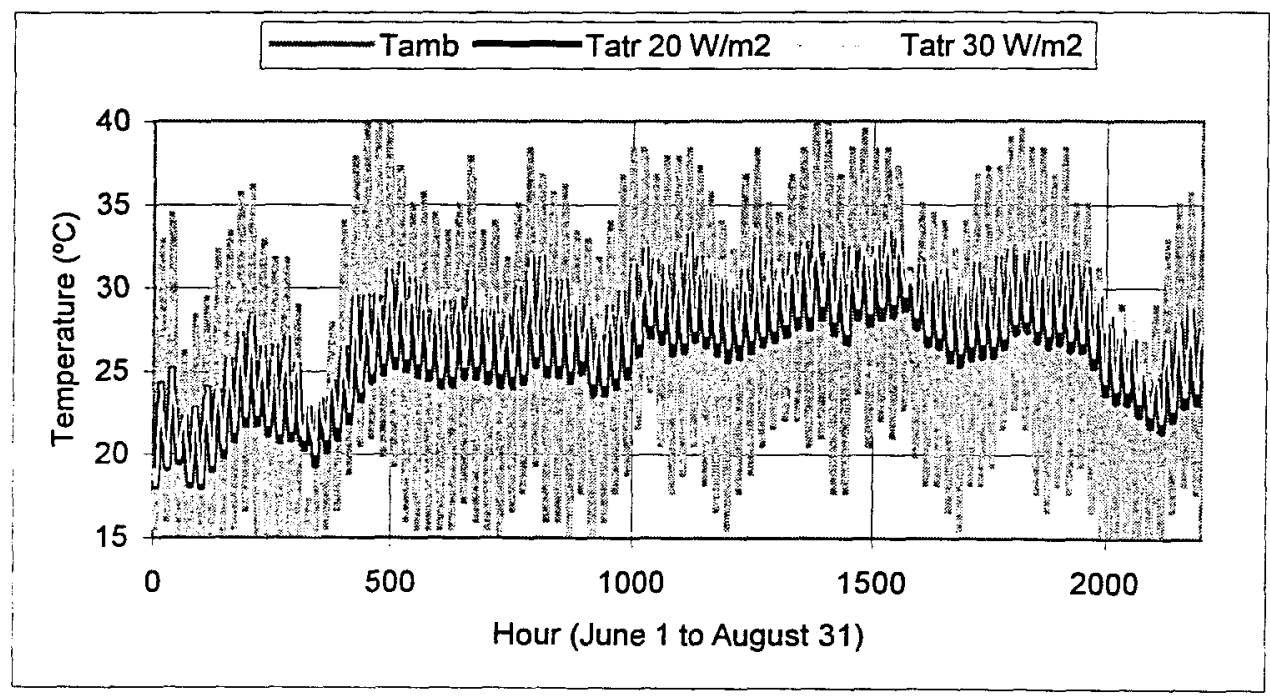

Figure 4.27 Atrium temperature response for the Enschede Tax Office building to Fresno's summer conditions operated in a natural night cooling mode. Results plotted for two assumed combined solar and internal gains $-20 \mathrm{~W} / \mathrm{m}^{2}$ and $30 \mathrm{~W} / \mathrm{m}^{2}$ - compared to ambient conditions.

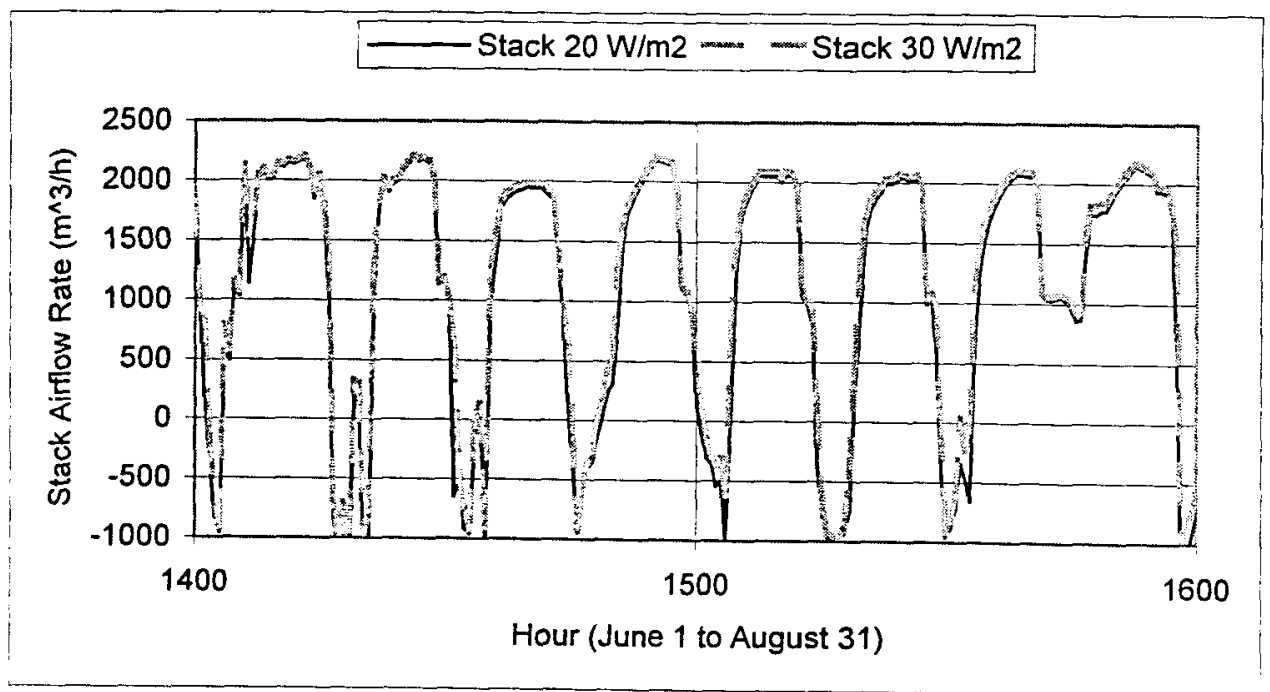

Figure 4.28 Stack airflow rate response for the Enschede Tax Office building to Fresno's summer conditions operated in a natural night cooling mode. Results plotted for two assumed combined solar and internal gains $-20 \mathrm{~W} / \mathrm{m}^{2}$ and $30 \mathrm{~W} / \mathrm{m}^{2}$ - compared to ambient conditions. 


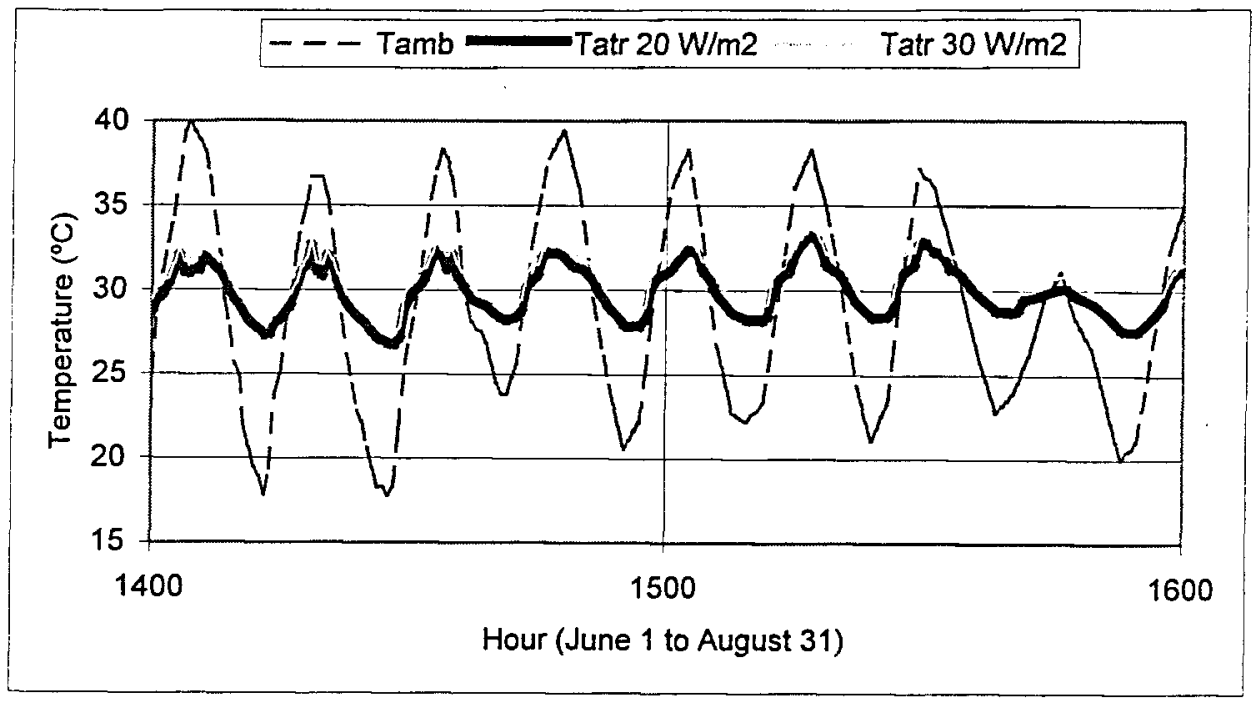

Figure 4.29 Atrium temperature response for the Enschede Tax Office building to Fresno's summer conditions operated in a natural night cooling mode. Results plotted for two assumed combined solar and internal gains $-20 \mathrm{~W} / \mathrm{m}^{2}$ and $30 \mathrm{~W} / \mathrm{m}^{2}$ - compared to ambient conditions.

During this hot period, the daytime temperatures consistently exceed $30^{\circ} \mathrm{C}$. It may be recalled, the loop design method was used to obtain preliminary sizes for system components using a 4 $\mathrm{m} / \mathrm{s}$ design reference wind velocity, yet the climatic analysis presented above indicates a lower value of $3 \mathrm{~m} / \mathrm{s}$ would be more appropriate. Thus, one may conclude that the natural ventilation system is simply undersized and should be altered. Alternatively, fan-assisted night cooling might improve the performance. Both design development strategies will be considered below. To provide the means to compare these strategies, the overheated degree hours for each strategy was also evaluated.

First for fan-assisted night cooling Figure 4.30 isolates the stack airflow rate response for the hot period and Figure 4.31 shows the corresponding atrium temperature responses. The fan clearly provides better control of ventilation airflow rates, but the degree of control improvement is marginal in this case. The atrium temperature response improves slightly for the slightly higher ventilation rate provided by the fan-assisted night cooling but apparently an even greater ventilation rate is required. The relatively large difference between atrium and ambient temperatures during nighttime hours indicates the full potential of night cooling has yet to be realized.

For the second natural ventilation alternative, the inlet vents were resized to provide a night ventilation rate twice that used in the Enschede Tax Office (i.e., $400 \mathrm{~m}^{3} / \mathrm{h}$ versus $200 \mathrm{~m}^{3} / \mathrm{h}$ per office) while daytime rates were maintained at the minimum (i.e., $100 \mathrm{~m}^{3} / \mathrm{h}$ per office). Through a process of trial and error performance evaluations, it also became clear that the exhaust stack opening was constricting flow so it was increased from $1 \mathrm{~m}^{2}$ to $2 \mathrm{~m}^{2}$. Figure 4.32 isolates the stack airflow rate response and Figure 4.33 shows the corresponding atrium temperature responses. The resized natural ventilation system provides a reasonably well-controlled and increased night ventilation rate although, as sized, it falls below the objective of $400 \mathrm{~m}^{3} / \mathrm{h}$ per office by 10 to $20 \%$. A corresponding improvement in the atrium temperature response is also seen but comfort levels (i.e., as described in Figure 3.1) are still exceeded by a degree or so. 


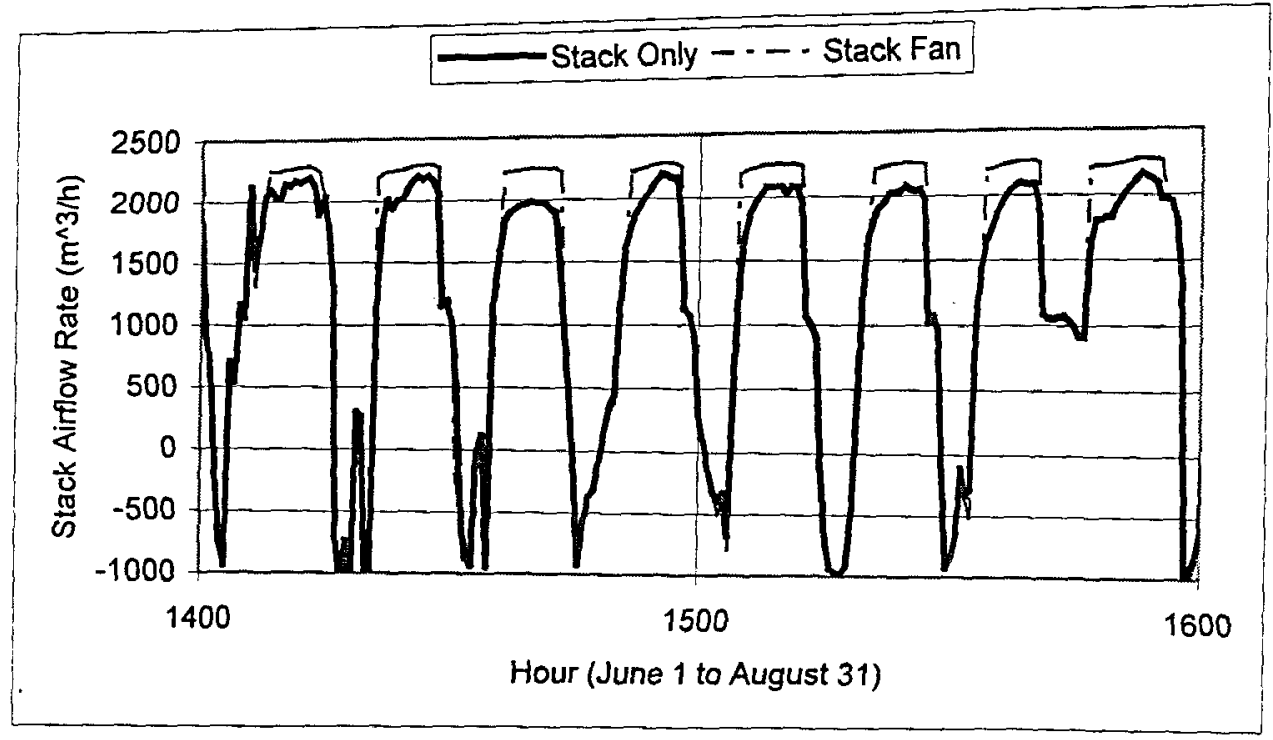

Figure 4.30 Stack airflow rate response for the Enschede Tax Office building to Fresno's summer conditions operated in a fan-assisted night cooling mode compared to the natural mode operation. Results plotted for assumed combined solar and internal gain of $27.5 \mathrm{~W} / \mathrm{m}^{2}$.

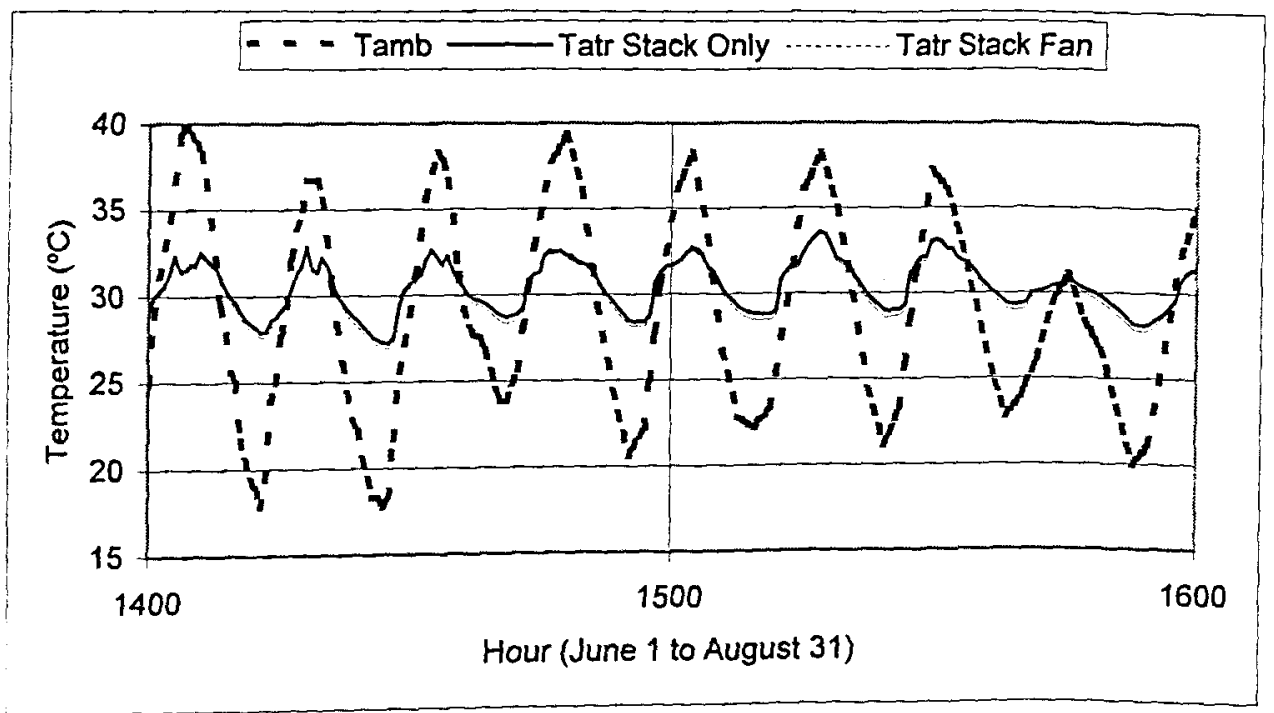

Figure 4.31 Atrium temperature response for the Enschede Tax Office building to Fresno's summer conditions operated in a fan-assisted night cooling mode compared to the natural mode operation. Results plotted for assumed combined solar and internal gain of $27.5 \mathrm{~W} / \mathrm{m}^{2}$. 


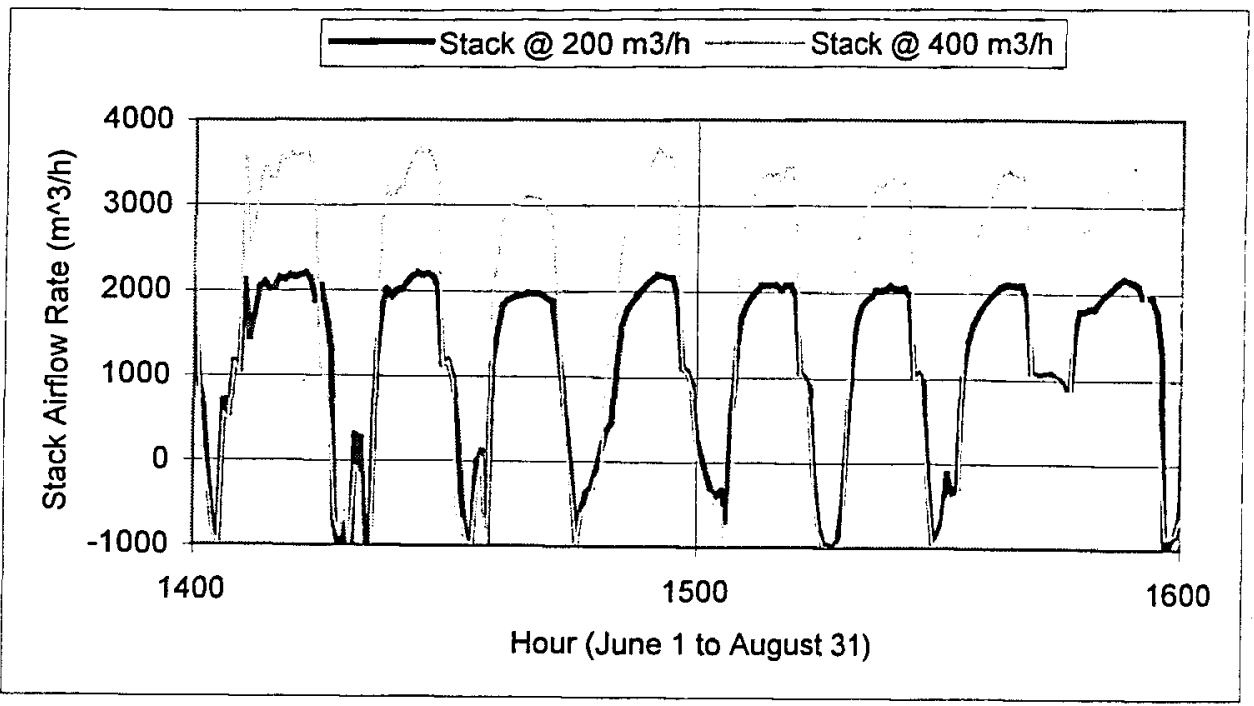

Figure 4.32 Stack airflow rate response for the Enschede Tax Office building to Fresno's summer conditions operated in a natural night cooling mode with inlet vents sized to provide 400 $\mathrm{m}^{3} / \mathrm{h}$ per office in night cool mode compared to the original $200 \mathrm{~m}^{3} / \mathrm{h}$ per office. Results plotted for assumed combined solar and internal gain of $27.5 \mathrm{~W} / \mathrm{m}^{2}$.

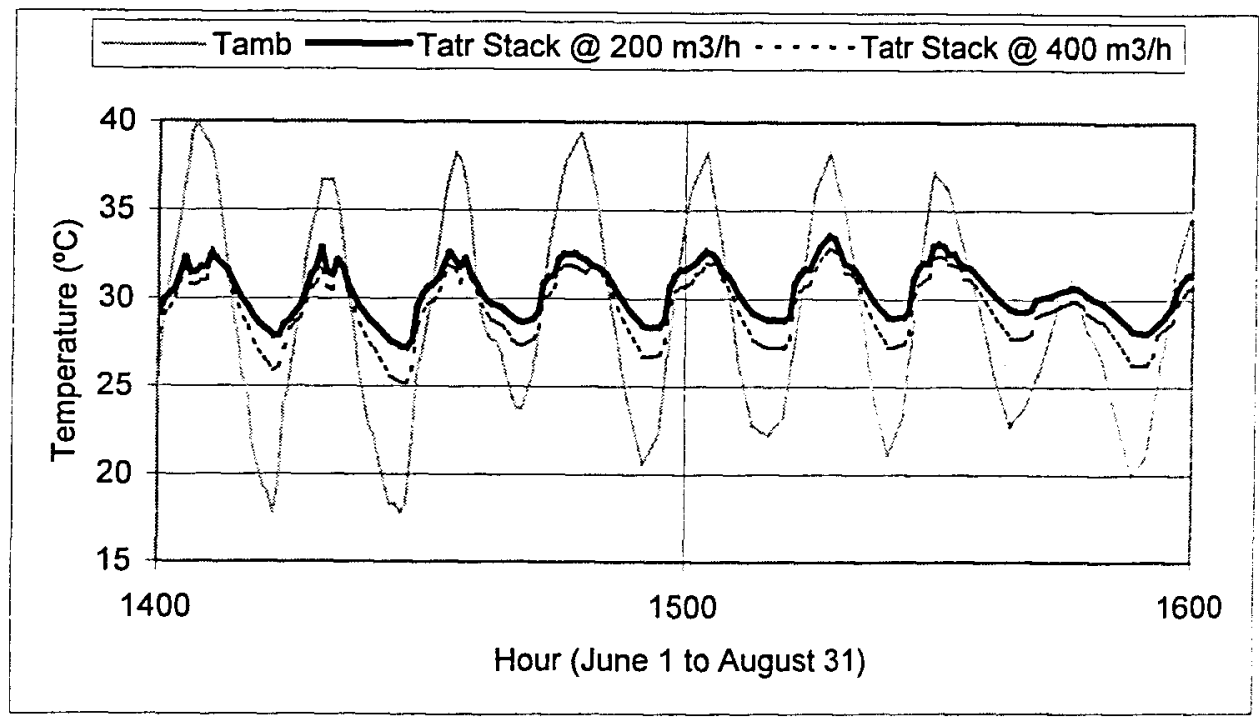

Figure 4.33 Atrium temperature response for the Enschede Tax Office building to Fresno's summer conditions operated in a natural night cooling mode with inlet vents sized to provide 400 $\mathrm{m}^{3} / \mathrm{h}$ per office in night cool mode compared to the original $200 \mathrm{~m}^{3} / \mathrm{h}$ per office. Results plotted for assumed combined solar and internal gain of $27.5 \mathrm{~W} / \mathrm{m}^{2}$.

One could attempt to continue this process of trial and error to improve the design of the night cooling system but to do so a performance metric is needed. The overheated degree hours ODH introduced in Chapter 3 can serve this purpose and may be conveniently compared to published values of cooling degree hours published for many North American locations. The overheated 
degree hours were computed for each of the design alternatives introduced above and are reported in Table 4.7.

Table 4.7 Computed overheating degree hours (Equation 3.3) for the night cooling design alternatives of the Enschede Tax Office for the June1 to August 31 weather record of Fresno, $\mathrm{CA}$. (These values should be compared to the cooling degree hours for the same climate and period - $10,009 \mathrm{CDH}_{80}{ }^{\circ}$.)

\begin{tabular}{|c|c|c|c|c|c|}
\cline { 2 - 6 } \multicolumn{1}{c|}{} & \multicolumn{3}{c|}{$\begin{array}{c}\text { Natural Ventilation } \\
200 \mathrm{~m}^{3} / \mathrm{h} \text {-office }\end{array}$} & $\begin{array}{c}\text { Fan-Assisted } \\
230 \mathrm{~m}^{3} / \mathrm{h} \text {-office }\end{array}$ & $\begin{array}{c}\text { Natural Vent. } \\
400 \mathrm{~m}^{3} / \mathrm{h} \text {-office }\end{array}$ \\
\hline Gain & $20 \mathrm{~W} / \mathrm{m}^{2}$ & $27.5 \mathrm{~W} / \mathrm{m}^{2}$ & $30 \mathrm{~W} / \mathrm{m}^{2}$ & $27.5 \mathrm{~W} / \mathrm{m}^{2}$ & $27.5 \mathrm{~W} / \mathrm{m}^{2}$ \\
\hline ODH & 111 & 177 & 210 & 145 & 91 \\
\hline
\end{tabular}

This objective performance criteria clearly indicates the relative improvement of each successive design "move" - decreasing from $177 \mathrm{ODH}$ for the original as-designed proposal to $145 \mathrm{ODH}$ for the fan-assisted, to $91 \mathrm{ODH}$ for the resized natural system. To gain some understanding of the relative impact night cooling has had it is useful to compare these results to the published cooling degree hours $-10,009 \mathrm{CDH}$ (base $80^{\circ} \mathrm{F}$ or $27^{\circ} \mathrm{C}$ ) - for the same weather record used for the analyses. In effect, then, the indoor environment has been significantly moderated in comparison to outdoor conditions - in spite of the significant daytime solar and internal gains considered. Nevertheless, the improved design performance at $91 \mathrm{ODH}$ still exceeds the Zurich acceptability limit of $30 \mathrm{ODH}$ discussed in Chapter 3. Thus, additional design refinement is still warranted.

Finally, it is useful to reconcile these results with the climate analysis discussed in section 4.2 of this chapter. Iterative design development via detailed modeling studies evaluation of performance made it clear that the natural ventilation system needed to be resized to increase night ventilation rates. The climatic data also indicated the system should have been redesigned for a design wind speed on the order of $3 \mathrm{~m} / \mathrm{s}$ rather than the $4 \mathrm{~m} / \mathrm{s}$ value originally used. This, if applied using the loop design method, would have resulted in larger component sizes. In addition, the climate suitability analysis for Fresno indicated a night cooling ventilation rate of 5.6 $\mathrm{ACH}$ on average and up to $14.4 \mathrm{ACH}$ may be required for night cooling. For the $3 \mathrm{~m} \mathrm{x} 5 \mathrm{~m} \mathrm{x}$ $3.33 \mathrm{~m}$ offices, the original night ventilation rate of $200 \mathrm{~m}^{3} / \mathrm{h}$ would have thus provided only 4 $\mathrm{ACH}$ while the resized system providing $400 \mathrm{~m}^{3} / \mathrm{h}$ would have provided $8 \mathrm{ACH}$ - within the range of night ventilation rates estimated by the climate suitability analysis. Thus, it would seem that a more logical approach to the design adaptation of the Enschede Tax Office to the Fresno climate would involve first a review of the climate suitability analysis followed by a loop design method sizing of components using averaged wind speed conditions. 


\section{SUMMARY AND RECOMMENDATIONS}

As stated at the outset, the success of innovative natural and hybrid ventilation systems constructed in central and northern European climates begs the question:

Can and should new European natural ventilation systems be adapted to the North American context?

This report has reviewed these systems, and the methods employed in their design, coming to the emphatic conclusion that:

Yes, European natural and hybrid ventilation systems can and should be adapted to the North American context!

Primary energy consumption may be saved, global emissions due to this energy consumption may be reduced, and occupant health and preferences will be served - hence occupant productivity may be expected to be enhanced. Operational costs will be reduced, of course, in direct proportion to the energy saved and first costs of supporting mechanical systems will be reduced in proportion to reductions in loads placed on these systems (i.e., when needed). Beyond this, natural ventilation systems may offset the need for costly air distribution systems or reduce them significantly and carry a first cost that is certainly significantly lower. In many cases, the cost of the natural ventilation system is so intimately tied to building geometry serving daylighting needs that disaggregating the actual cost of the natural ventilation system would prove difficult.

The concern for control - especially excessive wintertime ventilation and the costs and comfort problems associated with it - have been largely abated through the development of selfregulating inlet vents, supply air distribution strategies (e.g., injection across ceiling surfaces using the Coanda effect and low velocity displacement ventilation methods), and the more sophisticated use of available thermal mass. The concern for heat recovery is more problematic. Air-to-air heat recovery while readily implemented in mechanical systems has proven to be more challenging in natural ventilation systems due to the need to configure systems so that air supply and exhaust are proximate so their paths can be crossed and the reduction in buoyancy forces that must, necessarily, accompany this heat recovery. Run-around heat recovery systems solve the proximity issue and the buoyancy reduction issue is generally not problematic as wind forces are often dominant anyway and through sensible design the reduction of buoyancy forces can be minimized. Consequently, some very recent examples of air-to-air heat recovery subsystems have been implemented. Beyond these encouraging developments the strategic use of thermal mass, double skin envelopes, and dynamic insulation provide alternative heat recovery methods, albeit, not technically air-to-air heat recovery.

A healthy competition between European building service engineers, who design mechanical systems for buildings, and environmental engineers, who have promoted technically advanced natural ventilation systems, has nurtured the development of hybrid ventilation systems. These systems offer optimal combinations of both approaches - combinations that result in systems that must be described as extreme low-energy building systems when compared to traditional standards of performance. The emergence of these hybrid ventilation systems is most important to the North American context in three respects. First, their technical performance sets new benchmarks of excellence that demands emulation. Second, the competition that nurtured these 
developments, manifested in professional symposia and publication in popular architectural and engineering journals, does not presently exist in North America. It too should be emulated. Finally, hybrid systems may be an essential choice in those North American climates that are characterized by extreme conditions.

With the question of "can and should" resolved, this report turned to the question of "how" - a more problematic matter. European, especially British, natural ventilation system designs have long been tied to precedent and empirical studies of their performance in the relatively uniform climatic conditions of Northern Europe. Climatic conditions in North America are more varied, thus the direct application of these European precedents may not always be reasonable.

The development of analytical methods to predict airflow in buildings, both at the macroscopic and microscopic level of detail, has begun to free natural ventilation system design from the traditional empirical approach and place it on a more general foundation. The methods that are most useful model the couple thermal and airflow interactions that are central to natural and hybrid ventilation system behavior. However, very few computational tools are available that account for these interactions and most are limited to simplistic models of building systems (e.g., one, two, or three zone models) that, significantly, have little in common with the most innovative built systems. That is to say, the developers of computational tools to support design are being outpaced by innovative designers. Furthermore, most of the computational tools that are available are performance evaluation and, not strictly, design tools.

Finally, to practically apply analytical methods designers need guiding codes and standards. If we are to learn from the mistakes of the past, these needed codes and standards should be developed in parallel with the analytical methods needed to support both design and performance evaluation of natural and hybrid ventilation systems

\subsection{Design Recommendations}

Given this state of affairs, this report has promoted an approach to natural and hybrid ventilation system design that:

a) recognizes the need for a more fundamental, less empirical approach, to account for climatic differences and specific characteristics of building systems and

b) can serve the building designer at each distinct phase of design that characterizes North American practice (predesign analysis, preliminary or conceptual design, design development, and design performance evaluation).

\subsubsection{Predesign Analysis}

The climate suitability method presented in Chapter 2 of this report offers an approach to predesign analysis for ventilative cooling that is climate specific and accounts for the likely level of internal and solar gains that might be expected for a given building project. The climate suitability analysis also yields estimates of ventilation rates that are likely to be needed to achieve either a direct ventilative or night cooling design strategy. These estimated ventilation rates can be used directly in the design development phase to obtain component sizes.

Anticipating the use of the loop design method presented in Chapter 3, the designer should also complete predesign analysis of wind conditions. As the climate suitability method demands analysis of hourly weather data for the building location, this step simply involves routine 
statistical analysis of hourly wind data. An average seasonal wind speed may then be used as a reference design wind velocity for loop analysis. In addition, a histogram of seasonal wind speeds quantifies the probable minimum wind speed that may be used to establish "withoutwind" operational strategies, again, using the loop method.

\subsubsection{Preliminary or Conceptual Design}

Preliminary or conceptual design involves the development of the general configuration and topology (i.e., selection of the type and connectivity of the components) of the building ventilation system most often done with little quantitative analysis. The fundamental systems reviewed and the general guidelines cited in Chapter 3 may serve this phase of design. In addition, and perhaps even more useful, are the examples provided by the many precedents built in the past decade. The appendix to Chapter 3 cites a number of case studies of the most notable of these projects. Beyond this European professional architectural and building services journals should be reviewed and, ideally, attendance or better yet participation in European symposia like the annual Intelligent Building Symposium should be considered.

\subsubsection{Design Development}

Given a conceptual or preliminary design proposal design development - the development of system component sizes and details and system control and operational strategies - may proceed. Again, Chapter 3 cites a number of key references, approximate methods, correlation methods, and computational tools but most of these fall short of what is needed for application to the North American context. Most of these tools are based on simplistic models of natural ventilation systems not well suited to the complexity characteristic of innovative built systems that should reasonably be emulated. Few provide any guidance when it comes to sizing internal resistances to ventilation airflows. Many are limited to the more moderate climates of northern Europe or even more narrowly to southern England.

In lieu of these methods, the loop design method has been put forward - again in Chapter 3 - as a means to size all components of ventilation systems of arbitrary configuration and topology. Based on the same underlying theory used in modern general-purpose multizone airflow analysis programs, the loop design method uses a component assembly approach to form pressure loop equations that define feasible combinations of component sizes that will satisfy specific ventilation objectives. Within these equations buoyancy and wind-driven pressure differences are accounted for in an 'exact' and fundamental manner, given climatic design conditions. As suggested above, wind design conditions may be based on statistical analyses of wind data for specific locations. Alternatively, actual hourly buoyancy and wind pressure differences may be computed a priori and statistically analyzed to gain greater precision (e.g., see [72]). Using the loop equations, the designer is generally able to impose specific nontechnical design constraints (e.g., selecting component details from commercially available units) and specify operational strategies (e.g., for with-wind and without-wind conditions).

With preliminary sizes of components fixed and operational strategies defined, the designer is then in a position to proceed to performance evaluation of system performance. Chapter 3 presented a discussion of performance evaluation criteria relating to air quality, thermal comfort and energy conservation and of design conditions that must also be assembled to proceed to system performance evaluation. 


\subsubsection{Design Performance Evaluation}

In some respects, the contemporary (innovative) design of natural and hybrid ventilation systems differs from that of the past in that computational performance evaluation is now central to design. The greater reliance on computational performance evaluation is driven by the global and personal environmental concerns that now placed greater demands on energy conservation, thermal comfort, and air quality control. Ironically, however, there appears to be no computational tool generally available that can be applied to systems of arbitrary configuration and topology - a necessary condition to support innovation, account for the coupled thermal/airflow interactions that characterize natural and hybrid ventilation system behavior, and be used for long term, ideally annual, simulations.

The generally unavailable research program CONTAM97R presently under development has, in principle, these capabilities [214]. In addition, this program has been designed to enable modeling of system control and nontrace air contaminant dispersal. The latter is significant because it allows consideration of buoyancy forces due to density changes associated with moisture released in evaporative cooling schemes that are particularly attractive in hot-arid climates. Unfortunately, in its present state CONTAM97R is extraordinarily difficult to use, as it lacks a complete user interface, and is not fully operational. Furthermore, as coupled thermal/airflow analysis is numerically demanding, convergence problems add to the difficulty of using CONTAM97R.

Nevertheless, CONTAM97R was applied in Chapter 4 to the analysis of a reasonably welldocumented naturally ventilated building - the Tax Office building of Enschede, The Netherlands. Comparisons of measured and predicted performance of this building in its native climate were presented as a means to provide a first validation exercise of CONTAM97R and to calibrate the building models used for subsequent analytical studies. Three models of a fivestory segment of this building were formulated within CONTAM97R - a single-zone model with detailed representations of ventilation inlets and exhausts, a highly detailed 31-zone model accounting for all purpose-provided and infiltration flow paths, and a moderately detailed 11zone model falling between these two extremes.

The moderately detailed 11-zone model was then used to demonstrate the application of macroscopic coupled thermal/airflow performance evaluation, in general, and CONTAM97R more specifically to the design development of night ventilation cooling systems for the Enschede Tax Office placed in two hot-arid North American locations - Fresno and Los Angeles, California. Following a trial and error procedure using the overheated degree hour ODH performance metric presented in Chapter 3 (i.e., defined by Equation 3.3), component sizes were adjusted to achieve the night cooling objective.

The details of this demonstration need not be repeated here. Suffice it to say that a macroscopic tool like that provided by CONTAM97R provides essential spatial and temporal details that can guide design refinement relating to both whole-building and inter-room air distribution and thermal performance. In some cases, greater intra-room detail may be required. In these cases, performance evaluation would reasonably proceed to detailed computational fluid dynamic studies of individual rooms. This, however, was beyond the scope of this report. 


\subsection{Research Recommendations}

This report set out to consider the problem of adaptation of European natural and hybrid ventilation systems to the North American context using available methods - the report was not intended to be a literature review with the intention of identifying research needs to create new methods. Nevertheless, some research needs became evident in the process of preparing this report that will be briefly noted here.

Physical design strategies for natural and, now, hybrid ventilation systems have and continue to be in a constant state of change. In the current competitive professional European environment practically each new building employing natural or hybrid strategies offers some new innovation or twist on existing strategies. As a result, the building research community has found it difficult to keep up with the pace of change and, consequently, has not been able to serve the professional community as well as it should. Consequently, there is a need for the research community to systematically monitor developments in the professional design communities - ideally, to monitor and classify (i.e., with the intention of identifying gaps needing research) not only the physical design strategies used but the analytical design methods employed by leading professional firms.

Two areas where research has had a significant impact in the past decade are the development of self-regulating inlet vents and an improved understanding of stack terminal device behavior. Both have gone a long way to address the problem of ventilation rate control that must be expected to be problematic when relying on wind forces that vary stochastically. Due to the central importance of inlets and exhausts, more research is warranted.

Some progress has been made in the area of air-to-air heat recovery. This was discussed in. Chapter 3. Given the importance of air-to-air heat recovery during wintertime operation, more work is needed in this area.

The loop design method has been proposed as a general, fundamental means to size components of systems of arbitrary configuration and topology yet its reliability has yet to be evaluated. This needs to be done in a systematic manner. While the approach may be implemented manually, for systems of real complexity manual application of the method can prove tedious at best and errorprone. Consequently, there is a need to develop a computational tool to implement the loop design method. As this method shares the same theoretical base and diagrammatic (i.e., interface) conventions used in general purpose airflow and air quality analysis tools, the loop equation could be implemented within the framework of one or more of these performance evaluation tools (i.e., within the CONTAM or COMIS programs). This should be done. In addition, the step from component sizing to performance evaluation could then be automated greatly facilitating the size-evaluate design cycle that is characteristic of all technical design.

The need for general-purpose performance evaluation tools that can account for:

- the coupled thermal/airflow interactions that characterize naturally driven airflows,

- the control systems required to achieve optimal performance, and

- the buoyancy forces induced by evaporative cooling, when needed

is now generally recognized as a pressing need for the development of natural and hybrid ventilation systems. The application of CONTAM97R presented in Chapter 4 indicates this need can be met and when it is, great utility will result. Clearly, the development of CONTAM97R 
should be completed and validation studies and useful applications should be undertaken. This should not only entail completion of the current program design but a critical review of these features, the existing input interface, and the development of an appropriate output interface. Of these, the design of the control modeling interface demands serious reconsideration. The current primitive operation components offered should be replaced with symbolic representation of control logic as exemplified in system dynamics programs. Beyond this, more fundamental research is needed related to the solution, uniqueness and even existence of solutions of the coupled thermal/airflow/moisture problems associated with natural and hybrid ventilation system behavior. 


\section{REFERENCES}

1. Banham, R., The Architecture of the Well-Tempered Environment. 1969, London; Chicago: The Architectural Press; The University of Chicago Press.

2. Arnold, D., The Evolution of Modern Office Buildings and Air Conditioning. ASHRAE Journal, 1999. June 1999: p. 40-54.

3. Liddament, M. NatVent ${ }^{\mathrm{TM}}$; Accomplishments and Recommendations. in NatVent ${ }^{\mathrm{TM}}-A$ Better Way to Work. 1998. BRE, Garston, Watford, UK: BRE.

4. Kukadia, V. NatVent ${ }^{\mathrm{TM}}$ : Its Aims and Vision. in NatVent ${ }^{\mathrm{TM}}$ - A Better Way to Work. 1998. BRE, Garston, Watford, UK: BRE.

5. Allard, F., et al., Natural Ventilation Studies within the EC PASCOOL Joule II Project. Air Infiltration Review, 1996. Vol. 17(No. 4, September 1996): p. 1- 4.

6. Santamouris, M., A. Argiriou, and G. Deschamps, PASCOOL Final Products. 1996, Universty of Athens: Athens.

7. Santamouris, M. and D. Asimakopoulos, eds. Passive Cooling of Buildings. 1996, James $\&$ James Ltd.: London.

8. Allard, F., ed. Natural Ventilation in Buildings; A Design Handbook. 1998, James \& James * Science Publishers) Ltd.: London.

9. CIBSE, Natural Ventilation in Non-Domestic Buildings; A Guide for Designers, Developers and Owners. 1998, Chartered Institution of Building Services Engineers CIBSE: London.

10. Perera, E., NatVent: Overview of Investigated Buildings. 1998, BRE: Garston, Watford.

11. BRE, NatVent - CD-Rom. 1999, Building Research Establishment.

12. Olesen, B.W., Guidelines for Comfort. ASHRAE Journal, 2000. August: p. 41-46.

13. BRECSU, Energy Conusmption Guide 19: Energy Use in Offices. 2000, British Research Establishment Conservation Support Unit: Garston, Watford, UK.

14. Kavanaugh, S., Fan Demand and Energy. ASHRAE Journal, 2000. June: p. 47-55.

15. Heikkinen, J. and I. Heimonen. Hybrid Ventilation Expectations Among Finnish Designers and Decision Makers. in Healthy Building 2000. 2000. Espoo, Finland: SIT Indoor Air Information Oy, Helsinki, Finland.

16. Heiselberg, P. Design Principles for Natural and Hybrid Ventilation. in Healthy Building 2000. 2000. Espoo, Finland: SIT Indoor Air Information Oy, Helsinki, Finland.

17. Milton, D.K., P.M. Glencross, and M.D. Walters, Risk of Sick Leave Associated with Outdoor Air Supply Rate, Humidification, and Occupant Complaints. Indoor Air, 2000. Vol. 10(No. 4): p. 212-221.

18. Wargocki, P., et al., The Effects of Outdoor Air Supply Rate in an Office on Perceived Air Quality, Sick Building Syndrome (SBS) Symptons and Productivity. Indoor Air. 2000. Vol. 10(No. 4): p. 222-236.

19. Leyten, J.L. and S.R. Kurvers. Robustness of Buildings and HVAC Systems as a Hypothetical Construct Explaining Differences in Building Complaint Rates. in Healthy' Building 2000. 2000. Espoo, Finland: SIT Indoor Air Information Oy, Helsinki, Finland.

20. de Gids, W.F., Controlled Air Flow Inlets. 1999, BRE: London. 
1. de Gids, W.F. Controlled Air Flow Inlets. in 18th AIVC Conference - Ventilation and Cooling. 1997. Athens, Greece: AIVC.

2. Anon, European patent application: self regulating ventilation grate, in European Patent Office. 1992.

3. Knoll, B., Advanced ventilation systems - state of the art and trends. 1992. Coventry, Great Britain: AIVC.

4. Knoll, B. and W. Kornaat. Controlled Natural Ventilation. in 12th AIVC Conference - Air Movement \& Ventilation Control Within Buildings. 1991. Ottawa, Canada: AIVC.

5. Knoll, B. and J.C. Phaff. Controlled Natural Ventilation for Commercial and Industrial Buildings. in 19th AIVC Conference - Ventilation Technologies in Urban Areas. 1998. Oslo: AIVC.

6. Fisk, W.J., Improved Productivity and Health from Better Indoor Environments: Estimates of Potential National Benefits. 1998, Lawrence Berkeley Laboratory: Berkeley, CA.

7. Fisk, W.J. and A.H. Rosenfeld, Estimates of Improved Productivity and Health from Better Indoor Environments. Indoor Air, 1997. p. 158-172.

8. $\quad$ Mendell, M.J., et al., Elevated Sympton Prevalence Associated with Ventilation Type in Office Buildings. Epidemiology, 1996. November 1996, Vol 7 (No 6): p. 583-589.

9. Nicol, F. and I. Raja, Modeling Temperature and Human Behavior in Buildings. IBPSA News, 1997. Vol. 9(No. 1): p. 8-11.

0. Martinez, D., et al. Predicted Comfort Envelopes for Office Buildings with Passive Downdraught Evaporative Cooling. in RoomVent 2000: Ventilation for Health and Sustainable Environment. 2000. University of Reading: Elsevier.

1. Conte, E. and I. Fato. Thermal Comfort In Mixed Mode Buildings. in Healthy Building 2000. 2000. Espoo, Finland: SIT Indoor Air Information Oy, Helsinki, Finland.

2. Gunnarsen, L. Replacing Mechanical Ventilation with Natural Ventilation and Increased User Control- An Intervention Study in a School. in Healthy Building 2000. 2000. Espoo, Finland: SIT Indoor Air Information Oy, Helsinki, Finland.

3. Bradshaw, V.P.E., Building Control Systems. 1993, New York: John Wiley \& Sons.

4. Limb, M.J., Duct Cleaning: An Anotated Bibliography. 2000, Coventry, England: AIVC.

5. Säateri, J. A Proposal for the Classification of the Cleaniness of New Ventilation Systems. in 19th AIVC Conference - Ventilation Technologies in Urban Areas. 1998. Oslo: AIVC.

6. NAIMA, Cleaning Fibrous Glass Insulated Air Duct Systems. 1993, North American Insulation Contraactors Association: Alexandria, VA.

ASHRAE, ASHRAE Handbook of HVAC Systems and Equipment: Chapter 16 Duct Construction - Duct Cleaning. 2000, Atlanta: ASHRAE.

NADCA, Mechanical Cleaning of Non-porous Air Conveyance System Components. 1992, National Air Duct Cleaners Association: Washington, DC.

Martin, A. and J. Fitzsimmons, Guidance Note GN 7/2000: Making Natural Ventilation Systems Work. 2000, BSRIA - The Building Services Research and Information Association: Bracknell, Bershire, UK. 
40. Irving, S. and E. Uys, CIBSE Applications Manual: Natural Ventilation in Non-domestic Buildings. 1997, CIBSE: London.

41. Heiselberg, P., The Hybrid Ventilation Process - Theoretical and Experimental Work. Air Infiltration Review, 1999. Vol. 21(No. 1): p. 1-4.

42. Arnold, D., Thermal Storage Case Study: Combined Building Mass and Cooling Pond ASHRAE Transactions, 2000. Vol. 106(Part 1).

43. Braham, G.D., Comparative Performance of U.K. Fabric Energy Storage Systems. ASHRAE Transactions, 2000. Vol. 106(Part 1).

44. ASHRAE, WYEC2: Weather Year for Energy Calculations 2. 1997, ASHRAE.

45. Bourgeois, D., A. Potvin, and F. Haghighat. Hybrid Ventilation Of Canadian NonDomestic Buildings : A Procedure For Assessing IAQ, Comfort And Energy Conservation. in RoomVent 2000. 2000. University of Reading: Elsevier.

46. ASHRAE, 1997 ASHRAE Handbook - Fundamentals. SI Edition ed. 1997, Atlanta, GA: ASHRAE.

47. Oseland, N.A., Acceptable Temperature Ranges in Naturally Ventilated and AirConditioned Offices. ASHRAE Transactions, 1998. Vol. 104(Part 1).

48. Brager, G.S. and R. de Gear, A Standard for Natural Ventilation. ASHRAE Journal, 2000. October.

49. Komor, P., Space Cooling Demands from Plug Loads: Less Than One Watt per Square Foot. ASHRAE Journal, 1997. 1997(December): p.41-44.

50. Wilkins, C. and M.H. Hosni, Heat Gain from Office Equipment. ASHRAE Journal, 2000. June 2000: p. 33-44.

51. ASHRAE, ASHRAE Standard 62-99: Ventilation for Acceptable Indoor Air Quality. 1999, ASHRAE: Atlanta, GA.

52. Levermore, G.J., A.M. Jones, and A.J. Wright, Simulation of a Naturally Ventilated Building at Different Locations. ASHRAE Transactions, 2000. Vol. 106 (Part 2).

53. Linden, P.F., The Fluid Mechanics of Natural Ventilation. Annual Review of Fluid Mechanics, 1999. 31: p. 201-238.

54. Hunt, G.R., P. Cooper, and P.F. Linden. Thermal Stratification Produced by Plumes and Jets in Enclosed Spaces. in RoomVent 2000: Ventilation for Health and Sustainable Environment. 2000. University of Reading: Elsevier.

55. Hunt, G.R., P. Cooper, and P.F. Linden, Thermal Stratification Produced by Plumes and Jets in Enclosed Spaces. Building and Environment, 2001. Vol. 36: p. 871-882.

56. Jones, P., The Rationale for Mechanical Ventilation. Indoor + Built Environment, 2000. Vol. 9(No. 2): p. 63-64.

57. Zeidler, O. and K. Fitzner. Limits of Natural Ventilation through Windows in Office Buildings. in Indoor Air 99. 1999. Edinburgh: ISIAQ \& AIVC.

58. de Gear, R.J. and G.S. Brager, Developing and Adaptive Model of Thermal Comfort and Preference. ASHRAE Transactions, 1998. Vol. 104 (Part. 1).

59. Brager, G.S. and R.J. de Gear, Thermal Adaptation in the Built Environment: A Literature Review. Energy and Buildings, 1998. Vol. 27(No. 1): p. 83-96. 
60. Aynsley, R. Unresolved Issues in Natural Ventilation for Thermal Comfort. in HybVent Forum '99. 1999. Sydney, Australia.

61. Eastop, T.D. and W.E. Watson, Mechanical Services for Buildings. 1992, Hong Kong: Longman Scientific \& Technical (John Wiley \& Sons).

62. ISO, ISO 7730:1994 - Moderate thermal environments -- Determination of the PMV and $P P D$ indices and specification of the conditions for thermal comfort. 1994, International Organization for Standardization: Geneva.

63. Fitzgerald, E., et al., A Green Vitruvius - Principles and Practice of Sustainable Architectural Design. 1999, London: James \& James Ltd.

64. Braham, G.D., Mechanical Ventilation and Fabric Thermal Storage. Indoor + Built Environment, 2000. Vol. 9(No. 2): p. 102-110.

65. Berry, J., Super-Efficient Mechanical Ventilation. Indoor + Built Environment, 2000. Vol. 9(No. 2): p. 87-96.

66. Colliver, D.G., Energy Requirements for Conditioning of Ventilating Air. 1995. Coventry, Great Britain: AIVC.

67. Stein, B. and J.S. Reynolds, Mechanical and Electrical Equipment for Buildings. Eighth Edition ed. 1992, New York: John Wiley \& Sons. 1627.

68. Marion, W. and K. Urban, User's Manual for TMY2s - Typical Meteorological Years. 1995, National Renewable Energy Laboratory (NREL): Golden CO.

69. Liddament, M.W., A Guide to Energy Efficient Ventilation. 1996, AIVC: Coventry.

70. BRE, Natural Ventilation in Non-Domestic Buildings. 1994, Building Research Establishement: Garston, Watford, UK.

71. Wouters, P., et al. Classification of Hybrid Ventilation Concepts. in HybVent Forum '99. 1999. Sydney, Australia.

72. Axley, J.W., AIVC TechNote 54: Residential Passive Ventilation Systems: Evaluation and Design. 2000. Coventry, Great Britain: AIVC.

73. Deaves, D.M. and I.G. Lines, On the Persistence of Low Wind Speed Conditions. Air Infiltration Review - Web Edition, 1998. Volume 20(No. 1).

74. Deaves, D.M. and I.G. Lines, On Persistence of Low Speed Conditions. Air Infiltration Review, 1999. Vol. 20(No. 1): p. 6-8.

75. Skaret, E., P. Blom, and J.T. Brunsell. Energy Recovery Possibilities in Natural Ventilation of Office Buildings. in 18th AIVC Conference - Ventilation and Cooling. 1997. Athens, Greece: AIVC.

76. Thomas, R., ed. Environmental Design: An Introduction for Architects and Engineers Second Edition. 1999, E \& FN Spon: London.

77. Scott, A., ed. Dimensions of Sustainability. 1998, E \& FN Spon: New York.

78. Martin, A.J., Technical Note TN 11/95: Control of Natural Ventilation. 1996, BSRIA The Building Services Research and Information Association: Bracknell, Bershire, UK.

79. $\mathrm{AD}$, AD: The Architecture of Ecology. Architectural Design, 1997.

80. Yeang, K., The Skyscraper Bioclimatically Considered: A Design Primer. 1996, London: Academy Editions - Academy Group LTD. 
81. Yeang, K., The Green Skyscraper: The Basis for Designing Sustainable Intensive Buildings. 1999, Munich, London, New York: Prestel.

82. Girault, P. and B. Spennato. The Impact of Wind Turbulence on the Precision of a Numerical Modeling Study. in Indoor Air 99. 1999. Edinburgh: ISIAQ \& AIVC.

83. Saraiva, J.G. and F. Marques da Silva. Atmospheric Turbulence Influence on Natural Ventilation Air Change Rates. in Indoor Air 99. 1999. Edinburgh: ISIAQ \& AIVC.

84. Sirén, K. A Modification of the Power-Law Equation to Account for Large-Scale Wind Turbulence. in 18th AIVC Conference - Ventilation and Cooling. 1997. Athens, Greece: AIVC.

85. Kurabuchi, T., et al. Numerical Study of Airflow Structure of a Cross-ventilated Model Building. in RoomVent 2000: Ventilation for Health and Sustainable Environment. 2000. University of Reading: Elsevier.

86. Heiselberg, P., K. Svidt, and P.V. Nielsen. Windows - Measurements of Air Flow Capacity. in RoomVent 2000: Ventilation for Health and Sustainable Environment. 2000. University of Reading: Elsevier.

87. Fürbinger, J.M. Comparison of the Accuracy of Detailed and Simple Models of Air Infiltration. in 15th AIVC Conference - The Role of Ventilation. 1994. Buxton, Great Britain: AIVC.

88. Fürbringer, J.-M., et al. Air Flow Simulation of the LESO Building Including a Comparison with Measurements and Sensitivity Analysis. in Indoor Air 193: The 5th International Conference on Indoor Air Quality and Climate. 1993. Helsinki, Finland: Helsinki University of Technology.

89. Orme, M., M.W. Liddament, and A. Wilson, Numerical Data for Air Infiltration \& Natural Ventilation Calculations. 1998. Coventry, Great Britain: AIVC.

90. Etheridge, D. and M. Sandberg, Buildng Ventilation: Theory \& Measurement. 1996, Chichester: John Wiley \& Sons.

91. Li, Y., Prediction of Natural Ventilation in Buildings with Large Openings. Building and Environment, 2000. Vol 35: p. 191-206.

92. Pelletret, R., et al. Modelling of Large Openings. in 12th AIVC Conference: Air Movement and Ventilation Control Within Buildings. 1991. Coventry, Great Britain: AIVC

93. Efiekhari, M.M. and A. D'Ovidio. Thermal Comfort and Air Flow Measurements in a Single-Sided Naturally Ventilated Room. in Indoor Air 99. 1999. Edinburgh: ISIAQ \& AIVC.

94. Eftekhari, M.M., et al. Predicting Air Flow Distribution In A Naturally Ventilated Room. in RoomVent 2000 - 7th International Conference on Air Distribution in Rooms. 2000. University of Reading, UK: Elsevier.

95. Gan, G. Numerical Determination of the Effective Depth for Single-Sided Natural Ventilation. in Indoor Air 99. 1999. Edinburgh: ISIAQ \& AIVC.

96. Fracastoro, G.V., G. Mutani, and M. Perino. Numerical Simulation of Transient Effects of Window Openings. in RoomVent 2000: Ventilation for Health and Sustainable Environment. 2000. University of Reading: Elsevier. 
97. Murakami, S., S. Kato, and S. Akabayashi, Visualization with Laser Light Sheet Applied to Internal and External Air Flows in Building Environmental Engineering, in Fluid Control and Measurement, M. Harada, Editor. 1986, Pergamaon Press: Oxford. p. 731738.

98. Demeester, J. Natural Ventilation at Work: Case Studies of Innovative Commercial Buildings in Europe. in NatVent ${ }^{\mathrm{TM}}$ - A Better Way to Work. 1998. BRE, Garston, Watford, UK: BRE.

99. Martin, A.J., Control of Natural Ventilation. 1995, The Building Services Research and Information Association BSRIA: Bracknell, Bershire, UK.

100. Rodrigues, A.M., A.C. da Piedade, and H.B. Awbi. The Use of Solar Air Collectors for Room Ventilation: A Study Using Two Numerical Approaches. in RoomVent 20000. 2000. University of Reading: Elsevier.

101. Sandberg, M. Cooling of Building Integrated Photovoltaics by Ventilation Air. in HybVent Forum '99. 1999. Sydney, Australia.

102. Bansal, N.K., R. Mathur, and M.S. Bhandari, Solar Chimney for Enhanced Stack Ventilation. Building and Environment, 1993. Vol. 28(No. 3): p. 373-377.

103. Spencer, S., et al. Experimental Investigation of a Solar Chimney Natural Ventilation System. in RoomVent 2000 - 7th International Conference on Air Distribution in Rooms. 2000. University of Reading, UK: University of Reading, UK.

104. Schlaich, J., The Solar Chimney: Electricity from The Sun. 1995, Stuttgart: Edition Axel Menges.

105. Sutcliffe, G.L., Principles and Practice of Modern Construction. 1899.

106. Anon, Monodraught Windcatcher - Passive Stack Ventilation Systems. 1997, The Builder Group plc: Building Services Journal - OPUS '98. p. 144 and 145.

107. Gage, S., et al., Top Down Ventilation and Cooling in Urban Areas. 1999, The Bartlett School of Architecture: London.

108. Gage, S.A., P. Ayres, and J. Axon, The Use of Heat Pumps to Induce Airflow on Hot Days in Otherwise Passive Ventilation Systems - A Zonal Modeling Approach. Indoor + Built Environment, 2000. Vol. 9(No. 3-4): p. 127-142.

109. Hunt, G.R. and J.M. Holford. Top-Down Natural Ventilation of MultiStorey Buildings. in 19th AIVC Conference - Ventilation Technologies in Urban Areas. 1998. Oslo: AIVC.

110. Bowman, N.T., et al., Passive Downdraught Evaporative Cooling. Indoor + Built Environment, 2000. Vol. 9(No. 5): p. 284-290.

111. Cook, M.J., G.R. Hunt, and D. Robinson. Sizing of Ventilation Openings in Buildings with Passive Downdraught Evaporative Cooling. in RoomVent 2000 - 7th International Conference on Air Distribution in Rooms. 2000. University of Reading, UK: Elsevier.

112. Besant, R.W. and C.J. Simonson, Air-to-Air Energy Recovery. ASHRAE Journal, 2000. May: p. 31-42.

113. Anantapantula, V.S. and H.J.J. Sauer, Heat Recovery and the Economizer for HVAC Systems. ASHRAE Journal, 1994. November 1994: p. 48-53.

114. Sasaki, T., et al. Performance of Passive Stack Ventilation With Heat Recovery System. in Indoor Air 99. 1999. Edinburgh: ISIAQ \& AIVC. 
115. Riffat, S.B. and G. Gan, Passive Stack Ventilation with Heat Recovery. AIVC Air Infiltration Review, 1997. Vol. 18(No. 4): p. 7-9.

116. Sirén, K., et al. Solar Assisted Natural Ventilation with Heat Pipe Heat Recovery. in 18th AIVC Conference - Ventilation and Cooling. 1997. Athens, Greece: AIVC.

117. Dix, T.R., An Engineering Approach to Ventilation System Design. Indoor + Built Environment, 2000. Vol. 9(No. 2): p. 75-85.

118. Buchanan, C.R. and M.H. Sherman. Simulation of Infiltration Heat Recovery, in 19th AIVC Conference - Ventilation Technologies in Urban Areas. 1998. Oslo: AIVC.

119. Buchanan, C.R. and M.H. Sherman, Simulation of Infiltration Heat Recovery. 1998, Lawrence Berkeley Laboratory: Berkeley.

120. Sherman, M.H. and N. Matson, Residential Ventilation and Energy Characteristics. ASHRAE Transactions, 1997. Vol. 103(Pt. 1).

121. Etheridge, D.W. and J.J. Zhang, DRAFT: Dynamic Insulation and Natural Ventilation: A Feasibility Study. Submitted to BSERT, 1998.

122. Di Maio, F. and A.H.C. van Paassen. Simulation of Temperature and Air Flow in a Second Skin Façade. in RoomVent 2000 - 7th International Conference on Air Distribution in Rooms. 2000. University of Reading, UK: Elsevier.

123. Saelens, D. and H. Hens. Active Envelopes - Essential in Urban Areas? in 19th AIVC Conference - Ventilation Technologies in Urban Areas. 1998. Oslo: AIVC.

124. Southall, R.G. and M. McEvoy. Results from a Validated CFD Simulation of a Supply Air 'Ventilated' Window. in RoomVent 2000 - 7th International Conference on Air Distribution in Rooms. 2000. University of Reading, UK: Elsevier.

125. Schuler, M. and M. Schugmann, The Energy and Comfort Concept of the Developers Centre in Ingolstadt, J. Axley, Editor. 2000, Transsolar.

126. Welsh, P.A., Testing the performance of terminals for ventilation systems, chimneys and flues. 1995, BRE: Watford.

127. Welsh, P.A., Flow Resistance and Wind Performance of Some Common Ventilation Terminals. 1995, BRE: Watford.

128. Welsh, P., Free-Standing Ventilation Terminals: Testing and Rating. CIBSE-Building Service Engineering Research and Technology, 1995. Vol. 16(No. 4): p. 189-198.

129. Welsh, P. The Testing and Rating of Terminals Used on Ventilation Systems. in 15th AIVC Conference - The Role of Ventilation. 1994. Buxton, Great Britain: AIVC.

130. Graham, J.M.R. and N.H.A. Jenkins. Wind Energy Associated with Buildings. in Sustainable Building: A BEPAC + EPSRC Conference. 1997. Abingdon, England: BEPAC Web Site.

131. Liddament, M.W., Photovoltaics and Natural Ventilation as Part of Building Facade Design: A Synthesis - AIRLIT-PV. 1999, AIVC: Coventry.

132. Orme, M.S., Night Cooling with AIRLIT-PV. Air Infiltration Review, 2000. Vol. 21(No. 3): p. 1-5.

133. Kosonen, R., P. Horttanainen, and G. Dunlop. Integration of Heating Mode into Ventilated Cooled Beam. in RoomVent 2000: Ventilation for Health and Sustainable Environment. 2000. University of Reading: Elsevier. 
134. Hartman, H., Building Alliance. Building Design, 2000.

135. Atelier10, Keble College - Keble II. 2000, atelier ten.

136. Allen, I., Educating Essex: AHMM's Sustainable School. aj - The Architect's Journal, 1999. Vol. 4(11): p. 28-37.

137. Atelier10, 10 - atelier ten. 1999, atelier ten.

138. Transsolar, CLIMATE ENGINEERING: The Integration of Ecology and Architecture. 2000, Transsolar: Stuttgart.

139. Atelier10, Innovation: labyrinth. 2000, Atelier Ten: London.

140. Atelier10, Federation Square. 1998, Atelier Ten: London.

141. Atelier 10, The Earth Centre - Labyrinth Design Study. 2000, Atelier Ten: London.

142. Bunn, R., Cyberhenge: Passive Engineering Powers Doncaster's Earth Center. Building Service Journal - The Magazine of the CIBSE, 1999. July: p. 16-21.

143. Jones, P. and K. Kippenberg. Effect of Thermal Mass on the Airflow and Ventilation in Passive Building Design. in RoomVent 20000. 2000. University of Reading: Elsevier.

144. Barnard, N. and D. Jaunzens, eds. Early Design Guidance for Low Energy Cooling Technologies - IEA Annex 28 - Subtask 2 Report 2. 1999, BRE (British Research Establishment).

145. Martin, A. and J. Fletcher, Night Cooling Control Strategies. 1996, BSRIA - The Building Services Research and Information Association: Bracknell, Bershire, UK.

146. Martin, A. and J. Fletcher, Night cooling control strategies - Final report [RR 5/96, 11621/4]. 1996, Bracknell, UK: BSRIA.

147. Liem, S.H. and A.H.C. van Paassen. Hardware and Controls for Natural Ventilation Cooling. in Ventilation and Cooling - 18th AIVC Conference. 1997. Athens: AIVC.

148. van Paassen, A., S.H. Liem, and B.P. Gröninger. Control of Night Cooling with Natural Ventilation: Sensitivity Analysis of Control Strategies and Vent Openings. in 19th AIVC Conference - Ventilation Technologies in Urban Areas. 1998. Oslo: AIVC.

149. Kolokotroni, M., Night Ventilation for Cooling Office Buildings. 1998, BRE: Garston, Watford, U.K.

150. Turnpenny, J.R., D.W. Etheridge, and D.A. Reay. Novel Ventilation Cooling System for Reducing Air Conditioning Use in Buildings. in RoomVent 2000 - 7th International Conference on Air Distribution in Rooms. 2000. University of Reading, UK: Elsevier.

151. Svensson, C. and S. Aggerholm, The NatVent ${ }^{\mathrm{TM}}$ Programme 1.0 - Fundamentals. 1998, Building Research Establishment BRE: Watford, UK.

152. Svensson, C. and S. Aggerholm, The NatVent ${ }^{\mathrm{TM}}$ Programme 1.0 - User's Guide. 1998, Building Research Establishment BRE: Watford, UK.

153. White, M.K., M. Kolokotroni, and M. Perera, Trickle Ventilators in Offices. 1998, Building Research Establisment: Garston, Watford, UK.

154. Wouters, P. and L. Vandaele. Experimental Evaluation of a Hygroregulating Natural Ventilation System. in 11th AIVC Conference, "Ventilation System Performance". 1990. Belgirate, Italy: AIVC.

155. van Paassen, A.H.C., H.F. Broekhuizen, and M. Verwaal, Prototype of Night Ventilator for Cooling. 1998, BRE: Watford, UK. 
156. de Gids, W.F., Controlled Air Flow Inlets. 1997, BRE: Watford, UK.

157. Parkins, L.M. A Study of Various Passive Stack Ventilation Systems in a Test House. in 15th AIVC Conference - The Role of Ventilation. 1994. Buxton, Great Britain: AIVC.

158. de Gids, W.F. and H.P.L. den Ouden, Three Investigations of the Behaviour of Ducts for Natural Ventilation. 1974, TNO.

159. Alexander, D.K., H.G. Jenkins, and P.J. Jones. The Effects of Building Form on the Natural Ventilation of Commercial Buildings. in Optimum Ventilation and Air Flow Control in Buildings: 17th AIVC Conference. 1996. Gothenburg, Sweden: AIVC.

160. Alexander, D.K., H.G. Jenkins, and P.J. Jones. Investigating the Effects of Wind on Natural Ventilation Desing of Commercial Buildings. in Sustainable Building: A BEPAC + EPSRC Conference. 1997. Abingdon, England: BEPAC Web Site.

161. Jones, P.J., D.K. Alexander, and H.G. Jenkins, Investigating the Effects of Wind on Natural Ventilation Desing of Commercial Buildings: Final Report. 1997, Welsh School of Architecture: Cardiff.

162. Walton, G.N., CONTAM93 User Manual. 1994, National Institute of Standards and Technology (NIST).

163. Dols, W.S., G.N. Walton, and K.R. Denton, CONTAMW 1.0 User Manual: Multizone Airflow and Contaminant Transport Analysis Software. 2000, U.S. NIST: Gaithersburg, MD.

164. Haas, A., COMIS 3.1. 2000, EMPA - Swiss Federal Laboratories for Materials Testing and Research.

165. Feustel, H.E. and A. Raynor-Hoosen, eds. COMIS - Fundamentals. 1990, Lawrence Berkeley Lab: Berkeley, CA.

166. Dols, W.S., NIST Multizone Modeling Website. 2001, NIST: Gaithersburg, MD.

167. Persily, A.K. and E.M. Ivy, Input Data for Multizone Airflow and IAQ Analysis. 2001, NIST: Gaithersburg.

168. Chikamoto, T., S. Kato, and T. Ikaga. Hybrid Air-Conditioning System at Liberty Tower of Meiji University. in HybVent Forum '99. 1999. Sydney, Australia.

169. Yoshino, H. and J. Liu. Experimental Analysis of a Hybrid Ventilation System. in RoomVent 2000 - 7th International Conference on Air Distribution in Rooms. 2000. University of Reading, UK: Elsevier.

170. Li, Y., et al. Analysis Methods for Natural and Hybrid Ventilation - An IEA ECB Annex 35 Literature Review. in The 3rd International Symposium on Heating, Ventilation and Air Conditioning. 1999. Shenzhen, China.

171. Aynsley, R. Partial Cooling in a Naturally Ventilated Building in the Tropics. in RoomVent 2000 - 7th International Conference on Air Distribution in Rooms. 2000. University of Reading, UK: Elsevier.

172. Kato, S., et al. Room Air Distribution and Cooling Load of Hybrid Air-Conditioning System Utilizing Natural Ventilation in an Office. in RoomVent 2000 - 7 th International Conference on Air Distribution in Rooms. 2000. University of Reading, UK: Elsevier.

173. Kato, S., et al. Hybrid Air-Conditioning Based on Natural and Mechanical Ventilation in Office Building. in Indoor Air 99. 1999. Edinburgh: ISIAQ \& AIVC. 
174. Bellew, P. Labyrinth Thermal Storage Systems. in 6th Intenational "Intelligent Building" Symposium. 2000. Stuttgart, Germany.

175. Axley, J.W. Natural Ventilation Design Using Loop Equations. in Indoor Air 99. 1999. Edinburgh: ISIAQ \& AIVC.

176. Yannas, S. and E. Mandonado, eds. PASCOOL - Handbook on Passive Cooling Vol. 2: Case Studies. Vol. Vol. 2. 1995, University of Athens: Athens.

177. Yannas, S. and E. Mandonado, eds. PASCOOL - Handbook on Passive Cooling Vol. I: Comfort Climate \& Building Design. Vol. Vol. 1. 1995, University of Athens: Athens.

178. Fraser_\&_Associates, ed. Review of Low Energy Cooling Technologies: IEA Annex 28 Low Energy Cooling: Subtask 1 Report. 1995, Natural Resources Canada: Ottawa, ON, Canada.

179. Kolokotroni, M., Night Cooling Ventilation in UK Commercial Buildings, in Early Design Guidance for Low Energy Cooling Technologies - IEA Annex 28 - Subtask 2 Report 2, N. Barnard and D. Jaunzens, Editors. 1999, BRE: Watford, UK.

180. Zimmermann, M. and J. Andersson, eds. Annex 28 Low Energy Cooling - Case Study Buildings. 1998, International Energy Agency: Duebendorf, Switzerland or Coventry, UK.

181. Thomas, R., ed. Environmental Design: An Introduction for Architects and Engineers. 1996, E \& FN Spon: London.

182. Irving, S.J., P.J. Concannon, and H.S. Dhargalkar, Sizing and Location of Passive Ventilation Openings. 1995, Oscar Faber Applied Research: St.Albans, England.

183. Irving, S.J. and P.J. Concannon. An Inverse Solver for Sizing Passive Ventilation Openings. in CIBSE National Conference '95. 1995. Eastbourne, UK: CIBSE.

184. Aynsley, R.M., W. Melbourne, and B.J. Vickery, Architectural Aerodynamics. 1977, London: Applied Science Publishers Ltd.

185. Petherbridge, P., N.O. Millbank, and J. Harrington-Lynn, Environmental Design Manual: Summer Conditions in Naturally-Ventilated Offices. 1988, Building Research Establishment: Garston, Watford, UK.

186. Arisoy, A. Natural Ventilation of Buildings. in Healthy Building 2000. 2000. Espoo, Finland: SIT Indoor Air Information Oy, Helsinki, Finland.

187. Potangaroa, R. and R. Aynsley. A Tale of Four Cities: The Potential for Achieving Thermal Comfort Using Natural Ventilation In High Rise Buildings In Four Asian Cities. in RoomVent 2000 - 7th International Conference on Air Distribution in Rooms. 2000. University of Reading, UK: Elsevier.

188. Pelletret, R.Y. and W.P. Keilholz. COMIS 3.0 - A New Simulation Environment for Multizone Air Flow and Pollutant Transport Modeling. in Building Simulation '97 - Fifth International IBPSA Conference. 1997. Prague: IBPSA.

189. Walton, G., CONTAM96 User Manual. 1997, NIST: Gaithersburg, MD.

190. Axley, J.W. Zonal Models Using Loop Equations and Surface Drag Cell-to-Cell Flow Relations. in RoomVent 2000 - 7th International Conference on Air Distribution in Rooms. 2000. University of Reading, UK: Elsevier.

191. Axley, J.W., Passive Ventilation for Residential Air Quality Control. ASHRAE Transactions, 1999. Vol. 105(Part 2): p. 864-876. 
192. Axley, J.W. Design and Simulation of Natural Ventilation Systems Using Loop Equations. in Healthy Buildings 2000. 2000. Espoo, Finland: FiSIAQ \& ISIAQ.

193. Axley, J.W., Indoor Air Quality Modeling Phase II Report. 1987, U.S. DOC, NBS, Gaithersburg, MD.

194. Axley, J.W., Progress Toward a General Analytical Method for Predicting Indoor Air Pollution in Buildings: Indoor Air Quality Modeling Phase III Report. 1988, U.S. DOC, NBS, Gaithersburg, MD.

195. Feustel, H.E. and B.V. Smith, eds. COMIS 1.2 User Guide. 1992, Lawrence Berkeley Lab: Berkeley, CA.

196. Orme, M., AIVC Technical Note 51: Applicable Models for Air Infiltration and Ventilation Calculations. 1999. Coventry, Great Britain: AIVC.

197. Axley, J. Multi-Zone Contaminant Dispersal Analysis Using An Element Assembly Approach. in Proceedings of the 9th AIVC Conference: Effective Ventilation. 1988. Gent, Belgium: AIVC.

198. Walton, G. Airflow Network Models for Element-Based Building Airflow Modeling. in ASHRAE Symposium on Calculation of Interzonal Heat and Mass Transport in Buildings. 1989. Vancouver, B.C.: ASHRAE.

199. Solomons, D.E.W., BREEZE 5.0 User Manual. 1990, Building Research Establishment: London.

200. Axley, J. and R. Grot. Coupled Airflow and Thermal Analysis for Building System Simulation by Element Assembly Techniques. in RoomVent '90: Engineering Aero- and Thermodynamics of Ventilated Rooms Second International Conference. 1990. Oslo, Norway: NORSK VVS: Norwegian Association of Heating, Ventilating and Sanitary Engineers.

201. Axley, J. and R. Grot. The Coupled Airflow and Thermal Analysis Problem in Building Airflow System Simulation. in ASHRAE Symposium on Calculation of Interzonal Heat and Mass Transport in Buildings. 1989. Vancouver, B.C.: ASHRAE.

202. Kendrick, J., AIVC Technical Note 40: An Overview of Combined Modelling of Heat Transport and Air Movement. 1993, AIVC: Coventry, UK.

203. Clarke, J.A. and J.L.M. Hensen. An Approach to the Simulation of Coupled Heat and Mass Flows in Buildings. in Ventilation System Performance, 11th AIVC Conference. 1990. Belgirate, Italy: AIVC.

204. Hensen, J.L.M., ESPmfs, a building \& plant mass flow network solver. 1990, FAGO Eindhoven University of Technology.

205. Hensen, J.L.M. and J.A. Clarke. A Simulation Approach to the Evaluation of Coupled Heat and Mass Transfer in Buildings. in Building Simulation '91. 1991. Sophia-Antipolis, Nice, France: IBPSA (International Building Performance Simulation Association).

206. Hensen, J.L.M., J. Hand, and J.A. Clarke. Building Design Assessment Through Coupled Heat and Air Flow Simulation; Two Case Studies. in 12th AIVC Conference: Air Movement and Ventilation Control Within Buildings. 1991. Coventry, Great Britain: AIVC.

207. Hensen, J.L.M., On The Thermal Interaction of Building Structure and Heating and Ventilating System. 1991, Eindhoven University of Technology. 
208. Hensen, J.L.M. and J.A. Clarke. A Fluid Flow Network Solver for Integrated Building and Plant Energy Simulation. in The 3rd International Conference on System Simulation in Buildings. 1990. Liège, Belgium.

209. Mathews, E.H. and D.C. Arndt. Validation of a New Integrated Design Tool for Naturally Ventilated Buildings. in RoomVent 20000. 2000. University of Reading: Elsevier.

210. Santamouris, M., et al., AIOLOS: Creation of an Educational Structure on the Use of Passive Cooling Ventilation Techniques for Buildings. 1996: University of Athens, Greece.

211. Leal, V., et al. Energy Impact of Ventilation Rates. in RoomVent 2000 - 7th International Conference on Air Distribution in Rooms. 2000. University of Reading, UK: Elsevier.

212. Li, Y., et al. Some Examples of Solution Multiplicity in Natural Ventilation. in RoomVent 20000. 2000. University of Reading: Elsevier.

213. Crawley, D.B., et al., EnergyPlus: Energy Simulation Program. ASHRAE Journal, 2000. April: p. 49-56.

214. Walton, G., DRAFT: Notes on Simultaneous Heat and Mass Transfer [CONTAM97]. 1998, NIST: Gaithersburg.

215. Woloszyn, M., et al. Combined Moisture, Air and Heat Transport Modelling Methods for Integration in Building Simulation Codes. in RoomVent 2000 - 7th International Conference on Air Distribution in Rooms. 2000. University of Reading, UK: Elsevier.

216. Dabney, J.B. and T.L. Harman, The Student Edition SIMULINK® - Dynamic System Simulation for MATLAB囚. 1998, Upper Saddle River, NJ: Prentice Hall.

217. Hanselman, D. and B. Littlefield, The Student Edition of MATLAB® - Version 5 User's Guide. 1997, Upper Saddle River, NJ: Prentice Hall.

218. Vuolle, M. and A. Bring. An NMF Based Model Library for Building Climate and Energy Simulation. in Building Simulation '97 - Fifth International IBPSA Conference. 1997. Prague: IBPSA.

219. Vuolle, M. and J. Heinonen. Hybrid Ventilation Simulations in IDA Modular Simulation Environment. in Healthy Building 2000. 2000. Espoo, Finland: SIT Indoor Air Information Oy, Helsinki, Finland.

220. Haghighat, F., Y. Lin, and A.C. Megri, Zonal Model - A Simplified Multiflow Element Model, in HybVent Forum '99 - First International Ine Day Forum on Natural and Hybrid Ventilation. 1999: Sydney, Australia.

221. Inard, C. and D. Buty. Simulation of Thermal Coupling Between a Radiator and Room with Zonal Models. in 12th AIVC Conference: Air Movement and Ventilation Control Within Buildings. 1991. Coventry, Great Britain: AIVC.

222. Musy, M., et al., Generation of a Zonal Model to Simulate Natural Convection in a Room with Radiative/Convective Heater. DRAFT, 1999.

223. Wurtz, E., J.-M. Nataf, and F. Winkelmann, Two- and Three-dimenaional Natural and Mixed Convection Simulation using Modular Zonal Models in Buildings. International Journal of Heat and Mass Transfer, 1999(42): p. 923-940.

224. Allard, F. and C. Inard. Natural and Mixed Convection in Rooms: Prediction of Thermal Stratification and Heat Transfer by Zonal Models. in Internationa Symposium on Room 
Air Convection and Ventilation Effectiveness. 1992. University of Tokyo: Society of Heating, Air-Conditioning and Sanitary Engineers of Japan.

225. Swainson, M.J. and W.J. Batty. A Review of Physical Modeling Techniques to Aid in the Design of Natural Ventilation Building Components. in CIBSE National Conference. 1995. Eastbourne, Great Britain: CIBSE.

226. Holmes, M.J. and S. McGowan. Simulation of a Complex Wind and Buoyancy Driven Building. in Building Simulation '97 - Fifth International IBPSA Conference. 1997. Prague: IBPSA.

227. Gage, S.A. Stack Ventilation and Cooling For Urban Sites: Natural Ventilation with Roof Intakes for Improved Air Quality. in Ventilation and Cooling - 18th AIVC Conference. 1997. Athens: AIVC.

228. Jones, P.J., et al. Guidelines for the Design and Operation of Natural and Mixed-Mode Ventilation Systems in Commercial Buildings. in Sustainable Building: A BEPAC + EPSRC Conference. 1997. Abingdon, England: BEPAC Web Site.

229. Wong, N.H., et al. Natural Ventilation Characteristics of Courtyard Buildings in Singapore. in RoomVent 2000 - 7th International Conference on Air Distribution in Rooms. 2000. University of Reading, UK: Elsevier.

230. Sharples, S. and R. Bensalem. Wind Driven Ventilation in Courtyard and Atrium Buildings in Urban Areas. in 19th AIVC Conference - Ventilation Technologies in Urban Areas. 1998. Oslo: AIVC.

231. Harris, D.J. and R.S. Webb. Wind Towers - Old Technology to Solve a New Problem. in Optimum Ventilation and Flow Control in Buildings:17th AIVC Annual Conference. 1996. Gothenburg: AIVC.

232. Hunt, G.R. and P.F. Linden, Multiple Steady Airflows and Hysteresis When Wind Opposes Buoyancy. Air Infiltration Review, 2000. Vol. 21(No. 2): p. 1-3.

233. Hunt, G.R. and P.F. Linden. Passive Cooling by Natural Ventilation: Salt Bath Modeling of Combined Wind and Buoyancy Forces. in Ventilation and Cooling - 18th AIVC Conference. 1997. Athens: AIVC.

234. Riffat, S.B., et al. Heat-Pipe Recovery for Stack Ventilation. in Ventilation and Cooling 18th AIVC Conference. 1997. Athens: AIVC.

235. Chen, Z.D., Y. Li, and J. Mahoney. Modelling Ventilation Flows using a Fine-Bubble Technique. in HybVent Forum '99. 1999. Sydney, Australia.

236. Marques, J., F. Pagani, and J. Perdue, Process Makes Product: The C.K. Choi Building for the Institute of Asian Research at the University of British Columbia. ASHRAE Transactions, 1999. Vol. 105(Part 2).

237. Walker, I.S. and D.J. Wilson. Practical Methods for Improving Estimates of Natural Ventilation Rates. in 15th AIVC Conference - The Role of Ventilation. 1994. Buxton, Great Britain: AIVC.

238. Gage, S. Top Down Ventilation and Cooling in Urban Areas - Bartlett Research Paper No. 11. in DETR Partners Symposium. 1999. The Bartlett, Unversity College, London: Bartlett Research.

239. Cavannal, G., et al. Experimental Development of a Natural Controlled Ventilation Device. in Indoor Air 99. 1999. Edinburgh: ISIAQ \& AIVC. 
240. Schultz, J.M., Natural Ventilation with Heat Recovery - Naturlig Ventilation med Varmeganvinding. 1993, Danmarks Tekniske Hojskole, Laboratoriet for Varmeisolering: Denmark.

241. Dorer, V., A. Weber (1994). Multizone Air Flow Model COMVEN-TRNSYS. EMPA/IEA-ECB Annex 23, Bubendorf, Switzerland.

242. Arens,E., X.,T., Miura K. "A Study of Occupant Cooling by Personally Controlled Air Movement. 1998, Energy and Buildings, No. 27, pp. 45-59. 